\section{ADVANCED STEEL CONSTRUCTION}

\section{An International Journal}

Volume 7 Number 1

March 2011

CONTENTS

Technical Papers

Foreword

Dinar Camotim and Riccardo Zandonini

Partial Interaction Analysis with Shear-Lag Effects of Composite Bridges:

A Finite Element Implementation for Design Application

Fabrizio Gara, Gianluca Ranzi and Graziano Leoni

Experimental and Analytical Investigations of Steel and Composite Trusses

S.L. Chan and M. Fong

Design by Testing of Industrial Racks

N. Baldassino and R. Zandonini

Experimental Study on Behaviors of the Trapezoid Connectors of the Inverted T-Shaped Steel with Notched Web for a Novel Composite Beam

Li Guo-qiang, Li Liang and Li Xianhui

Enhancing the Robustness of Steel and Composite Buildings

D.A. Nethercot, P. Stylianidis, B.A. Izzuddin and A.Y. Elghazoul

Structural Behaviour of Elliptical Hollow Sections under Combined Compression and Uniaxial Bending L. Gardner, T.M. Chan and J.M. Abela

Local / Distortional / Global Mode Coupling in Fixed Lipped Channel Columns: Behaviour and Strength Pedro B. Dinis, Dinar Camotim, Eduardo M. Batista and Eliane Santos

Copyright $\odot 2011$ by :

The Hong Kong Institute of Steel Construction

Website: $h t t p: / / w w w . h k i s c . o r g$

ISSN 1816-112X

Science Citation Index Expanded, Materials Science Citation Index and ISI Alerting

Cover: Hong Kong Design Institute

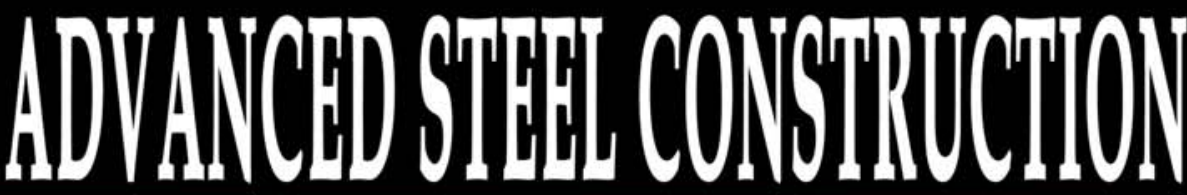

an International ]ounal ISSN 1816-112X

Volume 7 Number 1 (Special Issue)

March 2011

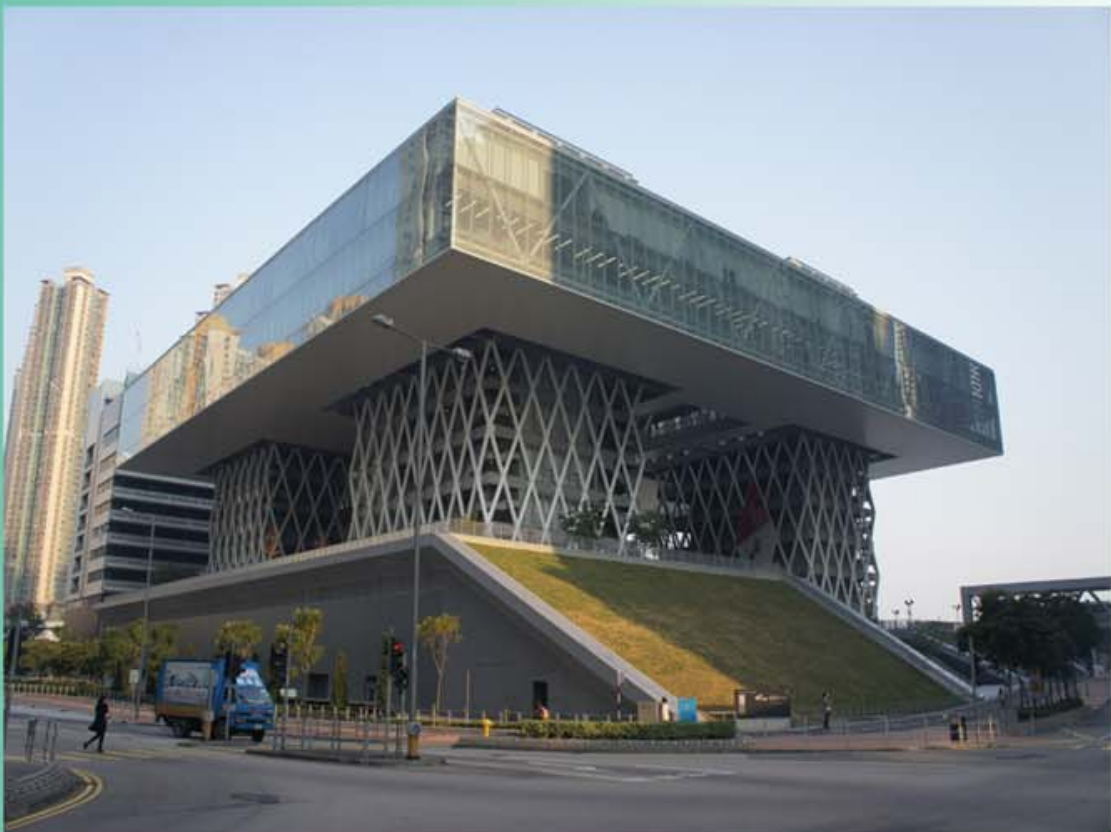

\section{Editors-in-Chief}

S.L. Chan, The Hong Kong Polytechnic University, Hong Kong

W.F. Chen, University of Hawaii at Manoa, USA

R. Zandonini, Trento University, Italy 


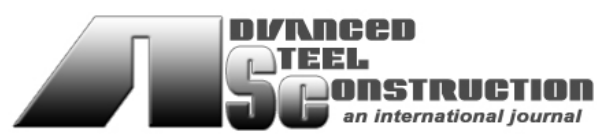

ISSN 1816-112X

Science Citation Index Expanded, Materials Science Citation Index and ISI Alerting

\section{EDITORS-IN-CHIEF}

Asian Pacific, African and organizing Editor

S.L. Chan

The Hong Kong Polyt. Univ., Hong Kong

\section{American Editor \\ W.F. Chen \\ Univ. of Hawaii at Manoa, USA}

\section{European Editor}

R. Zandonini

Trento Univ., Italy

\section{INTERNATIONAL} EDITORIAL BOARD

F.G. Albermani

The Univ. of Queensland, Australia

I. Burgess

Univ. of Sheffield, UK

F.S.K. Bijlaard

Delft Univ. of Technology, The Netherlands

R. Bjorhovde

The Bjorhovde Group, USA

M.A. Bradford

The Univ. of New South Wales, Australia

D. Camotim

Technical Univ. of Lisbon, Portugal

C.M. Chan

Hong Kong Uni v. of Science \& Technolog Hong Kong

T.H.T. Chan

Queensland Univ. of Technology, Australia

S.P. Chiew

Nanyang Technological Univ., Singapore

W.K. Chow

The Hong Kong Polyt. Univ., Hong Kong

K.F. Chung

The Hong Kong Polyt. Univ., Hong Kong

G.G. Deierlein

Stanford Univ., California, USA

\section{Advanced Steel \\ Construction an international journal}

L. Dezi

Univ. of Ancona, Italy

D. Dubina

The Politehnica Univ. of Tim

Romania

R. Greiner

Technical Univ. of Graz, Austria

L.H. Han

Tsinghua Univ. China

G.W.M. Ho

Ove Arup \& Pa rtners Hong Kon g Ltd., Hong Kong

B.A. Izzuddin

Imperial College of Science, Technology

and Medicine, UK

J.P. Jaspart

Univ. of Liege, Belgium

S. A. Jayachandran

IIT Madras, Chennai, India

S. Kitipornchai

City Univ. of Hong Kong, Hong Kong

D. Lam

Univ. of Bradford, UK

G.Q. Li

Tongji Univ., China

J.Y.R. Liew

National Univ. of Singapore, Singapore

E.M. Lui

Syracuse Univ., USA

Y.L. Mo

Univ. of Houston, USA

J.P. Muzeau

y, CUST, Clermont Ferrand, France

D.A. Nethercot

Imperial College of Science, Technology and Medicine, UK

Y.Q. Ni

The Hong Kong Polyt. Univ., Hong Kong

D.J. Oehlers

The Univ, of Adelaide, Australia

K. Rasmussen

The Univ. of Sydney, Australia

J.M. Rotter

The Univ. of Edinburgh, UK
C. Scawthorn

Scawthorn Porter Associates, USA

P. Schaumann

osoara, Univ. of Hannover, Germany

G.P. Shu

Southeast Univ. China

J.G. Teng

The Hong Kong Polyt. Univ., Hong Kong

G.S. Tong

Zhejiang Univ., China

K.C. Tsai

National Taiwan Univ., Taiwan

C.M. Uang

Univ. of California, USA

B. Uy

University of Western Sydney

M. Veljkovic

Univ. of Lulea, Sweden

F. Wald

Czech Technical Univ. in Prague, Czech

Y.C. Wang

The Univ. of Manchester, UK

Y.L. Xu

The Hong Kong Polyt. Univ., Hong Kong

D. White

Georgia Institute of Technology, USA

E. Yamaguchi

Kyushu Institute of Technology, Japan

Y.B. Yang

National Taiwan Univ., Taiwan

B. Young

The Univ. of Hong Kong, Hong Kong

X.L. Zhao

Monash Univ., Australia

Z.H. Zhou

Alpha Consultant Ltd., Hong Kong 


\begin{tabular}{ll}
\hline \hline & General Information \\
& Advanced Steel Construction, an international journal \\
\hline \hline Aims and scope
\end{tabular}

\section{Aims and scope}

The International Journal of Advanced Steel Construction provides a platform for the publication and rapid dissemination of ori ginal and up-to-date research and tec hnological developments in steel construction, design and anal ysis. Scope of research $p$ apers published in this journal includes but is not limite $d$ to theor etical and expe rimental research on elements, assemblages, sy stems, material, design philosophy and codification, standards, fabrication, projects of innov ative nature an d computer tech niques. The journal is specifically $t$ ailored to channel the e xchange of tec hnological know-ho $w$ bet ween $r$ esearchers an d practitioners. Contributions from all aspects related to the recent developments of advanced steel construction are welcome.

\section{Instructions to authors}

Submission of the manuscript. Authors may submit double-spaced manuscripts preferably in MS Word by emailing to one of the chief editors as follows for arrangement of review. Alternatively papers can be submitted on a diskette to one of the chief editors.

Asian Pacific, African and organizing editor : Professor S.L. Chan, Email: ceslchan@polyu.edu.hk

American editor:

European editor:

Professor S.L. Chan, Email: ceslchan@polyu.edu

Professor R. Zandonini, Email: riccardo_zandonini@ing.unitn.it

All manuscripts submitted to the journal are recommended to accompany with a li st of four potential reviewers suggested by the author(s). This list should include the complete name, add ress, telephone and fax numbers, em ail address, and at least five keywords that identify the expertise of each reviewer. This scheme will improve the process of review.

Style of manuscript

General. Author(s) should provide full postal and email addresses and fax number for correspondence. The manuscript including abstract, keywords, references, figures and tables should be in English with pages numbered and typed with double line spacing on single side of A4 or letter-sized paper. The front page of the article should contain:

a) a short title (reflecting the content of the paper);

b) all the name(s) and postal and email addresses of author(s) specifying the author to whom correspondence and proofs should be sent;

c) an abstract of $100-200$ words; and

d) 5 to 8 keywords.

The paper must contain an introduction and a conclusion. The length of paper should not exceed 25 journal pages (approximately 15,000 words equivalents).

Tables and figures. Tables and figures including photographs should be typed, numbered consecutively in Arabic numerals and with short titles. They should be referred in the text as Figure 1, Table 2, etc. Originally drawn figures and photographs should be provided in a form suitable for photographic reproduction and reduction in the journal.

Mathematical expressions and units. The Systeme Internationale (SI) should be followed whenever possible. The numbers identifying the displayed mathematical expression should be referred to in the text as Eq. (1), Eq. (2).

References. References to published literature should be referred in the text, in the order of citation with Arabic numerals, by the last name(s) of the author(s) (e.g. Zandonini and Zanon [3]) or if more than three authors (e.g. Zandonini et al. [4]). References should be in English $w$ ith occasional allow ance of 1-2 e xceptional referenc es in local lang uages and $r$ eflect the curren $t$ state-of-technology. Journal titles should be abbreviated in the style of the Word List of Scientific Periodicals. References should be cited in the following style [1, 2, 3].

Journal: [1] Chen, W.F. and Kishi, N., "Semi- rigid Steel Beam-to-column Connections, Data Base and Modellin g", Journal of Structural Engineering, ASCE, 1989, Vol. 115, No. 1, pp. 105-119.

Book: [2] Chan, S.L. and Chui, P.P.T., "Non-linear Static and Cyclic Analysis of Semi-rigid Steel Frames", Elsevier Science, 2000 .

Proceedings: [3] Zandonini, R. a nd Zanon, P., "Experimental Analy sis of S teel Beams with Semi -rigid Joint s", Proceedings of International Conference on Advances in Steel Structures, Hong Kong, 1996, Vol. 1, pp. 356-364.

Proofs. Proof will be sent to the c orresponding author to correct an y typesetting errors. Alternations to the original manuscript at this stage will not be accepted. Proofs should be returned within 48 hours of receipt by Express Mail, Fax or Email.

Copyright. Submission of an article to "Advanced Steel Construction" implies that it presents the original and unpublished work, and not under consideration for publication nor published elsewhere. On acceptance of a manuscript submitted, the copyright thereof is transferred to the publisher $b y$ the Transfer of $C$ opyright Agreement and upon the acceptance of publication for the $p$ apers, the corresponding author must sign the form for Transfer of Copyright.

Permission. Quoting from this journal is granted provided that the customary acknowledgement is given to the source.

Page charge and Reprints. There will be no page charges if the length of paper is within the limit of 25 journal pages. A total of 30 free offprints will be supplied free of charge to the corresponding author. Purchasing orders for additional offprints can be made on order forms which will be sent to the authors. These instructions can be obtained at the Hong Kong Institute of Steel Construction, Journal website: http://www.hkisc.org

The International Journal of Advanced Steel Construction is published quarterly by non-profit making learnt society, The Hong Kong Institute of Steel Construction, c/o Department of Civil \& Structural Engineering, The Hong Kong Polytechnic University, Hung Hom, Kowloon, Hong Kong.

Disclaimer. No responsibility is assumed for a ny injury and / or damage to per sons or property as a matter of products liability, negligence or otherwise, or from any use or operation of any methods, products, instructions or ideas contained in the material herein.

Subscription inquiries and change of address. Address all subscription inquiries and correspondence to Member Records, IJASC. Notify an address change as soon as possible. All communications should include both old and new addresses with zip codes and be accompanied by a mailing label from a recent issue. Allow six weeks for all changes to become effective.

The Hong Kong Institute of Steel Construction

HKISC

c/o Department of Civil and Structural Engineering,

The Hong Kong Polytechnic University,

Hunghom, Kowloon, Hong Kong, China.

Tel: 852- 27666047 Fax: 852- 23346389

Email: ceslchan@polyu.edu.hk Website: http://www.hkisc.org/

ISSN 1816-112X

Science Citation Index Expanded, Materials Science Citation Index and ISI Alerting

Copyright $\odot 2011$ by:

The Hong Kong Institute of Steel Construction. 


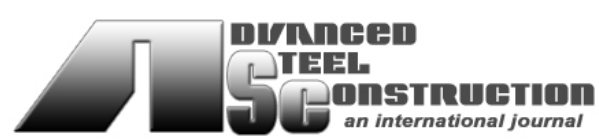

ISSN 1816-112X

Science Citation Index Expanded, Materials Science Citation Index and ISI Alerting

\section{EDITORS-IN-CHIEF}

Asian Pacific, African and organizing Editor

S.L. Chan

The Hong Kong Polyt. Univ., Hong Kong

Email: ceslchan@polyu.edu.hk

\section{American Editor}

W.F. Chen

Univ. of Hawaii at Manoa, USA

Email:waifah@hawaii.edu

\section{European Editor}

R. Zandonini

Trento Univ., Italy

Email: riccardo.zandonini@ing.unitn.it

\section{Advanced Steel \\ Construction an international journal}

VOLUME 7 NUMBER 1

MARCH 2011

Technical Papers (Special Issue)

Foreword

Dinar Camotim and Riccardo Zandonini

Partial Interaction Analysis with Shear-Lag Effects of Composite 1

Bridges: A Finite Element Implementation for Design

Applications

Fabrizio Gara, Gianluca Ranzi and Graziano Leoni

Experimental and Analytical Investigations of Steel and

Composite Trusses

S.L. Chan and M. Fong

Design by Testing of Industrial Racks

N. Baldassino and R. Zandonini

Experimental Study on Behaviors of the Trapezoid Connectors of

the Inverted T-Shaped Steel with Notched Web for a Novel

Composite Beam

Li Guo-qiang, Li Liang and Li Xianhui

Enhancing the Robustness of Steel and Composite Buildings D.A. Nethercot, P. Stylianidis, B.A. Izzuddin and A.Y. Elghazouli

Structural Behaviour of Elliptical Hollow Sections under Combined Compression and Uniaxial Bending

L. Gardner, T.M. Chan and J.M. Abela

Local / Distortional / Global Mode Coupling in Fixed Lipped

Channel Columns: Behaviour and Strength

Pedro B. Dinis, Dinar Camotim, Eduardo M. Batista and

Eliane Santos 


\section{FOREWORD}

This Special Issue of the International Journal of Advanced Steel Construction (IJASC) is devoted to several issues on which steel construction research focused recently its attention. Its publication is directly linked with the $6^{\text {th }}$ International Conference on Advances in Steel Structures held in Hong Kong, China, on December 16-18 2009, which was attended by more than 300 participants from all over the world. The Conference comprised 24 parallel sessions and encompassed 16 keynote lectures and the presentation of 146 papers, co-authored by researchers originating from 19 countries and 4 continents. On the basis of the quality of the presentations, some authors were invited to submit enhanced versions of their papers for publication in IJASC - those included in this Special Issue successfully went through a rigorous peer-review and revision process.

The 7 papers appearing in this Special Issue address a wealth of topics related to steel and steelconcrete composite structures, ranging from bridges to buildings, from elastic and inelastic buckling to robustness. Such complex problems are tackled by means of experimental, analytical and numerical research approaches. They are presented following a sequence that starts with steelconcrete composite systems, covering several advanced issues of bridge analysis and members in compression and in bending, touches the important novel area of robustness of frames and, finally, reaches the domain of thin-walled members, including a numerical-experimental investigation on column mode interaction and discussing open issues in the design of industrial racks. Next, a very brief overview of the content of each of these papers is provided:

(i) Gara, Ranzi and Leoni address the analysis of composite steel-concrete beams with partial interaction, accounting for the deformability of the shear connection. They use a FE numerical approach capable of capturing the beam structural response, including shear-lag effects and the concrete time-dependent behaviour. The versatility of the formulation is demonstrated for a wide range of realistic bridge arrangements, from twin-deck girders to cable-stayed bridges. The determination of steel effective widths and concrete stress distributions, as well as their variation in time, are also explored in the paper - these are important design issues.

(ii) Chan and Fong present an experimental and analytical investigation on the use of bare steel and steel-concrete composite rectangular hollow sections (RHS) as truss and frame members. The study enables the quantification of the beneficial effects of the concrete infill on the truss ultimate strength. A comparison between the test results and the estimates yielded by design approaches prescribed by the appropriate Eurocode documents shows that second-order analysis leads to more accurate predictions than design methods based on the combined use of linear analysis and effective lengths.

(iii) Gardner, Chan and Abela focus their attention on the structural behaviour of elliptical hollow sections (EHS) under combined compression and uniaxial bending (at the crosssectional level). Structural performance experimental data, obtained through a series of stub column tests involving various load eccentricities, are supplemented with further numerical results, determined by means of shell finite element analysis. Slenderness parameters and limits for EHS under combined compression and bending were developed. The available data also led to the proposal and validation of an interaction equation for the design of EHS under combined loading.

(iv) $\mathrm{Li}$ G.Q, Li L. and $\mathrm{Li} X$. study experimentally a novel steel-concrete composite beam with an inverted T-shaped steel section and trapezoidal connectors. The investigation aims at developing design criteria for these connectors and covers all the main aspects of their response: the behaviour in shear (through push tests), in tension (pull-out tests) and under local compression -punch tests have also been carried out. Design equations to estimate the beam shear capacity, local compressive strength and punch capacity are proposed in this work. 
(v) Nethercot, Stylianidis, Izzudin and Elghazouli address design provisions aimed at ensuring adequate robustness to steel and steel-concrete composite building frames. Following an approach devised earlier, and taking into account parametric studies that provided insight into the link between changes in a structure and its resistance to progressive collapse, the paper examines a number of different frame arrangements, for which key behavioural features are identified. The structural modifications are then classified according to their potential for improving the frame robustness and quantitative measures are developed to assess the amount of improvement.

(vi) Baldassino and Zandonini deal with the performance and design of industrial racks used for the storage of palletized goods. The large variability in terms of profile geometry, joints and perforations, as well the complexity of the phenomena affecting the member behaviour, do not yet allow the performance of a pure numerically-based design - instead, it is indispensable to carry out experimental tests, aimed at characterising the various structural components. Hence, the traditional design approaches combine experimental results and numerical analysis. This paper provides an overview of the experimental part of this approach, addressing both the European and North American standards. Open questions related to the clarity, accuracy and completeness of the current specifications are also pointed out and briefly discussed by the authors.

(vii) Dinis, Camotim, Batista and Santos present a numerical and experimental investigation on the (elastic and elastic-plastic) post-buckling behaviour and strength of fixed cold-formed steel lipped channel columns undergoing local-distortional-global (flexural-torsional) interaction. The numerical results provide in-depth understanding on the column triple interactive behaviour, namely on how it affects the column ultimate load and collapse mechanism. The few experimental results displayed (a full test program is under way at the Federal University of Rio de Janeiro) clearly show the column strength erosion due to the mode interaction, thus confirming the numerical findings. The paper closes with some preliminary considerations on the applicability of the current Direct Strength Method expressions to handle the interaction phenomenon under consideration.

Before closing, we would like to thank the authors of the papers for the quality of their work, and also for their patience and support during the preparation and revision of the manuscripts - it was a real pleasure to interact and cooperate with each one of them.

Likewise, the help of the reviewers was greatly appreciated - their valuable criticisms and suggestions contributed decisively to improve the technical content of this Special Issue. The careful and extremely professional handling of all the publishing matters by Ms. Freda Chow also deserves a special mention.

Finally, we would like to express our sincere gratitude to Prof. Siu Lai Chan, Chairman of ICASS'09 and Editor-in-Chief of IJASC, for having adhered so enthusiastically to the idea of this Special Issue.

\author{
Dinar Camotim ${ }^{1}$ \\ Riccardo Zandonini ${ }^{2}$ \\ Guest Co-Editors
}

\footnotetext{
1 Department of Civil Engineering and Architecture, ICIST/IST, Technical University of Lisbon, Portugal. E-mail:dcamotim@civil.ist.utl.pt

2 Department of Mechanical and Structural Engineering, University of Trento, Trento, Italy.

E-mail: riccardo.zandonini@unitn.it
} 


\title{
PARTIAL INTERACTION ANALYSIS WITH SHEAR-LAG EFFECTS OF COMPOSITE BRIDGES: A FINITE ELEMENT IMPLEMENTATION FOR DESIGN APPLICATIONS
}

\author{
Fabrizio Gara ${ }^{1}$, Gianluca Ranzi ${ }^{2}$ and Graziano Leoni ${ }^{3, *}$ \\ ${ }^{1}$ Department of Architecture Construction and Structures, Universita' Politecnica delle Marche, Ancona, Italy \\ ${ }^{2}$ School of Civil Engineering, The University of Sydney, Sydney, NSW2006, Australia \\ ${ }^{3}$ School of Architecture and Design, University of Camerino, Ascoli Piceno, Italy \\ *(Corresponding author: E-mail: graziano.leoni@unicam.it)
}

\begin{abstract}
This paper presents a numerical model for the analysis of composite steel-concrete beams with partial interaction to account for the deformability of the shear connection. The proposed approach is capable of capturing the structural response produced by shear-lag effects and by the time-dependent behaviour of the concrete. The versatility of the FE formulation is demonstrated for a wide range of realistic bridge arrangements, e.g. from twin-deck girders to cable-stayed bridges. The accuracy of the approach is validated against the results obtained from more refined models generated with shell elements using commercial finite element software. For each bridge typology considered, both deformations and stresses are calculated to provide greater insight into the structural performance. Particular attention is placed on the determination of the effective width to be used for design purposes and on the stress distribution induced in the concrete component, together with their variation with time due to creep and shrinkage.
\end{abstract}

Keywords: Cable stayed bridges, Composite bridge decks, Creep, Effective width, Shear-lag, Shrinkage, Steel-concrete members

\section{INTRODUCTION}

Steel-concrete composite decks are used in many bridge typologies. In addition to multi-span continuous beam arrangements, widely used in viaducts and flyovers, composite decks are also combined with other structural elements to achieve more articulated systems, such as arch bridges and cable stayed bridges, when longer spans are required. In the modelling of these structures it is common to use simple beam theory, according to which plane cross-sections remain plane after loading, even if such approach is not realistic as non-uniform stress distributions usually arise in the slab (shear-lag effect) reducing its effective width. These can also arise due to the application of concentrated loads, e.g. anchorage of prestressing cables or stays. When dealing with shear-lag effects international design guidelines recommend the use of the effective width method. While this approach is very efficient and useful for simple beam layouts, its fundamental assumptions are violated when applied to more articulated structural arrangements. In a design situation such structures may be analysed using refined models generated with shell or solid finite elements, in which case both model development and post-processing are very time-consuming. As required in international guidelines (e.g. Eurocode 4 [1]), a designer needs to evaluate the effective cross-section of a bridge girder to determine its resistance. Unfortunately, simple rules for the definition of the slab effective widths are available only for simple static cases. Another important aspect relates to the fact that the effective width is time-dependent when longitudinal concentrated forces are applied to the steel beam or to the concrete slab [2]. 
In this context, the finite element formulation adopted in this paper predicts the non-uniform distribution of stresses within the slab due to shear-lag effects, even in complex bridge arrangements, while maintaining the ease of use of standard line elements commonly used for frame analyses. The proposed technique is a powerful tool for the designer that can (i) analyse the structure without worrying about the effective width definition and (ii) perform the cross-sectional design calculations using the effective slab width determined from the appropriate static scheme and load layout.

The fundamental model was already proposed by the authors in [3], while in this paper the formulation is used to deal with a wide range of bridge arrangements and to account for time effects. Its use is proposed in combination with common truss and frame elements to enable the modelling of complex three-dimensional bridge arrangements.

The applications to realistic cases are discussed with particular emphasis to creep and shrinkage effects that have a great influence on the stress states and on the definition of the slab effective width.

\section{OVERVIEW OF THE ANALYTICAL AND NUMERICAL MODELS OF THE DECK}

A symmetric composite steel-concrete twin-girder bridge deck is considered (Figure 1). A local reference system $\left\{O ; x_{1}, x_{2}, x_{3}\right\}$ is introduced by placing the plane $x_{1}-x_{2}$ on the symmetry plane of the cross-section in such a way that $x_{1}$ and $x_{2}$ are longitudinal and vertical axes of the deck, respectively. The origin $O$ is located at an arbitrary location even if it may be conveniently placed at the centroid of the steel beams.

The cross-section is considered to be rigid in its own plane $\left(x_{2}-x_{3}\right)$ and the interface shear connection is assumed to prevent separation and lateral slips between the steel beam and the slab while permitting relative longitudinal displacements between them.

The kinematic model for a deck subjected to flexural and axial actions in the plane $x_{1}-x_{2}$ is briefly outlined in the following to provide a better insight into the results presented in the applications.

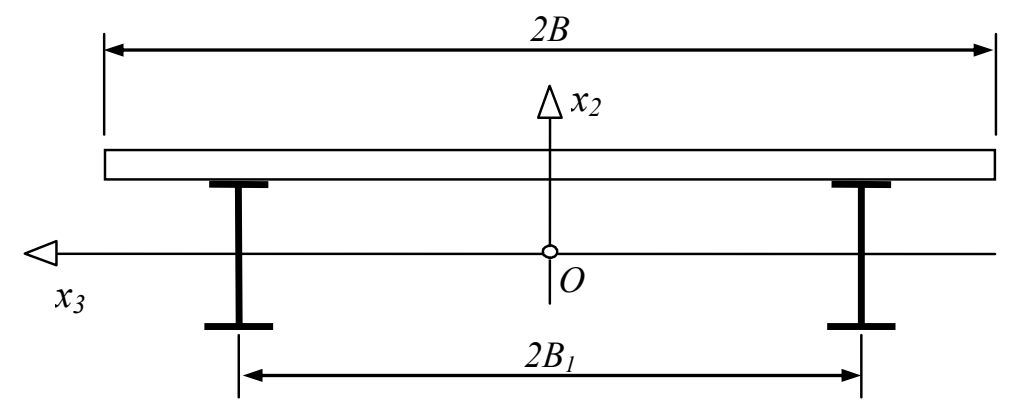

Figure 1. Steel-concrete Twin Girder Cross-section

Based on these considerations, and neglecting the shear deformability of the steel beams, the displacement of a generic point of the cross-section placed at $x_{1}$ is defined by the three components

$$
d_{1}\left(x_{1}, x_{2}, x_{3}\right)= \begin{cases}u_{1}\left(x_{1}\right)-x_{2} u_{2}^{\prime}\left(x_{1}\right) & \forall\left(x_{2}, x_{3}\right) \in A_{c} \\ u_{1}\left(x_{1}\right)-\Gamma\left(x_{1}\right)-x_{2} u_{2}^{\prime}\left(x_{1}\right)+\psi\left(x_{3}\right) \omega\left(x_{1}\right) & \forall\left(x_{2}, x_{3}\right) \in A_{a}\end{cases}
$$


$d_{2}\left(x_{1}, x_{2}, x_{3}\right)=u_{2}\left(x_{1}\right)$

$d_{3}\left(x_{1}, x_{2}, x_{3}\right)=0$

where the prime denotes the derivative with respect to $x_{1}, A_{c}$ and $A_{a}$ are the cross-sections of the concrete slab and the steel beam, respectively, $u_{1}$ and $u_{2}$ are the longitudinal and vertical displacements of the steel beam measured at the level of the reference axis $x_{1}, \Gamma$ is the longitudinal slip between the steel beams and the reinforced concrete slab and $\psi$ is the function describing the warping in the slab that is modulated along the deck axis by the intensity shear-lag function $\omega[4,5]$.

Given the particularity of the assumed deck cross-section, it is appropriate to adopt a function $\psi$ formed by three second order parabolic branches [6]

$$
\begin{array}{ll}
\psi\left(x_{3}\right)=\left(\frac{x_{3}}{B}\right)^{2}+2 \frac{x_{3}}{B}+\frac{B_{1}}{B}\left(2-\frac{B_{1}}{B}\right) & -B \leq x_{3} \leq-B_{1} \\
\psi\left(x_{3}\right)=\left(\frac{x_{3}}{B}\right)^{2}-\left(\frac{B_{1}}{B}\right)^{2} & -B_{1}<x_{3} \leq+B_{1} \\
\psi\left(x_{3}\right)=\left(\frac{x_{3}}{B}\right)^{2}-2 \frac{x_{3}}{B}+\frac{B_{1}}{B}\left(2-\frac{B_{1}}{B}\right) & +B_{1}<x_{3} \leq+B
\end{array}
$$

that describe rigorously the warping in the case of beams subjected to pure shear given the position of the main longitudinal beams.

Under the assumption of linear-elastic behaviour for the materials forming the cross section and for the shear connection, a displacement-based finite element has been developed [7] and implemented for the modelling of composite beams with complex static schemes [3]. A local reference system is introduced for each element with the origin located at node $i$ (Figure 2). If $\bar{x}_{1}$ is the longitudinal axis of the element, oriented from joint $i$ to joint $j$, axes $\bar{x}_{2}$ and $\bar{x}_{3}$ complete an ortho-normal reference system.

The nodal displacements of the finite element are defined according to the positive directions of the local reference axes. For each node, three displacement components and three rotation components are considered. Two additional degrees of freedom are introduced to define the beam-slab interface slip $\Gamma$ and the shear-lag function $\omega$ previously defined (Figure 2a). These last two generalized displacements are scalar quantities and thus do not depend on the adopted reference system.

Generalised stress resultants are defined corresponding to each of the displacements considered, i.e. three force components and three moments, the longitudinal shear force at beam slab interface and the slab bi-moment (Figure 2b). As for the displacements, the last two generalized actions are scalar quantities. 
The generalized nodal displacements and forces of element $e$ are grouped in the vectors

$$
\begin{aligned}
\boldsymbol{s}_{\boldsymbol{i}}{ }^{T} & =\left[\begin{array}{llllllll:llllllll}
u_{1 i} & u_{2 i} & u_{3 i} & \varphi_{1 i} & \varphi_{2 i} & \varphi_{3 i} & \Gamma_{i} & \omega_{i} & u_{1 j} & u_{2 j} & u_{3 j} & \varphi_{1 j} & \varphi_{2 j} & \varphi_{3 j} & \Gamma_{j} & \omega_{j}
\end{array}\right] \\
\boldsymbol{f}_{\boldsymbol{i}}{ }^{T} & =\left[\begin{array}{llllllllllllllllllll}
f_{1 i} & f_{2 i} & f_{3 i} & m_{1 i} & m_{2 i} & m_{3 i} & q_{i} & \beta_{i} & f_{1 j} & f_{2 j} & f_{3 j} & m_{1 j} & m_{2 j} & m_{3 j} & q_{j} & \beta_{j}
\end{array}\right]
\end{aligned}
$$

Based on the adopted material properties, the stiffness relationship of the line element can be expressed as $\overline{\boldsymbol{f}}_{\boldsymbol{e}}=\overline{\boldsymbol{K}}_{e} \overline{\boldsymbol{s}}_{e}$, where $\overline{\boldsymbol{K}}_{e}$ depicts its stiffness matrix. When modelling three-dimensional structural systems, this line element can be oriented freely. Adopting an ortho-normal global reference system and introducing $\boldsymbol{a}_{\alpha}$ and $\overline{\boldsymbol{a}}_{\alpha}(\alpha=1,2,3)$ as unit vectors of the global and local reference systems respectively, the rotation operator $\boldsymbol{R}_{e}$ can be expressed using the following matrices

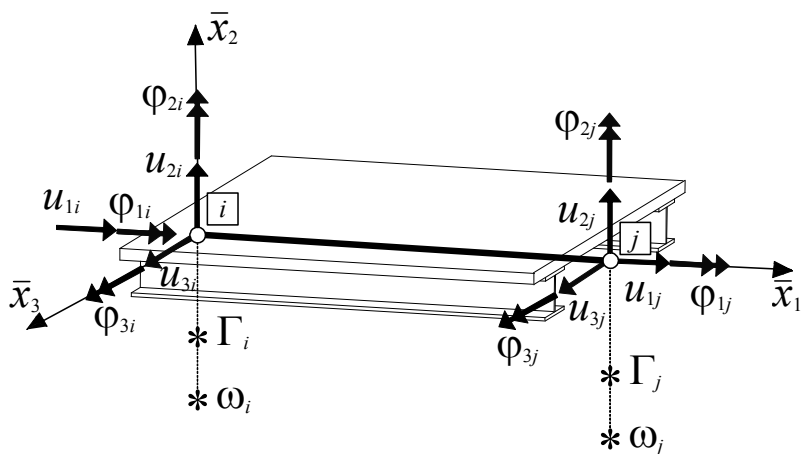

(a)

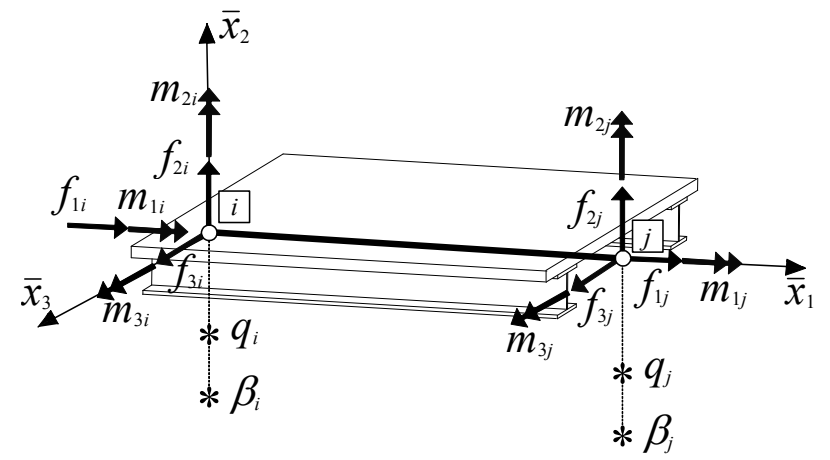

(b)

Figure 2. Composite Line Element: (a) Nodal Displacements; (b) Nodal Forces

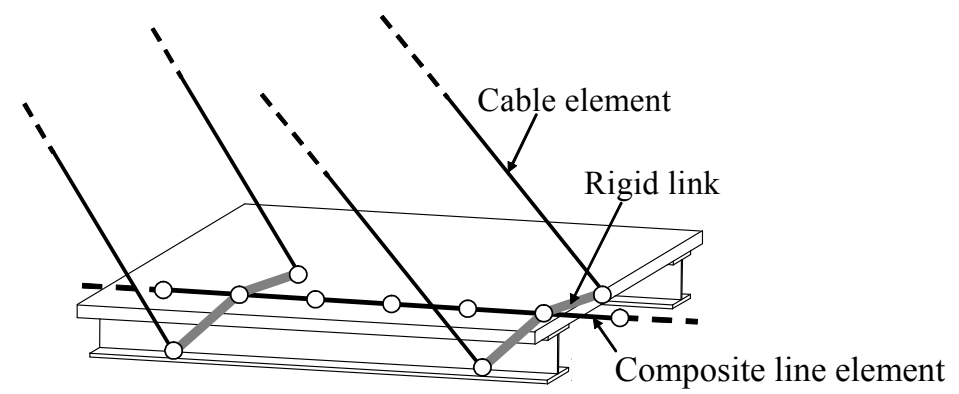

Figure 3. Combination of Composite Line Element with Rigid Links and Truss/Frame Elements

$$
\boldsymbol{R}_{\boldsymbol{e}}=\left[\begin{array}{cccccc}
\boldsymbol{R} & \mathbf{0} & \mathbf{0} & \mathbf{0} & \mathbf{0} & \mathbf{0} \\
\mathbf{0} & \boldsymbol{R} & \mathbf{0} & \mathbf{0} & \mathbf{0} & \mathbf{0} \\
\mathbf{0} & \mathbf{0} & \boldsymbol{I}_{22} & \mathbf{0} & \mathbf{0} & \mathbf{0} \\
\mathbf{0} & \mathbf{0} & \mathbf{0} & \boldsymbol{R} & \mathbf{0} & \mathbf{0} \\
\mathbf{0} & \mathbf{0} & \mathbf{0} & \mathbf{0} & \boldsymbol{R} & \mathbf{0} \\
\mathbf{0} & \mathbf{0} & \mathbf{0} & \mathbf{0} & \mathbf{0} & \boldsymbol{I}_{22}
\end{array}\right] \quad ; \quad \boldsymbol{R}=\left[\begin{array}{ccc}
\overline{\boldsymbol{a}}_{1} \cdot \boldsymbol{a}_{1} & \overline{\boldsymbol{a}}_{2} \cdot \boldsymbol{a}_{1} & \overline{\boldsymbol{a}}_{3} \cdot \boldsymbol{a}_{1} \\
\overline{\boldsymbol{a}}_{1} \cdot \boldsymbol{a}_{2} & \overline{\boldsymbol{a}}_{2} \cdot \boldsymbol{a}_{2} & \overline{\boldsymbol{a}}_{3} \cdot \boldsymbol{a}_{2} \\
\overline{\boldsymbol{a}}_{1} \cdot \boldsymbol{a}_{3} & \overline{\boldsymbol{a}}_{2} \cdot \boldsymbol{a}_{3} & \overline{\boldsymbol{a}}_{3} \cdot \boldsymbol{a}_{3}
\end{array}\right] ; \quad \boldsymbol{I}_{22}=\left[\begin{array}{cc}
1 & 0 \\
0 & 1
\end{array}\right] \quad(4 \mathrm{a}, \mathrm{b}, \mathrm{c})
$$

Based on these, the nodal displacement and force vectors are transformed from the local to the global reference system based on $\overline{\boldsymbol{s}}_{e}=\boldsymbol{R}_{e} \boldsymbol{s}_{e}$ and $\overline{\boldsymbol{f}}_{e}=\boldsymbol{R}_{e} \boldsymbol{f}_{e}$. In a similar manner, also the stiffness relationship can be expressed in global coordinates using $\boldsymbol{K}_{e}=\boldsymbol{R}_{e}{ }^{T} \overline{\boldsymbol{K}}_{e} \boldsymbol{R}_{e}$. 
It is worth noting that in the cases of composite line element subjected only to flexural actions in its vertical plane, being the composite element characterised by only 10 dof, the relative $10 \times 10$ stiffness matrix needs to be expanded to dimension $16 \times 16$ by adding rows and columns of zeros to comply with the three-dimensional problem. Obviously, this results in an ill-conditioned problem solved by imposing special constraints to the element to limit rigid motions in the horizontal plane and for torsional rotations.

The freedoms of the proposed finite element are presented in Figure 2a. This element can be connected to conventional frame and truss elements using standard assembling procedures. Although different choices of nodal displacements can be used to describe the displacement field of the proposed finite element, for the selection adopted in this paper (Figure 2), the element end freedoms available for assembling to other conventional line elements (i.e. frame and truss elements) consist of the vertical deflection, rotation and axial displacement of the steel joist. The beam-slab interface slip $\Gamma$ and the shear lag function $\omega$ cannot be constrained to freedoms of conventional line element and, as a consequence, no interaction can occur directly with the concrete slab. Such restriction can be easily overcome by adopting a set of independent end displacements in the formulation of the element which includes the axial displacement in the concrete component. The connectivity of the proposed element reflects common practice in which the connections among steel elements are usually preferred. For clarity, the possible connectivity used in the modelling of a cable stayed bridge is depicted in Figure 3, where the stays are connected laterally to the line element by means of rigid links.

In addition to the usual external restraints which prevent the six displacement components, other two kinds of restraints, able to prevent the interface slip and the slab warping, may be specified for the composite line element. The restraints on the slip can be used to model a deck with rigid shear connections whereas the restraint on the slab warping can simulate the presence of rigid structural elements (e.g. end transverse beams). The case of flexible transverse beams limiting the slab warping can be depicted by defining special generalized springs.

\section{VALIDATION OF THE FINITE ELEMENT FORMULATION}

The accuracy of the composite line element depicted in Figure 2 has been validated in the case of a realistic bridge. In the proposed application, the bridge on the Nive River built in Bayonne has been used as case study [8]. This bridge consists of a four-span continuous configuration and all relevant geometric properties are specified in Figures 4 and 5. Material properties for the steel, concrete and shear connection are: steel elastic modulus $E_{s}=210 \mathrm{GPa}$, concrete elastic modulus $E_{c}=32490 \mathrm{MPa}$, concrete Poisson's ratio $v=0.15$, and shear connection stiffness $\rho=12 \mathrm{kN} / \mathrm{mm}^{2}$. The slab is supported by cantilevered cross beams placed at a spacing of $3.78 \mathrm{~m}$. The results calculated modelling the bridge with the composite line elements are compared with those obtained with a shell model (Figure 6) implemented with SAP2000 [9]. In particular, 213 line elements are used to describe the bridge deck with a total of 1703 degrees of freedoms, significantly smaller than the 53750 degrees of freedom required by the shell element model. 


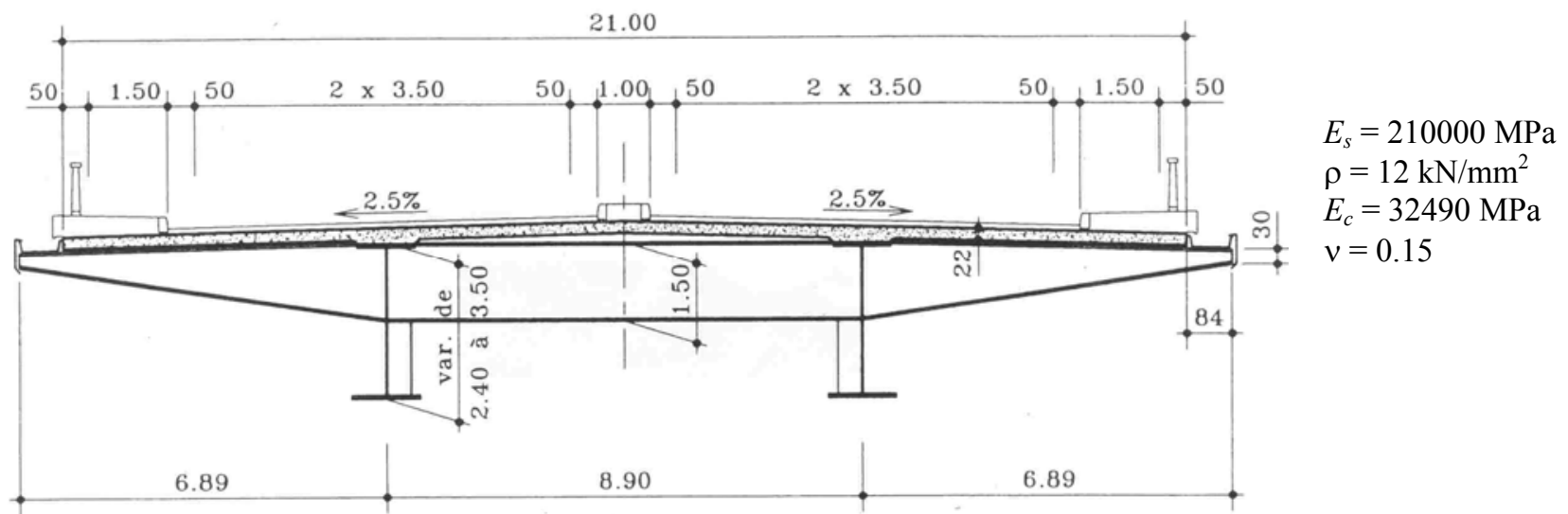

Figure 4. Bridge on Nive River: Cross-section
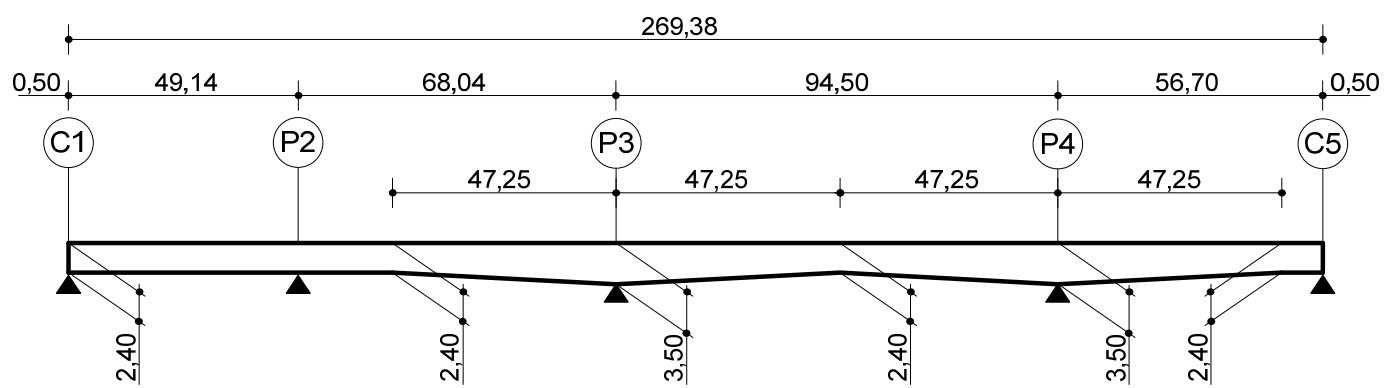

\begin{tabular}{|c|c|c|c|c|c|c|c|c|c|c|c|c|c|c|}
\hline $\begin{array}{c}\text { Top flange } \\
1100 x\end{array}$ & 40 & $\begin{array}{c}80 \\
+20\end{array}$ & 40 & 80 & $\begin{array}{c}80 \\
+60\end{array}$ & 80 & 40 & 55 & 60 & $\begin{array}{ll}55 & 40\end{array}$ & 80 & $\begin{array}{c}80 \\
+60\end{array}$ & 80 & 40 \\
\hline Web & 15 & 21 & 15 & & 21 & & & & 15 & & & 21 & & 15 \\
\hline $\begin{array}{c}\text { Bottom flange } \\
1300 \mathrm{x}\end{array}$ & 60 & $\begin{array}{c}60 \\
+35\end{array}$ & 60 & 80 & $\begin{array}{c}80 \\
+40\end{array}$ & 8 & 30 & & $80+40$ & & 30 & \begin{tabular}{|c|}
80 \\
+40
\end{tabular} & 80 & 60 \\
\hline
\end{tabular}

Figure 5. Bridge on Nive River: Thickness of Steel Plates within the Beams
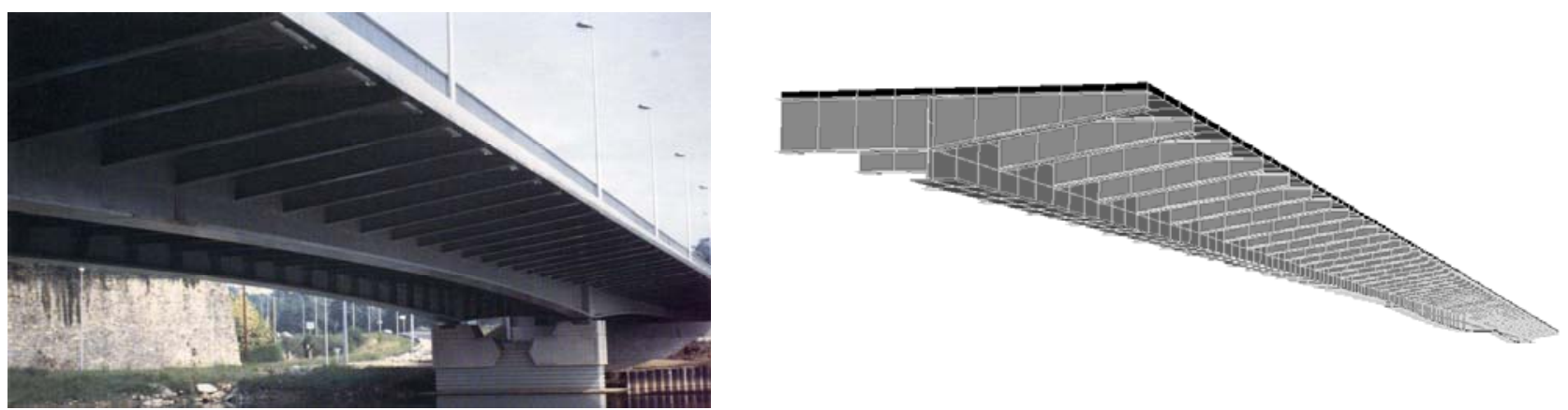

Figure 6. Bridge on Nive River: Shell Finite Element Model of the Deck

\subsection{Comparisons}

A vertical uniformly distributed load is applied to the top side of the slab. In the adopted numerical calculations, a line load is specified when using the line element while a surface distributed load is adopted in the shell element model. The selected case study is useful to provide insight into the influence of the cross beams, also connected to the concrete component, on the overall shear-lag behaviour of the slab. 
For clarity, the results obtained using the composite line elements are reported with continuous lines while those obtained with the shell element model are illustrated with markers (circles and triangles). Figure 7 depicts the deflection and the longitudinal stresses in the bottom flange of the steel girder and Figure 8 shows the longitudinal normal stress in the middle plane of the slab for a selected set of cross-sections placed along the bridge. Based on these comparisons it is shown that the use of the composite line elements provides a very good representation of the structural response calculated with the more refined shell element model. Small discrepancies between these results occur only for the concrete slab stresses at the cross-sections 1 and 2 in Figure 8 located over and close to the end support, respectively. This is justified by the fact that, at these sections, the local transverse behaviour affects the longitudinal behaviour of the girder and the adopted model captures this localised stress diffusion only in a simplified way. Despite this, these discrepancies are not significant since at these locations the stresses are small and do not govern the design.

When considering the evaluation of the deflections, errors higher than $10 \%$ are obtained by comparing the values calculated with the proposed numerical model with those of the shell element model plotted with a dotted line with triangles (Shell a). This discrepancy was already observed in [7] for simpler bridge arrangements and was justified by the shear deformability of the steel components that is neglected in the proposed numerical formulation. The same finite element model is re-utilised for this analysis while increasing the shear modulus of the materials adopted for the shell elements. The results of this latter model have been referred to in the following as 'Shell $b$ ' to distinguish them from those calculated using the initial FE model denoted as 'Shell a'. The discrepancies observed for the deflection using model 'Shell a' become negligible when using model 'Shell b' as shown with the dotted line and circular marks in Figure 7, in which case the latter line becomes coincident with the continuous curve representing the proposed numerical model. It is worth noting that this change in the shear modulus also affects the discrepancy of the concrete stress states at cross-section 4 (Figure 8), becoming less remarkable as the shear deformability of the beam becomes negligible.
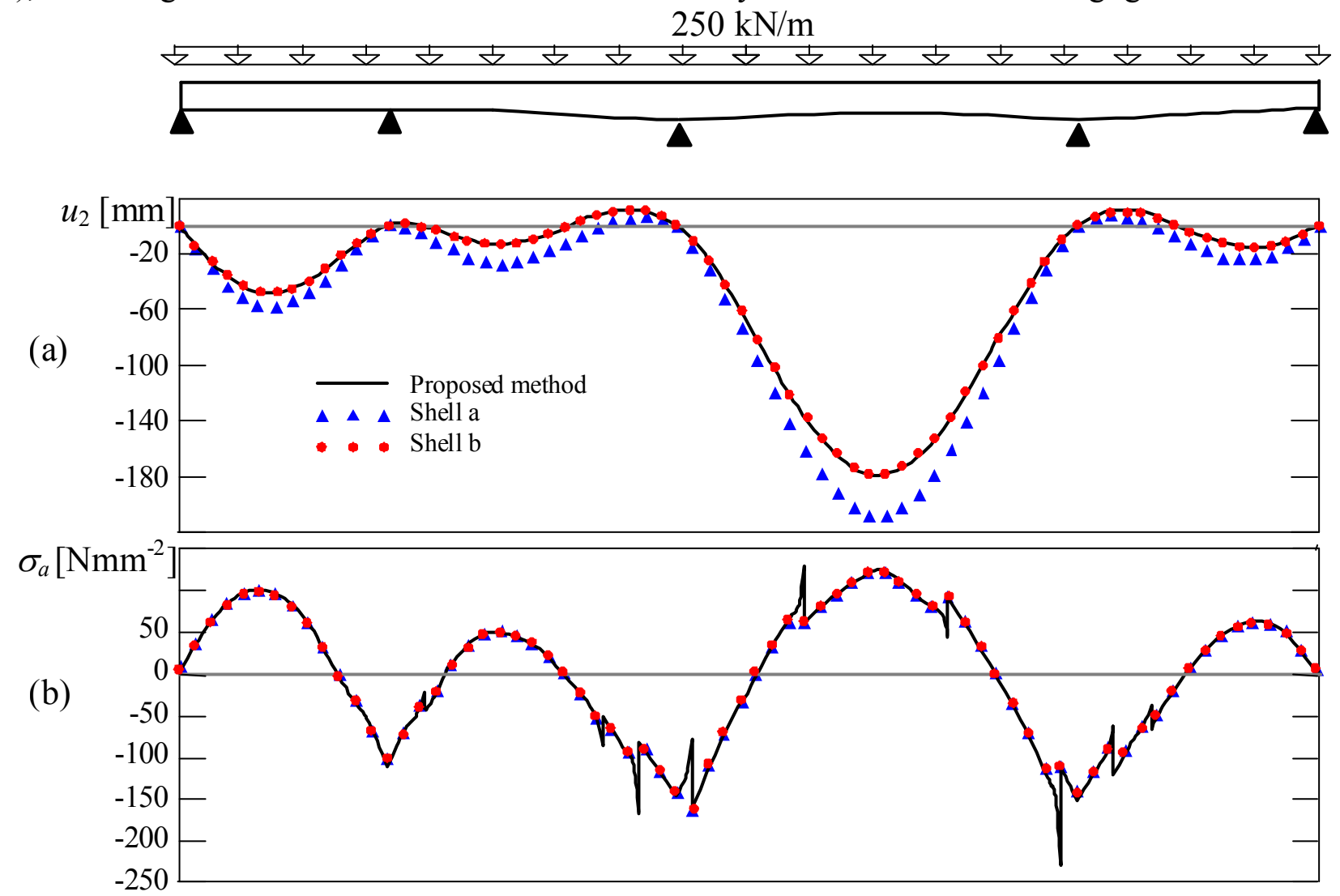

Figure 7. Bridge on Nive River:

(a) Deflection of the Deck (b) Longitudinal Stresses in the Bottom Flange of the Steel Girders 
In regards to the occurrence of shear-lag effects, the presence of cross beams does not affect the overall response. This is partially due to the fact that cross beams do not constitute a restraint against the slab warping because of their low lateral and torsional stiffness. As the concrete stresses are evaluated at the mid-height of the slab, these are only affected by the membrane action of the slab and not by its bending one that is more influenced by the presence of the cross-beams.

Of course this is a limit of the proposed model that nevertheless maintains its validity in describing the behaviour of the bridge and confirms to be a good tool for the verification of the composite cross-sections. It is worth noting that, if necessary, bending effects of the slab may be easily evaluated with partial models (or also with available charts) and superimposed to the membrane effects to evaluate the maximum stresses at the top or bottom plane of the slab.

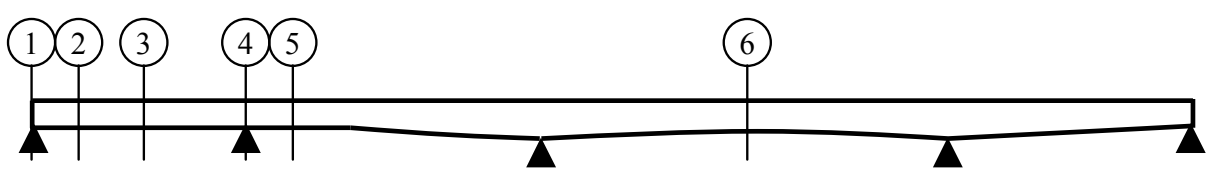

$\sigma_{c}\left[\mathrm{Nmm}^{-2}\right]$
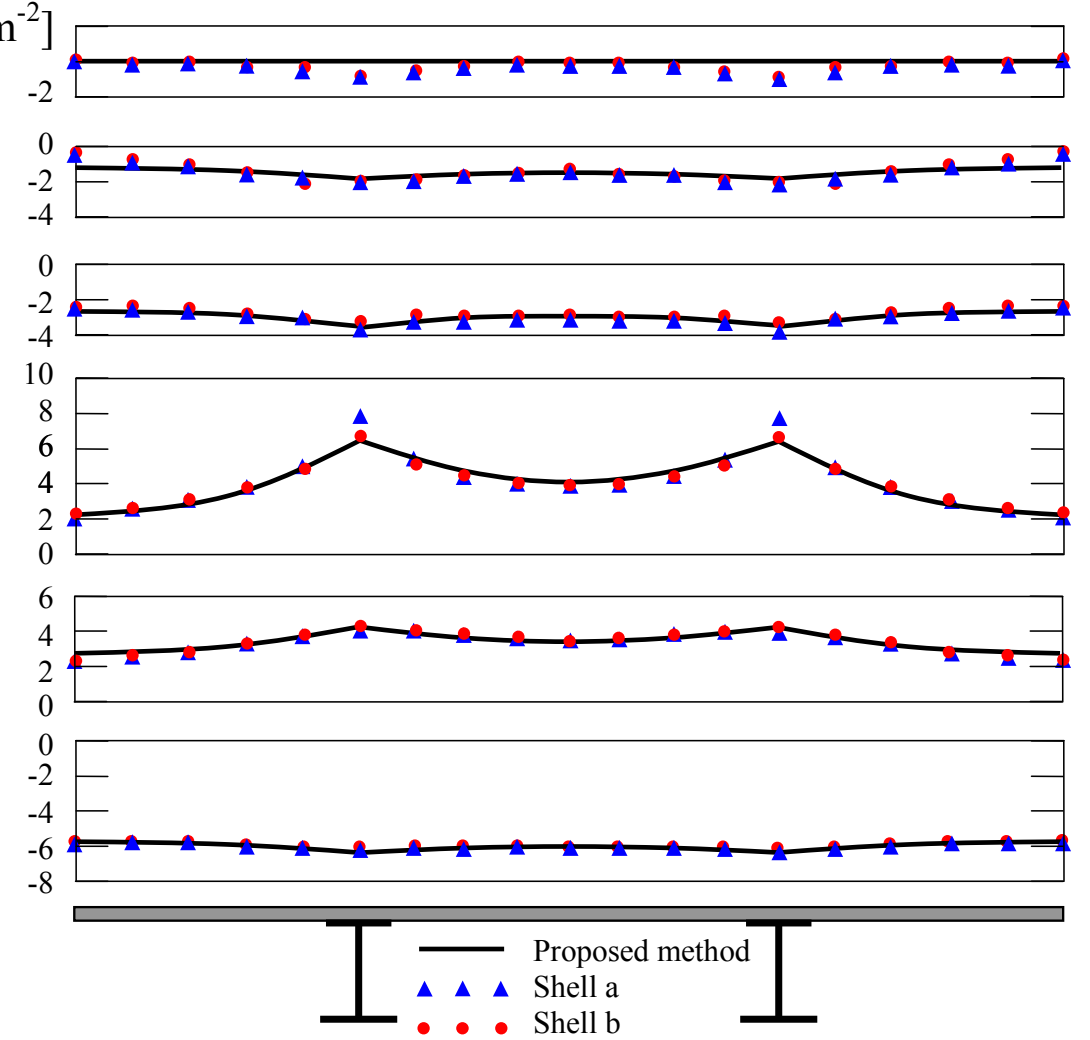

Figure 8. Bridge on Nive River: Longitudinal Stresses in the Middle Plane of the Slab

\section{APPLICATION TO A CABLE STAYED BRIDGE}

A cable-stayed bridge is considered to outline the capabilities of the proposed composite finite element, when combined with other truss and frame elements, to model complex bridge systems. The case study considered is shown in Figure 9. This consists of a steel-concrete composite deck supported by two reinforced concrete pylons, higher than $70 \mathrm{~m}$, and by 28 couples of stays pretensioned to control the deck deflection and the horizontal displacements of the pylons. Two anchor piers are placed at the bridge ends. The reinforced concrete slab of the deck is $0.23 \mathrm{~m}$ thick and is sustained by cross beams supported by the two longitudinal main girders. The spacing between 
stays' anchorages is $18 \mathrm{~m}$. The cylinder strength of the concrete used for the slab and the pylons is $f_{c k}=45 \mathrm{~N} / \mathrm{mm}^{2}$; the elastic constants $E_{\mathrm{s}}=165000 \mathrm{~N} / \mathrm{mm}^{2}$ and $E_{\mathrm{a}}=210000 \mathrm{~N} / \mathrm{mm}^{2}$ are considered for the stays and the structural steel, respectively.
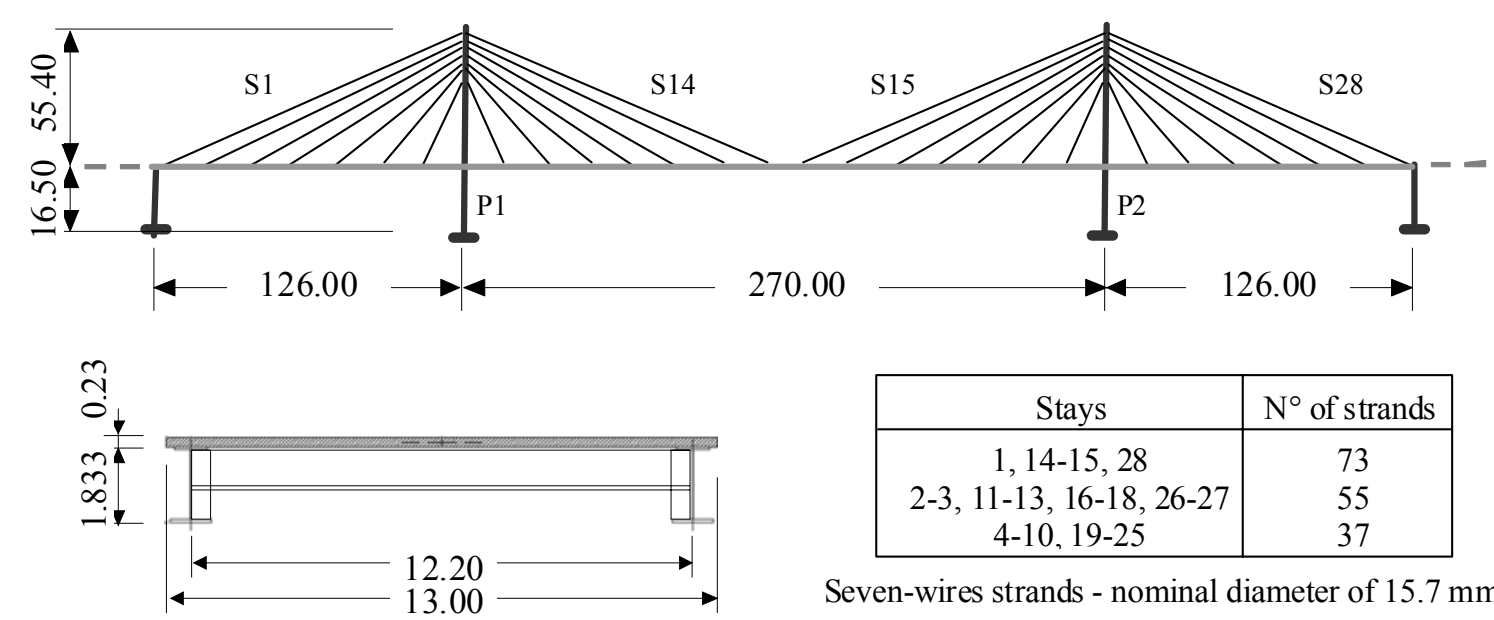

\begin{tabular}{|c|c|}
\hline Stays & $\mathrm{N}^{\circ}$ of strands \\
\hline $1,14-15,28$ & 73 \\
$2-3,11-13,16-18,26-27$ & 55 \\
$4-10,19-25$ & 37 \\
\hline
\end{tabular}

Seven-wires strands - nominal diameter of $15.7 \mathrm{~mm}$

Figure 9. General Layout and Dimensions of the Cable-stayed Bridge Considered

The proposed finite element is used for the composite deck whereas common truss and beam elements are used for the stays and the pylons, respectively; in order to ensure the correct positioning of the stays at the sides of the bridge, rigid links have also been used in the model.

Short- and long-term analyses are carried out considering the following loading conditions: (i) a uniformly distributed load (UDL) of $150 \mathrm{kN} / \mathrm{m}$, representing the self-weight and other permanent loads; (ii) UDL and shrinkage; and (iii) traffic loads (TL) applied at the central span.

The long-term analyses are carried out by means of the Effective Modulus Method as recommended in [1]. With this approach an effective elastic modulus $E_{\text {eff }}\left(t, t_{0}\right)$ is adopted for the concrete when considering the time-dependent behaviour which is calculated as:

$E_{e f f}\left(t, t_{0}\right)=\frac{E_{c}\left(t_{0}\right)}{1+\psi_{L} \phi\left(t, t_{0}\right)}$

in which $E_{c}\left(t_{0}\right)$ is the concrete elastic modulus calculated at the time of first loading $t_{0}, \phi\left(t, t_{0}\right)$ depicts the creep coefficient defining the creep occurred at time $t$ for a stress first applied at time $t_{0}$, and $\psi_{L}$ represents the creep multiplier which depends on the type of loading and its values are based on European guidelines [1]. In particular, the value for $\psi_{L}$ used for sustained loads and prestressing of stays is 1.1. The effects of concrete shrinkage are evaluated using a $\psi_{L}$ value of 0.55 and a creep coefficient $\phi\left(t, t_{s}\right)$ defined with respect to time $t_{s}$, which is the instant at which shrinkage is supposed to start (end curing). The creep coefficients and the shrinkage action are defined according to Eurocode 2 [10].

Results are presented in terms of deflections, stress state in the steel beams and concrete slab and effective width of the slab. Figure 10 shows the results obtained considering both short- and long-term actions calculated at 28 and 20000 days, respectively. In particular, the results of the short-term analysis carried out are reported along the whole bridge whereas long-term results are reported with and without shrinkage action in the left and right sides of the diagrams, respectively. The deck deflection is depicted in Figure 10a. The short-term results are characterised by null displacements at the stays anchorage as a consequence of the prestressing. Long-term deflections 
slightly increase as creep and shrinkage develop. It is worth noting that the configuration of zero-deflection, achieved in the instantaneous analysis balancing the self-weight of the deck by means of the stays' prestressing, is lost in the long-term even if the modifications are not important since they are within $80 \mathrm{~mm}$.

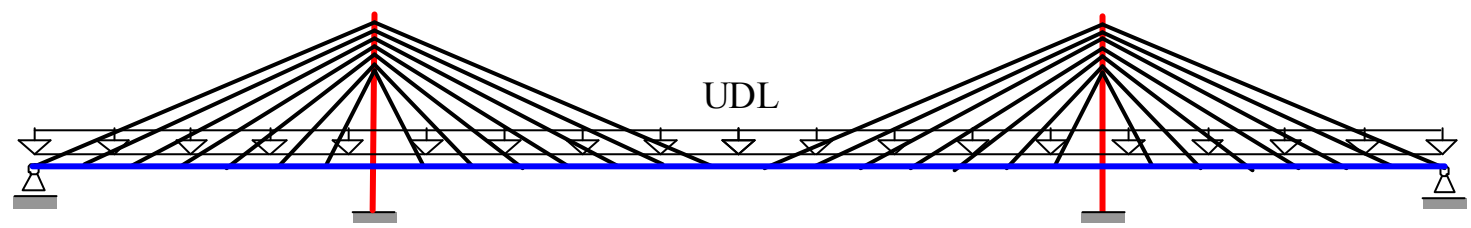

Without shrinkage With shrinkage

(a)

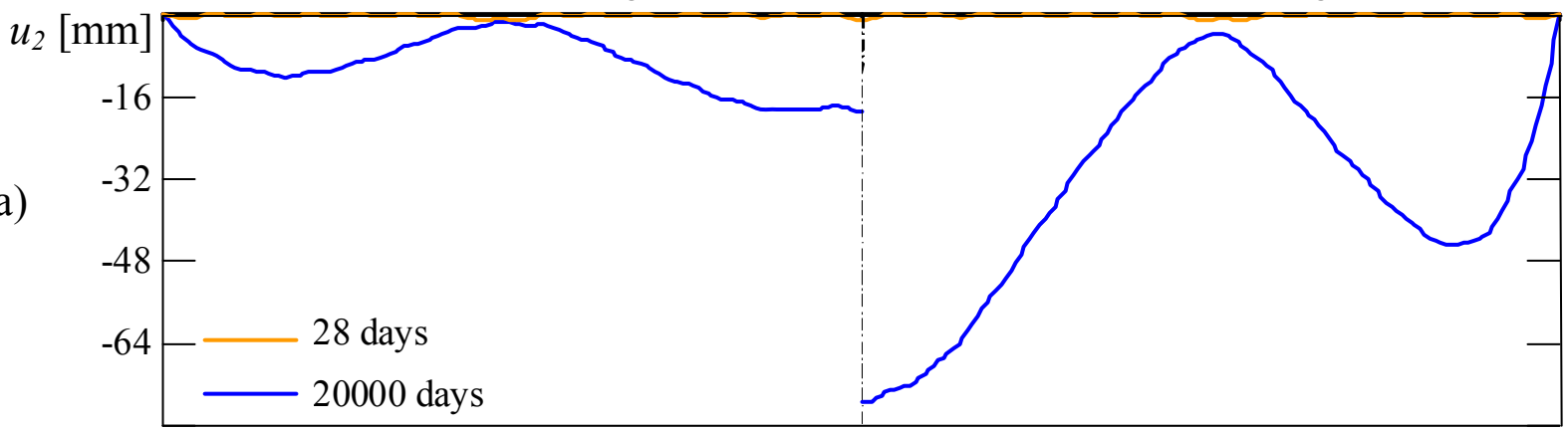

$\sigma_{a}\left[\mathrm{Nmm}^{-2}\right]$

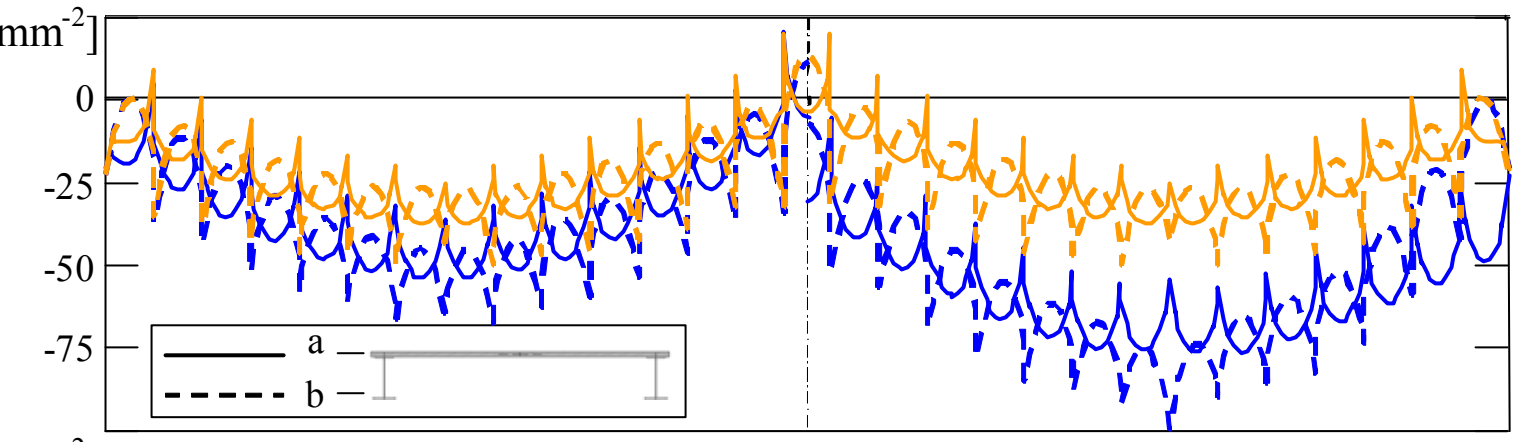

(b)

$\sigma_{c}\left[\mathrm{Nmm}^{-2}\right]$

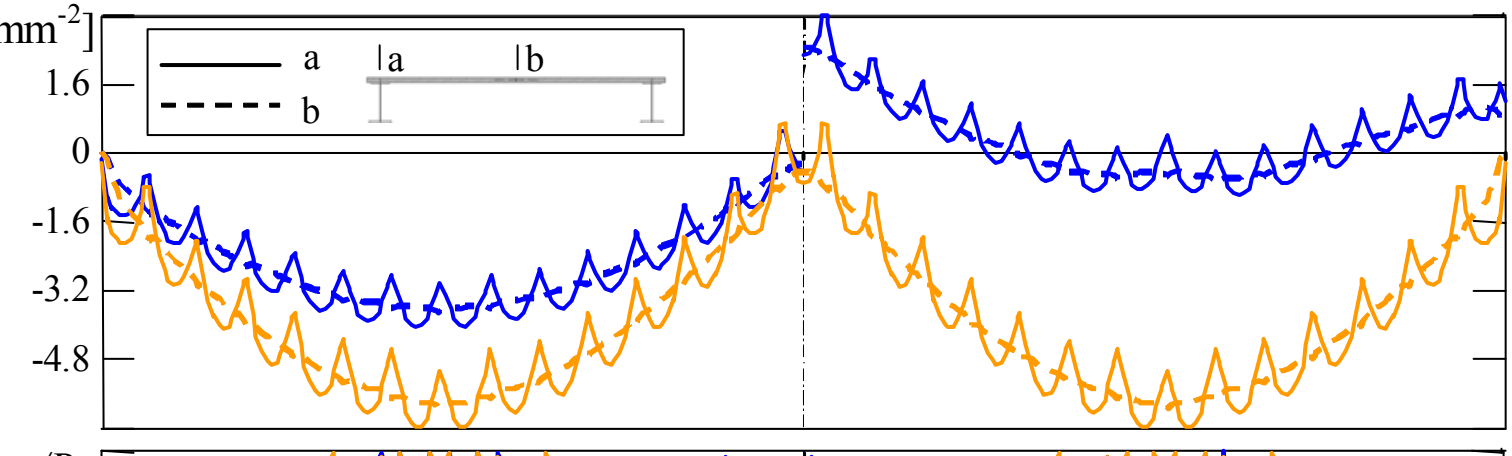

(c)

(d)

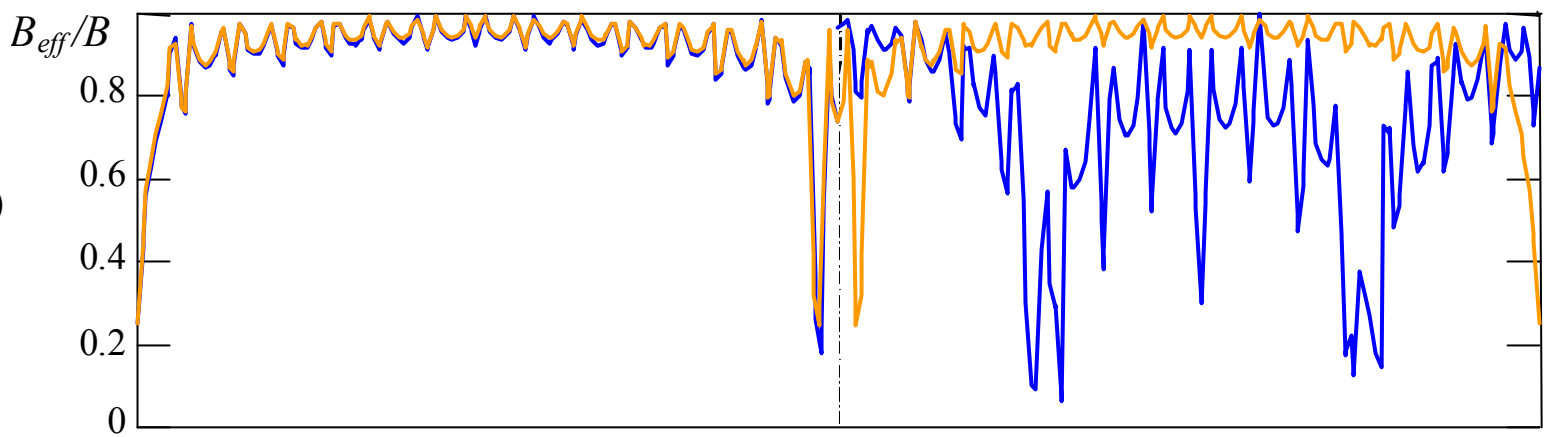

Figure 10. Permanent Actions: (a) Deck Deflection; (b) Longitudinal Normal Stresses in the Top and Bottom Flanges of the Steel Beam; (c) Longitudinal Normal Stresses at Mid-height of the Slab; (d) Effective Width over the Actual Deck Width 


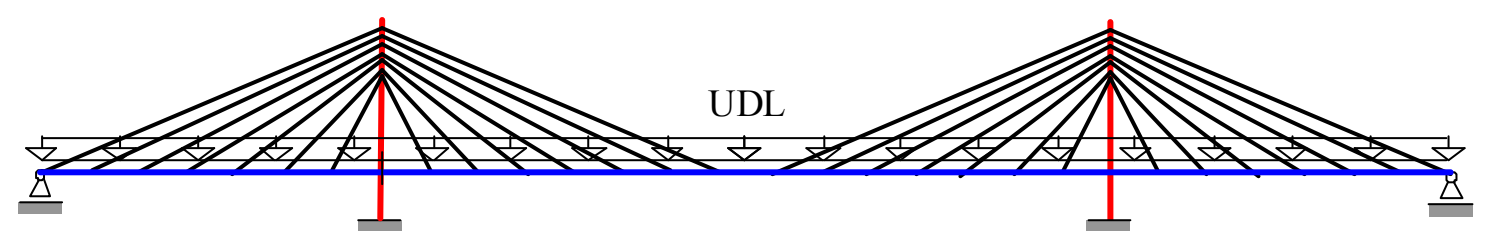

Without shrinkage

With shrinkage

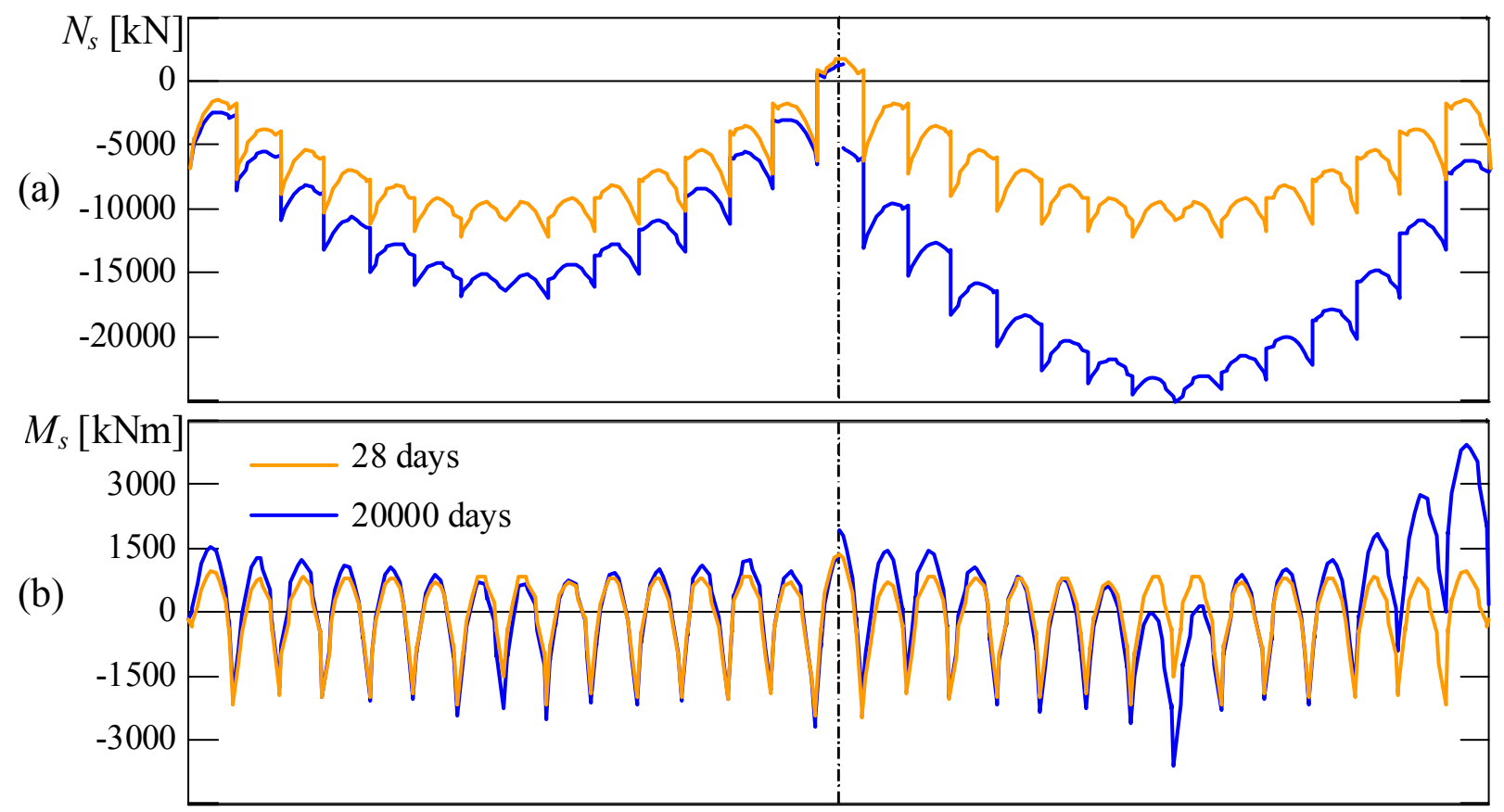

Figure 11. Permanent Actions: (a) Axial Force and (b) Bending Moment of the Steel Beam

The stresses obtained for the top and bottom steel flanges are illustrated in Figure 10b while Figure $10 \mathrm{c}$ plots the stresses calculated at mid-height of the slab along the bridge length at the location of the steel member axis and along the centre-line of the deck. The slab effective width is determined based on the calculated stress distributions and is illustrated in Figure 10d.

The stress distributions in the steel girders (Figure 10b) are determined based on the axial force that, as expected, is maximum near the pylons and minimum at the deck ends and at mid-span of the central span (Figure 11a), and on the bending moment that varies between each couple of stays according to parabolic curves (Figure 11b). Due to the long-term behaviour of the concrete, the compressive axial forces grow in time. In particular, the effect of shrinkage is quite remarkable as shown in the right side diagram of Figures $10 \mathrm{~b}$ and $11 \mathrm{a}$.

Near the longitudinal steel members the concrete stress distribution has a distinguished varying pattern which tends to smoothen when moving towards the centre-line of the cross-section (Figure 10c). This demonstrates the effects produced by the concentrated forces exerted by the stays' anchorages. The diffusion mechanism captured by the model is such that for cross-sections close to the stay anchorage, the higher stress value are obtained along the longitudinal beams while for cross-sections placed between two consecutive stay anchorages, the stress maximum value is obtained at the centre-line of the slab. When considering long-term effects, the concrete compressive stresses tend to reduce with time; in particular, the effects of shrinkage produces tensile stresses for large deck sections where prestressing due to stays becomes less significant. This is particularly evident from the contour diagrams of the slab that highlight sections characterised by peaks of tensile stresses for the slab sections in the proximity of stays' anchorages (Figure 12). 

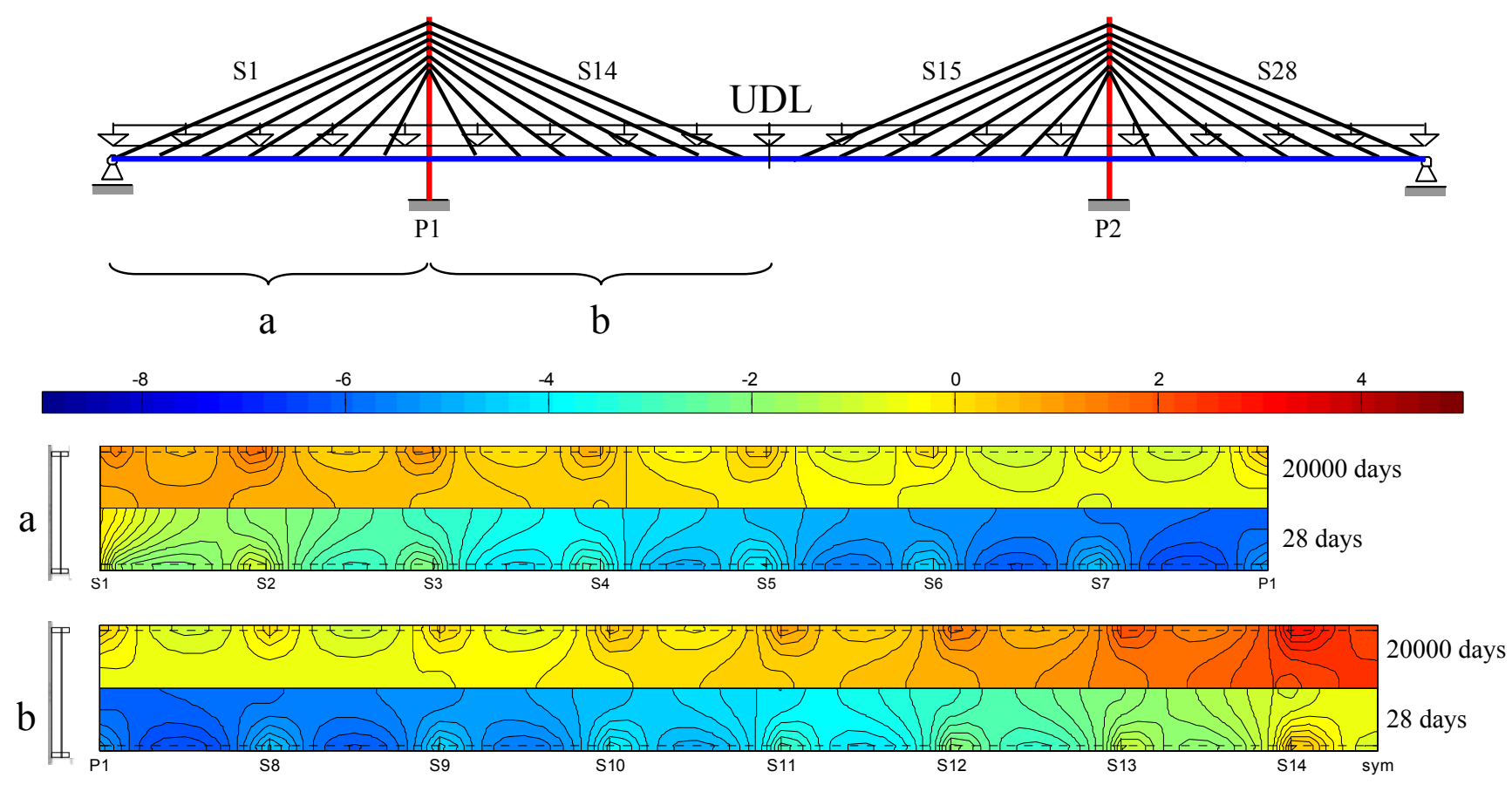

Figure 12. Permanent Actions: Contour Plots of Stresses in the Reinforced Concrete Slab due to Permanent Actions

Particular attention is required when analysing the results in Figure $10 \mathrm{~d}$ where the slab effective width is plotted. In the short term, it may be observed that the fluctuation reflects the variation of the compressive stresses in the slab and that, excepting for slab sections at the middle of the central span and at the bridge ends, the effective width remains within 0.9 and 1.0 times the real slab width; the very low values obtained for the other sections previously mentioned (less than 0.4 ) are due to the fluctuation of stress compared with the low overall compression of the slab. It is worth highlighting that the localised minimum values observed are not relevant from a design viewpoint as related to bridge segments along which the stress levels are relatively low.

The long-term effects on the definition of the slab effective width are strongly characterised by the concrete shrinkage; this produces a significant reduction of the effective width (down to 0.7 ) also for sections characterised in the short-term analyses by moderate effects of stress concentrations. This is due to shrinkage which is responsible for inducing tensile stresses, almost uniformly distributed within the whole slab except for the end sections, that superimpose onto stresses due to permanent loads and stays' pretensioning. In this process shrinkage does not modify the fluctuation at the lateral beam locations but mainly reduces the overall axial force in the slab by magnifying the stress concentration.

Table 1 shows the effects of the different load cases considered on the stays' pretensioning forces. It is evident that the long-term effects are such that only small variations of the internal forces are induced in the stays. 
Table 1. Axial Forces in the Stays due to Prestressing and Permanent Actions

\begin{tabular}{|c|c|c|c|}
\hline \multirow[t]{2}{*}{ Stays } & 28 days & $\begin{array}{l}20000 \text { days } \\
\text { Without } \\
\text { shrinkage }\end{array}$ & \multirow{2}{*}{$\begin{array}{c}20000 \text { days } \\
\begin{array}{c}\text { With } \\
\text { shrinkage }\end{array} \\
{[\mathrm{kN}](\%)}\end{array}$} \\
\hline & {$[\mathbf{k N}]$} & {$[\mathrm{kN}](\%)$} & \\
\hline 1,28 & 3800 & $3729 \quad(-1.9)$ & $3559 \quad(-6.3)$ \\
\hline 2,27 & 3333 & $3310 \quad(-0.7)$ & $3314 \quad(-0.6)$ \\
\hline 3,26 & 2869 & $2871 \quad(+0.1)$ & $2943 \quad(+2.6)$ \\
\hline 4,25 & 2589 & $2601 \quad(+0.5)$ & $2658 \quad(+2.7)$ \\
\hline 5,24 & 2225 & $2240 \quad(+0.7)$ & $2281 \quad(+2.5)$ \\
\hline 6,23 & 1805 & $1812(+0.4)$ & $1809 \quad(+0.2)$ \\
\hline 7,22 & 1570 & $1540 \quad(-1.9)$ & $1427 \quad(-9.1)$ \\
\hline 8,21 & 1570 & $1548 \quad(-1.4)$ & $1456 \quad(-7.3)$ \\
\hline 9,20 & 1804 & $1812(+0.4)$ & $1804 \quad(0.0)$ \\
\hline 10,19 & 2230 & $2242 \quad(+0.5)$ & $2254 \quad(+1.1)$ \\
\hline 11,18 & 2569 & $2579 \quad(+0.4)$ & $2600 \quad(+1.2)$ \\
\hline 12,17 & 2947 & $2943 \quad(-0.2)$ & $2958 \quad(+0.4)$ \\
\hline 13,16 & 3085 & $3061 \quad(-0.8)$ & $3057 \quad(-0.9)$ \\
\hline 14,15 & 3975 & $3917 \quad(-1.5)$ & $3864 \quad(-2.8)$ \\
\hline
\end{tabular}

Figure 13 shows the results obtained by considering traffic loads at the central span. According to the Load Model 1 of Eurocode 1-2 [11], four notional lanes are considered within the deck width; this results in a uniformly distributed load of $52 \mathrm{kN} / \mathrm{m}$ and in a couple of concentrated loads of $700 \mathrm{kN}$. On the left side of the diagrams, the results are superimposed on the short-term stresses due to permanent loads whereas on the right side the same are superimposed on long-term stresses inclusive of shrinkage. Also in this case it is interesting to highlight the differences between the short- and long-term behaviours, which are strongly characterised by shrinkage, and how the effective width is sensitive to the loading conditions. Figure 14 shows a contour plot of stresses at mid-height of the concrete slab.

\section{CONCLUSIONS}

This paper presented an implementation for design applications of a composite line finite element based on partial interaction theory. The element is suited for capturing the shear-lag effects and its use is suitable for composite steel-concrete decks for which the assumption of preservation of the plane cross-section is not valid due to the large widths of the slabs when compared to their thickness. Models of complex bridges may be easily developed without considerations of the definition of the effective cross-section when combining the use of this element with other line elements (trusses and frame beams).

The proposed formulation is able to account for shear-lag effects in complex bridges where simplified methods are not applicable. Based on this formulation, the effective widths to be used in design are calculated consistently for each load combination and the produced results can be used by a designer following standard procedures. 


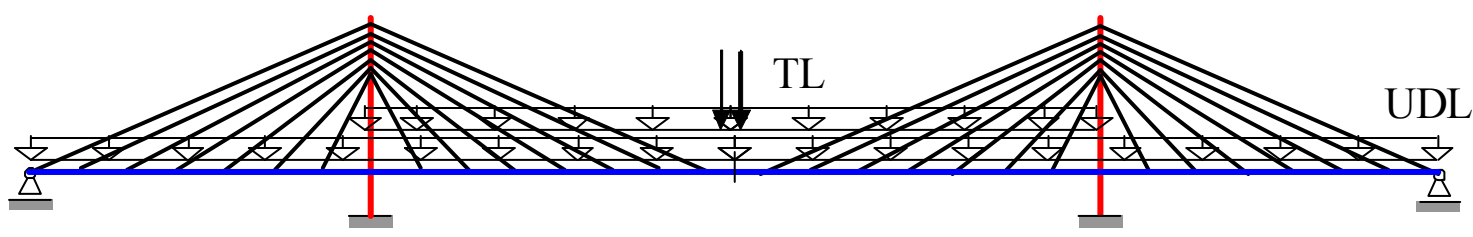

28 days

20000 days

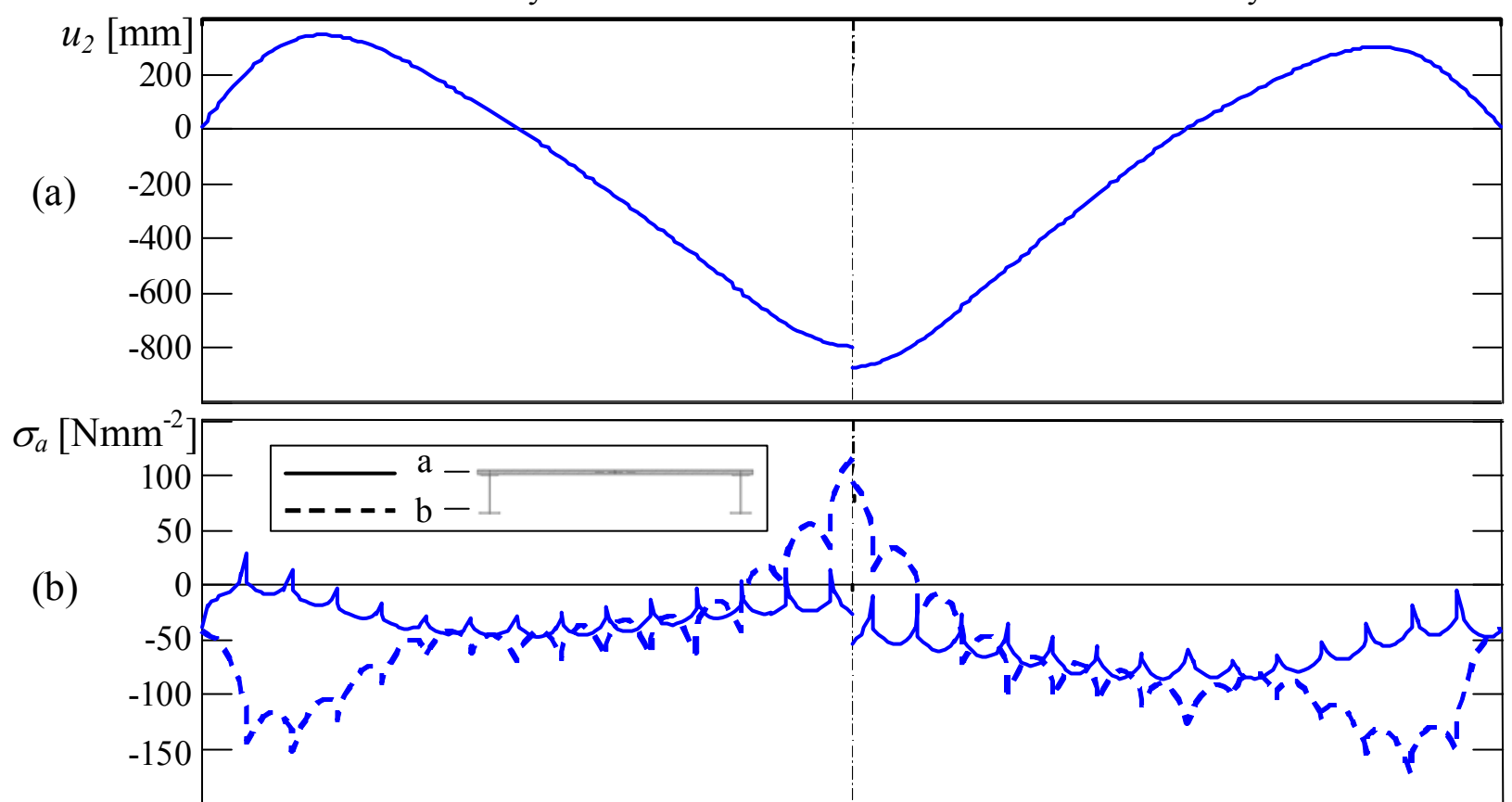

$\sigma_{c}\left[\mathrm{Nmm}^{-2}\right]$

(c)

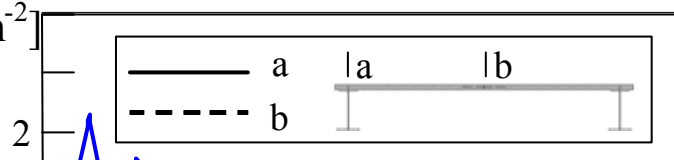

(d)
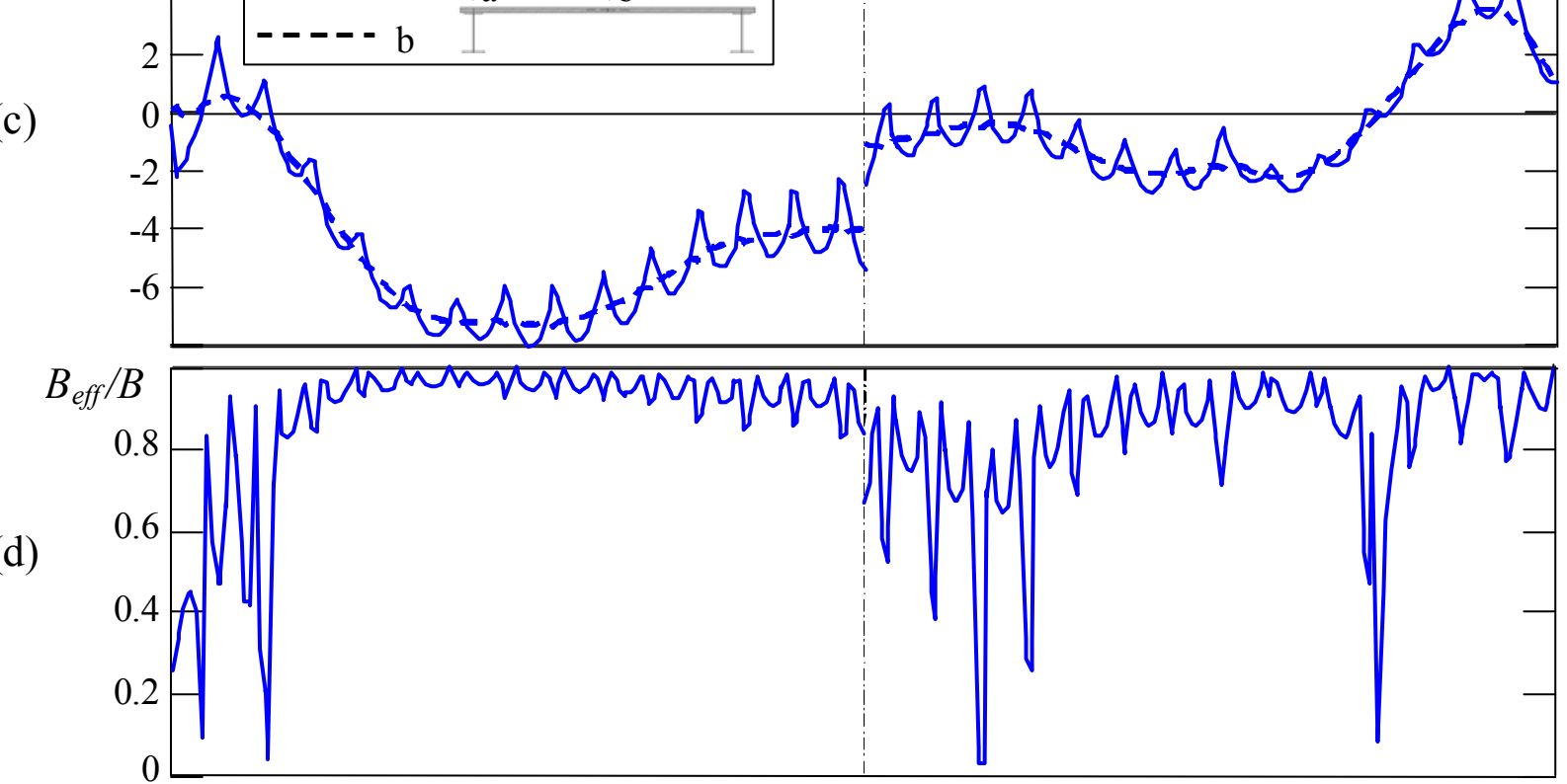

Figure 13. Traffic Loads: (a) Deck Deflection; (b) Longitudinal Normal Stresses in the Top and Bottom Flanges of the Steel Beam; (c) Longitudinal Normal Stresses at Mid-height of the Slab;

(d) Effective Width over the Actual Deck Width 

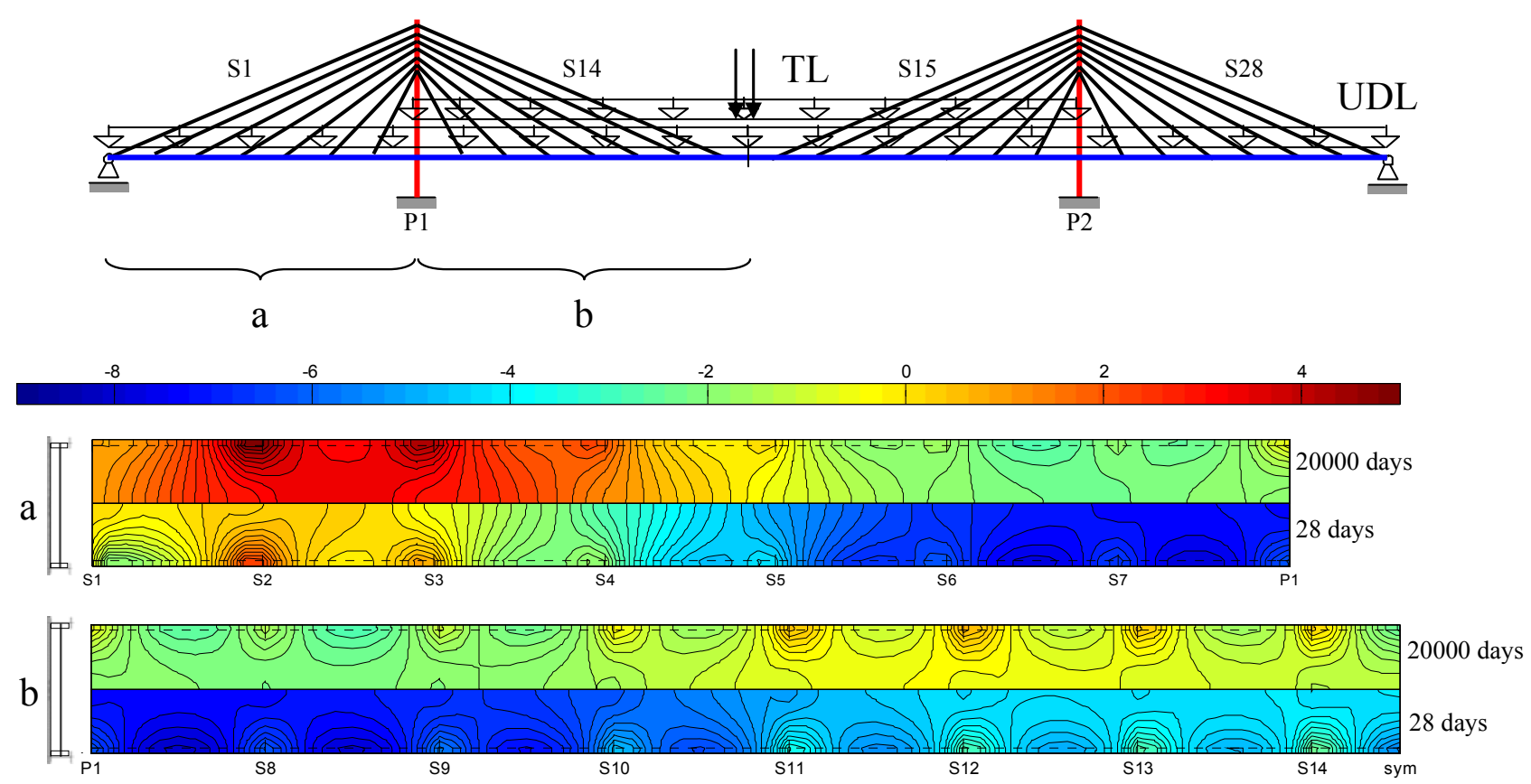

Figure 14. Traffic Loads: Contour Plots of Stresses in the Reinforced Concrete Slab due to Permanent Actions

With respect to refined finite element models (e.g. using shell elements) the method has the advantage of reducing the amount of degrees of freedom without loss of precision in evaluating stress states. The precision of the method was demonstrated by applying the use of the deck finite element to a real bridge and comparing the results with those given by refined shell finite elements. The proposed method produces very good results for what concern stresses in the steel beams and in the concrete slab while a lower level of precision is obtained in the evaluation of deflections due to the shear strains of the steel beams that are neglected in the model. The presence of cross beams, even if connected to the reinforced concrete slab, does not affect the results.

A cable stayed bridge subjected to different actions (permanent loads, shrinkage and traffic loads) has then been considered and analysed. Both short- and long-term analyses were carried out to demonstrate the importance of long-term effects and the difficulties that a designer could have in choosing adequate slab effective widths as these depend sensibly on the loading layouts and are time dependent.

The limitation of the proposed formulation relies on its inability to account for torsion and transverse bending but the authors do not feel that this compromises the usefulness of the proposed element which intends to complement the analysis tools available to bridge designers.

\section{ACKNOWLEDGEMENT}

The work carried out in this article by the second author was supported by a Discovery Project awarded under the Australian Research Council's funding scheme and through a research grant awarded by the Commonwealth through the Australia-Korea Foundation of the Department of Foreign Affairs and Trade. 


\section{REFERENCES}

[1] EN 1994-2, "EUROCODE 4: Design of Composite Steel and Concrete Structures - Part 2: General Rules and Rules for Bridges", European Committee for Standardization, 2005.

[2] Dezi, L., Gara, F., and Leoni, G., "Effective Slab Width in Prestressed Twin-girder Composite Decks", Journal of Structural Engineering, ASCE, 2006, Vol. 132, No. 9, pp. 1358-1370.

[3] Gara, F., Ranzi, G. and Leoni, G., "Analysis of the Shear Lag Effect in Composite Bridges with Complex Static Scheme by Means of a Deck Finite Element," International Journal of Steel Structures, 2008, Vol. 8, pp. 249-260.

[4] Reissner, E., "Analysis of Shear Lag in Box Beams by the Principle of the Minimum Potential Energy", Quarterly of Applied Mathematichs, 1946, Vol. 4, No. 3, pp. 268-278.

[5] Dezi, L., Gara, F., Leoni, G. and Tarantino, A.M., "Time Dependent Analysis of Shear-lag Effect in Composite Beams", Journal of Engineering Mechanics, 2001, Vol. 127, No. 1, pp. 71-79.

[6] Dezi, L., Gara, F. and Leoni, G., "Shear-lag Effect in Twin-girder Composite Decks", Steel and Composite Structures, 2003, Vol. 3, No. 2, pp. 111-122.

[7] Gara, F., Leoni, G. and Dezi, L., "A Beam Finite Element Including Shear Lag Effect for the Time-dependent Analysis of Steel-concrete Composite Decks”, Engineering Structures, 2009, Vol. 31, pp. 1888-1902.

[8] Kretz, T., Michotey, J. and Svetchine, M., "5ème pont sur la Nive", Bulletin Ponts Metalliques, SETRA, 1992, Vol. 15, pp. 133-136. (in French)

[9] SAP2000, "Computer and Structures, Inc. CSI Analysis Reference Manual”, Berkeley, California, 2004.

[10] EN 1992-1-1, "EUROCODE 2: Design of Concrete Structures - Part 1-1: General Rules and Rules for Buildings", European Committee for Standardization, 2004.

[11] EN 1991-2, "EUROCODE 1: Action on Structures - Part 2: Traffic Loads on Bridges", European Committee for Standardization, 2003. 


\title{
EXPERIMENTAL AND ANALYTICAL INVESTIGATIONS OF STEEL AND COMPOSITE TRUSSES
}

\author{
S.L. Chan ${ }^{1, *}$ and M. Fong ${ }^{2}$ \\ ${ }^{1}$ Professor, Department of Civil and Structural Engineering \\ The Hong Kong Polytechnic University, Hong Kong, China \\ ${ }^{2}$ Ph.D, Research Student, Department of Civil and Structural Engineering \\ The Hong Kong Polytechnic University, Hong Kong, China \\ *(Corresponding author: E-mail: ceslchan@polyu.edu.hk)
}

\begin{abstract}
The experimental and analytical investigations on bare and composite rectangular hollow sections (RHS) used as members of trusses are presented in this paper. The load resistances of the trusses consisted of steel and concrete-filled RHS tubes are compared to quantify the beneficial effects due to the in-filled concrete. The maximum loads on the trusses are also computed by the design method in Eurocode 3 (Steel member) and Eurocode 4 (Composite member) and compared with the test results. The results showed that the use of effective length method in linear analysis and design method is less convenient and accurate than the second-order analysis. The second-order analysis and design method not only gives a more accurate prediction than the linear analysis, but it also provides an efficient design as the assumption of effective length is not required to guess.
\end{abstract}

Keywords: Steel hollow sections, Concrete-filled steel hollow sections, Second-order analysis, Effective length method, Eurocode 3, Eurocode 4

\section{INTRODUCTION}

Experimental studies on concrete-filled steel tubes under different end conditions have been extensive conducted and the works include those by Knowles and Park [1], Bridge [2], Shakir-Khalil [3] and Lu and Kennedy [4] who investigated the axial and flexural behavior of the sections. Most experiments were focused on the behavior of single member with ends restrained against lateral movement. In this paper, the end movements of the members were restrained by other connecting truss members. The end movements of the member induce the P- $\Delta$ effect its inclusion is important in the analysis and design.

Several commonly used design codes provide different design methods on composite members such as Eurocode 4 [5], BS5400 [6] and CoPHK [7]. These codes contain various design methods for several types of composite columns and these methods include the first order linear analysis and effective length method for member buckling strength check. The accuracy of those design methods depend heavily on the precision of determination of effective length factor which is not quite possible to estimate since the idealized assumption for simple end conditions like pin and rigid ends are unrealistic in most practical structures. In this paper, two effective length factors were used to predict the design load, and the results will be compared with test results.

As an alternative to the first order linear analysis with effective length assumption, the second-order analysis and design method for steel tube and concrete-filled steel tube members is recommended in many design codes such as Eurocode 4 [5] and CoPHK [7] as a preferred design method, especially when the elastic critical load factor is small. In the second-order analysis, the nonlinear effects such as $\mathrm{P}-\delta, \mathrm{P}-\Delta$ effects and initial imperfection can be directly included in the analysis, and the estimation of the effective length is no longer required, and the member section capacity can be directly used for buckling strength check without modification factors. The individual member check is replaced by the section capacity check in a single equation in place of the approach 
requiring the use of several parameters embedded in the few checking equations such as the section capacity and the member buckling checks.

The pointwise equilibrium polynomial (PEP) element would be used in the paper for second-order analysis because of its simplicity and computational stability and efficiency allowing modeling one member by a single element. This modeling convenience reduces significantly the computational time and the process of separating the compressive and the tensile load cases is not needed because the matrix is valid for positive, negative and zero axial force. After modification of the PEP element by Chan and Zhou [8] and Zhou and Chan [9], not only the equivalent initial imperfection, which simulates the effect of geometric imperfection and residual stress, but also the semi-rigid joint at the ends of the member could be included in the PEP element. In the past few years, the second-order analysis and design method has been widely used for quite a few types of structures and the accuracy has been verified in many examples.

\section{EXPERIMENTAL PROGRAM}

\section{$2.1 \quad$ Specimens}

Two trusses were tested and their dimensions are shown in Figure 1. One truss was composed of RHS and square hollow section (SHS) steel tubes in all members and another truss was composed of concrete-filled RHS and SHS steel tube in compression members and SHS bare steel tube in tension members. Each three-dimensional truss consisted of 19 members which included two $50 \times 30 \times 3$ RHS tubes and seventeen $60 \times 60 \times 3$ SHS tubes. The two target failure members were $50 \times 30 \times 3$ RHS tube and the remaining members were $60 \times 60 \times 3$ SHS tube and the deflections of these target members are measured with full attention. The length of each truss member was $2 \mathrm{~m}$ approximately and the tie members connecting the two plane trusses were $0.8 \mathrm{~m}$ approximately. The ends of the members were connected rigidly by using $8 \mathrm{~mm}$ butt weld.

Target failure member $50 \times 30 \times 3 \mathrm{~mm}$

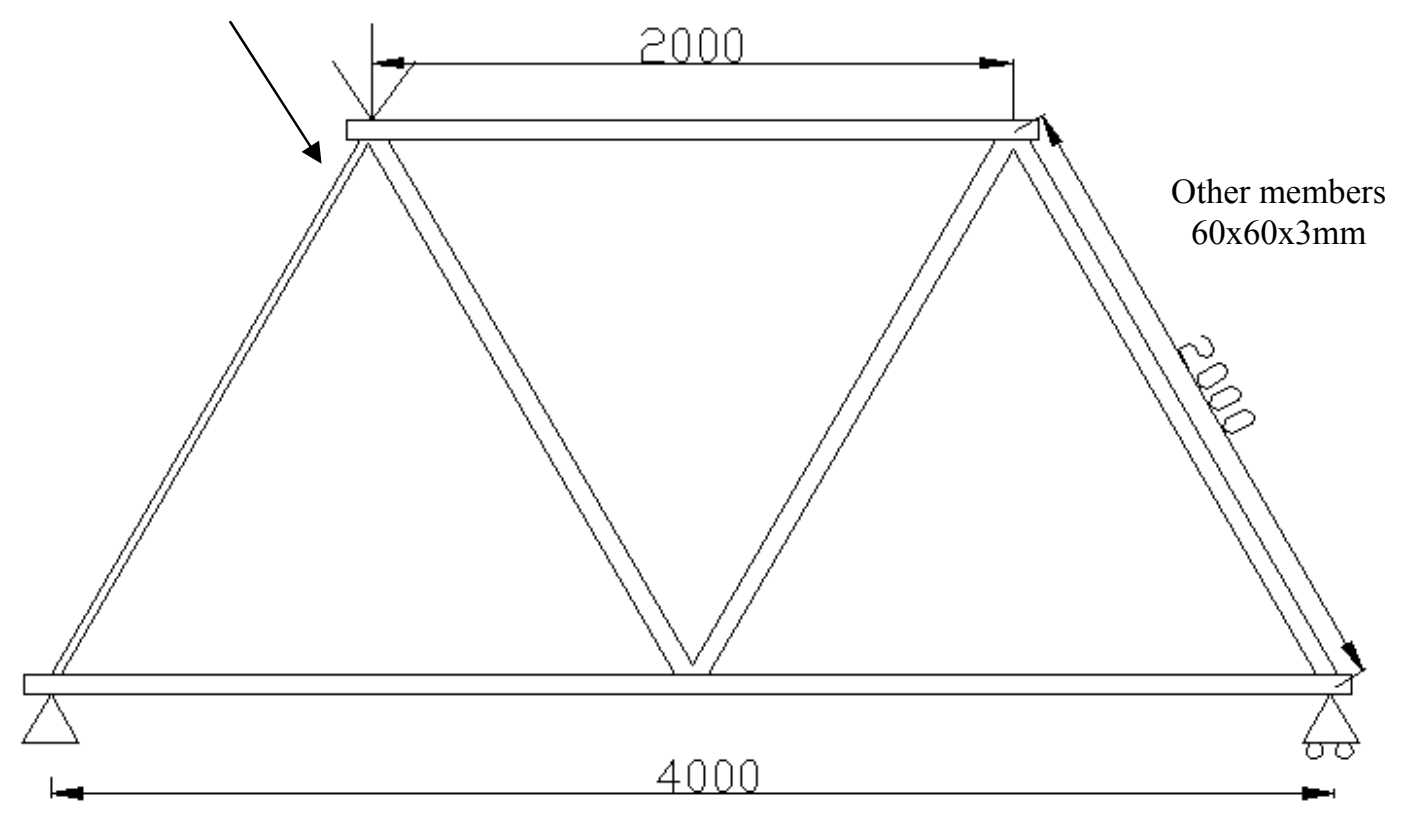

Figure 1. The Dimension of the Trusses 
The average width, depth and thickness of both sections are listed in Table 1. The coupon test was carried out to determine the stress-strain curve of the steel section. The average yield stress $\left(f_{y}\right)$, ultimate tensile stress $\left(f_{u}\right)$ and the Young's modulus $\left(E_{s}\right)$ are summarized in Table 1.

The high strength concrete was used in filling in the steel tubes The composition of concrete mix was water $\left(238.1 \mathrm{~kg} / \mathrm{m}^{3}\right)$, Ordinary Portland Cement $\left(479.5 \mathrm{~kg} / \mathrm{m}^{3}\right)$, coarse aggregate $\left(862.5 \mathrm{~kg} / \mathrm{m}^{3}\right)$, fine aggregate $\left(709 \mathrm{~kg} / \mathrm{m}^{3}\right)$ and Pulverized Fly Ash $\left(205.5 \mathrm{~kg} / \mathrm{m}^{3}\right)$. The average compressive cube and cylinder strength were $91.65 \mathrm{~N} / \mathrm{mm}^{2}$ and $89.87 \mathrm{~N} / \mathrm{mm}^{2}$ respectively and the modulus of elasticity of concrete was $37.45 \mathrm{kN} / \mathrm{mm}^{2}$.

Table1. Material Properties of RHS Tube

\begin{tabular}{|c|c|c|c|c|c|c|}
\hline Steel section & $\begin{array}{c}\mathrm{B} \\
(\mathrm{mm})\end{array}$ & $\begin{array}{c}\mathrm{D} \\
(\mathrm{mm})\end{array}$ & $\begin{array}{c}\mathrm{t} \\
(\mathrm{mm})\end{array}$ & $\begin{array}{c}\text { Yield stress }\left(f_{y}\right) \\
\mathrm{N} / \mathrm{mm}^{2}\end{array}$ & $\begin{array}{c}\text { Ultimate tensile } \\
\text { stress }\left(f_{u}\right) \\
\mathrm{N} / \mathrm{mm}^{2}\end{array}$ & $\begin{array}{c}\text { Young's } \\
\text { modulus }\left(E_{s}\right) \\
\mathrm{kN} / \mathrm{mm}^{2}\end{array}$ \\
\hline $50 \times 30 \times 3$ & 50.00 & 30.08 & 2.96 & 399.17 & 448.30 & 203.87 \\
\hline $60 \times 60 \times 3$ & 60.58 & 60.53 & 3.25 & 376.12 & 439.91 & 217.50 \\
\hline
\end{tabular}

\subsection{Test Results}

The trusses were simply supported at the two ends and loaded by the hydraulic jack of capacity $400 \mathrm{kN}$ and placed between the pair of trusses as shown in Figure 1. Totally 12 displacement transducers were placed at the loading point and the top, bottom and middle of the target failure member to measure the deflection of the member and deflection of the truss. 18 strain gauges were placed at 3 locations at the top, middle and bottom of each target failure member and six strain gauges were mounted at each location. The detailed locations of displacement transducers and strain gauges are shown in Figure 2.

Displacement transducers
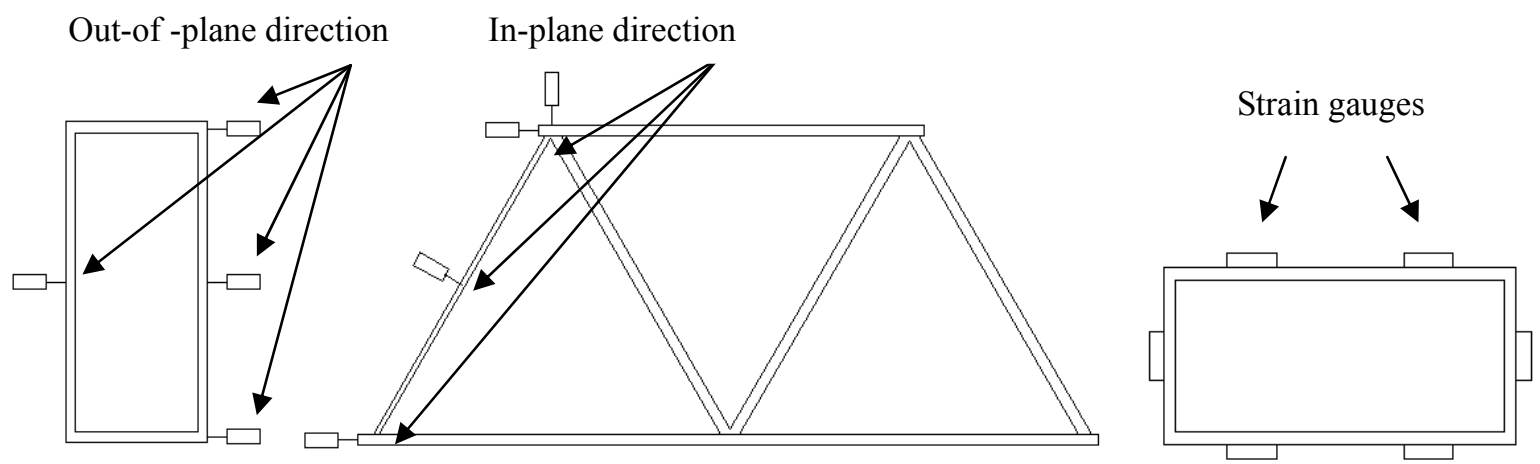

Figure 2. Displacement Transducers and Strain Gauges Location

The test results for both steel and concrete-filled steel tube are given in Table 2. The applied load at the top of the truss against mid-span in-plane deflection (the component normal to the truss member) of the failure members are plotted in Figure 3. For bare steel tube, the member deflection increased linearly with the applied load until it reached $36.85 \mathrm{kN}$, and the load-deflection relationship then became non-linear. The maximum applied load on the steel truss was $76.61 \mathrm{kN}$. For concrete-filled steel tube, the member deflection under applied load was similar to the steel tube in which linear relationship was observed before the applied load reaching $26.20 \mathrm{kN}$. After this load, the deflection increased with applied force nonlinearly and the maximum applied load was found to be $90.00 \mathrm{kN}$. The flexural buckling about the principal minor axis of the failure member took place and shown in Figures 4 and 5 for both trusses. The internet links of the videos are shown below.

http://www.nida-naf.com/index.php?option=com_content\&view=article\&id=121\%3 . 
Table2. Test Results

\begin{tabular}{|c|c|}
\hline Truss member & $\begin{array}{c}\text { Maximum Applied Force }(\mathrm{kN}) \\
\mathrm{P}_{\mathrm{t}}\end{array}$ \\
\hline Steel Tube & 76.61 \\
\hline Concrete-filled Steel Tube & 90.00 \\
\hline
\end{tabular}

Concrete-filled RHS steel tube member

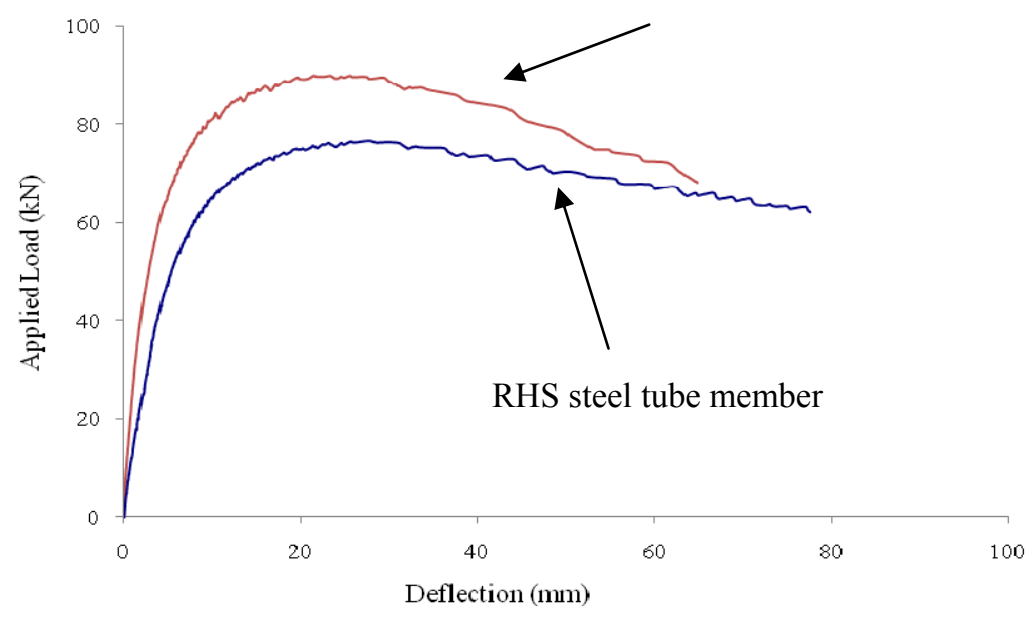

Figure 3. Load against in-plane Deflection of Failure Member

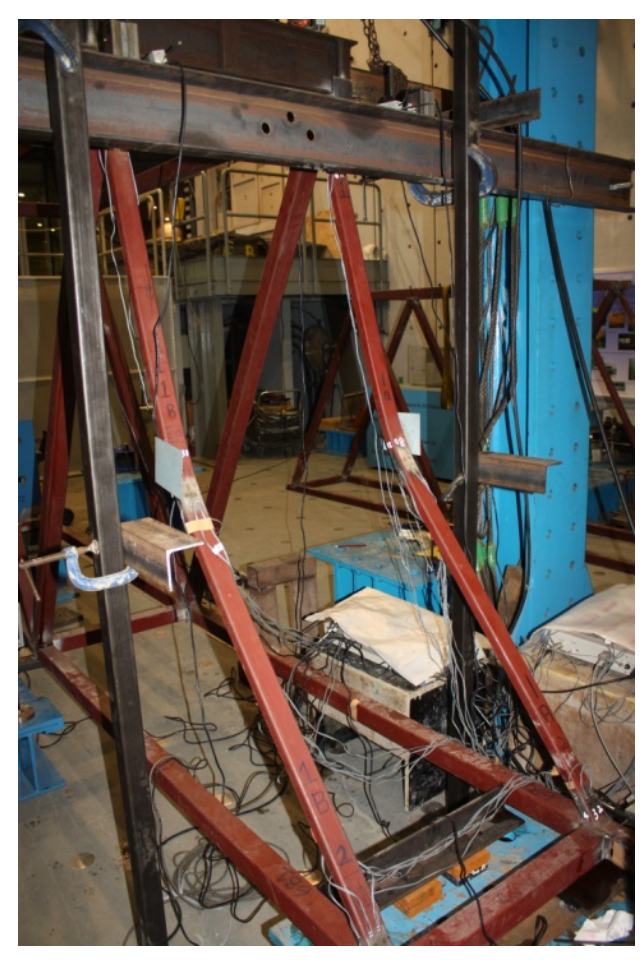

Figure 4. The Failure Shape of Steel Member Truss 


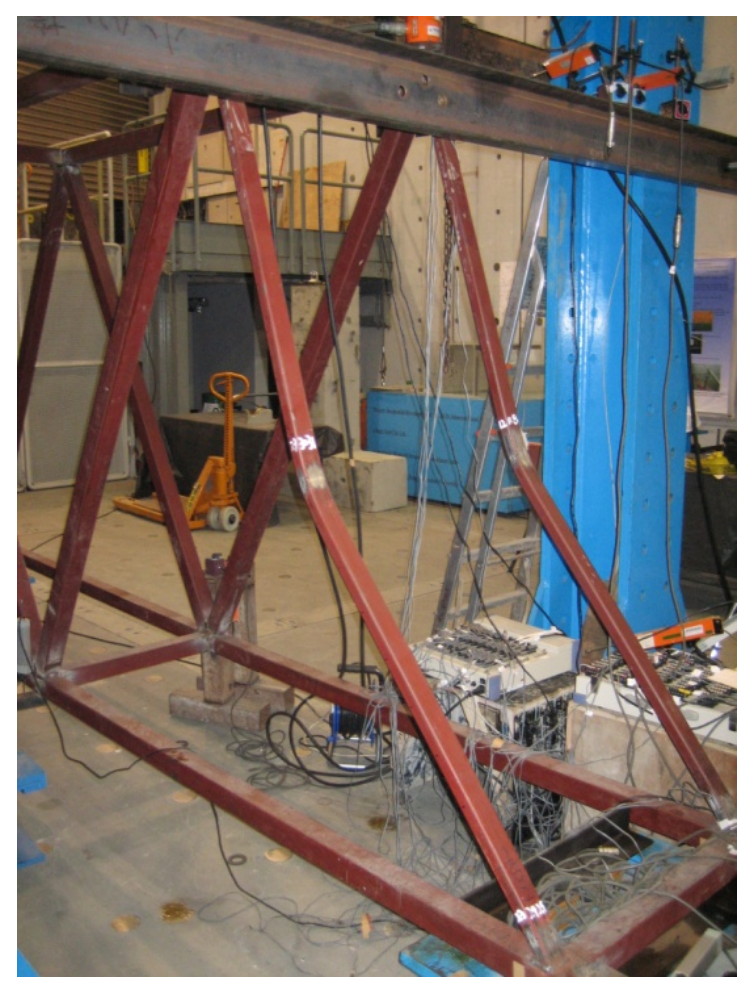

Figure 5. The Failure Shape of Composite Member Truss

The maximum load, which was taken by the member in composite truss, was $17.5 \%$ higher than the bare steel truss. The applied load against out-of-plane mid-span deflection of the failure members is also plotted in Figure 6. The curves showed that the out-of-plane deflection was small compared with the in-plane deflection at maximum applied load in both trusses.

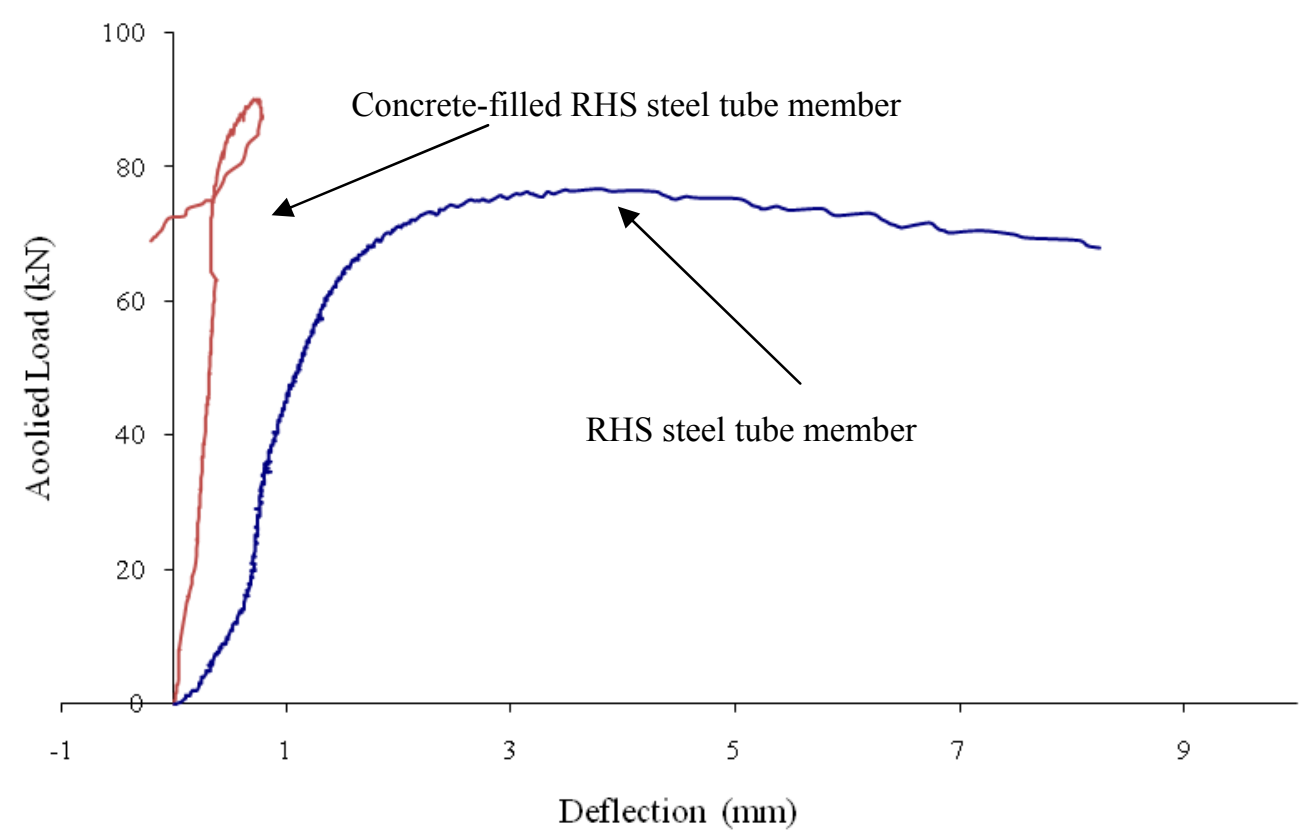

Figure 6. Load against Out-of-plane Deflection of Failure Member 
Applied load against the strain plots at the mid-length of the failure members are shown in Figure 7. As expected, non-linear relationship was observed and the post-failure behaviour could be obverved in both RHS steel and concrete-filled RHS steel tubes. The RHS steel and concrete-filled RHS steel tube gave similar behaviour in strain as shown in Figures $7 \mathrm{a}$ and $7 \mathrm{~b}$. The variation on the strain along the top fiber (SG1 and SG2) and along the bottom fiber (SG4 and SG5) is small, hence the average strain in top and bottom was plotted against the applied load and large compressive strains was developed at bottom fiber which gave a consistent result with displacement transducers. The readings from SG6 and SG3 were identical up and close to the failure load for concrete-filled RHS steel tube and these readings are slightly different in RHS steel tube, due to the out-of straightness imperfections in major axis direction. The result implied that the out-of plane deflection was insignificant before failure load after which the out-of plane deflection increased significantly with decreasing load, hence the load-strain curve started to diverge.

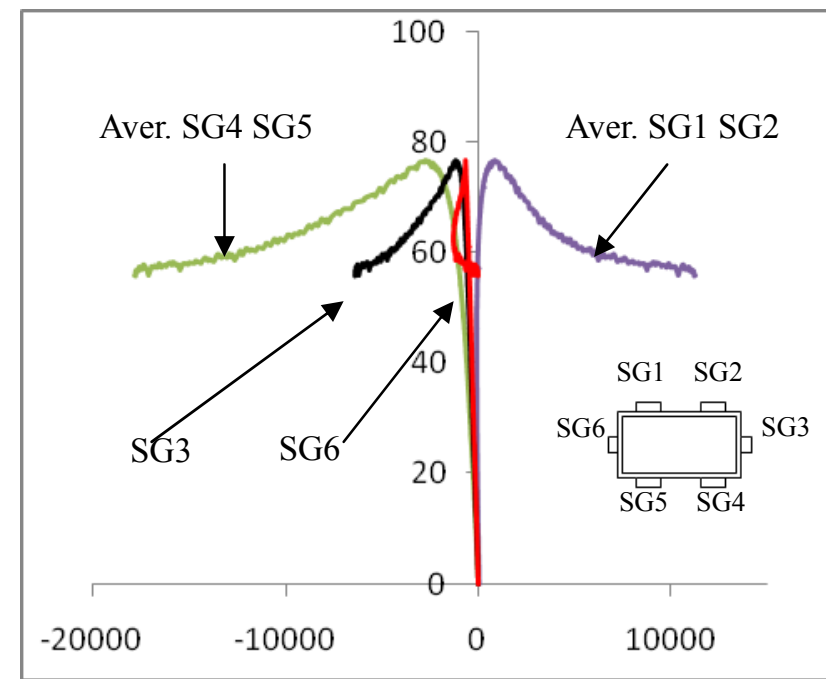

Figure 7a. Steel RHS Tube Member

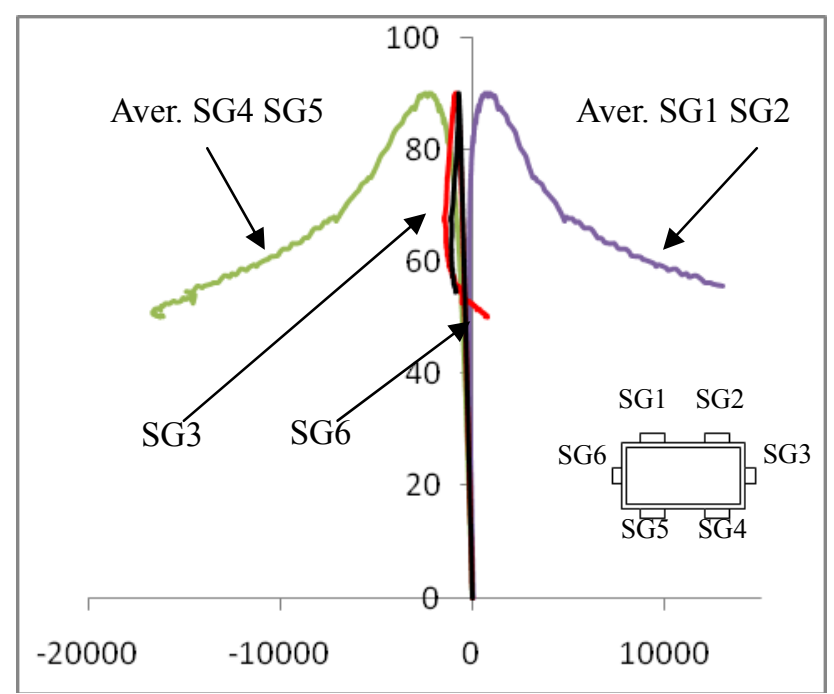

Figure 7b. Concrete-filled RHS Steel Tube Member

Figure 7. Load-Strain Cruve for the Failure Member

\section{CODE AND SECOND-ORDER ANALYSIS AND DESIGN METHOD}

\subsection{Predicted Results from Eurocode 3 and Eurocode 4}

The design method in Eurocode 4 [5] for concrete-filled steel tubular columns is briefly described here for clarity and completeness. The section capacity of concrete-filled steel tubular members is determined by simply adding the capacity of two components of concrete and steel tubes. The reduction factor $\chi$, which is a function of the effective slenderness ratio and section type, is multiplied to the section capacity to consider the stability. Thus, the member resistance is obtained as,

$P_{c p}=\chi\left(A_{s} f_{y d}+A_{c} f_{c d}\right)$

in which $A_{s}, A_{c}, f_{y d}$ and $f_{c d}$ are the cross-sectional area and design strength of the steel and concrete respectively.

The reduction factor $\chi$ is given by 


$$
\chi=\frac{1}{\phi+\sqrt{\phi^{2}-\bar{\lambda}^{2}}}
$$

and

$\phi=\frac{1}{2}\left[1+\alpha(\bar{\lambda}-0.2)+\bar{\lambda}^{2}\right]$

in which $\alpha$ is the imperfection factor and $\bar{\lambda}$ is the relative slenderness.

The predicted results using the design methods in Eurocode 3 [10] and Eurocode 4 [5] for RHS steel and concrete-filled RHS steel tube are summarized in Table 3. The effective length factor equal to $0.5\left(\mathrm{~L}_{\mathrm{e}}=1000\right)$ and $1.0\left(\mathrm{~L}_{\mathrm{e}}=2000\right)$ were assumed to simulate the fix end with fixed and free translations which are the upper and lower conditions to the actual behavior of the members in the truss. Predicted maximum applied loads according to the design codes were $31.77 \mathrm{kN}$ and $106.14 \mathrm{kN}$ for RHS steel tube, and $36.10 \mathrm{kN}$ and $130.49 \mathrm{kN}$ for concrete-filled RHS steel tube under these two different effective length factors. The ratios of tested to predicted load were about 0.7 and 2.4 for effective length factors $\left(\mathrm{L}_{\mathrm{e}} / \mathrm{L}\right)$ equal to 0.5 and 1.0. The results indicate that the true effective length of the members should be between these two values.

Table 3. Predicted Results by Design Codes

\begin{tabular}{|c|c|c|c|c|c|}
\hline \multirow{2}{*}{ Truss member } & \multicolumn{2}{|c|}{ Maximum Applied Force (kN) } & \multicolumn{2}{c|}{$\begin{array}{c}\text { Toad/Predicted } \\
\text { Load }\end{array}$} \\
\cline { 2 - 7 } & $\begin{array}{c}\text { Test } \\
\text { result } \\
\mathrm{P}_{\mathrm{t}}\end{array}$ & \multicolumn{2}{|c|}{$\begin{array}{c}\text { Results by Eurocode 3 } \\
\text { \& Eurocode 4 }\end{array}$} & $\mathrm{P}_{\mathrm{t}} / \mathrm{P}_{\mathrm{ec}}$ & $\mathrm{P}_{\mathrm{t}} / \mathrm{P}_{\mathrm{ec}}$ \\
\cline { 3 - 7 } & & $\mathrm{L}_{\mathrm{e}}=1000$ & $\mathrm{~L}_{\mathrm{e}}=2000$ & $\mathrm{~L}_{\mathrm{e}}=1000$ & $\mathrm{~L}_{\mathrm{e}}=2000$ \\
\hline Bare Steel Tube & 76.61 & 106.14 & 31.77 & 0.72 & 2.41 \\
\hline \multirow{2}{*}{ Concrete-filled Steel Tube } & 90.00 & 130.49 & 36.91 & 0.69 & 2.44 \\
\hline
\end{tabular}

\subsection{Second-order Design and Analysis Method}

The use of second-order analysis and design method has been widely adopted for different types of structures because this analysis and design method not only simplifies the design process, but also gives an accurate result. The non-linear effects, which including member imperfection, $\mathrm{P}-\delta$ and $\mathrm{P}-\Delta$ second-order moments, are included in analysis and hence, the uncertain design process demonstrated in the last section requiring determination of effective length and buckling reduction factors is not required. The formulation of the element tangent stiffness and secant stiffness matrix for steel and composite members have been detailed by Chan and Zhou [11, 12] and Chan et al. [13] and will not be repeated here.

\subsection{Section Capacity Check}

In the second-order analysis and design method, the section capacity check equation is used. For steel member, the equation below is adopted. 


$$
\frac{P}{P_{p}}+\frac{M_{y}+P\left(\delta_{y}+\Delta_{y}\right)}{M_{p y}}+\frac{M_{z}+P\left(\delta_{z}+\Delta_{z}\right)}{M_{p z}}=\phi \leq 1
$$

For composite member, two section capacity equations are used for the two load conditions. When the applied force is larger than the section capacity of concrete section (i.e. $\mathrm{P}>\mathrm{P}_{\mathrm{pm}}$ ), Eq. 5 will be used and it accounts for the effects of axial force and moments in the section capacity equation. When the applied force is not greater than the capacity of concrete section (i.e. $\mathrm{P} \leq \mathrm{P}_{\mathrm{pm}}$ ), only applied moments are considered since the axial force does not reduce the failure load and Eq. 6 is then used for section capacity check. These two sets of section capacity equations are given as follows.

$$
\begin{array}{ll}
\text { For } \mathrm{P}>\mathrm{P}_{\mathrm{pm}} & \frac{P-P_{p m}}{P_{c p}-P_{p m}}+\frac{M_{y}+P\left(\delta_{y}+\Delta_{y}\right)}{M_{c p y}}+\frac{M_{z}+P\left(\delta_{z}+\Delta_{z}\right)}{M_{c p z}}=\phi \leq 1 \\
\text { For } \mathrm{P} \leq \mathrm{P}_{\mathrm{pm}} & \frac{M_{y}+P\left(\delta_{y}+\Delta_{y}\right)}{M_{c p y}}+\frac{M_{z}+P\left(\delta_{z}+\Delta_{z}\right)}{M_{c p z}}=\phi \leq 1
\end{array}
$$

in which $P$ is the applied force, $P_{p}, P_{p m}, P_{c p}$ is compressive capacities of steel, concrete and composite cross-section, $M_{y}$ and $M_{z}$ are the external moments about the $\mathrm{y}$ and $\mathrm{z}$ axis, $P\left(\delta_{y}+\Delta_{y}\right)$ and $P\left(\delta_{z}+\Delta_{z}\right)$ are the P- $\delta$ and P- $\Delta$ moments about the y and z axes, $M_{p y}, M_{c p y}$, and $M_{p z}, M_{c p z}$ are the moment capacities of composite cross-section about the $\mathrm{y}$ and $\mathrm{z}$ axes.

As shown in the section capacity check equations that the P- $\Delta$ and $\mathrm{P}-\delta$ effects have been included such that the assumption of effective length is no longer required. Further, the inclusion of initial imperfection has been directly considered in analysis that the concept of section capacity check for imperfect columns can be applied directly in the integrated analysis and design model.

\subsection{Numerical Procedure}

The load control Newton Raphson method combined with the minimum residual displacement method [14] is used and the method is capable of tracing the path up to and beyond the limit point without numerical divergence.

\subsection{Analysis Results}

The analytical model and the deformed shape of the truss are shown in Figure 8. The average yield stress and Young's Modulus of steel and concrete from tested material were used in computer model. The initial imperfection of the member was taken as $L / 300$, where $L$ is the member length, according to Table 5.1 in Eurocode 3 [10] and Table 6.5 in Eurocode 4 [5] for steel and composite columns respectively. The center-to-center member length was used and rigid connection between each member was assumed. Two point loads were applied to the top of the truss on each side and load increment of $0.05 \mathrm{kN}$ was used in analysis until the section capacity factor was equal to 1 . The analysis results were presented together with test results in Table 4 . The failure loads of steel and composite truss were $77.80 \mathrm{kN}$ and $90.35 \mathrm{kN}$ respectively and the ratios of test to analysis result are 0.98 and 1.0 for RHS steel and concrete-filled RHS steel tube members. The analysis results show that the second-order analysis gives accurate results on prediction of resistance of the bare steel and concrete-filled steel tube members in a consistent manner. 
Table 4. Predicted Results by Second-order Analysis and Design Method

\begin{tabular}{|c|c|c|c|}
\hline \multirow[b]{2}{*}{ Truss member } & \multicolumn{2}{|c|}{ Maximum Applied Force (kN) } & $\begin{array}{c}\text { Test Load / } \\
\text { Predicted Load }\end{array}$ \\
\hline & $\begin{array}{c}\text { Test result } \\
\qquad \mathrm{P}_{\mathrm{t}}\end{array}$ & $\begin{array}{l}\text { Second-order analysis } \\
\text { and design method } \\
\qquad \mathrm{P}_{\mathrm{a}}\end{array}$ & $\mathrm{P}_{\mathrm{t}} / \mathrm{P}_{\mathrm{a}}$ \\
\hline Bare Steel Tube & 76.61 & 77.80 & 0.98 \\
\hline Concrete-filled Steel Tube & 90.00 & 90.35 & 1.00 \\
\hline
\end{tabular}

\section{CONCLUSIONS}

Experimental investigation on behavior of RHS steel and concrete-filled RHS steel tubes used as members in a truss was presented in the paper. The load capacity of the concrete-filled RHS steel tube member is $17.5 \%$ higher than the RHS steel tube member. The results by the Eurocode 3 [10] and Eurocode 4 [5] show that, with the assumption of effective length factor to be 0.5 , the code over-estimates the resistance of the failure member which leads to an unsafe design. On the other hand, when the assumption of the effective length factor as 1.0 is adopted, the code under-estimates the member resistance and the design is uneconomical. The second-order analysis and design method without assumption of effective length with non-linear buckling effects are directly included in analysis gives results much closer to the test results and this indicates clearly the superior performance of the second-order analysis for design of trusses made of steel and composite RHS sections. When dealing with the design of practical steel structures, the second-order analysis further improves the efficiency by skipping time for approximating a correct effective length for each member under different load case.

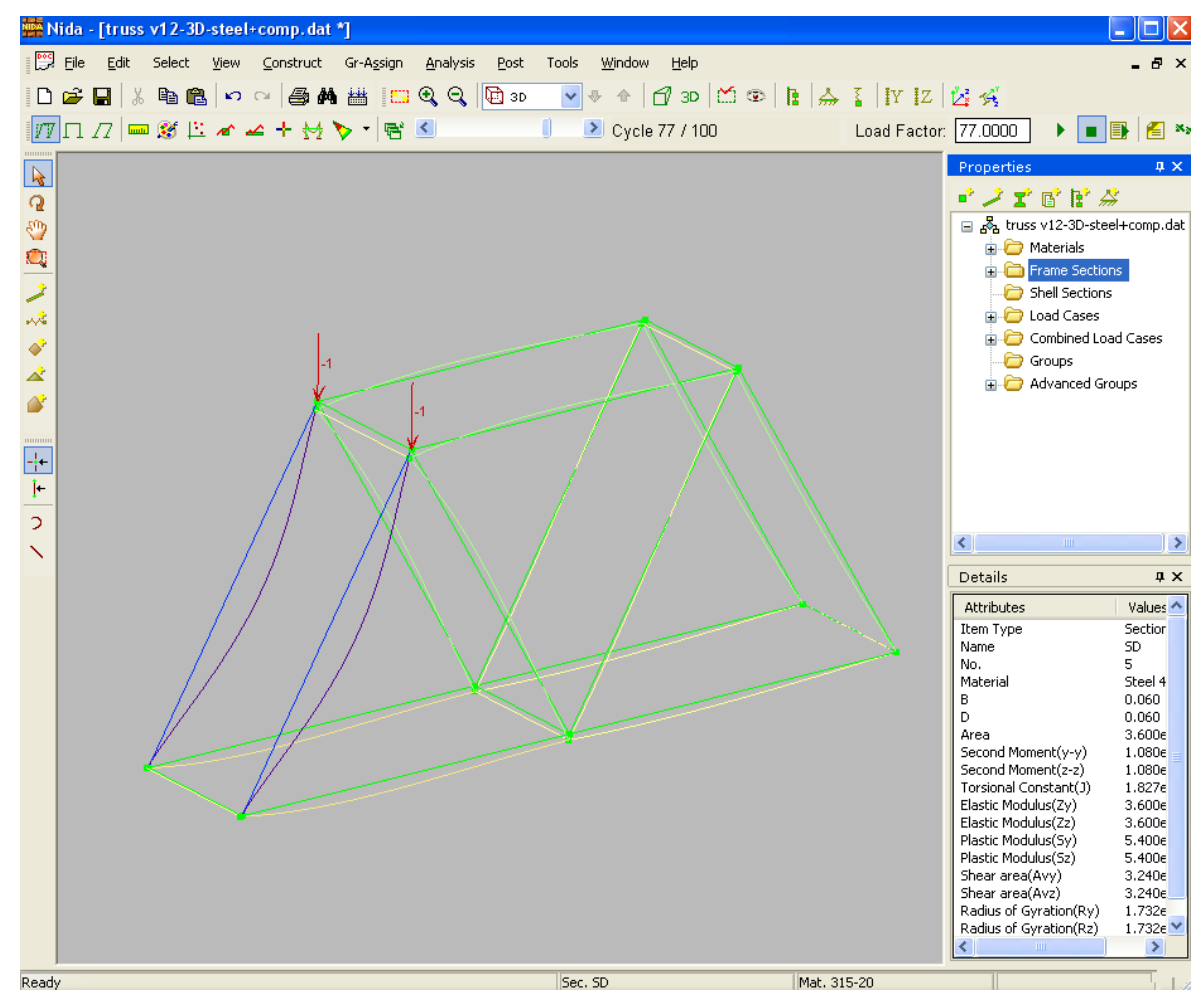

Figure 8. The Analytical Model of the Truss 


\section{ACKNOWLEDGEMENT}

The authors acknowledge the financial support by the Research Grant Council of the Hong Kong SAR Government and the Hong Kong Polytechnic University on the projects "Advanced analysis for progressive collapse and robustness design of steel structures (PolyU 5115/07E), "Second-order and Advanced Analysis and Design of Steel Towers Made of Members with Angle Cross-section (PolyU 5115/08E)" and "Simulation-based Second-order and Advanced Analysis for Strength, Stability and Ductility Design of Steel Structures (PolyU 5120/09E)".

\section{REFERENCES}

[1] Knowles, R.B. and Park, R., "Strength of Concrete-filled Steel Tubular Columns", Journal of Structural Division, ASCE, 1969, Vol. 95, No. 12, pp. 2565-87.

[2] Bridge, R.Q., "Concrete Filled Steel Tubular Columns", Civil Engineering Transactions, 1976, Vol. 18, No. 2, pp. 127-133.

[3] Shakir-Khalil, H., "Tests on Concrete-filled Hollow Section Columns", In: Proceedings of the Third International Conference on Steel-Concrete Composite Structures, Wakabayashi, M. (ed.), Fukuoka, Japan, September 26-29, 1991, Association for International Cooperation and Research in Steel-Concrete Composite Structures, pp. 89-94.

[4] Lu, Y.Q. and Kennedy, D.J.L., "The Flexural Behavior of Concrete-filled Hollow Structural Sections", Canadian Journal of Civil Engineering, 1994, Vol. 21, No. 1, pp. 111-130.

[5] CEN, EN1994-1-1, Eurocode 4: Design of Composite Steel and Concrete Structures, Part 1.1: General Rules and Rules for Buildings, 2004, BSI, London.

[6] BS5400. Steel, Concrete and Composite Bridges - Part 5: Code of Practice for the Design of Composite Bridges, 2005, BSI, London.

[7] CoPHK, Code of Practice for Structural Use of Steel 2005, Buildings Department, 2005, Hong Kong SAR Government.

[8] Chan, S.L. and Zhou, Z.H., "Second-order Elastic Analysis of Frames using Single Imperfect Element per Member”, J. Struct. Eng. ASCE, 1995, Vol. 121, No. 6, pp. 939-45.

[9] Zhou, Z.H. and Chan, S.L., "Self-equilibrating Element for Second-order Analysis of Semirigid Jointed Frames”, J. Eng. Mech. ASCE, 1995, Vol. 121, No. 8, pp. 896-902.

[10] CEN, EN 1993-1-1, Eurocode 3: Design of Steel Structures - Part 1.1: General Rules and Rules for Building, 2005, BSI, London.

[11] Chan, S.L. and Zhou. Z.H., "Pointwise Equilibrating Polynomial Element for Nonlinear Analysis of Frames", Journal of Structural Engineering ASCE, 1994, Vol. 120, No. 6, pp. 1703-1717.

[12] Chan, S.L. and Zhou, Z.H., "Second-order Elastic Analysis of Frames using Single Imperfect Element per Member", Journal of Structural Engineering ASCE, 1995, Vol. 121, No. 6, pp. 939-945.

[13] Chan, S.L. Fong, M. and Liu, Y.P., "Advanced and Second-order Analysis of Composite Columns", In: Proceeding of the Steel Concrete Composite and Hybrid Structures, D. Lam, Editor. 2009, Research Publishing Services: Leeds, UK. pp. 66-73.

[14] Chan, S.L., Geometric and Material Non-linear Analysis of Beam-columns and Frames using the Minimum Residual Displacement Method", Int. J. Numer. Methods Eng. 1988, Vol. 26, No. 12, pp. 2657-69. 


\title{
DESIGN BY TESTING OF INDUSTRIAL RACKS
}

\author{
N. Baldassino and R. Zandonini * \\ Department of Mechanical and Structural Engineering, University of Trento, \\ 38123 Povo, Trento, Italy \\ *(Corresponding author: E-mail: Riccardo.Zandonini@ing.unitn.it)
}

\begin{abstract}
Industrial racks are one of the most common structures for the storage of palletised goods. The behaviour of these structures, which are built-up from thin-walled cold-formed steel profiles, is quite complex. The sensitivity of the uprights to buckling, the presence of the perforations on the uprights, the non linearity of the connections, the frame sensitivity to the second-order effects and the influence of the imperfections are the main sources of complexity. The large variability in terms of geometry of the profiles, of the joints and of the perforations, and the complexity of the phenomena which affects the member behaviour do not yet allow performing a pure numerical design, but call for tests aimed at the characterisation of the structural components. Traditionally, the design of the racks is carried out by a procedure combining experiments and numerical analysis. This approach follows the so-called 'design by testing'. This paper intends to provide an overview of the experimental part of the approach. The specifications in the European and the North American standards are reviewed for the main structural components, i.e., the uprights, the upright frames and the joints. Problems related to the clarity, accuracy and completeness of the specifications are pointed out. The main results of some studies carried out by the authors provide a key to better understanding of the importance of testing.
\end{abstract}

Keywords: Industrial racks, design by testing, experimental analysis, numerical analysis, member buckling, semi-rigid joints

\section{INTRODUCTION}

In modern steel construction thin walled cold-formed profiles are becoming increasingly popular. The particular manufacturing processes [1] adopted for these profiles, which consist of rolling, pressing or bending brake of thin coils, lead to a great flexibility of the section shapes and to a significant weight reduction [2]. In recent years, the improvements of manufacturing techniques, the adoption of corrosion protection, the application of techniques of shape optimization and the increased structural performance have led to a wider use of cold-formed profiles. Roof and wall systems, trusses, wall framing, steel decking for composite structures, and industrial rack structures are some typical applications [2]. The design of each category of light gauge structures requires that some peculiar problems are mastered.

This paper focuses on the design of rack structures and, in particular, of pallet rack systems. These structures are one of the most common industrial storage systems for palletised goods. These systems are laid down along the aisles used to move the pallets. They are built up as a series of braced upright frames in the cross-aisle direction, connected in the transverse direction (the down-aisle direction) by beam elements (Figure 1). The efficiency of storage depends on the capability of the rack system to adapt to the type and geometry of the pallets. This goal is achieved mainly via a flexible geometry in terms of distance between upright frames and free height available between beam levels. 

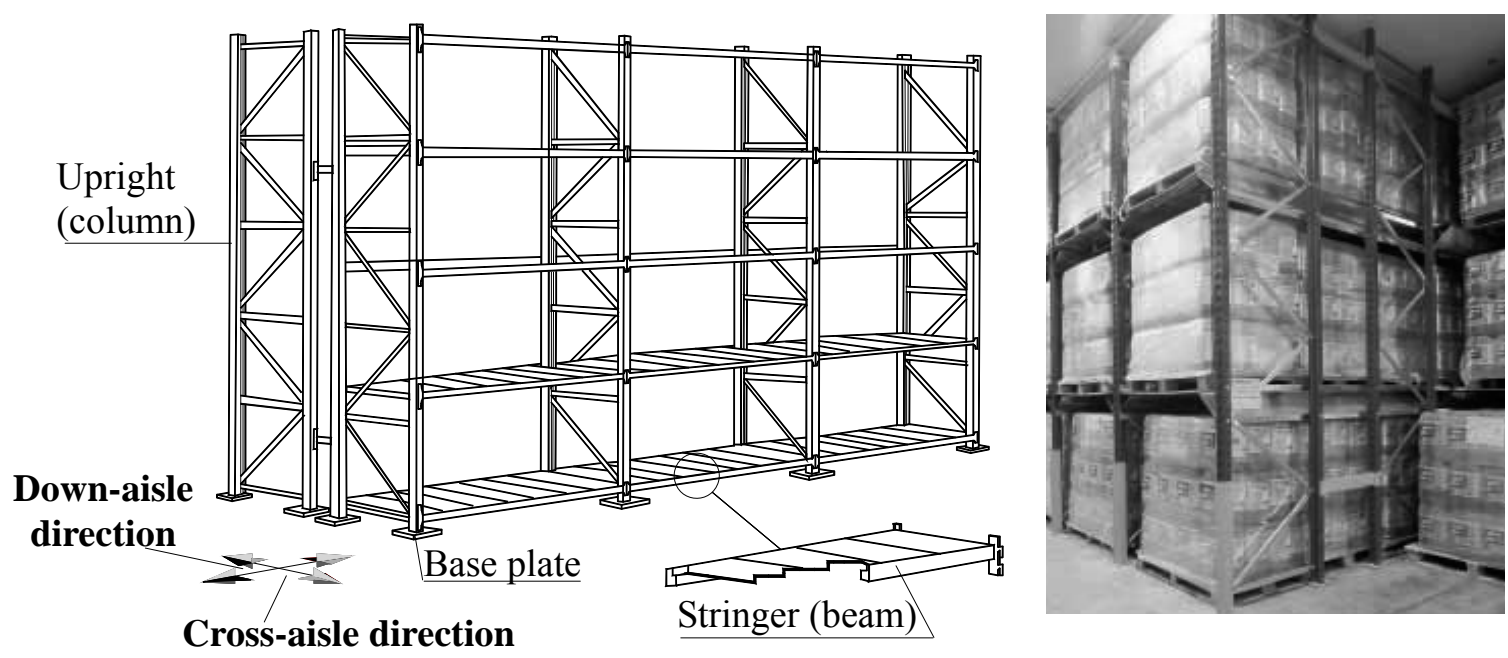

Figure 1. A Typical Steel Storage Pallet Rack System

The uprights are open thin-walled members. Their section shape is a ' $\mathrm{C}$ like' section stiffened by lips and, in some cases, by rear flanges and additional lips. The uprights usually contain holes and/or perforations at regular spacing to allow for the beam and the bracing connections. Beams, which usually have boxed cross sections, are provided by end-plates to allow for a mechanical connection to the uprights. The connection to the pavement is built-up by means of base plates, which can be either bolted or welded to the upright, and anchored to the floor. The bracings in the cross-aisle direction are usually made of open or closed cross section profiles eccentrically bolted to the uprights. In the down-aisle direction, racks are often unbraced frames: the need of efficiently storing and handling the pallets prevents the location of bracing systems in this plane. Therefore, the frame lateral stability in the down-aisle direction is generally provided by the degree of continuity offered by the beam-to-column and by the base-plate joints.

From the structural point of view racks can be considered as framed steel structures, characterised by a great sensitivity to second-order effects. For the purpose of global analysis, second-order analysis of the whole system (3-D analysis) or of the sub-frames in the planes parallel and perpendicular to the aisles (2-D analysis) may be performed. In the latter case, a semi-continuous frame model has to be considered in the down-aisle direction. The design of these structures is quite complex. The system members are prone to different forms of buckling, as all the thin walled members, while the perforation of the uprights adds further complexity to the instability phenomena. Moreover, both beam-to-column and base-plate joints are partial strength joints and exhibit a highly nonlinear response. Therefore, the analysis is fairly sophisticated and difficult to be mastered by numerical methods only. This is reflected in the design philosophy adopted by the main Standards for the design of pallet racks [3,4,5]. All Standards adopt a 'design by testing' approach which combines the results of experiments on components and sub-frames with the theoretical criteria developed and codified for traditional cold-formed members. Suitable tests are specified to define the main behavioural parameters of the key components or the sub-assemblages.

This paper intends to provide a concise overview of the experimental approach adopted by the European and the North American Standards for industrial racks [3,5]. The overview focuses on the key rack structural elements, i.e., the uprights, the upright frames and the beam-to-column and base joints. Problems related to the clarity, accuracy and completeness of the specifications are pointed out. Grounds for improving the Standards are identified. Furthermore, the main results of some studies carried out by the authors provide a better understanding of the importance of testing. 


\section{UPRIGHTS}

The columns of the pallet racks are mostly cold-formed open thin-walled steel sections. Their shape depends on the type of connection with the bracing members (cross-aisle direction) and with the beams (down-aisle direction). Complexity is also due to the constant process of innovation associated with competitive design. Moreover, in order to facilitate flexibility in the location of the connections, the upright is perforated along its length. Shape and distribution of perforations add complexity to the problem of defining the response of the upright itself. The behaviour of the uprights is in fact significantly affected by different forms of buckling. In addition to local and global buckling phenomena, distortional buckling should be considered. Interaction between the different buckling modes may also occur.

Since the 60 's, several studies were carried out aimed at investigating the behaviour of upright sections. The research work focused on different issues, such as the possible buckling modes $[6,7,8]$ and their interaction $[9,10]$, the influence of the residual stresses [11,12], and the influence of the perforation [13]. These studies combined experimental and numerical analyses.

The complexity of the phenomena characterising the upright response and the wide range of cross sectional shapes make it difficult to identify general solutions to the problem. The main Standards for the design of thin walled structures provide simplified equations which allow tackling the most common design cases. The effective width approach is adopted to account for local buckling; more complex, but conservative, equations are also proposed for checking distortional buckling, while separate formulas are given for verifying the overall instability.

For the more complex upright sections, the European and the North American Standards prescribe rational analysis or an experimental approach. The finite element method [14], the finite strip method [15], the generalised beam theory $[16,17,18]$ or the direct strength method [10] can be adopted as effective and rational tools of analysis.

The influence of the perforations is taken into account by the Standards only by modifying the effective area. Weakening of the resistant section, localised alteration of the material properties and stress concentrations due to the discontinuity are the principal consequences of perforations. The variety of the geometry and shape of both the perforations, the upright cross sections and the interval between perforations make each case unique and do not enable identification of general equations. Various numerical and experimental studies about the effects of perforations on the failure mode and collapse load were recently carried out [19-22]. Simplified relationships were also established, which do have the strong limitation that they are related to particular perforation geometries and sections. Therefore, the most appropriate solution to analyse the behaviour of the perforated sections seems to be the experimental approach, already specified by the European and the North American Standards [3,5] for perforated members. In particular, the European Standard [3] prescribes how to investigate the upright behaviour under compression and under bending, with the aim to assess the effective properties of the section. In the following, the case of an upright in compression is used for illustrative purposes.

The European Standard [3] specifies different compression tests aimed at investigating the sensitivity of the upright to local and distortional buckling. A minimum number of three tests is specified, in order to enable statistical evaluation of the parameters under consideration. The stub-column test, i.e., a compression test on a short specimen, is adopted for singling out the effect of local buckling. The length of the specimen should to be selected so that, on the one hand, local buckling is the sole buckling mode present and, on the other hand, there exists a uniformly compressed central zone. A further requirement of including at least 5 pitches of perforations is 
given. The ends of the specimen are welded to steel plates which allow the connection to the test rig (Figure 2). The end fixtures should provide hinged restraints.

A key point in compression tests is the selection of the point of application of the load. Since the section properties change along the upright due to the presence of the perforations, it is not possible to identify a centroidal axis of the member. In other words, concentrically loaded specimens do not exist. The problem is further complicated when local buckling takes place, inducing additional changes of the effective cross section.
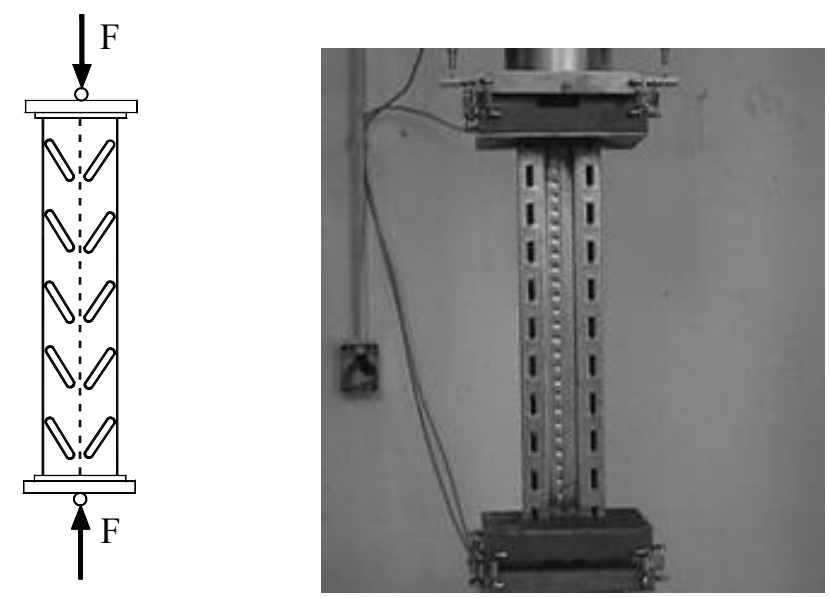

Figure 2. Stub-column Test Set-up

Baldassino and Hancock [23] studied the influence of the load eccentricities on the upright response under compression. They analysed a particular section profile and compared the experimental results of specimens with and without perforations. The non negligible influence of the load eccentricity on both the collapse load and failure mode was unveiled. Such an influence is strongly dependent on the length of the specimen. No general rule can be given for the load eccentricity. Therefore, the European Standard [3] recommends applying the load in the location between the centroids of the gross and net areas that provides the 'maximum failure load'. In order to satisfy this condition, a series of preliminary tests is required.

The final purpose of the stub-column tests is the assessment of the upright effective area ( $\mathrm{A}_{\text {eff }}$ ), which is determined as:

$$
A_{\text {eff }}=\frac{R_{k}}{f_{y}}
$$

where $R_{k}$ is the characteristic value of the collapse load and $f_{y}$ is the yield stress of the steel.

The effective area $\mathrm{A}_{\text {eff }}$ takes into account, in a simplified way, the effect of local buckling, the perforations and the cold-work process.

The North American Standard [5] prescribes a similar approach. The main difference is the end restraint conditions, which are fixed instead of hinged. The tests allow the definition of a reduction factor $\mathrm{Q}$, obtained as the ratio between the collapse load and the maximum resistance of the minimum net section $\left(\mathrm{f}_{\mathrm{y}} * \mathrm{~A}_{\text {net,min }}\right)$. In design, this $\mathrm{Q}$-factor enables the determination of the effective properties of the cross-section. 
The particular shape of the upright, with additional lips or rear flanges and additional lips, certainly improves the performance of the section against overall buckling, but increases its sensitivity to distortional buckling. Occurrence of distortional buckling generally triggers rapid failure: the associated in-plane deformation can induce remarkable membrane stresses which can lead to the yielding with subsequent failure of the stiffeners.

In order to investigate this feature, both the European and the North American Standards [3,5] specify the use of numerical or experimental approaches. Furthermore, the European Standard [3] provides a procedure that combines theoretical and experimental analysis and appears the most suitable for perforated members.

The European Standard [3] specifies two experimental approaches involving a quite different amounts of work. In both cases the tests are aimed at investigating the sensitivity of the upright to distortional buckling in the down-aisle direction. The test should be performed considering, as much as possible, the actual restraint conditions provided by the bracing system in the cross-aisle direction and by the beams in the down-aisle direction. In racks, the peculiar type of beam-to-column joints and the regularity of the perforation on the upright allow modifying the beam levels during the structural life of the storehouse. The uncertainty in the beam positions suggests disregarding, in the tests, the restraint offered by the beams. Both proposed experimental approaches adopt this simplification.

The 'simpler' approach consists of a compression test of an upright specimen of length equal to that of the single bracing panel closest to one meter. The provision 'closest to one meter' is of unclear origin and seems not reasonable in the case of bracing panel lengths different from one meter. Moreover, it seems to contradict a prescription of the same Standard which states that all bracing lengths should be experimentally or numerically investigated. The specimen set-up and the test procedure are the same as those prescribed for the stub-column test. Preliminary trial tests must be carried out to select the point of application of the axial force. When distortional buckling governs, its effect is accounted for by a suitable re-definition of the effective cross sectional area.

The second approach for the distortional check consists of the determination of the upright buckling curve. The compression tests are performed so that a representative range of upright frame lengths is covered. Two alternative test set-ups can be adopted, as shown in Figure 3. The failure load data associated to the tested bracing lengths are evaluated following the prescription of the European Standard [3]. The final goal of the test procedure is to plot a curve providing the variation of a stress reduction factor $\left(\chi_{\mathrm{ni}}\right)$ with the non-dimensional slenderness $\left(\bar{\lambda}_{\mathrm{ni}}\right)$.

Concerning global buckling, no specific test procedure is prescribed by the Standards. The buckling theory of thin walled members is adopted to define the curves for flexural or flexural-torsional buckling. It is implicit that perforations do have a limited influence on the overall upright response.

This brief summary clearly points out the complexity of the procedure adopted by the Standards. With the exception of the simpler upright geometries (simple section shapes and/or no perforations), a significant effort is required on both the experimental and the numerical sides. Tests certainly allow investigating the more complex problems but a strong limitation is the difficulty in reproducing the actual restraint conditions. The number of tests is further increased by the need for a statistical assessment. If the same upright section is used in different panel lengths or with different wall thickness, the experimental effort increases proportionally. Although the numerical approach makes it possible to reduce the number of tests, it must be viewed as a complementary tool: due to the presence of the perforations, quite complex models are required which, in any case, must be calibrated against experimental results. 

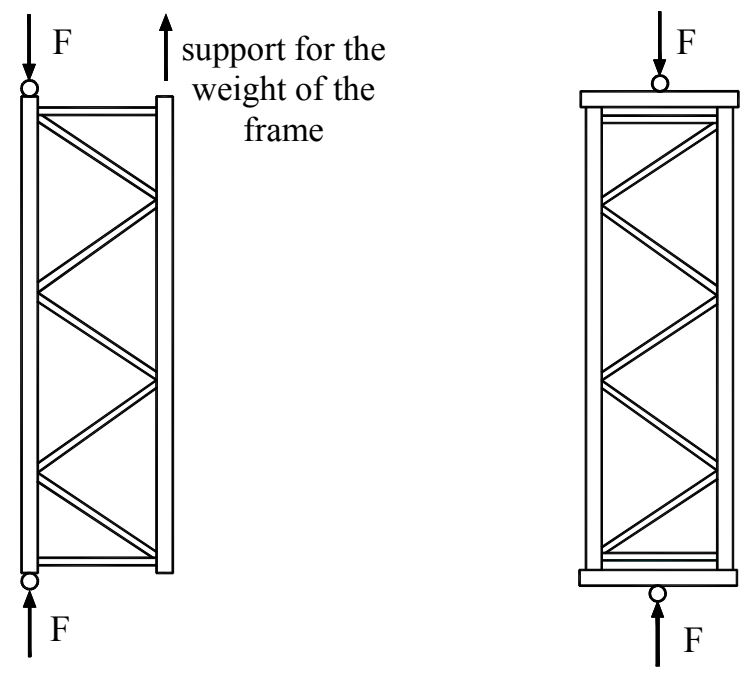

Figure 3. Test Set-ups for the Evaluation of the Buckling Curve

\section{UPRIGHT FRAMES}

The stability of rack systems in the cross-aisle direction is provided by the bracing system which connects the uprights. In this plane, the rack is hence comparable to a latticed column. The particular features of these systems, which are characterised by uprights with open cross section, by bracing members eccentrically connected to the uprights and, in the case of bolted connection, by a non-negligible lack of fits, make them particularly sensitive to second-order effects. This aspect stresses the need of an accurate evaluation of their deformability and of the selection of the most appropriate method of analysis.

In lattice structures the evaluation of the elastic critical load $V_{c r}$ requires taking into account both the flexural deformability and the shear deformability. For these systems, $\mathrm{V}_{\mathrm{cr}}$ is given by:

$$
\mathrm{V}_{\mathrm{cr}}=\frac{1}{\frac{1}{\mathrm{~V}_{\mathrm{cr}}^{*}}+\frac{1}{\mathrm{~S}_{\mathrm{D}}}}
$$

where $\mathrm{V}^{*}$ cr is the elastic critical load disregarding the shear deformability of the bracing system and $\mathrm{S}_{\mathrm{D}}$ is the shear stiffness per unit length of the bracing system, both of which can be determined theoretically. Both the European and the North American Standards provide specific equations for the most common types of bracing systems [3,5]. These equations are based on the assumption of elastic behaviour of 'ideal' upright frame systems [6]. Factors such as the axial shortening of the uprights, the eccentricities of the bracing, the connections lack of fit and the structural imperfections are neglected. To analyse the influence of such factors, the European Standard [3] recommends the experimental approach as an alternative to the theoretically evaluation. With this aim a testing procedure is specified. A shear force $(\mathrm{F})$ is applied to an upright frame segment composed by at least two complete bracing panels (Figure 4). The purpose of the test is to determine the 'initial' frame elastic shear stiffness. A value of $\mathrm{F}$ equal to $2 * \mathrm{n} \mathrm{kN}$ is indicated, where $\mathrm{n}$ is the number of bracing panels of the specimen. The displacement of the loaded upright is measured and the load-displacement curve ( $F-\delta$ curve) enables the evaluation of the shear stiffness $\mathrm{S}_{\mathrm{D}}$ as: 
$\mathrm{S}_{\mathrm{D}}=\frac{\mathrm{k}_{\mathrm{ti}} \mathrm{d}^{2}}{\mathrm{~h}}$

where $\mathrm{k}_{\mathrm{ti}}$ is the slope of the best-fit straight line of the experimental curve (F- $\delta$ curve), $\mathrm{d}$ is the distance between the centroidal axes of the uprights (Figure 5) and $\mathrm{h}$ is the distance between the restraints on the uprights (Figure 5).
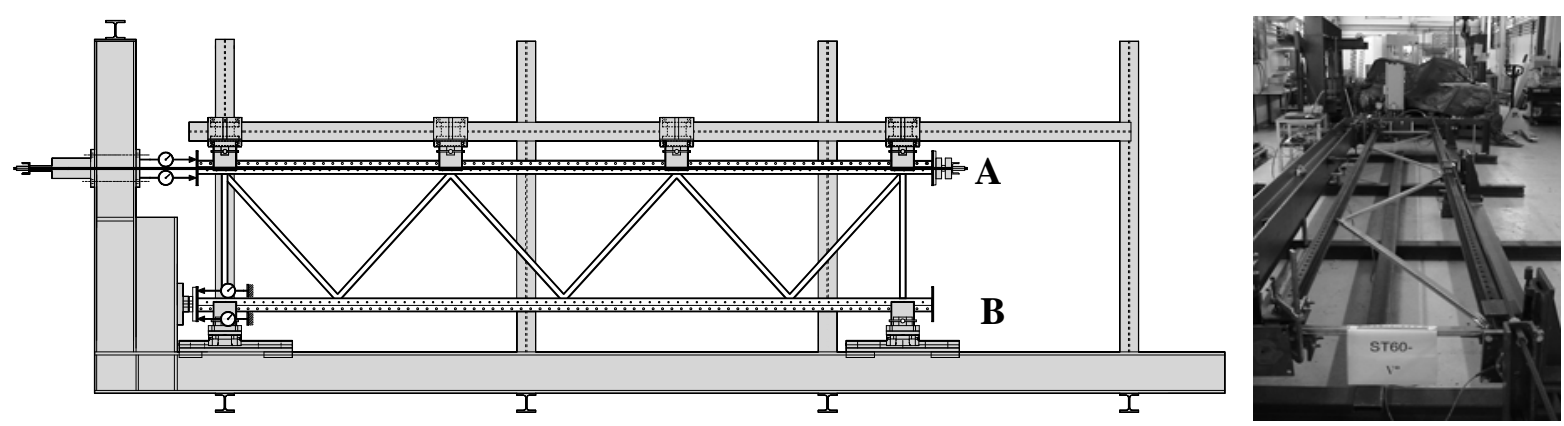

Figure 4. Tests Set-up for Shear Test on Upright Frames Designed at the University of Trento

The shear stiffness $S_{D}$ may be employed to determine a reduced bracing area or to characterise an equivalent spring for the bracing connections.

The authors carried out an experimental campaign which comprised approximately 100 tests on 23 different typologies of upright frames. The specimens, consisting of 3 complete panels, involved different upright dimensions, bracings systems and panel geometries. The ratio between the width and the length of the panel (aspect ratio) ranged between 0,33 and 0,85. In all specimens, the connections between the uprights and the bracing system were bolted. The load was increased up to collapse, in order to obtain information on the overall behaviour of the frame in the full range of its response. This information might be important for modelling the rack system.

Particular care was taken with the design of the test rig. One upright (upright B in Figure 4), is hinged at its ends, while the other (upright $\mathrm{A}$ in Figure 4), rests on frictionless supports, so as to guarantee the planarity of the frame. The tests were carried out for the two configurations shown in figure 5 . Four tests were carried out for each type of upright frame: three with configuration 1 and one with configuration 2.

\section{Test configuration 1}

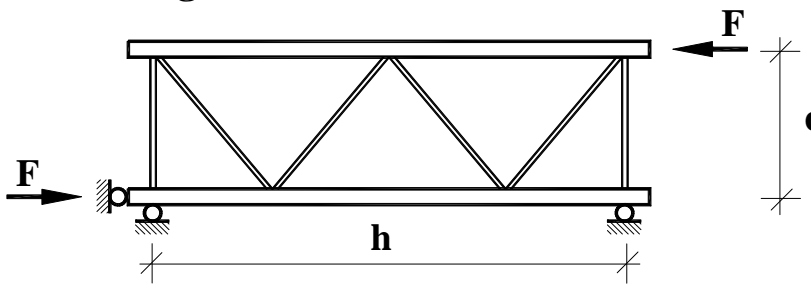

Test configuration 2

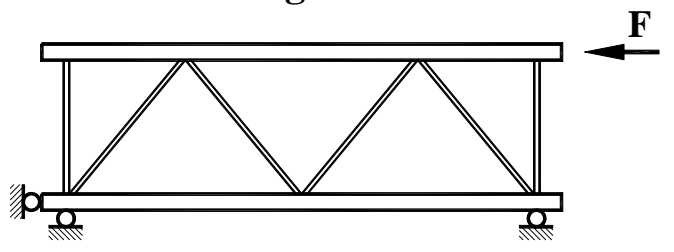

Figure 5. Test's Configuration

The experiments also allowed for a check of the applicability of the European testing procedure. Moreover, they enabled understanding the effectiveness of the bracing system in both configurations and the influence of the connections between the upright and the bracing members. 
The results showed that:

- the test configuration affects in a negligible way the load-displacement curve in the load range addressed by the European Standard $(0-6 \mathrm{kN})$ [3]. As shown in Figure 6, more pronounced differences were observed as the load increased due to the different load resistance mechanisms associated with each configuration. Furthermore, a more favourable mechanism results in a substantial increase of the collapse load (Figure 6 a);

- the connection system between the upright and the bracing members strongly affects the frame performance. Figure 7 compares the test results related to two upright frames differing only in the connection system between the uprights and the bracing members. The noticeable differences in the load-displacement responses can be explained by observing that the connection systems exhibit different local effects. Focusing the attention on a nodal point of the lattice structure, it can be noted that the bracing members are eccentrically connected to the uprights, which results in local torsion. As the distance between the bracing members increases, the local torsion applied to the upright is more pronounced. The global response of the uprights, which have a low torsional stiffness, is greatly influenced by these local effects occurring even for very small loads. Torsion associated with eccentricities of the upright-bracing connections reduces substantially both the stiffness and the strength and, therefore, should be absolutely minimised;

- the torsional deformation of the uprights was observed near collapse in all the specimens, also in the case of bracing systems with small eccentricities (e value in Figure 7). Such a phenomenon is enhanced by the buckling of the compressed diagonal;

- the collapse was caused by the instability of the bracing members (Figure 8a) and involved significant deformations of the connections (Figure $8 b$ ). In a few cases the connections failed (Figure 8c).

a)

b)
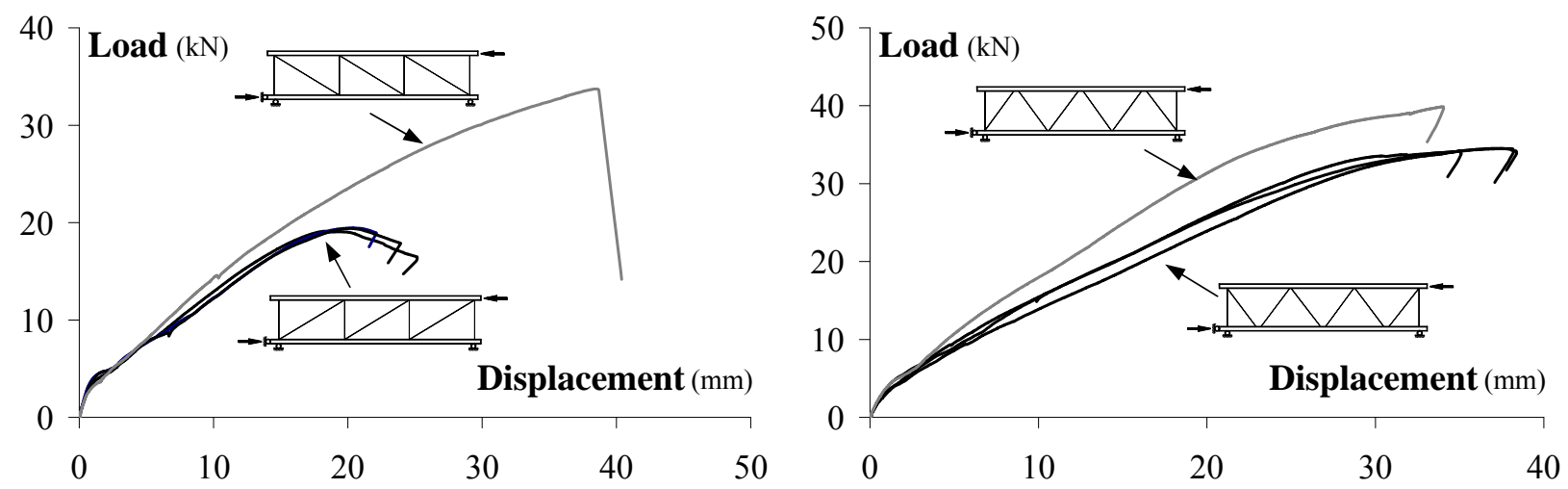

Figure 6. Typical Experimental Load-displacement Curves 


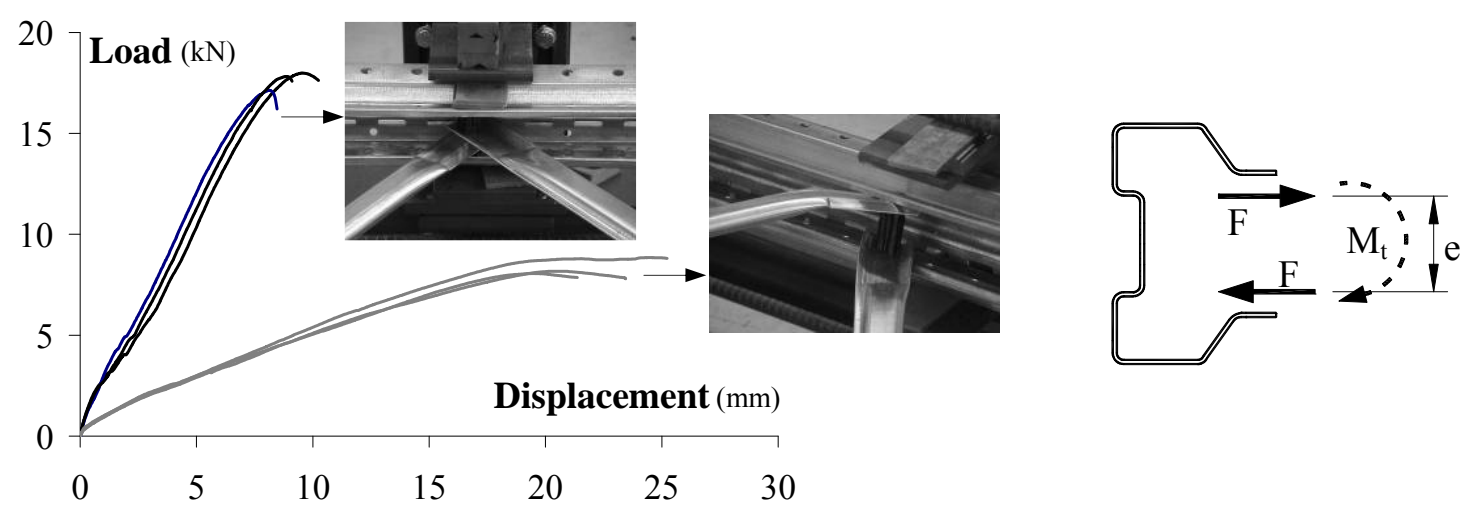

Figure 7. Influence of the Connection System between the Bracings and the Uprights
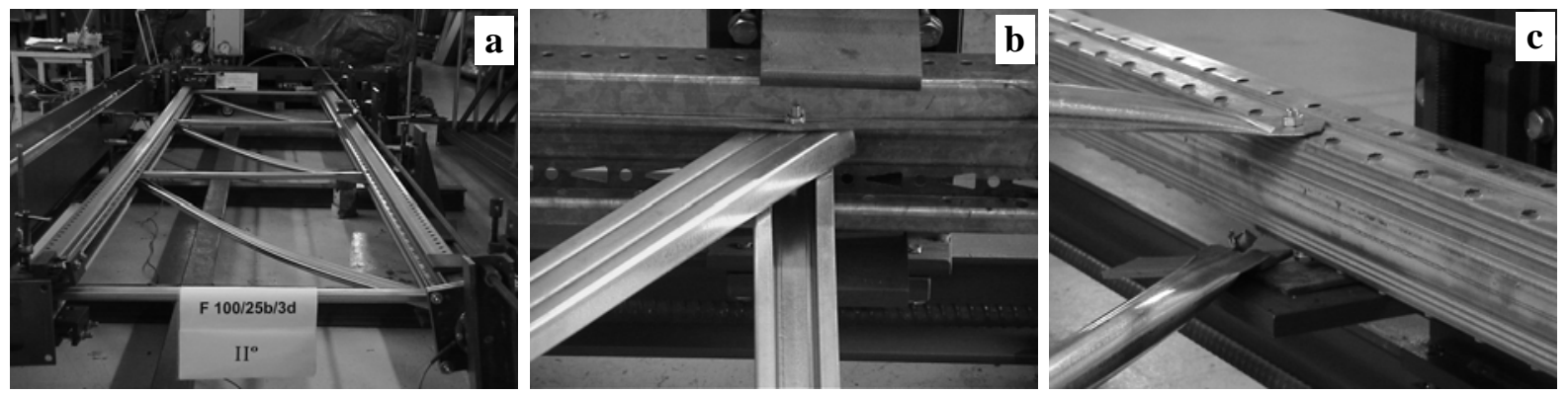

Figure 8. Typical Collapse Modes

The evaluation of the test results in accordance with the European Standard [3] made it possible to point out a few critical aspects of the recommended procedure.

The load-displacement curves (F- $\delta$ curves) are non-linear from the very beginning. This leads to difficulties in applying the procedure of the Standard [3], which requires the determination of a best fit straight line.

The theoretical values of the shear stiffness $\mathrm{S}_{\mathrm{D}}$ are substantially higher than the experimental ones (up to 60 times). The 'uncertainty' on the evaluation of the experimental shear stiffness and the assumptions underlying the theoretical $\mathrm{S}_{\mathrm{D}}$ are the two main causes explaining such an enormous difference.

Similar conclusions were reached in the study carried out by Godley and Beale [24]. The authors analysed the response of upright frames characterised by different upright sizes, numbers of panels and bracing patterns. The study comprised 80 tests on upright frames and numerous FE numerical simulations. The work pointed out that parameters such as the connection eccentricity, the bolt bending or the axial shortening of the uprights must be included in the theoretical analysis to obtain satisfactory agreement between theory and experimental results. If such contributions are considered the scatter between the theoretical and experimental values of $\mathrm{S}_{\mathrm{D}}$ is reduced. Further improvements could be achieved if effects such as the local distortion of the uprights at the connection with the bracings and the bolt looseness are taken into account.

The above considerations clearly indicate the need for testing. The theoretical equations for $\mathrm{S}_{\mathrm{D}}$ should not be used directly. They rather enable the determination of an equivalent value of the bracing area from experimental results. A numerical approach to the problem, whenever possible, is quite complex due to the substantial influence of the local effects on the frame response. The 
reliability of the analysis requires the ability to reproduce the actual frame behaviour and, therefore, leads to complex models, which must, in any case, be validated against the experimental results.

\section{THE JOINTS}

In racks, as in traditional framed structures, joints play a fundamental role in the frame performance. This is clear in the down-aisle direction, since the degree of continuity of the beam-to-column and the base-plate connections is fundamental in providing stability to the system. Therefore, an adequate approximation of the joint behaviour is of vital importance for the analysis and design of rack structures.

Studies carried out by different authors [25,26,27] enabled an overall understanding of the quite complex response exhibited by the joint types usually employed in pallets racks. The presence of lack of fit and the local deformation of both the connected members and the connector lead to moment-rotation relationships that are highly nonlinear even for very small loads. Beside this semi-rigid nature, the joints are 'partial strength joints'. Moreover, the variety of joint components and connection systems is fairly large and in permanent 'evolution', due to the need of innovation typical of a competitive market. As a consequence, the well-known models to estimate the joint performance in traditional steel framed systems [28] cannot be straightforwardly extended to rack joints. Furthermore, the complexity of the various phenomena involved in the joint response (e.g., large plastic deformation, highly localized contact forces, inelastic local buckling...) calls for experimental analysis.

Tests to determine the behaviour of beam-to-column joints appear in all codes for pallet racks [3,4,5]. The European Standard [3] also specifies a test to characterise the response of base-plate connections.

The following two sections focus on joint performance and on its influence on the frame response. From the perspective of design by testing, the code specifications to perform tests and evaluate results are first addressed. The discussion is focused on the main issues of the experimental analysis and the possible 'limits' of the code recommendations. Frame studies carried out by the authors are presented in order to illustrate the sensitivity of the frame response to the joint behaviour and/or modelling.

\subsection{Beam-to-column Joints}

In pallets racks, the connection between the upright and the beam is an easy-to-handle mechanical connection. As already mentioned, the connected profiles and the connection itself may exhibit a wide variety of shapes, dimensions and wall thickness of members, and of shape and dimensions of connecting elements. Nevertheless, some common features can be identified, which are summarised next.

Beams are usually built by welding two thin-walled channels to form a closed section. End connectors are welded at the beam ends, positioned either symmetrically or asymmetrically with respect to the beam axis. The connectors include tangs that accommodate into the holes located on the front wall of the upright, thus creating the connection (Figure 9). This simple connection system allows the rack levels to be adjusted to the storage needs. The geometries of the tangs, beam-end-connector and holes on the upright are designed to facilitate the engaging and to reduce as much as possible the lack of fit and the joint looseness. Moreover, connections are usually provided with locking devices to prevent accidental unlocking or knocking-out of the beam. 

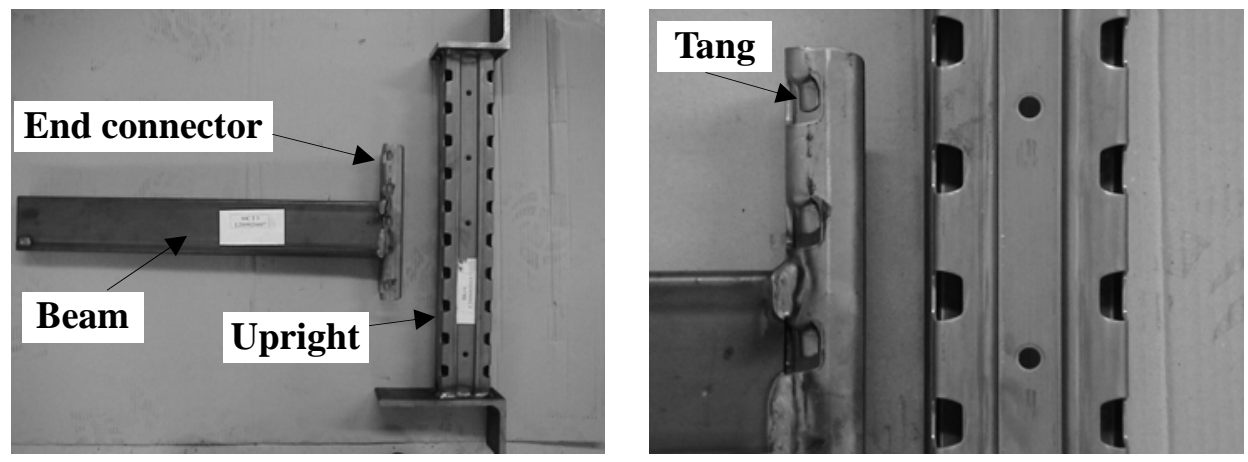

Figure 9. Typical Beam-to-column Connection

When subject to a bending moment, the connectors rotate outwards and tend to tighten up. The moment transferred from the beam to the upright is associated with distortion of the end connectors and local deformation of the upright wall. According to the traditional criterion, these joints would be classified as semi-rigid [28] as pointed out by various authors [25,26,27]. Baldassino and Bernuzzi [26] analysed the results of more than 200 tests on 52 types of beam-to-column connections under bending. Their work showed that the considered connections were characterized by a limited degree of flexural continuity. However, the results of an extensive numerical investigation clearly indicated that such flexible joints have a significant influence on the frame performance. Therefore, it was concluded that when the joint response falls in the flexible domain, the semi-continuous frame model has to be adopted in order to accurately assess the frame response.

This central role in providing the rack lateral stability calls for specific analyses aimed at investigating the joint performance under bending. With this aim, the European and the North American Standards [3,5] provide recommendations for designing, performing and evaluating 'ad hoc' tests to assess the stiffness and moment capacity of the joint. Although the purpose of the tests is the same, the test set-up, procedure and method of evaluating the results are quite different.

The European Standard [3] specifies two types of tests: the bending test and the looseness test. While the former is aimed at assessing the stiffness and the moment resistance, the latter enables the determination of the initial looseness of the joint, an important parameter also for determining the rack frame geometrical imperfection. Both tests adopt the same specimen geometry: a stub of the upright section, connected to a counter frame, and a short length of beam, connected to the central part of the upright (Figure 10). The load is applied at a distance of $400 \mathrm{~mm}$ from the face of the upright. During the tests, the rotation of the end connector is measured (Figure 10). The bending and looseness tests differ in the loading history. In the former, a first cycle of loading and unloading allows for the lack of fit to take place before the load is increased up to the collapse of the specimen. The latter involves a single load cycle up to a moment approximately equal to $\pm 10 \%$ of the joint ultimate moment.
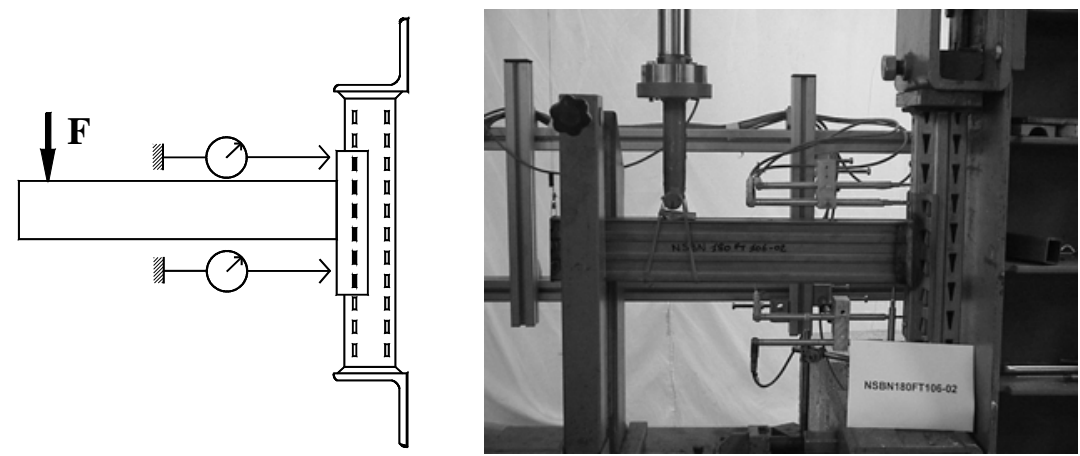

Figure 10. Typical Beam-to-column Connection 
Typical experimental responses from a bending and a looseness test are shown in figures 11a and $11 \mathrm{~b}$, respectively. The European Standard [3] provides detailed methods for evaluating the test data and for defining a design moment-rotation relationship. The amplitude of the initial looseness is obtained by means of a quite simple procedure. The intersection points between the rotation-axis and the lines characterising the 'linear range' of the moment-rotation relation (i.e., points A and B in figure 12) enable the determination of a segment (segment $\mathrm{AB}$ in figure 12), whose length is assumed to be twice the value of the initial looseness $\left(\theta_{1}\right)$.

The moment-rotation law is obtained by means of a time consuming procedure, which also accounts for the deviations of the actual thicknesses and steel yield strength of the joint components, with respect to their nominal values.

Two design models are possible: while one approximates the experimental results by a multi-linear relationship, the other one adopts an elastic-perfectly plastic law. In both cases, it is necessary to determine the design moment resistance $\left(\mathrm{M}_{\mathrm{Rd}}\right)$, computed in accordance with the limit states approach [3]. The experimental moment-rotation curves, as well as the related models, are assumed to be bound by the $\mathrm{M}_{\mathrm{Rd}}$ value.

The multi-linear law is selected by approximating the experimental moment-rotation relationship, while strictly remaining below it (see the dashed line in Figure 13). No practical rules are given.

In the case of a bi-linear moment rotation relationship, the stiffness of the elastic range $\left(k_{n, i}\right)$ is selected as the slope of the secant line passing through the origin and defining approximately equal areas between it and the experimental curve (i.e., areas $A_{1}$ and $A_{2}$ in figure 14). To reduce the deviation between the experimental and numerical results, the stiffness should be selected by considering as additional criterion the condition $\mathrm{k}_{\mathrm{n}, \mathrm{i}} \leq 1,15 \cdot \mathrm{M}_{\mathrm{Rd}} / \theta_{\mathrm{i}}$ (Figure 14). The stiffness to be adopted in design $\left(\mathrm{k}_{\mathrm{m}}\right)$ is the average value of at least three tests.

a)

b)
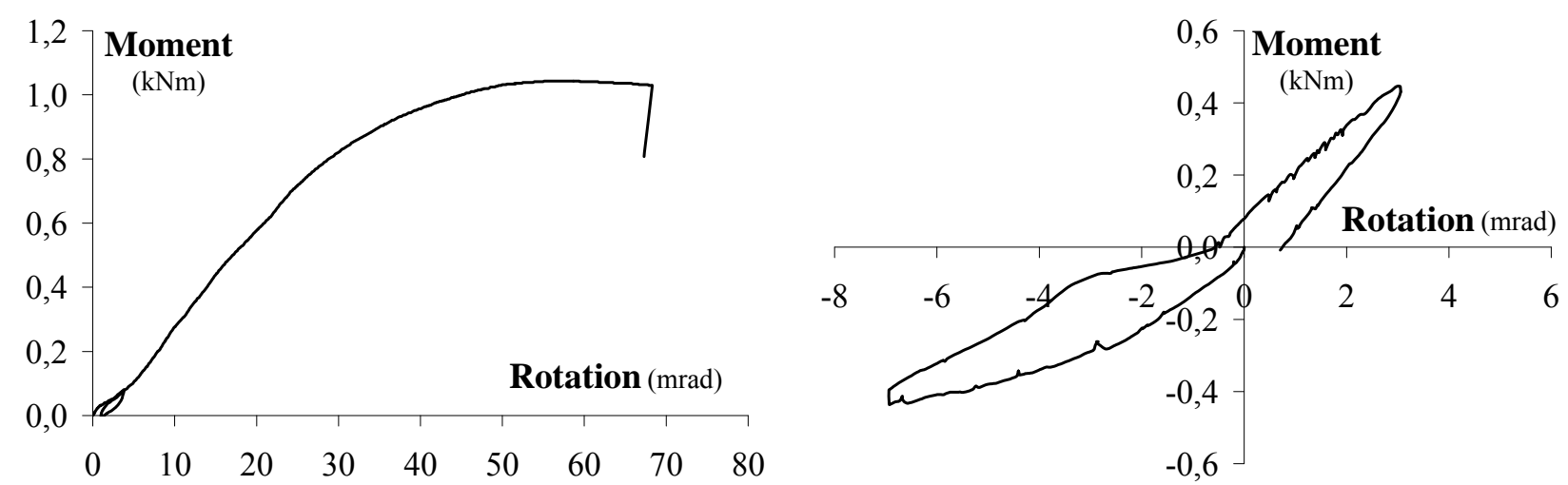

Figure 11. Typical Test Results of a Beam-to-column Connection:

a) Bending Tests and b) Looseness Test 


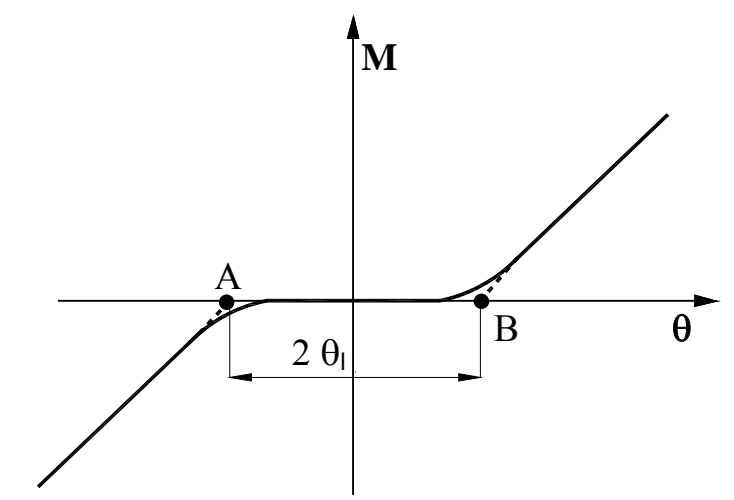

Figure 12. Evaluation of the Initial Looseness
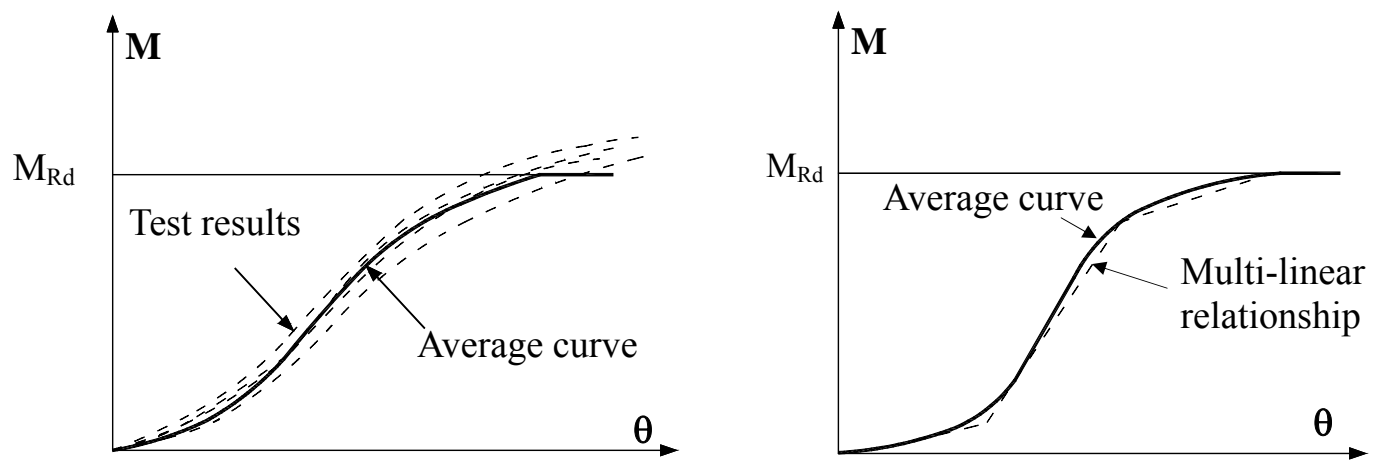

Figure 13. Evaluation of a Multi-linear Moment-rotation Relatonship for Beam-to-column Connection
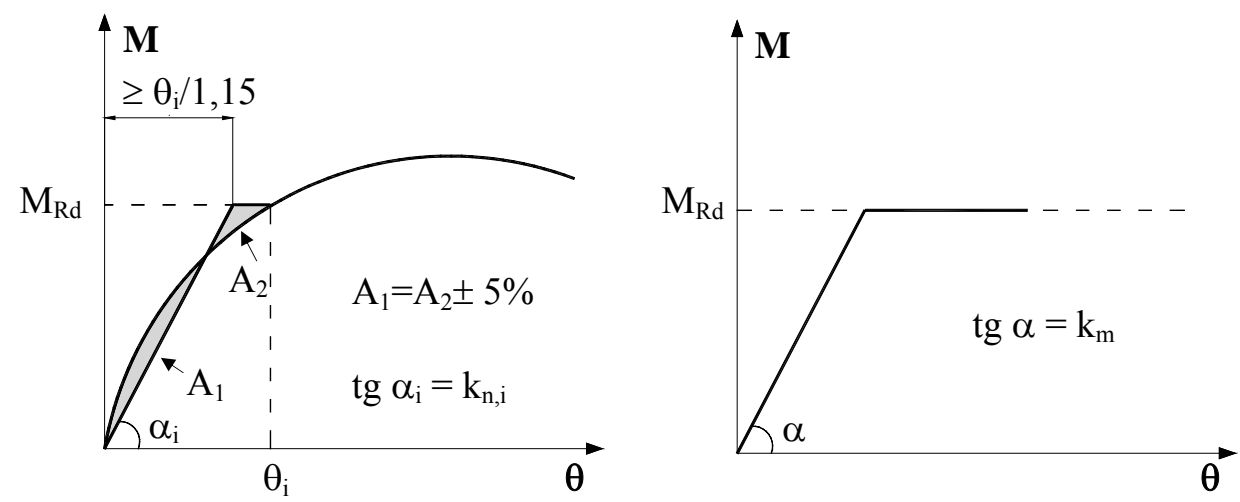

Figure 14. Evaluation of the Initial Stiffeness

The initial looseness and linearised moment-rotation relationship define the beam-to-column joint behaviour in bending. In the frame analysis, the initial joint looseness $\left(\theta_{1}\right)$ is incorporated as an additional sway frame imperfection. A more accurate approach is usually precluded by numerical difficulties. The moment-rotation response is then simulated by means of rotational springs. The European Standard [3] assumes a $\mathrm{M}-\theta$ relationship symmetric for both positive and negative bending moments. It should be mentioned that this assumption is not consistent with the experimental results (Figure 15) [26], nevertheless it is be acceptable for design purposes. Numerical studies carried out on typical rack configurations confirmed the negligible influence of the joint symmetry assumption on the frame performance [26]. 


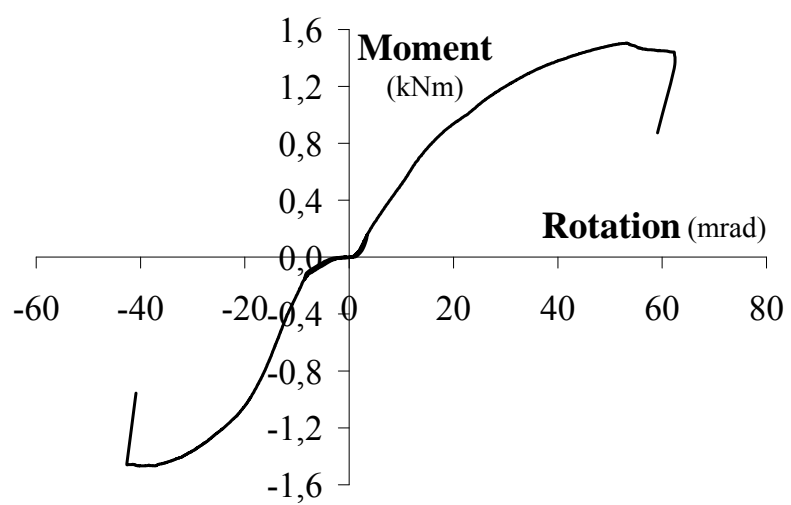

Figure 15. Beam-to-column Joint Response under Positive and Negative Bending Moment

The North American Standard [5] specifies two different tests on beam-to-column joints: the cantilever test and the portal test. The cantilever test, which is similar to the European bending test, is aimed at assessing both the joint stiffness and moment capacity. However, it is mentioned that, in this test, the joint deformability (or stiffness) might be non negligibly affected by the shear force. Therefore, the portal test must be considered in order to provide a more accurate evaluation of the joint stiffness (Figure 16a). The test is carried out on a substructure composed by four uprights, hinged at the base, connected by two beams. The specimen is first subject to the vertical service load, followed by the corresponding design horizontal load, applied at the beam level. The frame sways and the beam-to-column connections rotate in opposite directions, so that the rotation caused by the vertical load increases in one connection and decreases in the other one. The analysis of the portal test results leads to an appraisal of the average value of the joint stiffness, accounting for the joint behaviour asymmetry when the frame sways. However, Harris and Hancock [29] observed that the portal test enables the evaluation of the joint behaviour only for relatively small joint rotations, which does not fully reflect the actual joint response in a sway frame. In particular, they point out that the portal frame results greatly depend on the level of joint bending moment under the vertical loads, due to the non-linear joint behaviour (Figure 16b).

a)

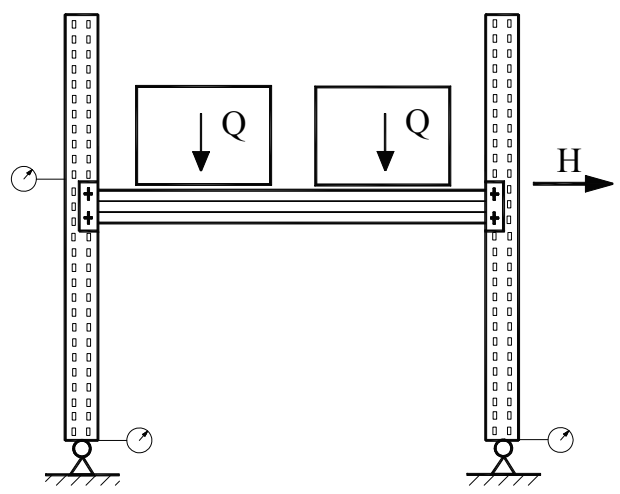

b)

Figure 16. Test Set-up for Portal Test

The remarkable influence of the joint response on the frame performance justifies the great attention paid by the Standards to its characterisation. The authors carried out a numerical study aimed at investigating such an influence [30]. Two rack configurations, involving different numbers of bays and levels, were selected within a typical practical range. The attention was focussed on the rack behaviour in the down-aisle direction. For both frame configurations, the same profiles (uprights and beams) and connections (base-plate and beam-to-column) were considered. All the joints were experimentally characterised in accordance with the European Standard [3]. The 
analyses were performed with the PEP program [31], which enables the incorporation of material and geometrical non-linearity, semi-continuity and the influence of the axial load on the response of the base joints. A simplified bi-linear relationship was assumed for the end connectors. The influence of the beam-to-column joints on the frame performance was studied by selecting 3 joint stiffness values: $2 \mathrm{k}, \mathrm{k}, 0,5 \mathrm{k}$, where $\mathrm{k}$ is the experimental joint stiffness. In addition, initial frame out-plumb angles of 1/1000,1/200 and 1/100 were considered to simulate a wide range of joint looseness amplitudes. Three models were adopted for the base joint: hinge, fixed base and semi-rigid. For the last one a simplified bi-linear curve was assumed. A total of 54 cases were analysed.

The results of this study showed that:

- an increase of the beam-to-column joint stiffness may not lead to an increase of the load capacity. This is mainly due to the change of the collapse mode, which may be associated with the reaching of the maximum rotation capacity of the joint;

influence of the initial out-of-plumb: the increase of the beam-to-column looseness leads to a decrease of the load capacity, for realistic out-of-plumb angles. However, the results do not show any clear relation between the out-of-plumb and the ultimate load;

- the single parameter affecting the frame performance the most appears to be the base restraint.

The above results point out the importance of the joint rotation capacity. No attention is given in the Standard [3] to this parameter and such a gap needs to be filled. Indeed, the accuracy required in the looseness tests seems to be insufficient, and a more accurate assessment of the end connector stiffness is required. However, the results also seem to confirm that a more refined moment-rotation law (i.e., the multi-linear model) does not lead to a real increase of the accuracy of the frame analysis.

As pointed out in this section, the experimental procedures appear fairly demanding on both the test performance and the evaluation of the test results. Moreover, even a small variation of the joint configuration calls for a new series of tests. The numerical analysis based on the FE method [14] seems to be a viable alternative, which would also allow for a deeper understanding of the importance of the various factors involved. In recent years, some attempts were made along this direction. The results obtained showed a general good agreement between the experimental and numerical analyses, but also made it clear that the reliability of the numerical models strongly depends on their calibration against experimental results. In addition, a labour-intensive and time-consuming data input (including the FE mesh) is always required in order to adequately capture the local phenomena, that affect the joint performance and trigger the frame collapse [32]. A convenient alternative is the so-called 'component method' [28], which builds up the joint response on the basis of the behaviour of its components. Recently, Kozłowski and Ślęczka [33] presented a preliminary research study of the application of the component method to rack joints. This work involves five joint typologies, identifies the key joint components and proposes equations to evaluate their stiffness and flexural resistance. Although the results are encouraging, an in-depth study aimed at further validating the model for a wider range of joint typologies remains a necessary pre-requisite for any possible use in design practice.

\subsubsection{Base-plate connection}

Base joints of rack frames are peculiar due to the configuration and components adopted. Therefore, their response is different from that of base joints in traditional steel frames. If reference is made to the Italian practice, base joints are typically built up from 'ad hoc' designed base-plate elements bolted to the uprights and connected to the floor by means of fixing systems (chemical plugs, 
bolts...). Lack of fit between the base-plate element and the upright, local plastic deformations of the upright at the connection to the base-plate element, local buckling of the upright, the interactions between the aforementioned phenomena and the base plate deformation are the main factors influencing the stiffness, resistance and ductility of the joint.

In order to account for the base joints response in the analysis, different approaches are prescribed by the European and the North American Standards [3,5]. The European Standard [3] provides two possible approaches: either to neglect any rotational restraint (i.e., model the joint as a hinge) or to perform 'ad hoc' tests. In the latter case, to account for the influence of the axial load on the joint response, it is recommended that tests are performed for at least two different axial load levels, selected in the range up to the maximum design load for the upright.

The North American Standard [5] adopts a simplified approach: the base joint is modelled by a linear moment-rotation (M- $\theta$ ) relationship. The joint stiffness is determined by considering only the elastic deformation of the concrete floor and does not depend on the axial load. The rotational stiffness of the joint depends only on the dimensions of the upright. Such a difference between the North American and the European Standards [5,3] can be explained by the different base joint typologies employed.

In recent years, the authors carried out an experimental study of base-plate joints of Italian rack frames [34]. The campaign comprised 200 tests on 25 different types of commercial connections, performed in accordance with the European Standard [3]. The specimens consisted of two stub-columns symmetrically connected to a concrete cube by the fixings adopted in the actual structure (Figure 17).
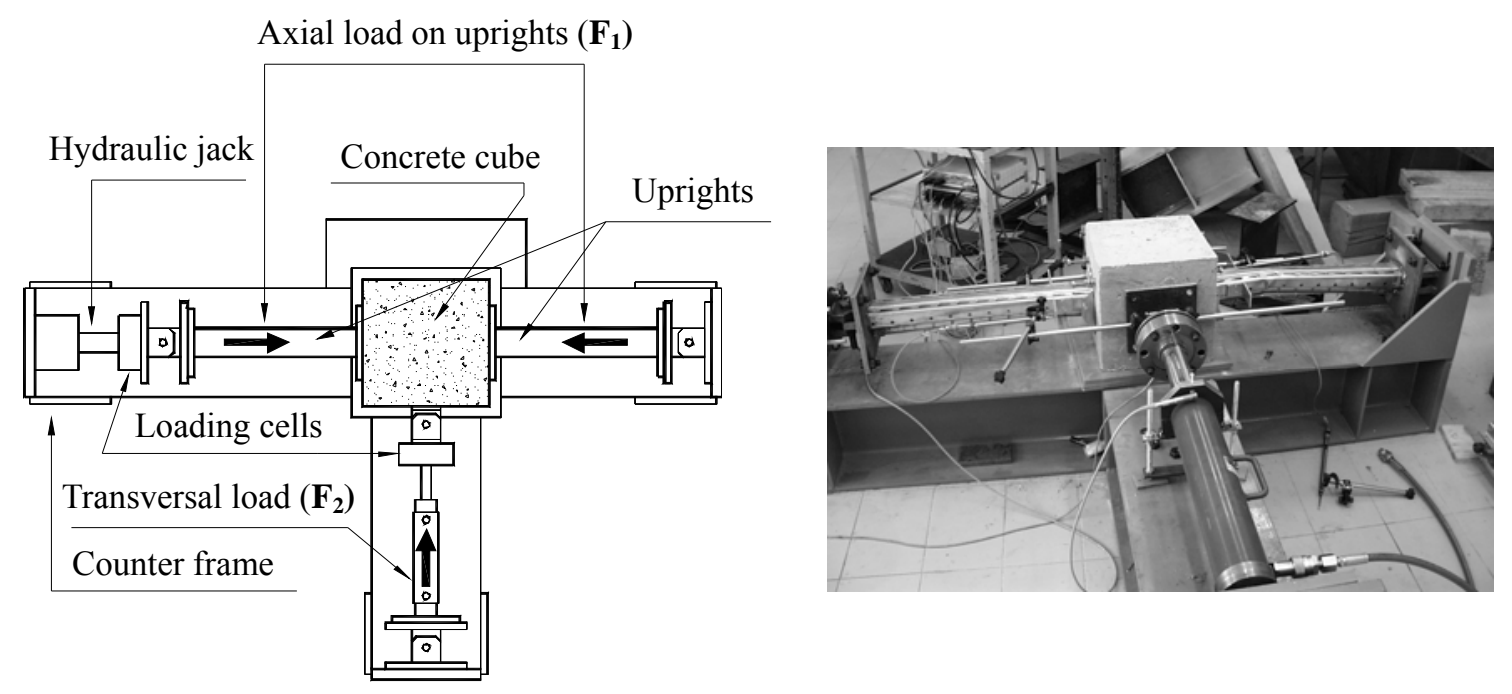

Figure 17. Test set-up for Tests on Base-plate Connections

The concrete cube simulating the floor surface is free to move horizontally in the direction of the applied lateral force and restrained from rotating about the vertical axis. Two hydraulic jacks apply the loads to the specimen: while the first one imposes the specified axial load $\mathrm{F}_{1}$ on the upright, the second one applies a transverse load $F_{2}$ to the centre of the cube. During the test, the rotation of the column bases, with respect to the concrete cube, and the horizontal displacement of the cube are measured.

The test results showed a non-negligible sensitivity to some features of the testing rig. Indications on how to improve the test apparatus were obtained and summarised next: 
- the joint response is highly sensitive to small variations of the axial load $F_{1}$ occurring during the test, stemming from the modified system configuration due to force $F_{2}$. Therefore, it is important to have a reliable load control system to keep the axial load $F_{1}$ constant;

- a vertical displacement of the concrete cube can occur, due to the unavoidable geometrical imperfections of the base connections and/or eccentricities of forces $F_{1}$ and $F_{2}$ with respect to the centre of this element. This effect requires an efficient vertical restraint.

Furthermore, the concrete cube tends to rotate near the collapse, thus inducing a parasitic bending contribution triggering the premature collapse of the base joint. The magnitude of this perturbation cannot be determined.

Typical moment-rotation relationships are presented in figure $18 \mathrm{a}$. The rotation is evaluated as the average value of the relative rotations between the cube and the base joint, measured on the right and left hand sides of the concrete cube. The moment applied to the column base is calculated by considering both the first-order contribution of the transversal load $\mathrm{F}_{2}$ and the second-order effect of the axial load $\mathrm{F}_{1}$, due to the lateral displacement of the concrete cube.

a)
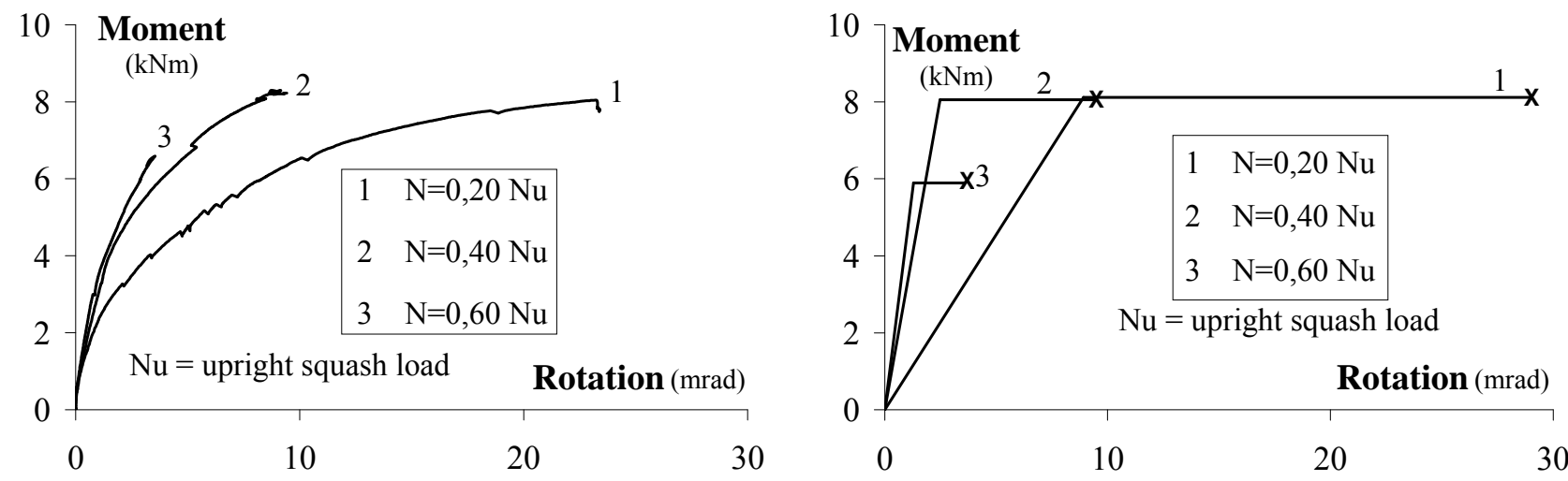

Figure 18. Typical Moment Rotation Relationship for Base-plate Connections:

a) Experimental Results and b) Simplified Relationships

Due to the large variability of the typologies tested and the range of axial load applied to the specimens, it is not possible a direct comparison between the tests results. However, a few general comments on the experimental results can be made:

- the influence of the axial load on both the stiffness and the ultimate moment is substantial. This confirms the need to perform tests for an adequate number of axial load values within the range of use of the upright;

- collapses were caused by plasticity and instability of the upright near to the base-plate. Remarkable deformations of the fixing system to the concrete never occurred;

- the interaction between the base-plate element and the upright could significantly affect the whole joint response. In particular, the local restraint offered by this element to the upright deformation influences both the collapse mode and the joint stiffness [34].

For design purposes, test results should be 'transformed' into simplified moment-rotation relationships accounting for the influence of the axial load on the base joint performance. The European Standard [3] specifies a procedure to evaluate the tests results: for each axial load level, the experimental curves are handled following the procedure prescribed for beam-to-column joints, and an elastic-perfectly plastic moment-rotation relationship is obtained. Typical results of such analyses are presented in figure $18 \mathrm{~b}$. 
A crucial question for design purposes concerns the way in which such simplified relationships should be considered in numerical simulations. In principle, a domain $\mathrm{M}-\mathrm{N}-\phi$ should be defined, with associated rules enabling the determination of the elastic stiffness. In order to simplify the joint model, and in the absence of adequate knowledge, the European code [3] specifies a linear interpolation between the ultimate moment and the joint stiffness for different axial load levels. No rules are given for determining the rotation capacity.

As mentioned before, the North American Standard [5] adopts a very simple theoretical model for the base joint, which relates the elastic stiffness to the joint geometry and the concrete elastic modulus. Recently Sarawit and Peköz [35] carried out an extensive numerical study of base joints for different upright sections, relative positions upright-base plate, and base plate thickness. The study made it possible to improve the equation proposed in the Standard.

From the design point of view, the adoption of a base joint model, even in the simple form specified by the European Standard [3], leads to a more reliable evaluation of the frame performance, but also it significantly increases the computational effort and, requires codes able to incorporate M-N-k- $\theta$ relationships to model the joint. Such a complexity can only be justified if the base joint strongly affects the frame performance.

In order to investigate this issue, the authors recently carried out a numerical study of rack systems with very flexible beam-to-column joints $[34,36]$. The influence of the base restraint, as well as of the way the base joint response is incorporated into the down-aisle frame model, were investigated using the program PEP micro [31]. Each frame configuration combined different base connections and beam-to-column joints. Each joint type was experimentally characterised in accordance with the European Standard [3]. The program linearly interpolates the base joint M- $\theta$ curves associated with different axial load level and the analyses incorporated values of the out-of-plumb angle $\phi$ ranging from 0,001 to $0,01 \mathrm{rad}$. The beam-to-column joints were modelled as semi-rigid and a wide range of stiffness was considered (starting from the experimental value). Four restraint conditions at the base were investigated: hinge, fixed and two semi-continuous joints. The last ones differ in the location of the rotational springs: one model concentrates all the joint deformation at the base, while the other separates the contributions of the end-plate and the upright, locating them in the appropriate positions.

The results of the study showed that:

- the frame response is strongly influenced by the base restraint condition, regardless of the stiffness of the beam-to-column joint. If the load multiplier is considered, the assumption of a fixed base, leads to an increase of the load multiplier by up to $209 \%$, with respect to the hinged base;

- the sway imperfection has a non-negligible influence on the frame response: this parameter becomes less important when the end connector flexibility increases;

the assumption of an hinged base, prescribed by the European Standard [3] in the absence of tests results, is fairly penalising: the load multiplier for the actual base restraint is, on average, $103 \%$ larger than the hinged base one;

- the influence of the variation of the beam-to-column joint stiffness increases with the base joint stiffness. As a consequence, it is not worth improving the beam-to-column joint performance when the base joints are very flexible;

- the frame response determined by considering the semi-rigid base joint behaviour appears not to be sensitive to the way in which the joint flexibility is incorporated into the model.

The above results clearly indicate the need of an experimental characterisation of the base joint. A key parameter for the complete characterisation of the base joint is its maximum rotation capacity. 
Like for beam-to-column joints, no specific requirements are given by the Standard [3] for base joints.

The FE numerical analysis is a useful tool to reduce the cost of experimental studies. Researches carried out in the recent past [36,37], show the potential of this technique in predicting both the joint overall response and collapse mode, even if the complex behaviour of the base joints leads to vey complex numerical models. The need to reproduce the upright boundary conditions and the local phenomena, due to the interaction between the base plate, upright and floor, requires numerical simulations, involving very refined meshes and elements able to model contacts, which should be accurately calibrated against the experimental results. This means that the role of tests remains very important, since they cannot be fully replaced by FE numerical simulations.

\section{CONCLUDING REMARKS}

This paper provides a general overview of the 'design by testing' of steel storage pallet racks. The experimental approach provided by the main standards, namely the European and the North American Standards was presented and discussed. Attention was focused on the key rack components: the upright under compression, the upright frame under shear, the beam-to-column joints in bending and the base joints under compression and bending.

The following issues deserve to be specially mentioned:

- uprights: the experimental procedure proposed by the European Standard appears to be fairly complex. A critical aspect for member testing is the selection of the point of load application. The variable geometry of the cross section along the member length does not allow a definition of a 'centroidal axis of the profile'. Clear guidance on this issue is missing;

- upright frames: the theoretical evaluation of the shear stiffness substantially overestimates the experimental value. Key factors, such as eccentricities of bracing members, bending deformation of the bolts or lack of fits, are not taken into account by the theoretical method. Either experimental values or values yielded by 'realistic' numerical analysis need to be used in design;

beam-to-column joints: since this play a fundamental role in the stability of rack frames in the down-aisle direction, an adequate characterisation is required. Nevertheless, the results of frame analyses seem to indicate that a refined moment-rotation law does not lead to a real increase in accuracy. Bi-linear joint models are satisfactory. Although the approach proposed by the European code is fairly demanding, it pays no attention to the joint rotation capacity, even if extensive numerical studies carried out by the authors showed the importance of this parameter;

- base-plate connections: the experimental characterisation is the most appropriate way to capture the behavioural complexity of these joints, as specified by the European Standard. Code recommendations should be improved to include a more complete characterisation of the joint response, namely the influence of the axial load and the maximum rotation.

Design by testing is a demanding procedure due to both the number and complexity of tests required. At present, numerical tools do not seem to be a fully viable alternative: tests are always required to validate numerical models. However, a reduction of the experimental effort may be foreseen as a consequence of the continuous and fast advances in both software and hardware capabilities. 
Industrial rack design would greatly benefit from a deeper knowledge of several issues that need further investigation. For instance, the influence of the perforations on the upright response, the definition of 'realistic' numerical models for upright frames, the application of the 'component method' to rack beam-to-column and base joints, the criteria to estimate the base joint response accounting for bending, axial force, stiffness and rotation capacity.

\section{REFERENCES}

[1] Ghersi, A., Landolfo, R. and Mazzolani, F.M., "Design of Metallic Cold-formed Thin-walled Members", Spon Press, London and New York, 2002, pp. 164.

[2] Hancock, G.J., "Design of Cold-formed Steel Structures", Australian Institute of Steel Construction, 2nd Edition, 1994, pp. 240.

[3] CEN, "EN 15512, Steel Static Storage Systems - Adjustable Pallet Racking Systems Principles for Structural Design", CEN European Committee for Standardization, 2009, pp. 137.

[4] AS, "AS 4084 - Steel Storage Racking", AS Standards Australia, 1993, pp. 41.

[5] RMI, "MH 16.1- Specification for the Design, Testing and Utilization of Industrial Steel Storage Racks", RMI - Rack Manufactures Institute, 2008, pp. 59.

[6] Timoshenko, S.P. and Gere J.M., "Theory of Elastic Stability", 2nd Edition, McGraw-Hill Book Company, New York, 1961, pp. 541.

[7] Hancock, G.J., "Ligth Gauge Construction", Progress in Structural Engineering and Materials, 1997, Vol. 1, No. 1, pp. 25-30.

[8] Trahair, N.S., "Flexural-torsional Buckling", E \& FN Spon, London, UK, 1993, pp. 420.

[9] Gioncu, V., "General Theory of Coupled Instabilities", Thin-Walled Structures, 1994, Vol. 19, No. 2-4, pp. 81-128.

[10] Pekoz, T., "Development of a Unified approach to the Design of Cold-formed Steel Members", American Iron and Steel Institute, Research Report, CF87, No. 1, 1987.

[11] Weng, C.C. and Peköz, T., "Residual Stresses in Cold-formed Steel Members", Journal of Structural Engineering, ASCE, 1990, Vol. 116, No. 6, pp. 1611-1625.

[12] Moen, C.D., Takeru Igusa and Schafer, B.W., "Prediction of Residual Stresses and Strains in Cold-formed Steel Members", Thin-Walled Structures, 2008, Vol. 46, No. 11, pp. 1274-1289.

[13] LaBoube, R.A., Yu, W.W., Langan, J.E. and Shan, M.Y., "Cold-formed Steel Webs with Openings: Summary Report", Thin-Walled Structures, 1997, Vol. 27, No. 1, pp. 79-84.

[14] Zienkiewicz, O.C., "The Finite Element Method", 3rd Edition, McGraw-Hill Company, London, UK, 1977, pp. 787.

[15] Cheung, Y.K., "Finite Strip Method in Structural Analysis", Pergamon Press, Oxford, New York, 1976, pp. 232.

[16] Schardt, R., "The Generalised Beam Theory, Instability and Plastic Collapse of Steel Structures", Proceedings of the M.R. Horne Conference, University of Manchester, Granada, London, 1983, pp. 469-475.

[17] Davies, J.M. and Leach, P., "First-order Generalised Beam Theory", Journal of Constructional Steel Research, 1994, Vol. 31, No. 2-3, pp. 187-220.

[18] Davies, J.M., Leach, P., and Heinz, D., "Second-order Generalised Beam Theory", Journal of Constructional Steel Research, 1994, Vol. 31, No. 2-3, pp. 221-241.

[19] El-Sawy, K.M. and Nazmy, A.S., "Effect of the Aspect Ratio on the Elastic Buckling of Uniaxially Loaded Plates with Eccentric Holes", Thin-Walled Structures, 2001, Vol. 39, No. 12, pp. 983-998.

[20] Moen, C.D. and Schafer, B.W., "Experiments on Cold-formed Steel Columns with Holes", Thin-Walled Structures, 2008, Vol. 46, No. 10, pp. 1164-1182. 
[21] Moen, C.D. and Schafer, B.W., "Elastic Buckling of Thin Plates with Holes in Compression or Bending", Thin-Walled Structures, 2009, Vol. 47, No. 12, pp. 1597-1607.

[22] Eccher, G., Rasmussen, K. and Zandonini R., "Elastic Buckling Analysis of Perforated Thin-walled Structures by the Isoparametric Spline Finite Strip Method", Thin-Walled Structures, 2008, Vol. 46, No. 2, pp. 165-191.

[23] Baldassino, N. and Hancock, G.J., "Distortional Buckling of Cold-formed Steel Storage Rack Sections including Perforations", Proceedings of the Fourth International Conference on Steel and Aluminium Structures (ICSAS '99), Elsevier, Espoo, Finland, 20-23 June 1999, pp. 131-138.

[24] Sajja, S.R., Beale, R.G. and Godley, M.H.R., "Shear Stiffness of Pallet Rack Upright Frames", Journal of Constructional Steel Research, 2008, Vol. 64, No. 7-8, pp. 867-874.

[25] Markazi, F.D., Beale, R.G. and Godley, M.H.R., "Experimental Analysis of Semi-rigid Boltless Connectors", Thin-Walled Structures, 1997, Vol. 28, No. 1, pp. 57-87.

[26] Baldassino, N. and Bernuzzi, C., "Analysis and Behaviour of Steel Storage Pallet Racks", Thin-Walled Structures, 2000, Vol. 37, No. 4, pp. 277-304.

[27] Baldassino, N. and Zandonini, R., "Performance of Base-plate Connections of Steel Storage Pallet Racks", Proceedings of the International Colloquium dedicated to the 70th Anniversary of Professor Victor Gioncu, May 7-8 2004, Timisoara, Romania, pp. 11-20.

[28] CEN, "Eurocode 3 - Design of Steel Structures - Part 1-8: Design of Joints", CEN European Committee for Standardization, 2005, pp. 133.

[29] Harris, E. and Hancock, G., "Stability Testing of Sub-assemblages of High Rise Steel Storage Racks", Proceedings of the International Conference on Advances in Structures (ASSCCA '03), Sidney, Australia, 22-25 June 2003, Vol. 1, pp. 251-256.

[30] Giovannini, M., "On the Response of Industrial Racks" (in Italian), Master Thesis, University of Trento, 2008, pp. 137.

[31] Galea Y. and Bureau A., "PEP Micro - Manuel d'Utilisation", Centre Tecnique Industriel de la Construction Métallique (CTiCM), France, 1998.

[32] Bajoria, K.M. and Talikoti, R.S., "Determination of Flexibility of Beam-to-column Connectors used in Thin Walled Cold-formed Steel Pallet Racking Systems ", Thin-Walled Structures, 2006, Vol. 44, No. 3, pp. 372-380.

[33] Kozłowski, A. and Ślęczka, L., "Preliminary Component Method Model of Storage Rack Joint", Proceedings of Connections in Steel Structures V, Amsterdam, June 3-4 2004, pp. 253-262.

[34] Baldassino, N. and Zandonini, R., "Performance of Base-plate Connections of Steel Storage Pallet Racks", Proceedings of Fifth International Conference on Coupled Instabilities in Metal Structures (CIMS2008), Gregory J. Hancock Symposium, Sydney, Australia, 23-25 June, 2008, pp. 119-130.

[35] Sarawit, A.T. and Peköz, T., "Cold-formed Steel Frame and Beam-column Design", Report of a Research Project AISI-RMI, Report 03-03, 2003, pp. 330.

[36] Scandola, A., "Analysis of Industrial Racks" (in Italian), Master Thesis, University of Trento, 2007, pp. 129.

[37] del Coz Díaz, J.J., García Nieto, P.J., Betegón Biempica, C. and Fernández Rougeot, G., "Non-linear Analysis of Unbolted Base Plates by FEM and Experimental Validation", Thin-Walled Structures, 2006, Vol. 44, No. 5, pp. 529-541. 


\title{
EXPERIMENTAL STUDY ON BEHAVIORS OF THE TRAPEZOID CONNECTORS OF THE INVERTED T-SHAPED STEEL WITH NOTCHED WEB FOR A NOVEL COMPOSITE BEAM
}

\author{
Li Guo-qiang ${ }^{1,2, *}$, Li Liang ${ }^{2}$ and Li Xianhui ${ }^{2}$ \\ ${ }^{I}$ State Key Laboratory for Disaster Reduction in Civil Engineering, Tongji University, Shanghai 200092, \\ People's Republic of China \\ ${ }^{2}$ College of Civil Engineering, Tongji University, Shanghai 200092, People's Republic of China \\ *(Corresponding author: E-mail: gqli@tongji.edu.cn)
}

\begin{abstract}
An innovative steel-concrete composite beam with embedding the notched web of the inverted T-shaped steel into the concrete slab is introduced in this paper. The behaviors of the trapezoid connectors of the notched web of the inverted T-shaped steel for the composite beam are experimentally investigated. Firstly, the shear behavior of the connectors is investigated through the tests on ten push-out specimens, and a formula on the base of the test results is proposed to estimate the ultimate shear capacity of the trapezoid connectors. Then the pull-out behavior is studied through tests on six specimens, and the comparisons between pull-out and shear capacities are conducted. Next, the local compressive behavior is studied through tests on four local compressive specimens, and an equation on local compressive capacity of the connectors is proposed on the base of the test results. Finally, testes are conducted on eight specimens to investigate the punch behavior of the connectors, and a formula on punch capacity of the connectors is recommended. According to the experimental results, the trapezoid connectors may promise the reliability of the connection between the concrete slab and the inverted T-shaped steel beam, and the formulas proposed can be practically used to estimate the shear, local compressive and punch capacities of the trapezoid connectors for the novel composite beam.
\end{abstract}

Keywords: Steel-concrete composite beam; T-shaped steel; push-out specimens; trapezoid connectors

\section{INTRODUCTION}

The conventional composite beam is composed of a steel beam with H-shaped section and a concrete slab [1-4], and headed studs are used as shear connectors to combine the steel beam and the concrete slab together, as shown in Figure 1(a). In H-shaped steel concrete composite beam, the top flange of the steel beam is at the vicinity of the neutral axis of the section, its stress level is low and the material is not fully used under sagging moment [5]. If the top flange of the steel beam is removed and the isosceles trapezoid notch is cut at the top of web to work as the shear connectors, the steel and headed studs can be saved, as shown in Figure 1(b). The inverted T-shaped steel-concrete composite beam is mainly made up of the steel component with inverted T-shaped section and concrete slab, generally designed to bear sagging moment.

Comparing with the H-shaped steel-concrete composite beam [6-11], the following advantages are found in the inverted T-shaped steel-concrete composite beam:

(1) The top flange of H-shaped steel beam is removed, which would reduce about $20 \%$ of steel consumption;

(2) The headed studs are replaced by trapezoid connectors, and the welding process of headed studs is avoided;

(3) Two T-shaped steel beams can be made by cutting along a trapezoid path on the web of one $\mathrm{H}$-shaped steel beam, which would accelerate the pace of construction, as shown in Figure 2. 


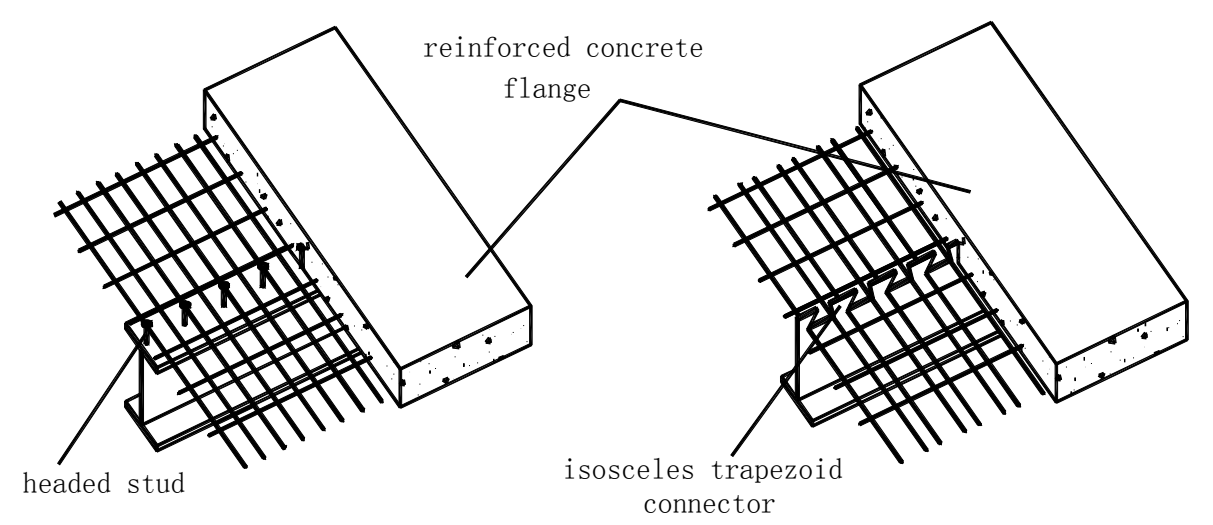

(a) H-shaped Steel-concrete Composite Beam

(b) Inverted T-shaped Steel-concrete Composite beam

Figure 1. Steel-concrete Composite Beam with Different Connectors

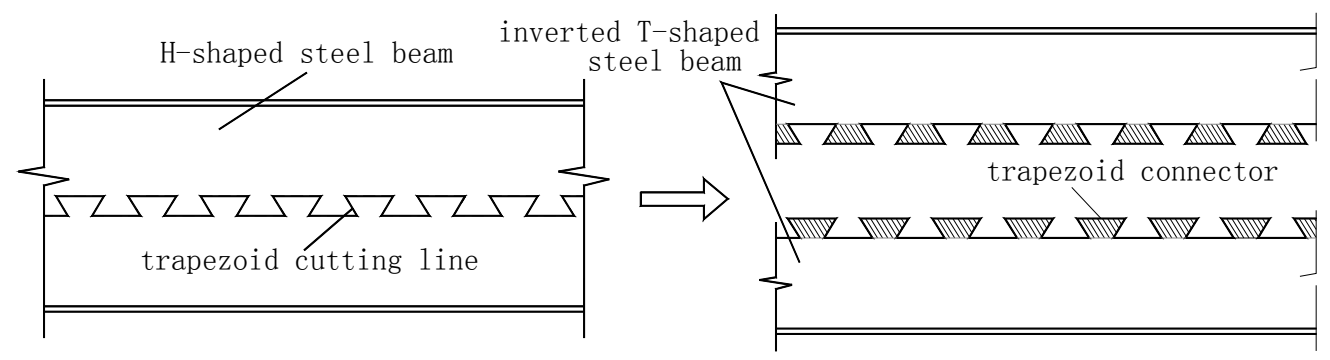

Figure 2. Construction Process of the Inverted T-shaped Steel Beams

For proper design and use of the novel composite beam, the behaviors of the trapezoid connectors of the inverted T-shaped steel with notched web needs to be clearly identified. For this purpose, a series of tests are conducted on behavior of the connection of the specimens to investigate the shear, pull-out, local compression and punch behavior. According to the test results, formulas for estimating the shear, local compressive and punch capacities of the connectors are proposed.

\section{PUSH-OUT TEST}

\subsection{Specimens and Test Set-up}

The shear behavior between concrete slab and steel beam may be studied through push-out tests. To study the shear performance of the trapezoid connectors for the novel composite beam, tests are conducted on 10 push-out specimens. Each specimen is composed by an H-shaped steel component, two pieces of connecting plates and two blocks of concrete slabs. One edge of the connecting plate is welded on the flange of the H-shaped steel component, and the other edge is embedded into the concrete slab. A $50 \mathrm{~mm}$ wide gap is retained between the end of concrete slab and the steel component, as shown in Figure 3. 


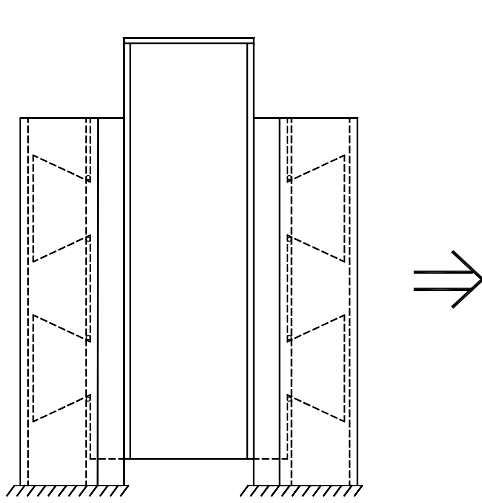

(a) Push-out Specimen
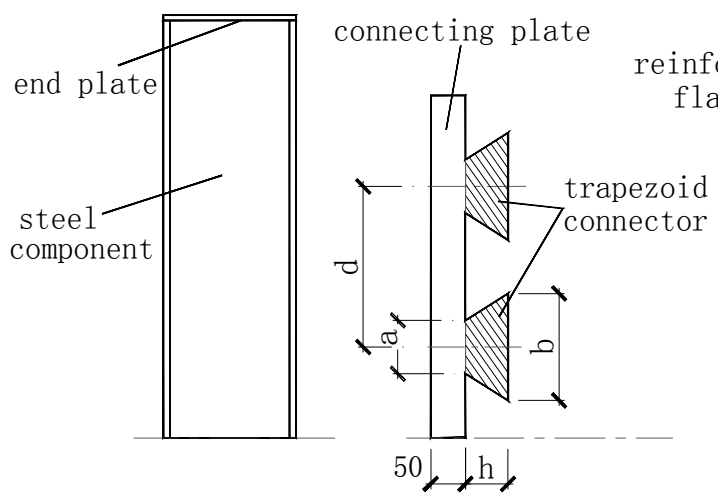

einforced concrete

flange

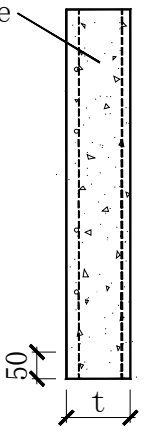

Figure 3. Components of the Push-out Specimen

Settle the specimen vertically on the loading equipment, and apply vertical load on the top of the steel component, as shown in Figure 4. The slip increases with the increasing of the shear between concrete slab and steel component. The shear-slip curves are obtained by recording the vertical load and the slip at every load step.

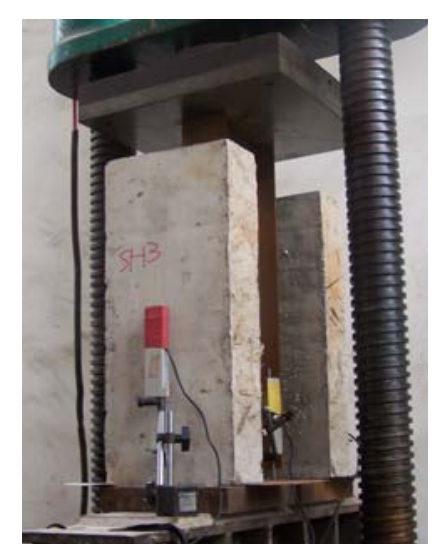

(a) Photo of the Test Set-up

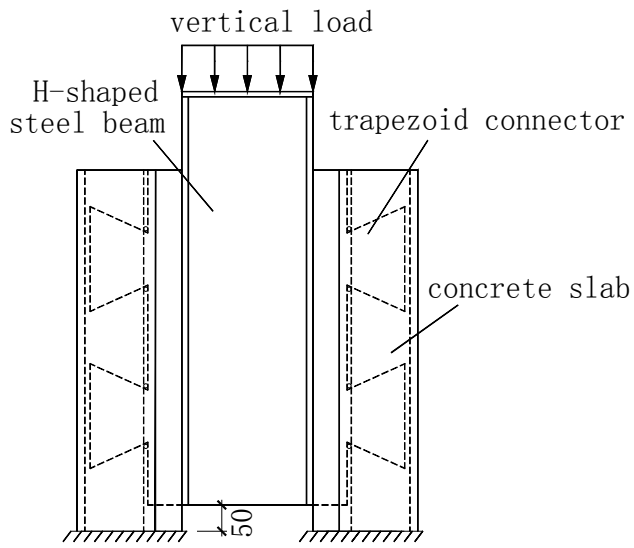

(b) Description of the Test Set-up

Figure 4. Push-out Specimen Settled on Loading Device

In order to study the influence of different parameters, 10 specimens are divided into 5 groups, and the 2 specimens in one group are all the same to consider the discreteness of the test results. The specimens SH1 SH6 are designed to study the influence of the strength grade of concrete; the specimens SH5 SH10 are designed to study the influence of dimension of the trapezoid connector, the thickness of the concrete slab and the reinforcement ratio. The details of the specimens are shown in Figure $5 \sim$ Figure 7 . The parameters of the specimens are listed in Table 1. 
Table 1. Parameters of Push-out Specimens

\begin{tabular}{|c|c|c|c|c|c|c|c|c|c|c|}
\hline \multirow{2}{*}{ No. } & \multirow{2}{*}{ Specimen } & \multirow{2}{*}{$\begin{array}{c}f_{c u} \\
\left(\mathrm{~N} / \mathrm{mm}^{2}\right)\end{array}$} & \multirow{2}{*}{$\begin{array}{c}t \\
(\mathrm{~mm})\end{array}$} & \multicolumn{4}{|c|}{$\begin{array}{c}\text { Dimension of the trapezoid } \\
\text { connector }\end{array}$} & \multirow{2}{*}{$\begin{array}{c}d \\
(\mathrm{~mm})\end{array}$} & \multirow{2}{*}{$\begin{array}{l}\rho \\
(\%)\end{array}$} & \multirow{2}{*}{$\begin{array}{c}L \\
(\mathrm{~mm})\end{array}$} \\
\hline & & & & $\begin{array}{c}t_{w} \\
(\mathrm{~mm})\end{array}$ & $\begin{array}{c}h \\
(\mathrm{~mm})\end{array}$ & $\begin{array}{c}a \\
(\mathrm{~mm})\end{array}$ & $\begin{array}{c}b \\
(\mathrm{~mm})\end{array}$ & & & \\
\hline 1 & SH1,SH2 & 27.5 & 120 & 10 & 80 & 100 & 200 & 300 & $0.56 \%$ & 840 \\
\hline 2 & SH3,SH4 & 42.5 & 120 & 10 & 80 & 100 & 200 & 300 & $0.56 \%$ & 840 \\
\hline 3 & SH5,SH6 & 34.2 & 120 & 10 & 80 & 100 & 200 & 300 & $0.56 \%$ & 840 \\
\hline 4 & SH7,SH8 & 34.2 & 150 & 12 & 110 & 100 & 200 & 300 & $0.70 \%$ & 840 \\
\hline 5 & SH9,SH10 & 34.2 & 100 & 8 & 60 & 60 & 160 & 240 & $0.84 \%$ & 740 \\
\hline
\end{tabular}

In Table 1, $f_{c u}$ is the cubic compressive strength of concrete; $t$ is the thickness of reinforced concrete flange; $t_{w}$ is the thickness of the connecting plate; $h$ is the height of trapezoid connector; $a$ is the width of lower side of the trapezoid connector; $b$ is the width of the upper side of trapezoid connector; $d$ is the distance between the middle lines of adjacent connectors; $\rho$ is the transverse reinforcement ratio of the concrete slab; and $L$ is the length of the specimen.

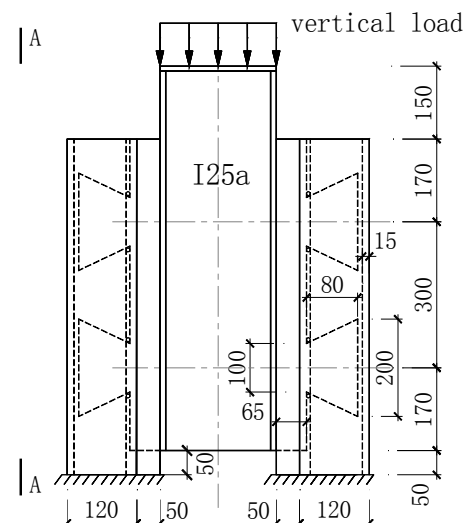

(a) Front Profile

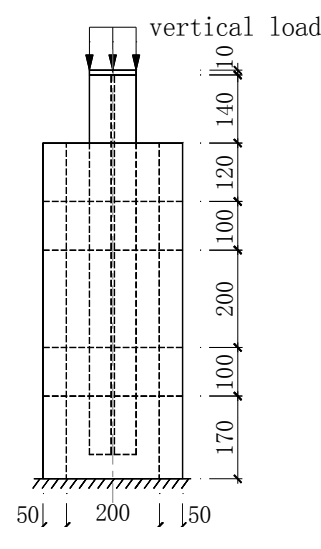

(b) Section A-A

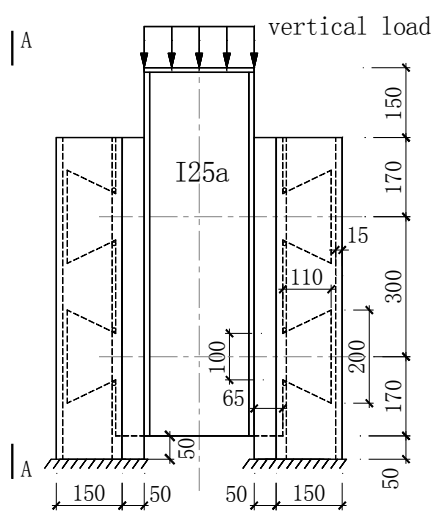

(a) Front Profile

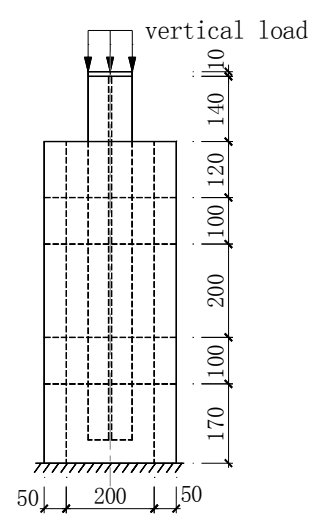

(b) Section A-A

Figure 5. Details of Push-out Specimens SH1 SH6

Figure 6. Details of push-out Specimens SH7 SH8

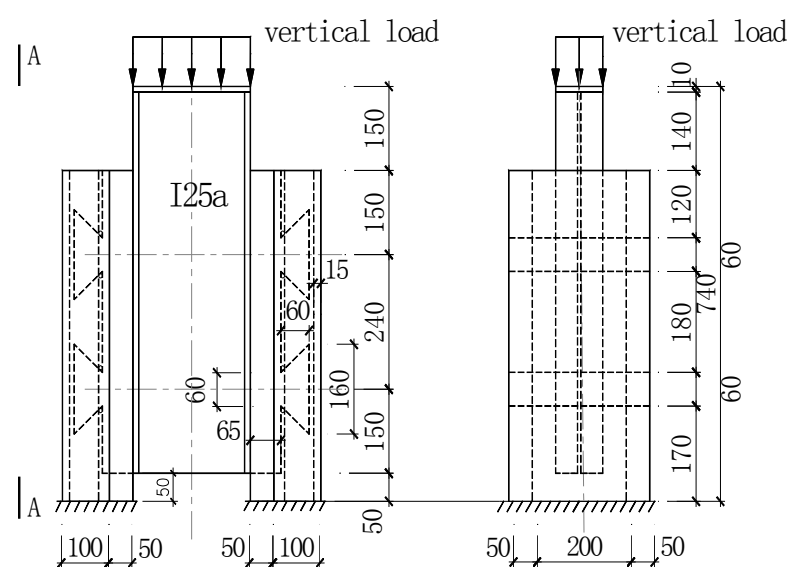

(a) Front profile

(b) Section A-A

Figure 7. Details of Push-out Specimens SH9 SH10 
The yield strength of the steel for steel component and connecting plate is $345 \mathrm{MPa}$, and the tensile strength is $480 \mathrm{MPa}$. The diameter of reinforcing bars in the concrete slab is $8 \mathrm{~mm}$, and the yield strength of the bars is $370 \mathrm{MPa}$.

\section{$2.2 \quad$ Test Phenomenon and Results}

When the shear is less than $0.6 V u$ ( $V u$ is the ultimate shear capacity of the specimen), there is no crack observed on the concrete slab, which indicates that the specimens remain in elastic state. The elastic modulus and compressive capacity of concrete is much less than that of steel, when the shear reaches $0.6 \sim 0.7 V u$, some transverse cracks are firstly observed on the concrete slab, as shown in Figure 8(a). With the further increasing of the shear, some longitudinal cracks emerge on the concrete slab in the direction of the shear force, and simultaneously accompanied by the sound of the concrete cracking. With the development of the cracks, the shear resisted by concrete is transmitted to the transverse reinforcement and longitudinal cracks interconnect with each other, and the excellent ductility is observed with the increasing of the longitudinal slip. Finally, vertical splitting damage takes place on the concrete slab, as shown is Figure 8(b) and Figure 9 (a). After the tests, there is no damage observed on the trapezoid connectors as the concrete slab is removed, as plotted is Figure 9(b).

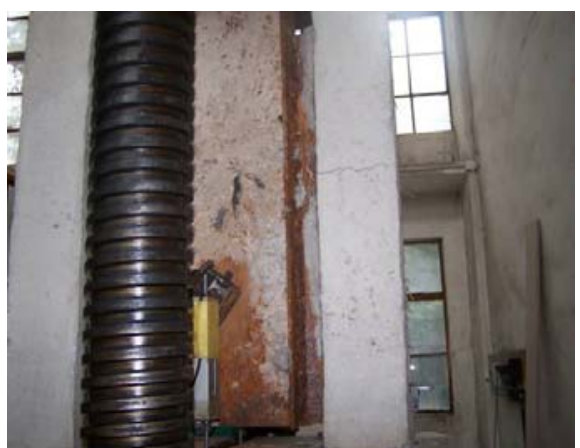

(a) The Transverse Cracks on the Side Profile

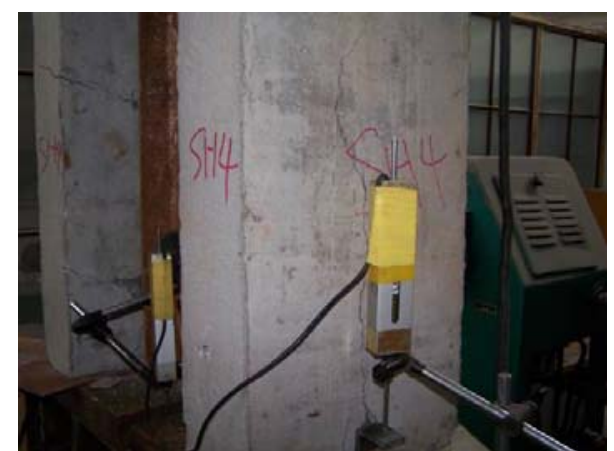
(b) The Longitudinal Cracks on the Front Profile Figure 8. Lateral and Vertical Cracks of Push-out Specimens during the Test

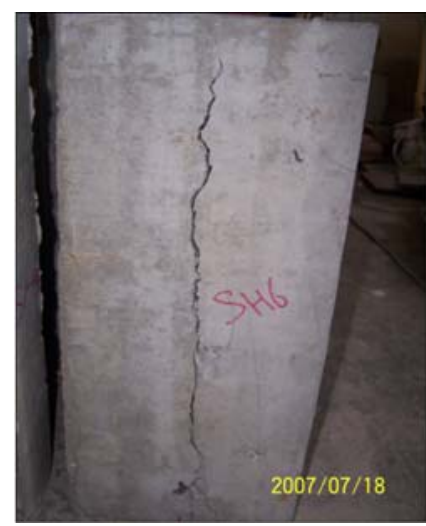

(a) Longitudinal Cracks on the Concrete Slab

(b) Steel Component after the Removal of Concrete Figure 9. The Failure Conditions of Different Parts after Test

The shear-slip curves of the specimens are shown in Figure 10. It can be seen that non-linear characteristic of the shear-slip curve is very obvious. Though there is no obvious yield plateau on the shear-slip curve, the ductility of the connectors for shear-resistance is fine. 


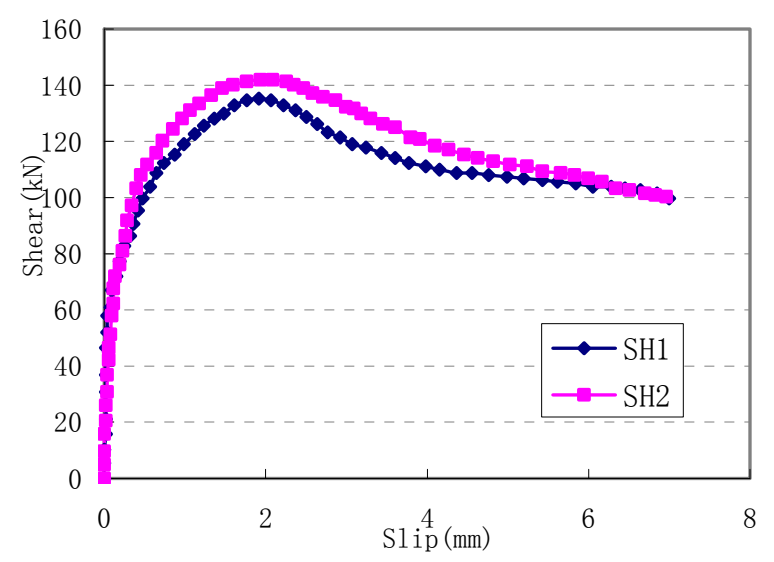

(a) Specimens $\mathrm{SH} 1 \sim \mathrm{SH} 2$

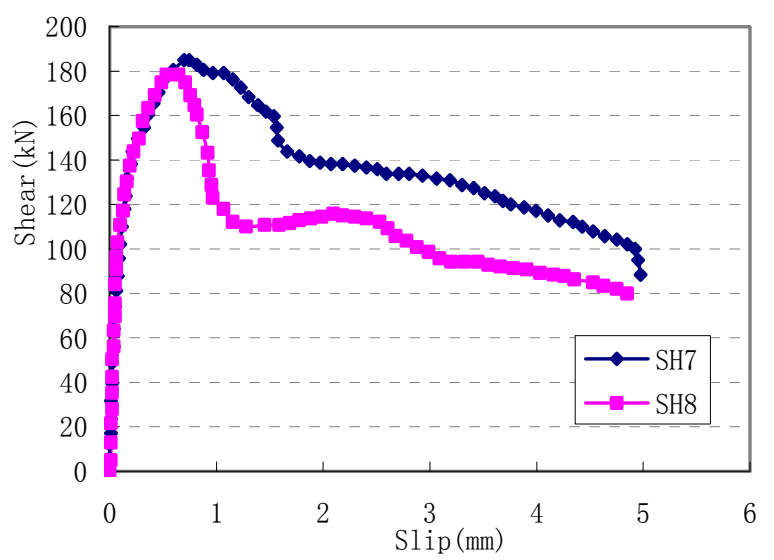

(c) Specimens $\mathrm{SH} 7 \sim \mathrm{SH} 8$

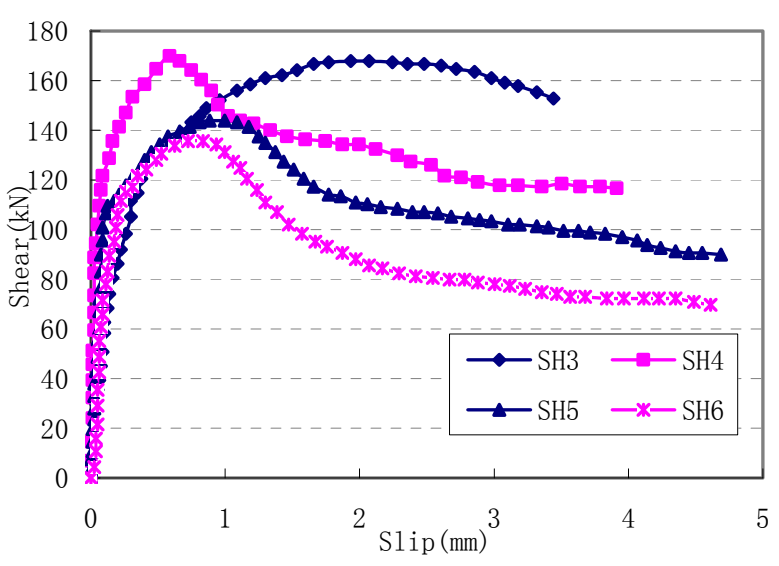

(b) Specimens SH3 SH6

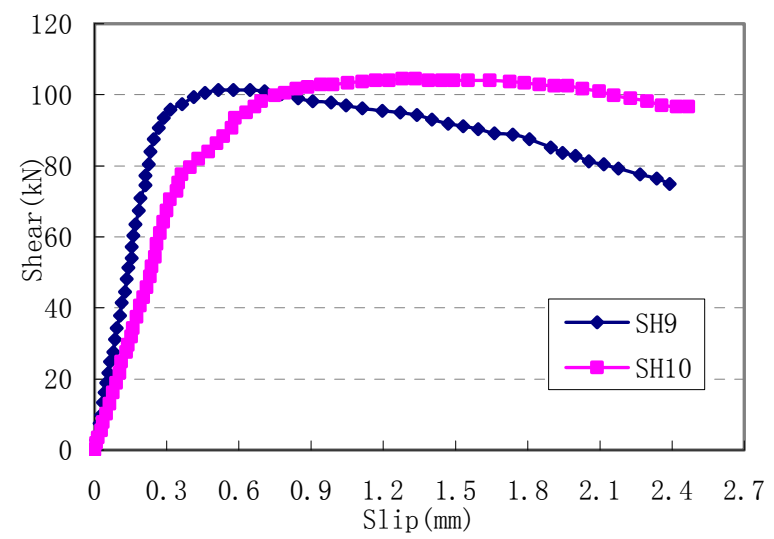

(d) Specimens SH9 $\sim$ SH10

Figure 10. Shear-slip Curves of Push-out Specimens

The main results of the push-out tests are shown in Table 2. According to the test results of specimens SH1 SH6, the shear capacity increases with the improvement of the strength of concrete, but the ductility decreases on the contrary. In the light of the results of the specimens SH5 $\sim$ SH10, the shear capacity increases with the increase of thickness and height of trapezoid connector.

Table 2. Main Results of Push-out Tests

\begin{tabular}{c|cccc|c|cccc}
\hline Specimen & $\begin{array}{c}\text { Cracking } \\
\text { load }(\mathrm{kN})\end{array}$ & $\begin{array}{c}\text { ultimate } \\
\text { load }(\mathrm{kN})\end{array}$ & $\begin{array}{c}\text { Cracking } \\
\text { slide }(\mathrm{mm})\end{array}$ & $\begin{array}{c}\text { ultimate } \\
\text { slide }(\mathrm{mm})\end{array}$ & Specimen & $\begin{array}{c}\text { Cracking } \\
\text { load }(\mathrm{kN})\end{array}$ & $\begin{array}{c}\text { ultimate } \\
\text { load(kN) }\end{array}$ & $\begin{array}{c}\text { Cracking } \\
\text { slide(mm) }\end{array}$ & $\begin{array}{c}\text { ultimate } \\
\text { slide }(\mathrm{mm})\end{array}$ \\
\hline SH1 & 98.50 & 135.20 & 0.31 & 1.85 & SH6 & 105.60 & 135.80 & 0.25 & 0.79 \\
SH2 & 100.70 & 140.60 & 0.35 & 1.92 & SH7 & 120.10 & 185.10 & 0.15 & 0.75 \\
SH3 & 110.50 & 165.20 & 0.40 & 1.50 & SH8 & 122.80 & 180.10 & 0.18 & 0.56 \\
SH4 & 112.20 & 170.40 & 0.21 & 0.65 & SH9 & 90.10 & 105.60 & 0.11 & 1.90 \\
SH5 & 110.10 & 140.20 & 0.40 & 1.12 & SH10 & 83.60 & 110.40 & 0.11 & 1.50 \\
\hline
\end{tabular}

\subsection{Estimation of Ultimate Shear Capacity}

According to the test results, and referring to the formula of the shear capacity of the steel studs for steel-concrete beams [12], the equation for estimating the ultimate shear capacity of the trapezoid connector can be formulated as:

$N_{v}^{c}=0.85 t_{\mathrm{w}}^{2} \sqrt{E_{\mathrm{c}} f_{\mathrm{c}}}+57.25$ 
where $E_{c}$ is the elastic modulus of concrete $\left(\mathrm{N} / \mathrm{mm}^{2}\right) ; f_{c}$ is the design value of strength of concrete $\left(\mathrm{N} / \mathrm{mm}^{2}\right)$; and $t_{w}$ is the thickness of trapezoid connector $(\mathrm{mm})$. It should be pointed out that the effectiveness of the Eq. 1 is based on the limitation that the height of the trapezoid connector, $h$, is no less than 6 times of its thickness, $t$, according to the test phenomenon and results. The comparisons between measured and predicted values are tabulated in Table 3.

Table 3. Comparison between Measured and Predicted Values

\begin{tabular}{c|cccccccccc}
\hline Specimen & SH1 & SH2 & SH3 & SH4 & SH5 & SH6 & SH7 & SH8 & SH9 & SH10 \\
\hline Measured & 98.50 & 100.70 & 110.50 & 112.20 & 110.10 & 105.60 & 120.10 & 122.80 & 90.10 & 83.60 \\
Cracking load(kN) & & & & & & & & & & \\
$\begin{array}{l}\text { Predicted cracking } \\
\quad \text { capacity (kN) }\end{array}$ & 99.31 & 99.31 & 124.22 & 124.22 & 112.92 & 112.92 & 137.42 & 137.42 & 92.88 & 92.88 \\
$\quad$ Relative error & $0.8 \%$ & $1.4 \%$ & $11.0 \%$ & $9.6 \%$ & $2.5 \%$ & $6.5 \%$ & $12.6 \%$ & $10.6 \%$ & $3 \%$ & $7.8 \%$ \\
\hline
\end{tabular}

\section{PULL-OUT TEST}

\subsection{Specimens and Test Set-up}

In order to study the pull-out behavior of trapezoid connectors, tests are conducted on 6 pull-out specimens. The specimens are divided into 3 groups, and the specimens in one group are all the same to consider the discreteness of the test results. Each specimen is composed by a block of concrete slab and a piece of connecting plate, as shown in Figure 11. The details about the specimens are tabulated in Table 4.

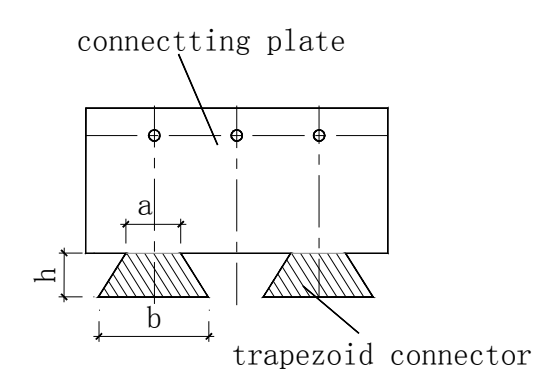

(a) Connection Plate

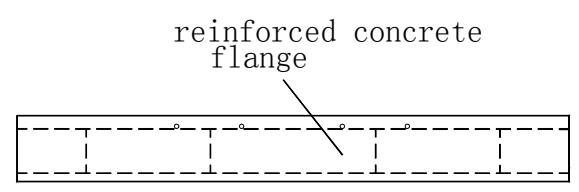

(c) Reinforced Concrete Flange

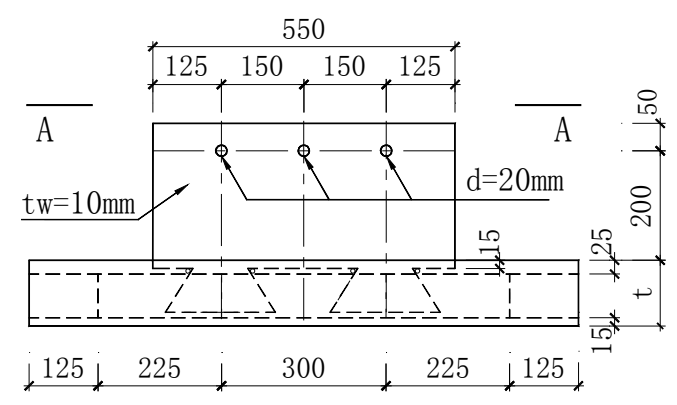

(b) Front Profile

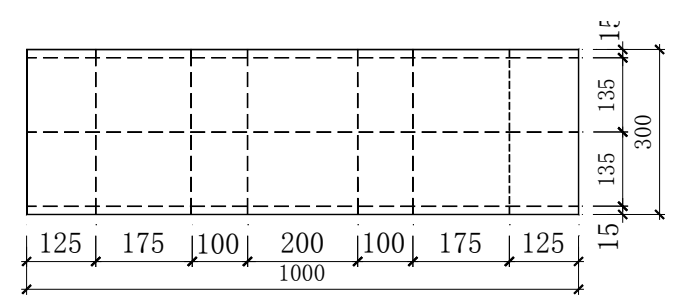

(d) Section A-A

Figure 11. Components of the Pull-out Specimen

Self-balance loading equipment is adopted in the test, and the pull-out force $F$ applied by jack can be balanced by two H-shaped steel beams, as plotted in Figure 12. The stiffness of H-shaped steel beam is large enough to pledge the force be uniformly applied on connecting plate. 


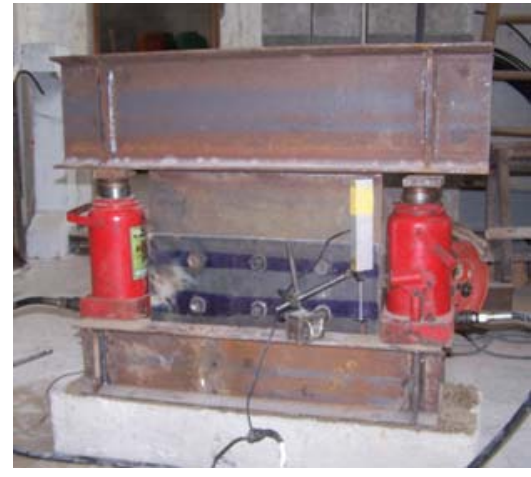

(a) Photo of the Test Set-up

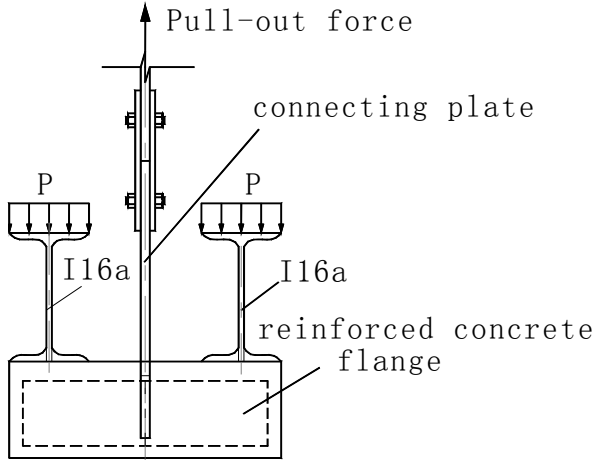

(b) Description of the Test Set-up

Figure 12. Test Set-up for the Pull-out Test

Table 4. Parameters of Specimens

\begin{tabular}{c|cccccccc}
\hline Specimen & $\begin{array}{c}t \\
(\mathrm{~mm})\end{array}$ & $\begin{array}{c}t_{w} \\
(\mathrm{~mm})\end{array}$ & $\begin{array}{c}h \\
(\mathrm{~mm})\end{array}$ & $\begin{array}{c}a \\
(\mathrm{~mm})\end{array}$ & $\begin{array}{c}b \\
(\mathrm{~mm})\end{array}$ & $\begin{array}{c}d_{i} \\
(\mathrm{~mm})\end{array}$ & $\rho$ & $\begin{array}{c}L \\
(\mathrm{~mm})\end{array}$ \\
\hline B-1 & 120 & 10 & 80 & 100 & 200 & 8 & $0.56 \%$ & 1000 \\
B-2 & 120 & 10 & 80 & 100 & 200 & 8 & $0.56 \%$ & 1000 \\
B-3 & 100 & 8 & 60 & 60 & 160 & 8 & $0.84 \%$ & 1000 \\
B-4 & 100 & 8 & 60 & 60 & 160 & 8 & $0.84 \%$ & 1000 \\
B-5 & 150 & 12 & 110 & 100 & 200 & 10 & $0.70 \%$ & 1000 \\
B-6 & 150 & 12 & 110 & 100 & 200 & 10 & $0.70 \%$ & 1000 \\
\hline
\end{tabular}

In Table $4, d_{i}$ is the diameter of the transverse rebar. The yield strength of the connecting plate is $345 \mathrm{MPa}$, and the tensile strength is $480 \mathrm{MPa}$. The steel of reinforcing bars in the concrete slab is HRB335, and the yield strength is 370MPa. The grade of concrete is C30, and the compression strength is $34.2 \mathrm{MPa}$.

\subsection{Test Phenomenon and Results}

Monotonic loading is adopted during the pull-out test. While the pull-out force is less than $0.9 \mathrm{Vu}$ ( $V u$ is the ultimate pull-out capacity of the specimen), there is no crack observed on the concrete slab. While the force arrives at $V u$, some longitudinal cracks are observed, as shown is Figure 13. The main results of the tests are listed in Table 5, and the force-slip curves of the pull-out tests are plotted in Figure 14. When the displacements are $1.2 \mathrm{~mm} \sim 3.1 \mathrm{~mm}$, the pull-out force arrives at the ultimate value.

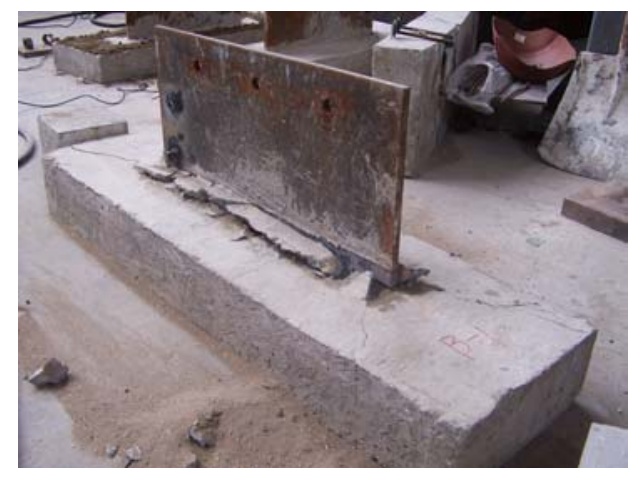

(a) Specimens B1 and B2

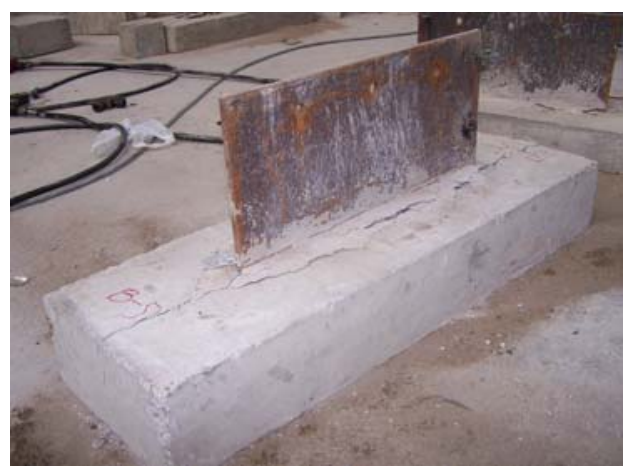

(b) Specimens B3 B6

Figure 13. Failure Phenomenon of the Pull-out Specimens 


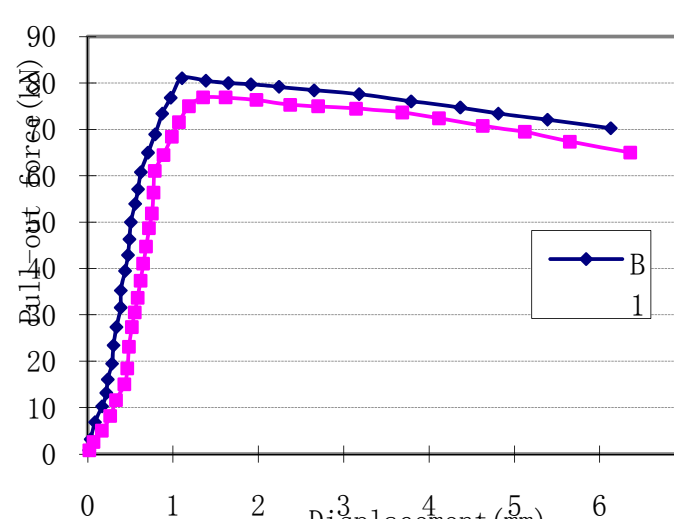

(a) Specimens B1 and B2

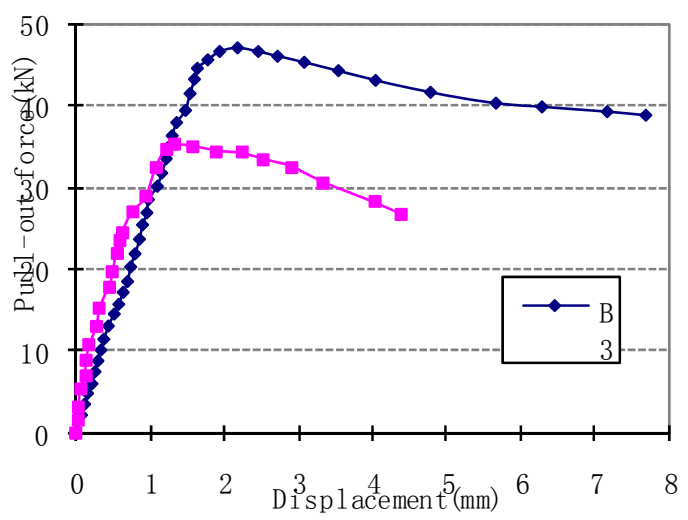

(b) Specimens B3 and B4

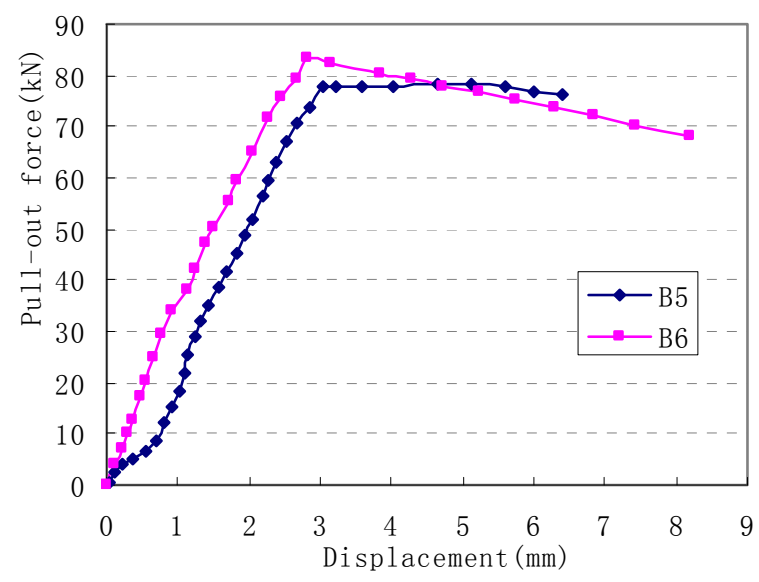

(c) Specimens B5 and B6

Figure 14. Load-displacement Curves of Pull-out Specimens

Table 5. Main Results of Pull-out Tests

\begin{tabular}{c|cccccc}
\hline Specimen & B-1 & B-2 & B-3 & B-4 & B-5 & B-6 \\
\hline Failure displacement $(\mathrm{mm})$ & 1.2 & 1.5 & 2.2 & 1.3 & 3.1 & 2.8 \\
Ultimate pull-out capacity $P_{\mathrm{u}}(\mathrm{kN})$ & 81.2 & 77.1 & 45.0 & 36.7 & 84.9 & 80.5 \\
\hline
\end{tabular}

\subsection{Comparison between Pull-out and Shear Capacities}

It is generally believed that the pull-out capacity of the connector is large enough for pull-out resistance of steel-concrete beams if it exceeds $10 \%$ of the shear capacity [12]. According to the pull-out capacities of the specimens measured from the tests and the shear capacities estimated with equation (1), the ratios of pull-out capacities to shear capacities of the pull-out specimens are much larger than 0.1 , as tabulated in Table 6 . Obviously, the pull-out capacity of trapezoid connectors is strong enough and may satisfy the requirement for pull-out capacity of steel-concrete composite beams.

Table 6. Comparison between Pull-out and Shear Capacities

\begin{tabular}{c|cccccc}
\hline specimen & B-1 & B-2 & B-3 & B-4 & B-5 & B-6 \\
\hline Pull-out capacity $(\mathrm{kN})$ & 81.2 & 77.1 & 45.0 & 36.7 & 84.9 & 80.5 \\
Shear capacity $(\mathrm{kN})$ & 113 & 113 & 92.9 & 92.9 & 137 & 137 \\
Pull-out capacity / shear capacity & 0.72 & 0.68 & 0.48 & 0.40 & 0.62 & 0.59 \\
\hline
\end{tabular}




\section{LOCAL COMPRESSIVE TESTS}

\subsection{Specimens and Test Set-up}

To study the local compressive behavior of the novel composite beam, tests are conducted on 4 local compressive specimens. Each specimen is composed by a T-shaped steel component and a block of concrete slab, as shown in Figure 15. The parameters of the specimens are listed in Table 7. The yield strength of the steel component is $300 \mathrm{MPa}$, and the tensile strength is $380 \mathrm{MPa}$; the yield strength of the reinforcing bar is $314 \mathrm{MPa}$, and the diameter of reinforcing bar is $8 \mathrm{~mm}$.

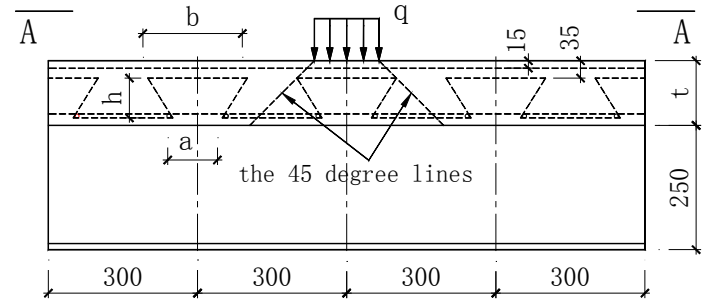

(a) Front profile

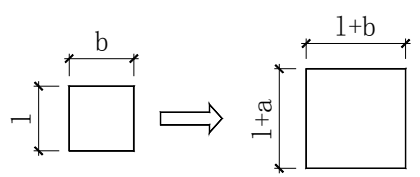

(b) Desceiption of load transmit

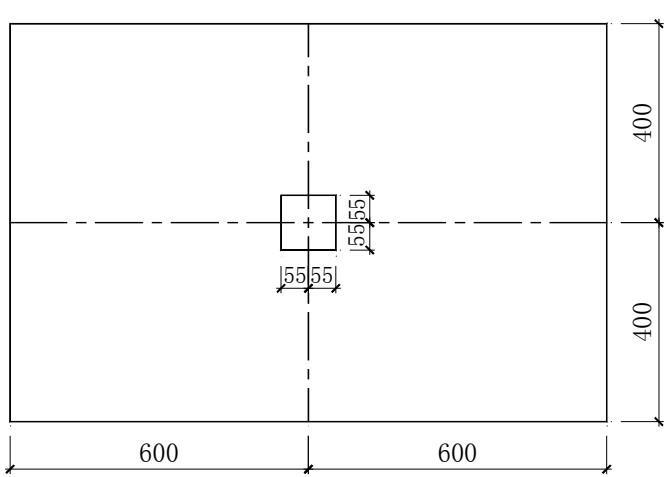

(c) Section A-A

Figure 15. Components of Local Compressive Specimen

Table 7. Parameters of Specimens

\begin{tabular}{c|cccccccc}
\hline Specimen & $t(\mathrm{~mm})$ & $\begin{array}{c}f_{c u} \\
\left(\mathrm{~N} / \mathrm{mm}^{2}\right)\end{array}$ & $\begin{array}{c}h \\
(\mathrm{~mm})\end{array}$ & $\begin{array}{c}a \\
(\mathrm{~mm})\end{array}$ & $\begin{array}{c}b \\
(\mathrm{~mm})\end{array}$ & $\begin{array}{c}t_{w} \\
(\mathrm{~mm})\end{array}$ & $\begin{array}{c}\rho \\
(\%)\end{array}$ & $\begin{array}{c}L \\
(\mathrm{~mm})\end{array}$ \\
\hline CQ1 & 130 & 31.2 & 80 & 100 & 200 & 10 & $0.81 \%$ & 1000 \\
CQ2 & 130 & 24.4 & 80 & 100 & 200 & 10 & $0.81 \%$ & 1000 \\
CQ3 & 120 & 31.2 & 70 & 80 & 160 & 8 & $0.70 \%$ & 960 \\
CQ4 & 120 & 24.4 & 70 & 80 & 160 & 8 & $0.70 \%$ & 960 \\
\hline
\end{tabular}

Settle the specimen on the test machine, and apply vertical force on top of the slab by jack, as shown in Figure 16. A rectangular steel cushion block is used to transmit the vertical force uniformly on the top of the slab.

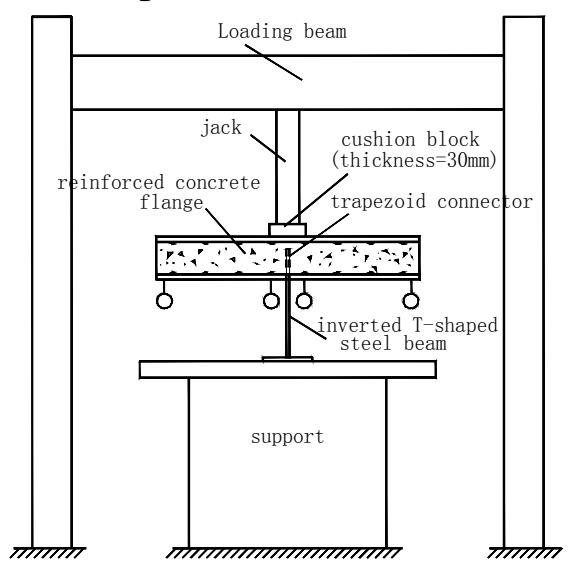

(a) Description of Local Compressive Device

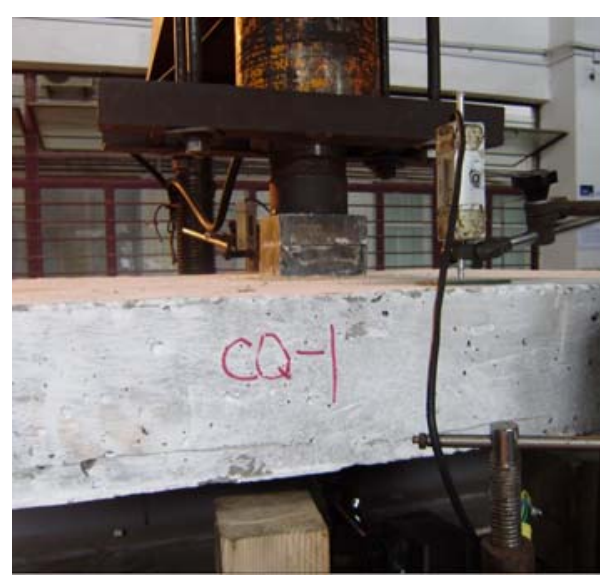
(b) Load Device of Local Compressive Test Figure 16. Test Set-up for the Local Compressive Test 


\subsection{Test Phenomenon and Results}

When the force is less than $0.7 V u$ ( $V u$ is the ultimate local compressive capacity of the specimen), there is no crack observed on the concrete slab, which indicates that the specimen is in elastic state. When the force reaches $0.7 V u$, some transverse cracks are observed in the profile of the concrete slab, as shown in Figure 17(a). With the further increasing of the local pressure, the transverse cracks swiftly interconnect with each other, as shown in Figure 17 (b). When the ultimate local compressive capacity is achieved, there is an obvious groove observed below the cushion block, as shown in Figure 17(c).
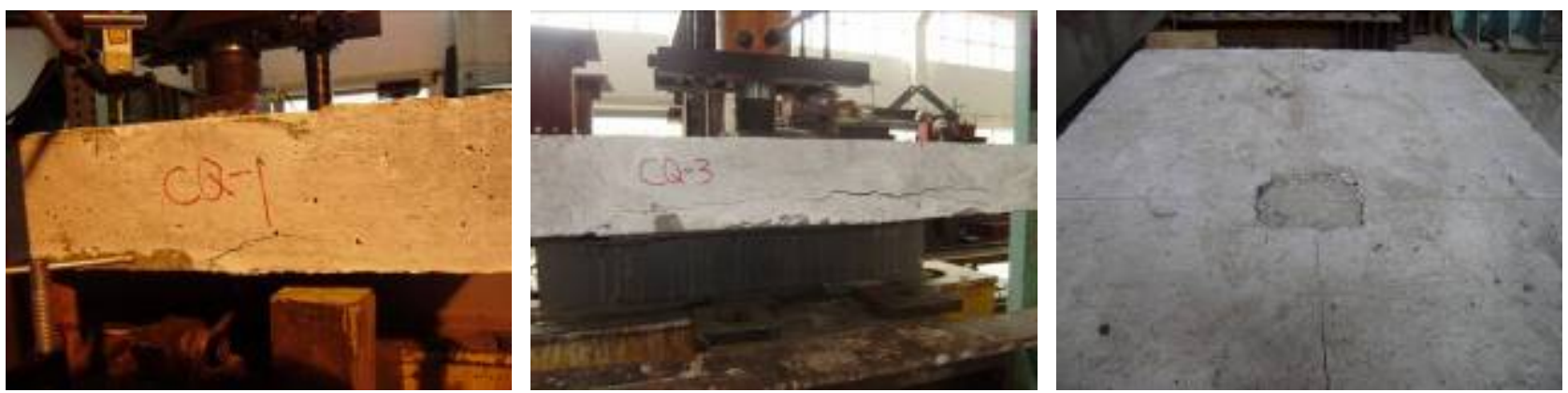

(a) Emergence of Initial Lateral Cracks (b) Extension of the Lateral Cracks (c) Local Groove on the Concrete Flange

Figure 17. Phenomenon of the Local Compressive Test

The load-displacement curves of the specimens are plotted in Figure 18. When the force is less than $0.7 \mathrm{Vu}$, the relationship between force and displacement is linear; when the force exceeds $0.7 \mathrm{Vu}$, the non-linear characteristic of the curve is very obvious. The final failure displacements are tabulated in Table 8.

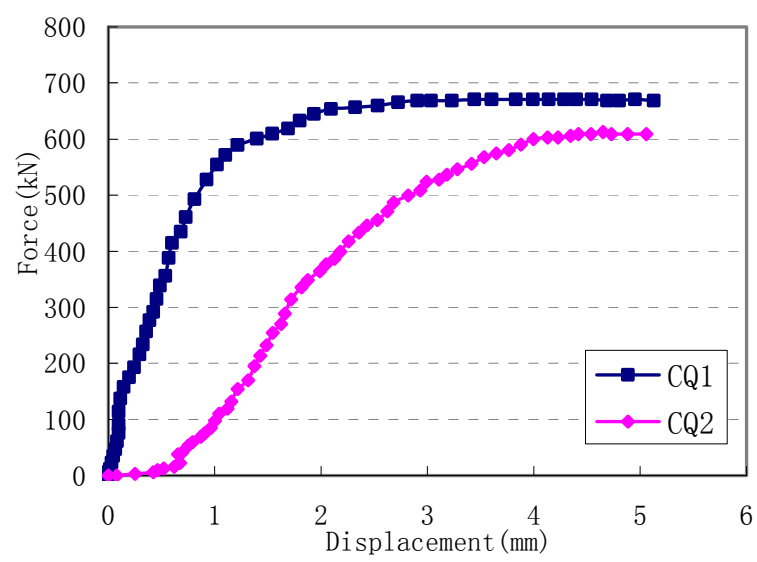

(a) Specimen CQ1 and CQ2

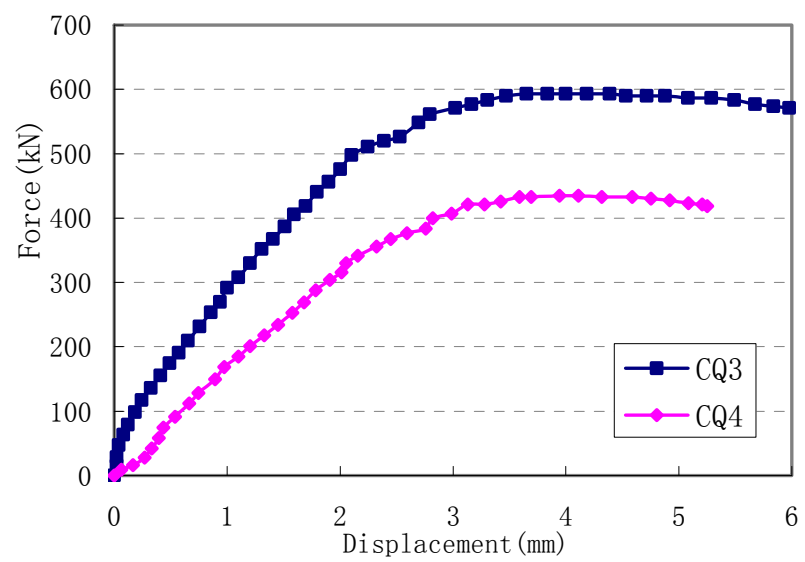

(b) Specimen CQ3 and CQ4

Figure 18. Local Pressure -displacement Curves

Table 8. Main Results of Local Compressive Tests

\begin{tabular}{c|cccc}
\hline Specimen & CQ1 & CQ2 & CQ3 & CQ4 \\
\hline Measured failure displacement (mm) & 3.93 & 4.63 & 3.86 & 4.02 \\
Measured ultimate local compressive capacity $(\mathrm{kN})$ & 670.4 & 610.9 & 592.6 & 433.8 \\
Theoretical value $(\mathrm{kN})$ & 640.4 & 535.3 & 563.5 & 445.4 \\
Relative error between theoretical and tested value & $4.5 \%$ & $12.4 \%$ & $4.9 \%$ & $2.5 \%$ \\
\hline
\end{tabular}




\subsection{Estimation of Ultimate Local Compressive Capacity}

From the results of the tests, the local compressive capacity is related to the strength grade of concrete, the area of local compression and the distance from the top of connector to the top surface of concrete slab. Referring to the formula of the local compressive capacity of the steel studs for steel-concrete beams [12], the following formula estimating the ultimate local compressive capacity are obtained as:

$$
F_{c} \leq 1.35 \beta_{c} f_{c u}(b+a)(l+a)
$$

where $\beta_{c}$ is the strength coefficient of the concrete; $f_{c u}$ is the design compressive strength of concrete $\left(\mathrm{N} / \mathrm{mm}^{2}\right) ; \quad b, l$ is the width and length of the local pressure (mm); $a$ is the distance from the top of connector to the surface of the concrete slab (mm).

\section{PUNCH TEST}

\subsection{Specimens and Test Set-up}

To study the punch behavior of the composite beam with notched web, tests are conducted on 8 punch specimens. Each specimen is composed by an inverted T-shaped steel component and a block of concrete slab. The coincide-work of the steel component and the concrete slab is pledged by trapezoid connectors which are embedded in the concrete slab, as shown in Figure 19. The parameters of specimens are listed in Table 9. The yield strength of the steel is 300MPa, and the tensile strength is $380 \mathrm{MPa}$; the yield strength of the reinforcing bars is $314 \mathrm{MPa}$, and the diameter is $8 \mathrm{~mm}$.

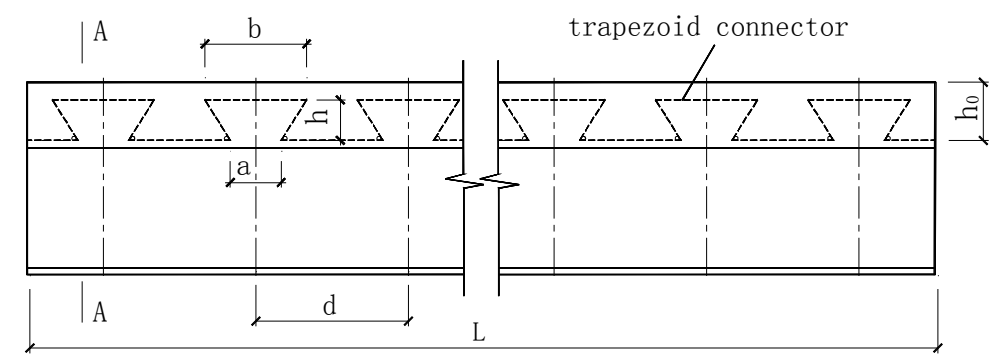

(a) Front Profile

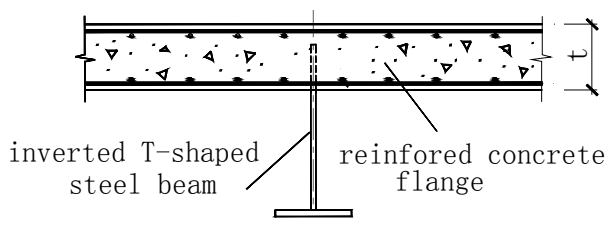

(b) Section A-A

Figure 19. Components of Punch Specimens

Table 9. Parameters of the Punch Specimens

\begin{tabular}{|c|c|c|c|c|c|c|c|c|c|c|}
\hline Specimen & $\begin{array}{c}t \\
(\mathrm{~mm})\end{array}$ & $\underset{\left(\mathrm{N} / \mathrm{mm}^{2}\right)}{f_{c u}}$ & $h(\mathrm{~mm})$ & $a(\mathrm{~mm})$ & $b(\mathrm{~mm})$ & $t_{w}(\mathrm{~mm})$ & $d_{i}(\mathrm{~mm})$ & $\rho$ & $L(\mathrm{~mm})$ & $m$ \\
\hline CB-1 & 130 & 31.2 & 80 & 100 & 200 & 10 & 10 & $0.81 \%$ & 1200 & 1 \\
\hline CB-2 & 130 & 24.4 & 80 & 100 & 200 & 10 & 10 & $0.81 \%$ & 1200 & 1 \\
\hline CB-3 & 120 & 31.2 & 70 & 80 & 160 & 8 & 8 & $0.70 \%$ & 960 & 1 \\
\hline CB-4 & 120 & 24.4 & 70 & 80 & 160 & 8 & 8 & $0.70 \%$ & 960 & 1 \\
\hline CQ-5 & 130 & 31.2 & 80 & 100 & 200 & 10 & 10 & $0.81 \%$ & 1200 & 2.5 \\
\hline CQ-6 & 130 & 24.4 & 80 & 100 & 200 & 10 & 10 & $0.81 \%$ & 1200 & 2.5 \\
\hline CQ-7 & 120 & 31.2 & 70 & 80 & 160 & 8 & 8 & $0.70 \%$ & 960 & 2.5 \\
\hline CQ-8 & 120 & 24.4 & 70 & 80 & 160 & 8 & 8 & $0.70 \%$ & 960 & 2.5 \\
\hline
\end{tabular}

In Table 9, the punch-span ratio $m$ is defined by punch length $s$ divided by effective height $h_{0}$ of the concrete slab. Punch length $s$ is the distance from the mid-area of the web to the inner edge of the support, as plotted in Figure 20(b). 
The monotonic loading is adopted in the test. Settle the specimen on the test machine, and apply vertical force by jack, as shown in Figure 20. A closed ribbed H-shaped steel beam is adopted to transmit the vertical force uniformly on the top of the steel beam.

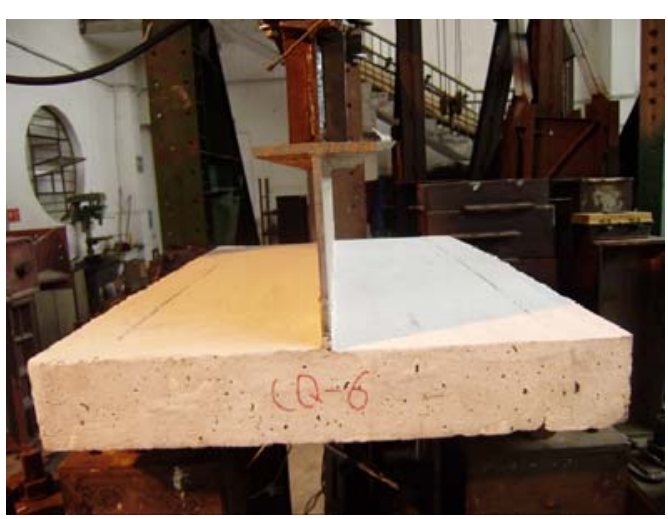

(a) Photo of the Punch Set-up

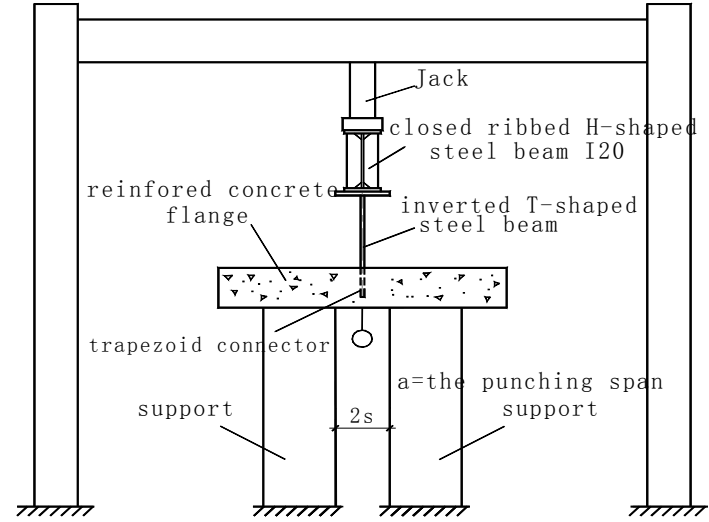

(b) Description of Punch Set-up

Figure 20. Test Set-up for of the Punch Test

\section{2}

\section{Test Phenomenon and Results}

When the punch-span ratios $m$ is 1 (specimens CB1 CB4), the failure mode is punch failure. When the punch force is less than $0.3 V u$ ( $V u$ is the ultimate punch capacity of the specimen), there is no crack observed on the concrete slab, which indicates that the specimen remains in elastic state. When the punch force reaches $0.4 \sim 0.6 \mathrm{Vu}$, some cracks are observed on the concrete around the trapezoid connectors, as shown in Figure 21(a). With the further increasing of the punch force, the cracks develop along the 45 angle lines, as shown in Figure 21(b).

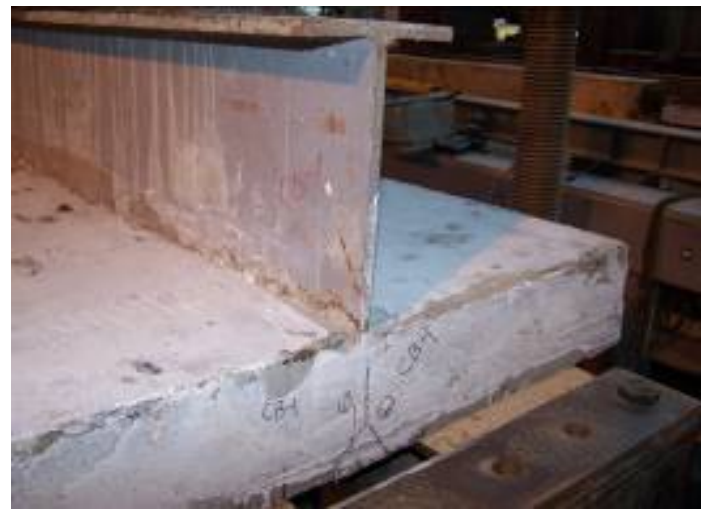

(a) Initial Cracks of the Specimen



(b) Punch Failure of the Specimen

Figure 21. Test Phenomenon of the Specimens $(\mathrm{CB} 1 \sim \mathrm{CB} 4)$

When the punching-span ratio $m$ is 2.5 (specimens $\mathrm{CB} 5 \sim \mathrm{CB} 8$ ), the failure mode is shear damage. When the punch force is less than $0.6 \mathrm{Vu}$, there is no crack observed on the concrete slab. When the punch force reaches 0.6 0.7Vu, some cracks are observed, as shown in Figure 22(a). With the increasing of the punch force, apparent bending is observed, and the damage takes place in the concrete slab, as shown in Figure 22(b). 


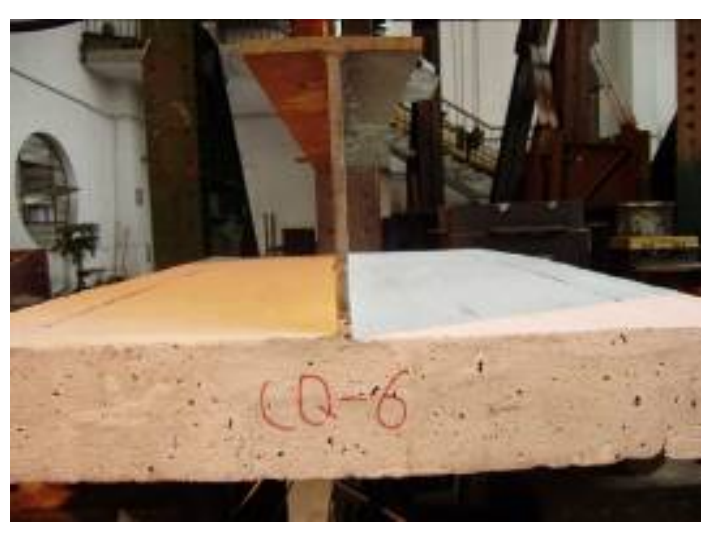

(a) Initial Cracks of the Specimen

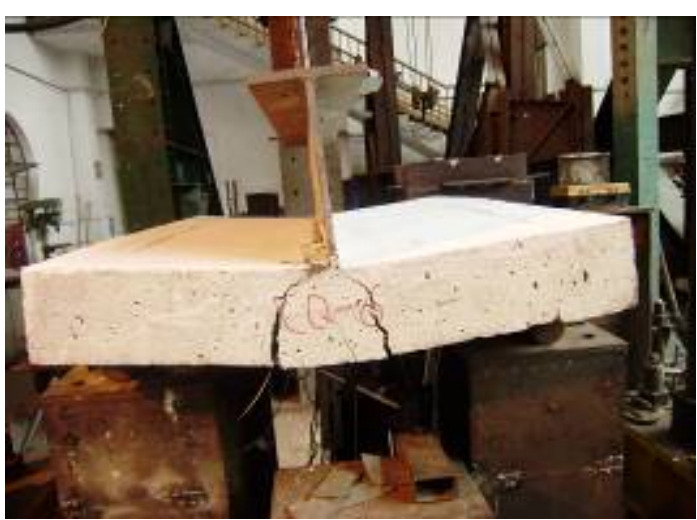

(b) Shear-bending Failure of the Specimen

Figure 22. Test Phenomenon of the Specimens (CB5 CB8)

The force-displacement curves of the specimens are shown in Figure 23. When the punch force is less than $0.3 \sim 0.5 \mathrm{Vu}$, the relationship between force and displacement is linear. While the force exceeds $0.5 \mathrm{Vu}$, the concrete slab cracks, the tension stress would transmit from the cracked concrete to reinforcing bars, the stiffness of the specimen reduces rapidly, and the force-displacement curve develops into nonlinear phase. The failure displacements and ultimate punch capacity obtained from the tests are tabulated in Table 10.

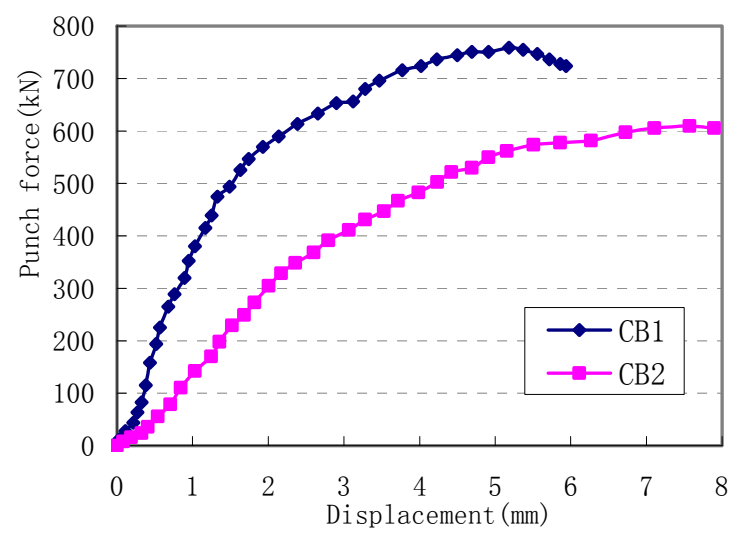

(a) Specimens CB1 and CB2

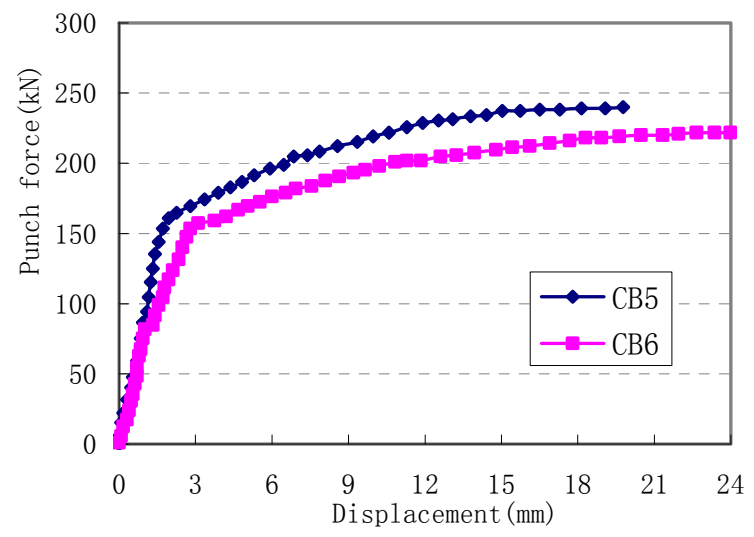

(c) Specimens CB5 and CB6

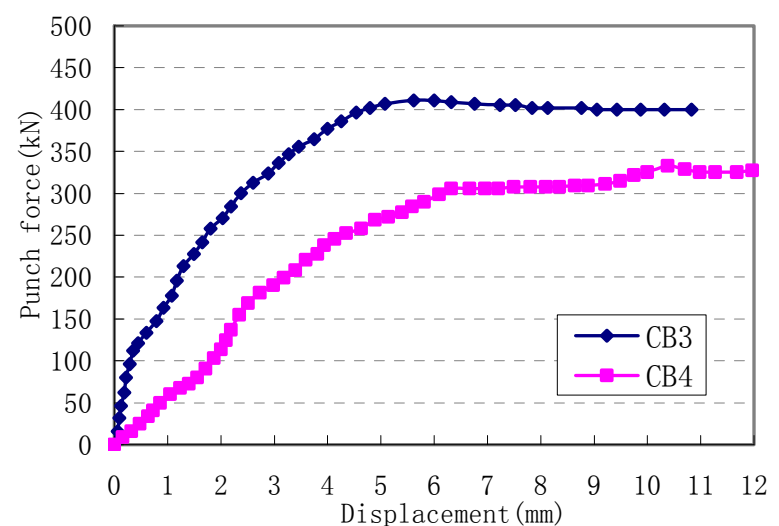

(b) Specimens CB3 and CB4

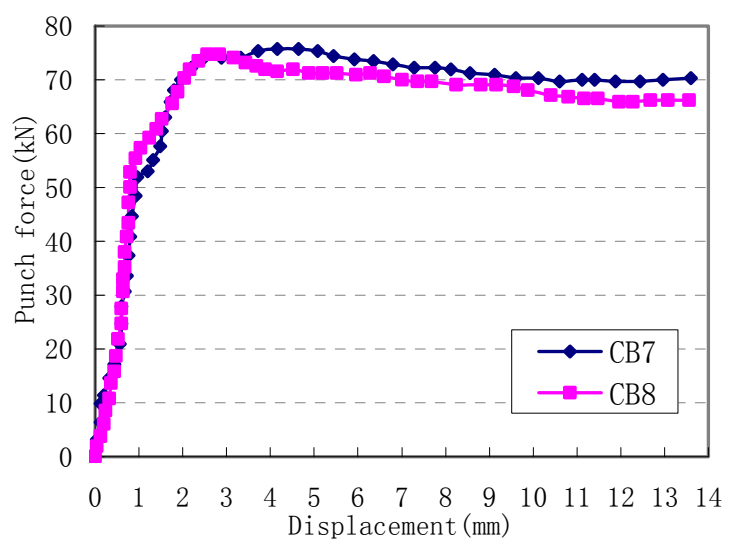

(d) Specimens CB7 and CB8

Figure 23. Punch Force-displacement Curve for Specimens 


\subsection{Estimation of Ultimate Punch Capacity}

In light of the test results, and referring to the formula of the punch capacity for steel-concrete beams [12], the following formula for estimating the ultimate punch capacity is proposed as:

$$
F_{l} \leq 0.9 \beta_{h} f_{t} u_{m} h_{0}
$$

where $\beta_{h}$ is the factor of the section height; $f_{t}$ is design tension strength of concrete $\left(\mathrm{N} / \mathrm{mm}^{2}\right)$; $u_{m}$ is the total length of the upper and lower punch failure lines (mm); $h_{0}$ is the effective height of the section (mm), as shown in Figure 24.

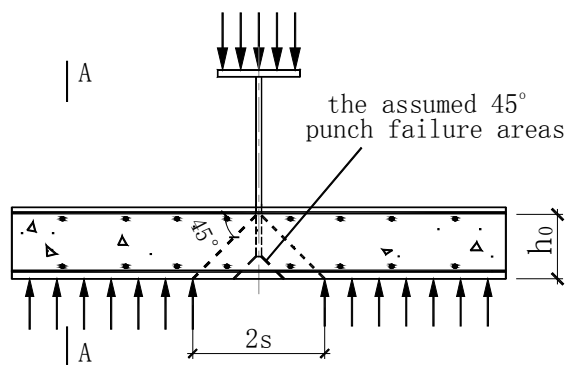

(a) Front Profile

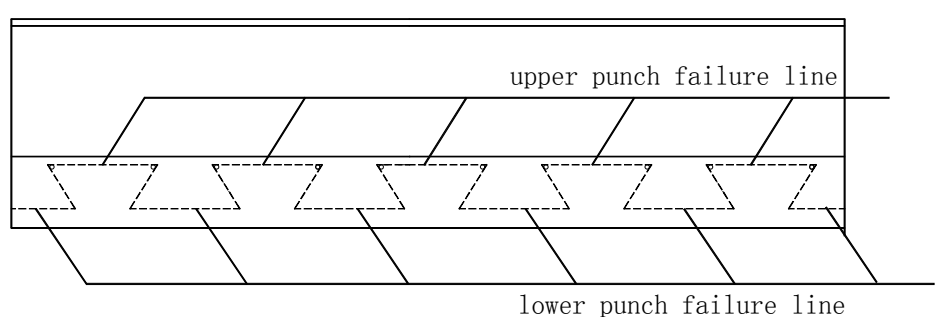

(b) Section A-A

Figure 24. Punch Failure Lines

Predicted punch capacities of the tested specimens is listed in Table 10, which match the measured results well. Tests show that the punch capacity of the specimen increases with the improvement of the ultimate compressive strength of concrete $f_{\mathrm{cu}}$.

Table 10. Test Results of the Punch Tests

\begin{tabular}{|c|c|c|c|c|c|c|c|c|}
\hline Specimen & CB-1 & CB-2 & CB-3 & CB-4 & CQ-5 & CQ-6 & CQ-7 & CQ-8 \\
\hline $\begin{array}{c}\text { Measured failure } \\
\text { displacements(mm) }\end{array}$ & 3.12 & 3.95 & 5.12 & 5.86 & 3.45 & 3.78 & 3.2 & 3.8 \\
\hline $\begin{array}{c}\text { Measured ultimate } \\
\text { punch capacity } \\
\mathrm{P}(\mathrm{kN})\end{array}$ & 652.1 & 501.6 & 418.7 & 312.3 & 230.5 & 218.6 & 76.8 & 71.6 \\
\hline $\begin{array}{l}\text { Predicted punch } \\
\text { capacity }(\mathrm{kN})\end{array}$ & 567 & 458.7 & 413.3 & 333.5 & No & No & No & No \\
\hline Relative error & $-13 \%$ & $-8.5 \%$ & $-1.3 \%$ & $+6.8 \%$ & No & No & No & No \\
\hline Failure style & Punch & Punch & Punch & Punch & Shear-bending & Shear-bending & Shear-bending & Shear-bending \\
\hline
\end{tabular}

\section{CONCLUSIONS}

This paper systematically investigates the push- and pull-out, local compressive and punching behaviors of the trapezoid connectors of the inverted T-shaped steel with notched web through the experimental studies, and the following conclusions are drawn:

(1) The trapezoid connector of the inverted T-shaped steel-concrete composite beam may strongly combine the steel component and concrete slab together, which may pledge concrete slab and steel beam to work commonly.

(2) The elastic modulus and compressive capacity of concrete are much less than that of steel, and there is no damage observed on the trapezoid connectors after the tests compared to the longitudinal slip, even the concrete slab is severely damaged.

(3) The formulas proposed in this paper are based on the test results presented, the reliability of which needs to be checked with further more tests. 


\section{ACKNOWLEDGEMENTS}

The work reported hereinabove is financially supported by the ministry of science and technology of China through projects SLDRCE08-A-06 and 2006BAJ01B02, which is gratefully acknowledged.

\section{REFERENCES}

[1] Newmark, N.M., Siess, C.P. and Viest, I.M., “Test and Analysis of Composite Beams with Incomplete Interaction”, Experimental Stress Analysis, 1951, Vol. 9, No. 6, pp. 896-901.

[2] Johnson, R.P., "Partial-interaction Design of Composite Beams”, The Structural Engineer, 1975, Vol. 3, No. 8, pp. 1-21.

[3] Crisinel, M., "Partial-interaction Analysis of Composite Beams with Profiled Sheeting and Non-welded Shear Connectors”, Journal of Construction Steel Research, 1990, Vol. 15, pp.65-98.

[4] Grant, J.A. and Fisher, J.W., "Composite Beams with Formed Steel Deck”, Engineering Journal, AISC, 1977, Vol. 14, No. 1, pp. 24-43.

[5] Christopher, H., "Behavior of Composite Bridge Decks with Alternative Shear Connectors”, Journal of Bridge Engineer, 2001, pp. 17-22.

[6] Li, G.Q. and Li, X.H., "Study on a Novel Steel-concrete Composite Beam”, ICASS '09 / IJSSD / IStructE Asia-Pacific Forum Sixth International Conference on Advances in Steel Structures, Nov, 2009.

[7] Galambos, T.V., "Recent Research and Design Developments in Steel and Composite Steel-concrete Structures in USA”, J. Constructional Steel Research, 2000, Vol. 55, No. 1, pp. 289-303.

[8] Roger, G., Slutter, “Flexural Strength of Steel-concrete Composite Beams”, Proceedings of ASCE, Journal of the Structural Division, 1965, Vol. 91, No. 4, pp. 71-99.

[9] Li, X.H. and Li, G.Q., "Study on the Behavior of Embedded Steel-Concrete Composite Beams with Notched Web during Construction Stage", 9th International Conference on Steel Concrete Composite and Hybrid Structures, Leeds UK, July, 2009.

[10] Brian, Uy, "Application Behavior and Design of Composite Steel-concrete Beams subjected to Combined Actions", Proceedings of the $9^{\text {th }}$ International Conference on Steel Concrete Composite and Hybrid Structures (ASCCS2009), Leeds, UK, July 2009.

[11] Eurocode 4, "Design of Composite Steel and Concrete Structures, Part 1.1: General Rules and Rules for Buildings”, 1994.

[12] GB50017-2003, “Code for Design of Steel Structures”, Beijing: Chinese Construction Industry Press, 2002. 


\title{
ENHANCING THE ROBUSTNESS OF STEEL AND COMPOSITE BUILDINGS
}

\author{
D.A. Nethercot ${ }^{*}$, P. Stylianidis, B.A. Izzuddin and A.Y. Elghazouli \\ Department of Civil and Environmental Engineering \\ Imperial College, South Kensington Campus, London SW7 2BU, UK \\ *(Corresponding author: E-mail: d.nethercot@imperial.ac.uk)
}

\begin{abstract}
Methods intended for use in the design of steel and composite building frames covering the provision of adequate robustness so as to guard against progressive collapse are in the process of moving from prescriptive to quantitative. An approach that recognises all the important complex physical phenomena, employs a realistic criterion of failure and is capable of being implemented at a variety of levels has been devised at Imperial College London. Recent further development of this method has streamlined the necessary analyses, thereby making it possible to conduct parametric studies that provide insights into the link between changes to the structure and quantitative measures of resistance to progressive collapse. This approach is used herein to examine a number of different arrangements, from which key features of behaviour are identified. It has therefore been possible to isolate those structural modifications with the greatest potential for improving robustness and, moreover, to associate quantitative measures of that improvement with each scheme.
\end{abstract}

Keywords: Alternative load path, Column removal, Composite structures, Nonlinear static response, Parametric studies, Progressive collapse, Robustness, Simplified model

\section{INTRODUCTION}

Progressive Collapse of building structures is a topic that has come much to the fore in recent years. It does, however, have a chequered history - with its generally agreed genesis being the Ronan Point Collapse of 1968. This was followed by a somewhat fallow period characterised by Bruce Ellingwood's comment at the 1997 SEWC Conference in San Francisco:

"There is currently a virtual absence of research activity or interest in the United States in the topic".

and a recent surge of interest stimulated most notably by the World Trade Centre collapses in New York. But it is also possible to identify aspects of the topic in studies of WW2 bomb damage to structures in London, in measures designed to combat the IRA bombing campaigns and in various forensic studies on public safety issues that typically followed any major bomb blast on a significant structure e.g. the Murragh Building in Oklahoma City. As interest in the more scientific treatment of the topic has increased so also has the realisation that knowledge and evidence from adjacent fields e.g. seismic resistant design, can inform the process of developing strategies and procedures to better address a lessening of both the likelihood of a progressive collapse failure and the consequences should one be initiated.

This paper briefly reviews the current state of the art relating to both the development of a better understanding of progressive collapse and its treatment in design and then proceeds to present new developments in the Imperial College London approach, concluding with illustrative results for a range of cases of both steel and composite frames. These highlight certain limitations in existing design approaches. 


\section{POSSIBLE DESIGN APPROACHES}

The Ronan Point collapse demonstrated to the Structural Engineering Community in the UK the need for resistance to Progressive Collapse to become part of the routine design process for at least some types of structure. The absence of any basic theory meant that this could not follow the usual structural design approach of:

- Identifying a representative form of applied loading.

- Devising an analysis model from which to calculate structural response to this loading.

- Identifying key outputs from this analysis e.g. moments, stresses, deflections etc.

- Comparing the calculated values of these key outputs with suitable limits.

Instead, rather more indirect and essentially prescriptive approaches were devised. These fell into one of three types:

- Tying force.

- Alternate load path.

- Key elements.

Requiring that building frames be adequately tied together, including the specific requirement for steel frame structures that beam to column connections possessed a certain limited tying capacity (the ability to transmit an axial force from the beam into the column) should ensure greater robustness i.e. the ability that in the event of the structure suffering an incident for which it had not been specifically designed it would not suffer disproportionately. These concepts of robustness (a property of the structure) and disproportionate collapse (the initiation of progressive collapse) thus entered the vocabulary.

Tying has the advantage of being simple to appreciate, easy to implement through simple design calculations and being readily achievable in practice providing the required tying forces are not too large. Its main disadvantage is that it is entirely prescriptive in nature i.e. it is of the form "providing the provisions are satisfied behaviour will be better than if they are not", but there is no basis for comparing alternative arrangements nor for assessing the actual margin of safety against progressive collapse. Because of its simplicity, it has been widely, if not always correctly, used in the UK and has been introduced in other parts of the world as they too, developed design provisions against progressive collapse.

In the alternate load path approach a member is notionally removed and the ability of the damaged structure to resist some reduced level of applied load is then assessed. Most usual is column removal with the damaged floor(s) bridging over the increased span. The level of structural analysis used to examine the behaviour of the damaged structure varies from static applications using elastic theory and individual members to sophisticated numerical approaches including dynamic effects, large deformations and inelastic material behaviour. Clearly this approach entails more effort than does a simple application of the tying force approach; in return it provides information on the relative merits of different configurations and allows the designer to assess the effects of structural changes in a quantitative fashion.

In certain cases e.g. transfer girders, damage to a particular element would leave the structure with no alternate load path. Such members may be designed as "key elements", with their basic design being conducted to a larger load factor so as to provide a (supposedly) greater margin of safety to the structure. One of the most obvious key elements is the single spindle supporting the wheel of the London Eye; it is of considerable interest to read how the engineers responsible took into consideration the many features with the potential for unwanted consequences and rationalised their approach so as to provide an acceptably safe structural component. 
Clearly tying forces and key elements can only be regarded as prescriptive approaches yielding no information on the behaviour of the damaged structure and thus providing no insights into how a designer's knowledge of structural principles might be utilised in the search for the best solution to a given set of circumstances. Alternate load path analysis does, however, offer more possibilities particularly if it can be developed in a way that models the key features of progressive collapse whilst remaining tractable in terms of mathematical and computational complexity. It is, therefore, not surprising, that, particularly post WTC collapse, considerable effort has been focussed on developing and applying this approach, both by the research communities and by those responsible for deriving design rules.

Work conducted at Imperial College London during the past 5 years has been aimed at developing a complete design method - essentially based on the alternate load path concept of sudden column removal - that combines sufficient rigour that all essential physical features are correctly modelled with the simplicity of application necessary if it is to be attractive for use in practice. Its core is a quantitative assessment of the ability (or not) of the damaged structure to attain a new equilibrium position in its grossly deformed state. It incorporates dynamic effects (but without the need for dynamic analysis), allows for gross changes of geometry and inelastic material behaviour and recognises that the key governing property is the ability of the beam-to-column connections to deliver the necessary rotations.

Originally the analysis step was conducted using ADAPTIC [1] - although any suitable software package may be employed. The most recent advance is the possibility to use only "hand calculations" based on an extended slope-deflection approach suitable for the rapid examination of many alternative arrangements [2]. In parallel, work has also been conducted on modelling the behaviour of connections subject to the combined beam axial load plus moment forms of loading that arise during a progressive collapse [3].

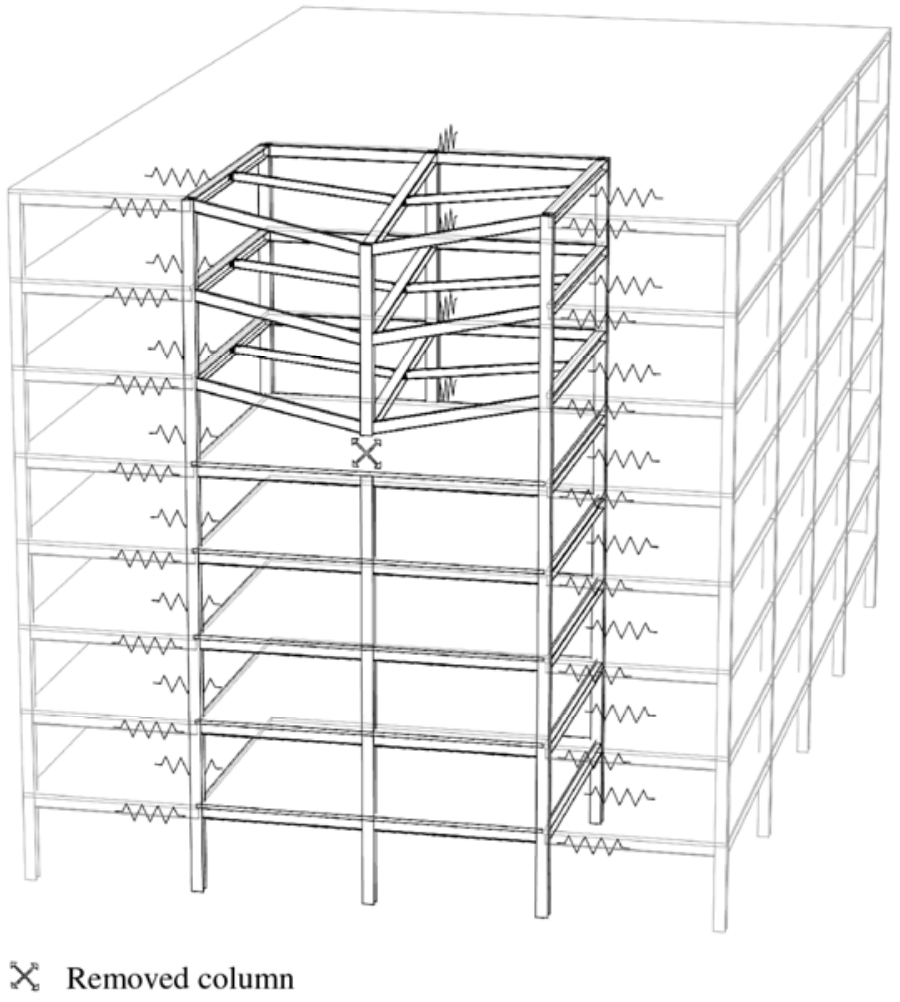

a. Full structure/affected bay

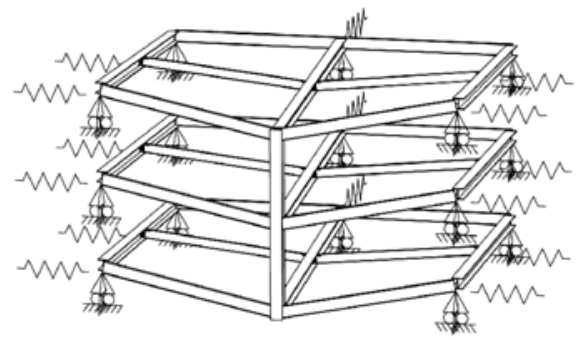

b. Multiple floor system

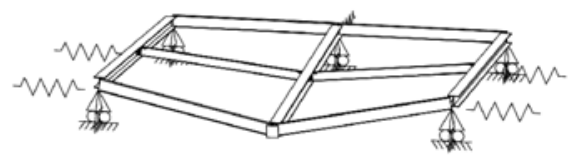

c. Single floor system

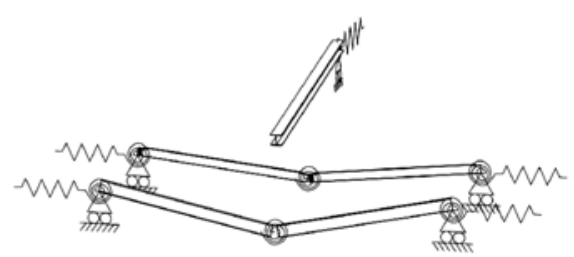

d. Individual beams

Figure 1. Simplified Multi-level Approach for Progressive Collapse Assessment 


\section{THE IMPERIAL COLLEGE METHOD}

Based on the sudden column removal scenario and the alternative load path concept, a complete design framework for progressive collapse assessment has been developed at Imperial College London $[4,5,6]$. The method is able to model the basic features of the problem and it offers the simplicity needed for routine use in practice.

The Imperial College method allows application at various levels of structural idealization via a simplified multi-level approach where implementation may be at member, affected floor, affected substructure or full structure as illustrated in Figure 1.

For removal of a peripheral column of the multi-storey building depicted in Figure 1a, the analysis can be limited to the affected bay provided the interaction with the surrounding structure is represented with suitable boundary conditions. Provided the remaining columns of the affected bay can resist the redistributed loading, the model can further be reduced to the number of floors above the removed column (Figure 1b). If these floors are identical in terms of structure and loading, their loading redistributions and responses are also identical and the model can be reduced to a single floor (Figure 1c). Finally, individual beam models can be considered if the slab membrane effect is ignored (Figure 1d).

The response at higher levels can be assembled from the responses at lower levels; therefore, the nonlinear static response at any level of structural idealization can be determined relatively easily. The nonlinear static response at the lower levels of structural idealization may be obtained by either detailed or simplified models.

However, since the actual response after sudden column removal is dynamic, the Imperial College framework proposes a simplified dynamic approach which transforms the static response under gravity loading to a dynamic response based on an energy equivalence concept. The resulting response is called pseudo-static and this simple approach eliminates the need for a detailed dynamic analysis. Finally, the dynamic capacity is obtained based on the available connection ductility.

\section{REPRESENTATION OF BEAM NONLINEAR STATIC RESPONSE}

As mentioned above, the nonlinear static response at the lowest level of structural idealization (i.e. individual beams) can be obtained by any type of analysis, thus by either detailed finite element or simplified analytical models. In this respect and in order to streamline the process, a simplified hand-calculation method for prediction of the beam nonlinear static response following column removal has been derived and is presented herein. The method is able to represent the basic features of beam behaviour such as material and geometric nonlinearity and connection bending moment-axial load interaction; it can be applied both in bare steel and composite arrangements.

Considering the double-span condition subject to removal of the intermediate column shown in Figure 2a, the response of a single beam can be modelled with the structural system depicted in Figure 2 b. In composite beams, a reduced cracked stiffness $\left(E I^{\prime}\right)$ is considered in the region of hogging bending moment. The model can be simplified by reasonably assuming a fixed point of inflexion at the mid-span $(L / 2)$. Beam deflection $(w)$ due to lateral loading $(q)$ is associated with beam bending, support axial deformation $\left(\Delta_{\mathrm{S}}\right)$ as well as rotation of the mid-span $(\Phi)$ and support $\left(\Phi^{\prime}\right)$ connections of the double-span beam as illustrated in Figure 2c. 


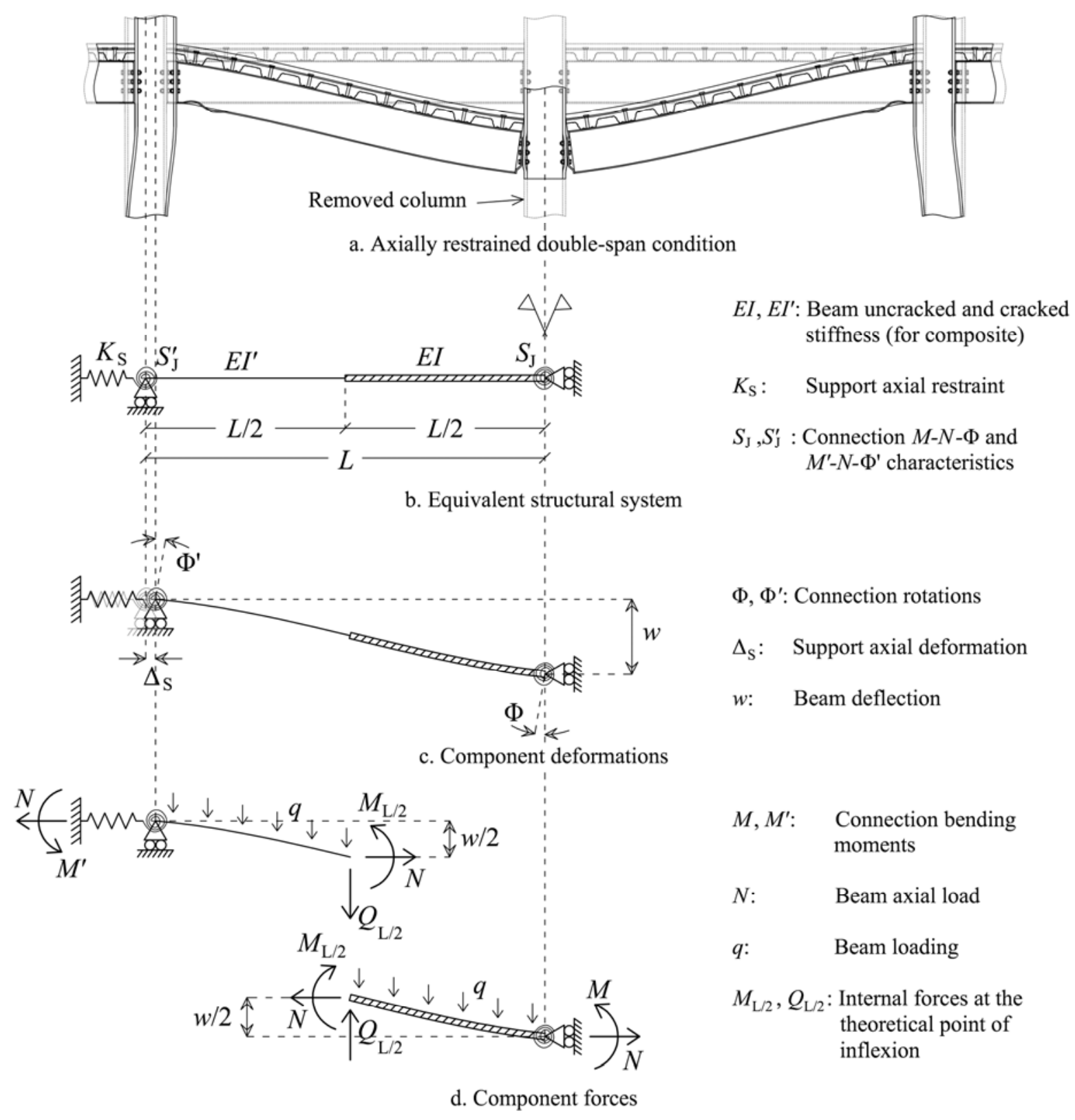

Figure 2. Representation of Beam Load-deflection Response Following Column Removal

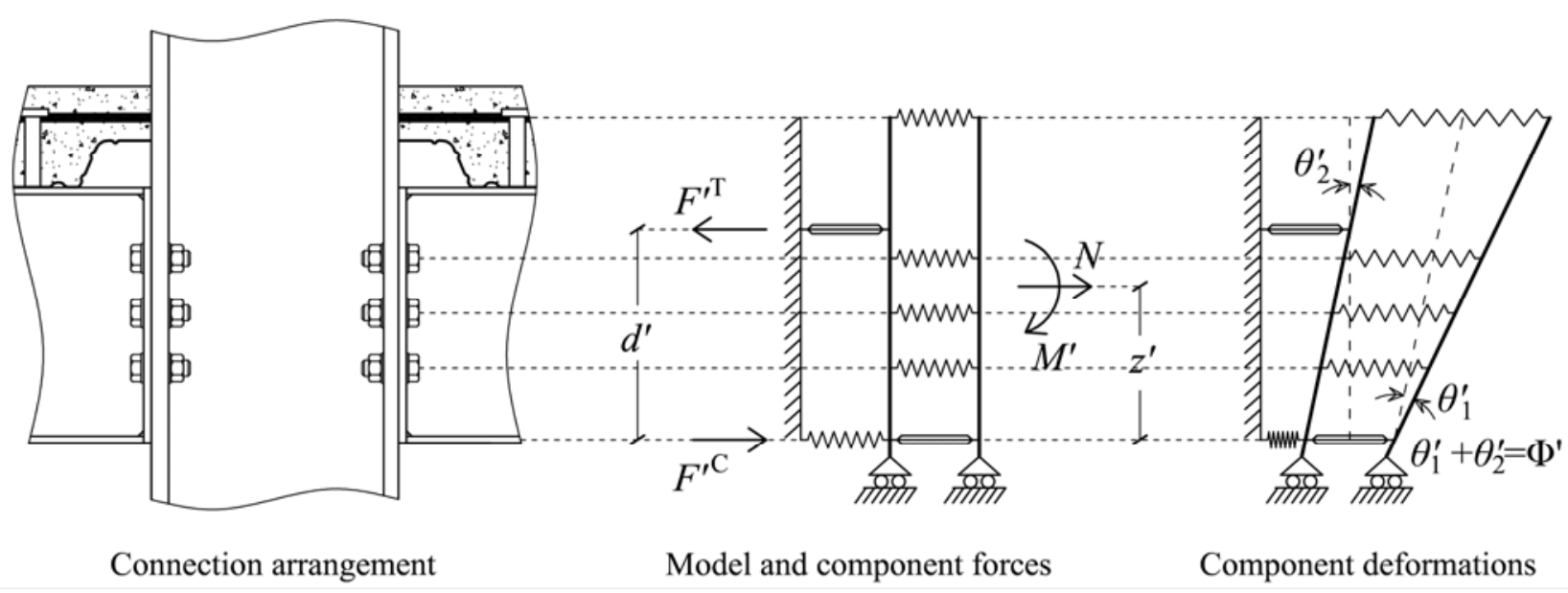

Figure 3. Connection Mechanical Spring Model 
Based on the mechanical spring model depicted in Figure 3 [7], the connection behaviour under combined bending moment $(M)$ and axial load $(N)$ has been explicitly studied [3]. The component method of EC3 [8] and EC4 [9] has been extended so as to incorporate the levels of axial load generated in column removal and the following connection bending moment-axial load-rotation relationship has been developed [3]:

$$
\begin{aligned}
& \Phi=M \alpha_{1}+N z \beta_{1}-\gamma_{1} \\
& \Phi^{\prime}=M^{\prime} \alpha_{1}{ }^{\prime}+N z^{\prime} \beta_{1}{ }^{\prime}-\gamma_{1}{ }^{\prime}
\end{aligned}
$$

where the parameters $\alpha_{1}, \beta_{1}, \gamma_{1}$ and $\alpha_{1}^{\prime}, \beta_{1}^{\prime}, \gamma_{1}^{\prime}$ are associated with the geometric and material properties of the mid-span and support connections respectively, whereas $z$ and $z^{\prime}$ correspond to the level of application of $N$, measured from the centre of compression of each connection respectively.

For the structural system depicted in Figure 2, the mid-span and support connection bending moments $\left(M, M^{\prime}\right)$ as well as the bending moment at the theoretical point of inflexion $\left(M_{\mathrm{L} / 2}\right)$ are determined by the sum of the equivalent nodal forces of the corresponding clamped structure (Figure 4a) and the nodal forces caused by the deformations of the corresponding released structure (Figure $4 \mathrm{~b}$ ) according to the stiffness method. By substituting the resulting expression for $M_{\mathrm{L} / 2}$ into the equilibrium equations of the two sections shown in Figure $2 \mathrm{~d}, \Phi_{\mathrm{L} / 2}$ and $w_{\mathrm{L} / 2}$ can be expressed in terms of the remaining parameters. By substituting $\Phi$ and $\Phi^{\prime}$ from Eq. 1a and Eq. $1 \mathrm{~b}$ respectively and solving the resulting set of equations for $M$ and $M^{\prime}$, the relationships between the connection bending moments, the beam axial and lateral load and the beam deflection are obtained as follows:

$$
\begin{aligned}
& M=N \lambda+q \mu+v \\
& M^{\prime}=N \lambda^{\prime}+q \mu^{\prime}+v^{\prime}
\end{aligned}
$$

where $\lambda, \mu, v$ and $\lambda^{\prime}, \mu^{\prime}, v^{\prime}$ are associated with $w, E I, E I^{\prime}, L$ and the connection geometric and material properties.

Furthermore, the overall equilibrium equation (Figure $2 \mathrm{~d}$ ) is given by:

$$
M^{\prime}=\frac{q L^{2}}{2}-N w-M
$$

Finally, the total axial deformation of the system can be defined quite accurately by a second order approximation:

$$
\frac{w^{2}}{2 L}=u+u^{\prime}+\frac{N}{K^{a}}
$$

- $\quad K^{\mathrm{a}}$ is the equivalent axial stiffness of the beam $(E A / L)$ and adjacent structure $\left(K_{\mathrm{s}}\right)$

- $\quad u$ and $u^{\prime}$ are the connection axial deformations which are defined in a similar fashion to the connection $M-N-\Phi$ and $M^{\prime}-N-\Phi^{\prime}$ relationships [3]:

$$
u=M \alpha_{2}+N z \beta_{2}-\gamma_{2}
$$


$u^{\prime}=M \alpha_{2}^{\prime}+N z^{\prime} \beta_{2}^{\prime}-\gamma_{2}^{\prime}$

By solving the set of Eq. 1 - 5, explicit equations linking:

- the connection bending moments $\left(M, M^{\prime}\right)$ and deformations $\left(\Phi, \Phi^{\prime}\right.$ and $\left.u, u^{\prime}\right)$,

- the beam axial load $(N)$ and axial deformation $\left(\Delta_{\mathrm{s}}\right)$, and

- the beam deflection $(w)$

with the beam loading $(q)$ may be derived.

This set of equations provides an analytical method for prediction of the beam nonlinear static response. This method facilitates rapid quantitative parametric studies and assists with understanding the mechanics of the problem.

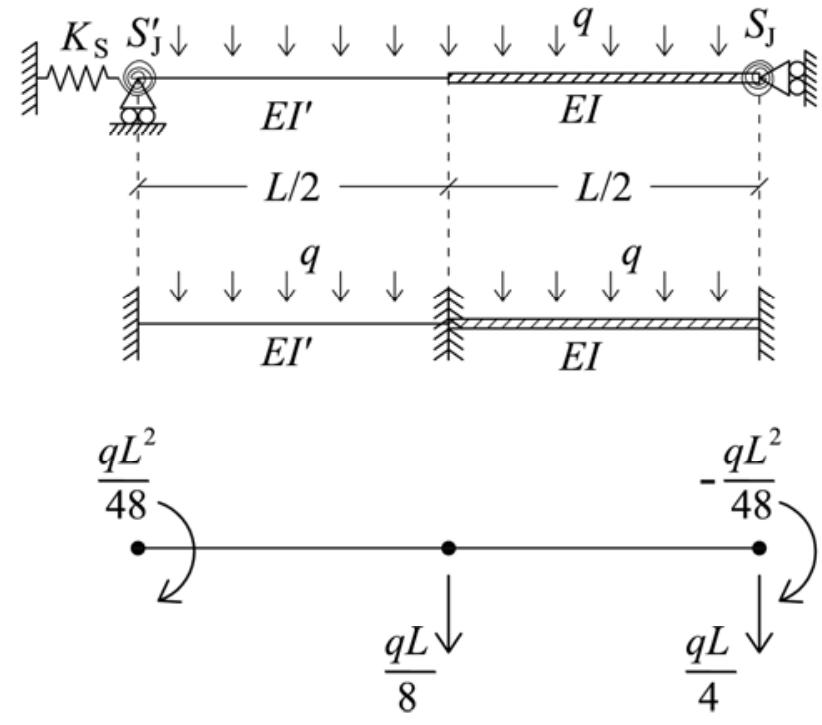

a. Equivalent clamped structure and nodal forces
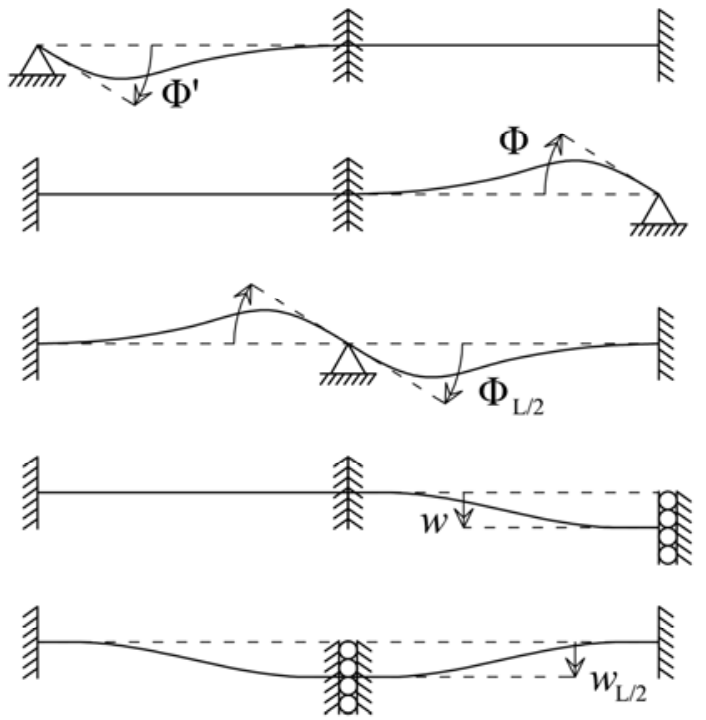

b. Basic displacement modes

Figure 4. Application of the Stiffness Method

\section{APPLICATION AND VERIFICATION OF THE SIMPLIFIED METHOD}

The simplified method described in the previous section has been applied for examination of various beam arrangements and some representative cases are presented herein. The responses of these arrangements are used in a parametric study where the interplay between the various structural parameters is explored and the most effective considerations in enhancing beam performance are identified. In addition, a second analysis has been conducted for each arrangement using the nonlinear analysis program ADAPTIC [1], with the results being used for verification of the simplified method.

\subsection{Layout of the Study}

For each of the sixteen different arrangements presented in Table 1, the nonlinear static response of the double-span beam after removal of the intermediate column as shown in Figure $2 \mathrm{a}$ has been determined. The full-depth flush endplate minor-axis beam-to-column connection type shown in Figure 5 has been considered, with the arrangement varying accordingly for each case (Table 1). A specific column section has been used for all the cases (Figure 5) and it has been considered as rigid, thus the column web has not been included in the connection analysis. 
Table 1. Beam Arrangements used in the Parametric Study

\begin{tabular}{|c|c|c|c|c|c|c|c|c|c|c|}
\hline $\begin{array}{c}\text { Case } \\
\text { no. }\end{array}$ & $\begin{array}{c}L \\
(m)\end{array}$ & Beam & Type & $\begin{array}{l}\text { Axial } \\
\text { restr. }\end{array}$ & $\begin{array}{c}D_{p} \\
(\mathrm{~mm})\end{array}$ & $\begin{array}{c}t_{p} \\
(\mathrm{~mm})\end{array}$ & $\begin{array}{c}e_{1} \\
(\mathrm{~mm})\end{array}$ & $\begin{array}{c}p_{I} \\
(\mathrm{~mm})\end{array}$ & $\begin{array}{l}\text { bolt } \\
\text { rows }\end{array}$ & $\begin{array}{c}\text { rebar } \\
\text { no. }\end{array}$ \\
\hline 1 & 6 & UB406x140×39 & Bare steel & yes & 398 & 10 & 90 & 70 & 4 & -- \\
\hline 2 & 6 & UB406x140x39 & Composite & yes & 398 & 10 & 90 & 70 & 4 & 2 \\
\hline 3 & 6 & UB406x140x39 & Composite & yes & 398 & 10 & 90 & 70 & 4 & 4 \\
\hline 4 & 6 & UB406×140×39 & Composite & yes & 398 & 10 & 90 & 70 & 4 & 6 \\
\hline 5 & 6 & UB406x140x39 & Composite & yes & 398 & 10 & 90 & 70 & 4 & 8 \\
\hline 6 & 6 & UB406x140×39 & Composite & no & 398 & 10 & 90 & 70 & 4 & 8 \\
\hline 7 & 6 & UB406x140x39 & Bare steel & yes & 398 & 12 & 90 & 70 & 4 & --- \\
\hline 8 & 6 & UB406x140x39 & Composite & yes & 398 & 12 & 90 & 70 & 4 & 8 \\
\hline 9 & 6 & UB406x140x39 & Composite & yes & 398 & 8 & 90 & 70 & 4 & 4 \\
\hline 10 & 6 & UB305x165x40 & Composite & yes & 303 & 8 & 90 & 60 & 3 & 4 \\
\hline 11 & 6 & UB254x102×22 & Composite & yes & 254 & 8 & 70 & 60 & 3 & 4 \\
\hline 12 & 4 & UB254×102×22 & Composite & yes & 254 & 8 & 70 & 60 & 3 & 4 \\
\hline 13 & 6 & UB533×210x92 & Composite & yes & 533 & 8 & 90 & 70 & 6 & 4 \\
\hline 14 & 6 & UB533×210x92 & Composite & no & 533 & 8 & 90 & 70 & 6 & 4 \\
\hline 15 & 9 & UB610x229x101 & Composite & yes & 602 & 12 & 90 & 60 & 8 & 8 \\
\hline 16 & 9 & UB610x229x101 & Composite & no & 602 & 12 & 90 & 60 & 8 & 8 \\
\hline
\end{tabular}

By considering the first case as a starting point, the effects of various structural parameters on beam performance are explored through examination of the remaining cases (Table 1). These parameters are the beam span, the beam section, the composite action, the degree of axial restraint, the connection bare steel components and the rebar ratio.

For the composite beams, the concrete slab acts compositely with the profiled steel decking. The dimensions of these components as well as the height of the connection reinforcement within the slab are given in Figure 5 and they are considered as constant. On the other hand, the slab effective breadth varies for each case according to the beam span. The connection reinforcement bars have constant diameter and properties (Figure 5) but their number varies between 2 and 8 as shown in Table 1. Finally, full shear connection between the composite slab and the bare steel section is provided in all composite beams.

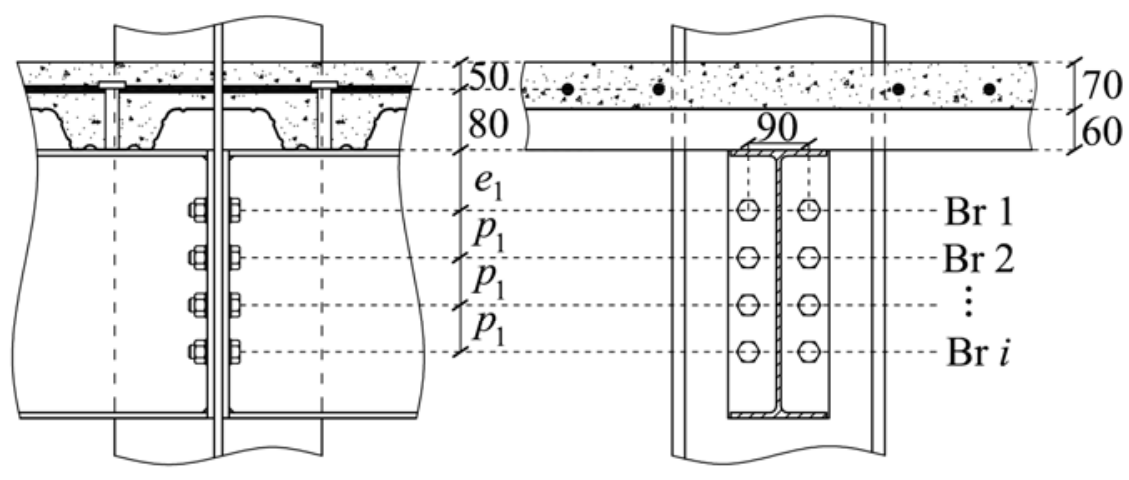

Beam [S355]: (section varies)

Column [S355]: UC305×305x118

Concrete [C30]

Rebar [S460]: $\Phi 16$

Bolts [8.8]: M20

Plate [S275]: $D_{\mathrm{p}} \times 150 \times t_{\mathrm{p}}$

$D_{\mathrm{p}}$ : plate depth

$t_{\mathrm{p}}$ : plate thickness

(Dimensions in $\mathrm{mm}$ )

Figure 5. Minor-axis Beam-to-column Flush Endplate Composite Connection Arrangement

Within a structural system the degree of beam axial restraint depends on the axial stiffness of the structure beyond the beam ends, within at least one further beam span on each side. In this respect, for the axially restrained cases, the degree of axial restraint corresponds to the equivalent axial stiffness of the beam and connection adjacent to the support connection (Figure 2). These are considered as identical to the corresponding components of the system under consideration. 
Therefore, the axial restraint is different for each case and may also vary depending on the sign of the axial load (compressive or tensile).

The resistance of the welds between the beam and the endplate has been excluded from the connection analysis. Bilinear characteristics with $1 \%$ strain hardening have been considered for the remaining tensile and rigid-plastic characteristics for the compressive components respectively. The initial stiffness and strength of these components have been determined based on the component method of EC3 and EC4.

\subsection{Application and Results}

As mentioned in Section 3, the dynamic capacity is defined based on the available connection ductility according to the Imperial College framework. For each case shown in Table 1, the connection ductility has been determined based on suitably selected connection failure criteria. For the bare steel components the failure deformation of each bolt row has been defined as the minimum between endplate bending equivalent to approximately $30 \mathrm{~mm}$ axial deformation (an average value based on experimental studies) and the deformation associated with failure of the bolts in tension. The deformation capacity of the connection reinforcement has been determined based on the model proposed by Anderson et al. [10].

The most critical component is associated with either the support or the mid-span connection of the double-span beam (Figure 2). Based on the above criteria the corresponding available rotation capacities $\theta_{1, \mathrm{f}}^{\prime}$ and $\theta_{1, \mathrm{f}}$ of the support and mid-span connection respectively are presented in Table 2 . These rotations are associated with deformations of the connection tensile components only $\left(\theta_{1}\right.$ in Figure 3). The centre of rotation for these components is the connection centre of compression as shown in Figure 3. For the support connection (region of hogging bending moment) the centre of compression is within the beam bottom flange, whereas for the mid-span connection (region of sagging bending moment) the centre of compression is within the beam top flange for bare steel or the concrete slab for composite beams.

Table 2. Structural Parameters and Beam Capacities

\begin{tabular}{|c|c|c|c|c|c|c|c|c|c|c|}
\hline $\begin{array}{c}\text { Case } \\
\text { no. }\end{array}$ & $L / D$ & $\begin{array}{c}S_{\mathrm{J}}^{\prime} \\
(\mathrm{kNm} / \mathrm{mrad})\end{array}$ & $\frac{S_{\mathrm{J}}}{(\mathrm{kNm} / \mathrm{mrad})}$ & $\begin{array}{c}F^{\prime \mathrm{T}} \mathrm{Rd} \\
(k N)\end{array}$ & $\begin{array}{c}F_{\mathrm{Rd}}^{\mathrm{T}} \\
(\mathrm{kN})\end{array}$ & $\begin{array}{c}F_{\mathrm{f}, \mathrm{Rd}} \\
(\mathrm{kN})\end{array}$ & $\begin{array}{c}\theta_{1, \mathrm{f}}^{\prime} \\
(m r a d)\end{array}$ & $\begin{array}{c}\theta_{1, \mathrm{f}} \\
(m r a d)\end{array}$ & $\begin{array}{c}\text { Critical } * \\
\text { component }\end{array}$ & $\begin{array}{c}q_{\mathrm{d}, \mathrm{Rd}} \\
(\mathrm{kN} / \mathrm{m})\end{array}$ \\
\hline 1 & 15.4 & 69.0 & 64.5 & 313.3 & 313.3 & 660.0 & 98.8 & 101.5 & $\mathrm{Br} 1^{1} / \mathrm{epb}$ & 11.3 \\
\hline 2 & 14.0 & 116.7 & 134.6 & 489.4 & 313.3 & 660.0 & 14.9 & 75.9 & $\mathrm{Br} 4 / \mathrm{epb}$ & 17.8 \\
\hline 3 & 14.0 & 164.3 & 134.6 & 665.4 & 313.3 & 660.0 & 27.9 & 75.9 & $\mathrm{Br} 4 / \mathrm{epb}$ & 19.7 \\
\hline 4 & 14.0 & 212.0 & 134.6 & 841.5 & 313.3 & 660.0 & 29.1 & 75.9 & $\mathrm{Br} 4 / \mathrm{epb}$ & 21.5 \\
\hline 5 & 14.0 & 259.6 & 134.6 & 1017.5 & 313.3 & 660.0 & 29.9 & 75.9 & $\mathrm{Br} 4 / \mathrm{epb}$ & 23.2 \\
\hline 6 & 14.0 & 259.6 & 134.6 & 1017.5 & 313.3 & 660.0 & 29.9 & 5.9 & $\mathrm{Br} 4 / \mathrm{epb}$ & 21.0 \\
\hline 7 & 15.4 & 107.4 & 100.3 & 450.7 & 450.7 & 660.0 & 61.9 & 63.6 & $\mathrm{Br} 1^{1 / b t}$ & 13.7 \\
\hline 8 & 14.0 & 298.0 & 209.6 & 1155.0 & 450.7 & 660.0 & 29.9 & 47.6 & $\mathrm{Br} 4 / \mathrm{bt}$ & 21.9 \\
\hline 9 & 14.0 & 133.3 & 73.9 & 552.7 & 200.6 & 660.0 & 27.9 & 75.9 & $\mathrm{Br} 4 / \mathrm{epb}$ & 17.2 \\
\hline 10 & 18.0 & 76.2 & 39.0 & 508.3 & 156.2 & 754.3 & 35.5 & 98.4 & rebar & 13.2 \\
\hline 11 & 21.0 & 57.1 & 32.9 & 508.2 & 156.1 & 371.9 & 40.8 & 105.3 & rebar & 9.4 \\
\hline 12 & 14.0 & 57.1 & 32.9 & 508.2 & 156.1 & 371.9 & 42.8 & 105.3 & rebar & 21.0 \\
\hline 13 & 10.7 & 261.4 & 182.4 & 629.9 & 277.8 & 1618.9 & 18.7 & 56.1 & $\mathrm{Br6} / \mathrm{epb}$ & 46.1 \\
\hline 14 & 10.7 & 261.4 & 182.4 & 629.9 & 277.8 & 1618.9 & 18.7 & 56.1 & rebar & 22.2 \\
\hline 15 & 14.3 & 842.9 & 740.6 & 1412.9 & 708.7 & 1518.9 & 18.5 & 30.2 & $\mathrm{Br} 8 / \mathrm{bt}$ & 26.2 \\
\hline 16 & 14.3 & 842.9 & 740.6 & 1412.9 & 708.7 & 1518.9 & 18.5 & 30.2 & $\mathrm{Br} 8 / \mathrm{bt}$ & 25.5 \\
\hline & & & & & & & & & very & \\
\hline
\end{tabular}


The critical connections and the corresponding critical connection components are presented in Table 2. Provided the rotations of the support $\left(\Phi^{\prime}\right)$ and mid-span $(\Phi)$ connections vary similarly (especially beyond the elastic stage) comparison between the critical component and the rotation capacities of the tensile components $\left(\theta_{1, \mathrm{f}}^{\prime}\right.$ and $\left.\theta_{1, \mathrm{f}}\right)$ shows that the deformation of the compressive components $\left(\theta_{2}^{\prime}\right.$ and $\theta_{2}$ in Figure 3$)$ may have a significant influence on the determination of the critical connection (since $\Phi^{\prime}=\theta_{1}^{\prime}+\theta_{2}^{\prime}$ and $\Phi=\theta_{1}+\theta_{2}$ as defined in Figure 3). This is most noticeable in some of the composite beams where the ductility of the support connection is distinctly lower than the ductility of the mid-span connection but the latter fails first.

The static responses obtained by the simplified method have been converted to pseudo-static based on the simplified dynamic approach of the Imperial College method (Section 3) and the resulting dynamic capacities are presented in the last column of Table 2. The full pseudo-static responses are presented next. The remaining parameters shown in Table 2 are used for appraisal of these responses. These parameters are the beam span-to-depth ratio $(L / D$, where $D$ is the distance between the centres of compression of the support and mid-span connections) as well as the connection stiffness $\left(S_{\mathrm{J}}^{\prime}, S_{\mathrm{J}}\right)$ and strength. The latter is given based on the connection tying capacity $\left(F^{\prime}{ }_{R d}^{\mathrm{T}}, F^{\mathrm{T}}{ }_{\mathrm{Rd}}\right)$ and the beam flange compressive resistance $\left(F_{f, R d}\right)$. The concrete flange compressive capacity is not given as it is not reached in any of these cases due to the opposite balance between the tensile and compressive capacities of the support and mid-span connections respectively of the composite beams.

\subsection{Verification and Appraisal of the Results}

The pseudo-static responses and dynamic capacities obtained from the simplified method are presented in Figures 6-8. These are compared with the corresponding ADAPTIC predictions. It is confirmed that the proposed method is able to predict the beam nonlinear static response and capacity with excellent accuracy, even for large beam deflections beyond the theoretical failure. Furthermore, the two methods of analysis exhibit excellent agreement on the prediction of the component forces and deformations and subsequently on the determination of the critical components.

Based on the results, the most important parameters have been identified and their effects are discussed next. These parameters are the connection strength, stiffness and ductility as well as the beam axial restraint and span-to-depth ratio.

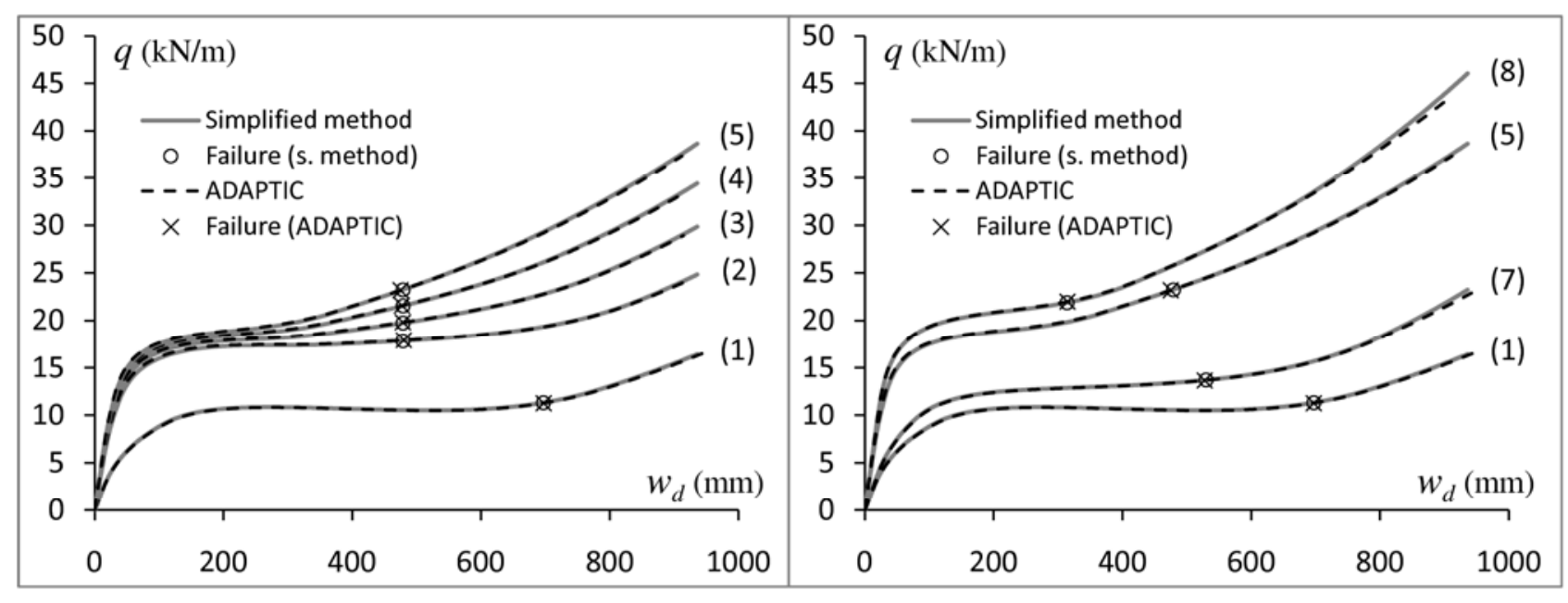

a. Reinforcement ratio

b. Endplate thickness

Figure 6. Beam p-s Responses for Various Characteristics of Connection Tensile Components 


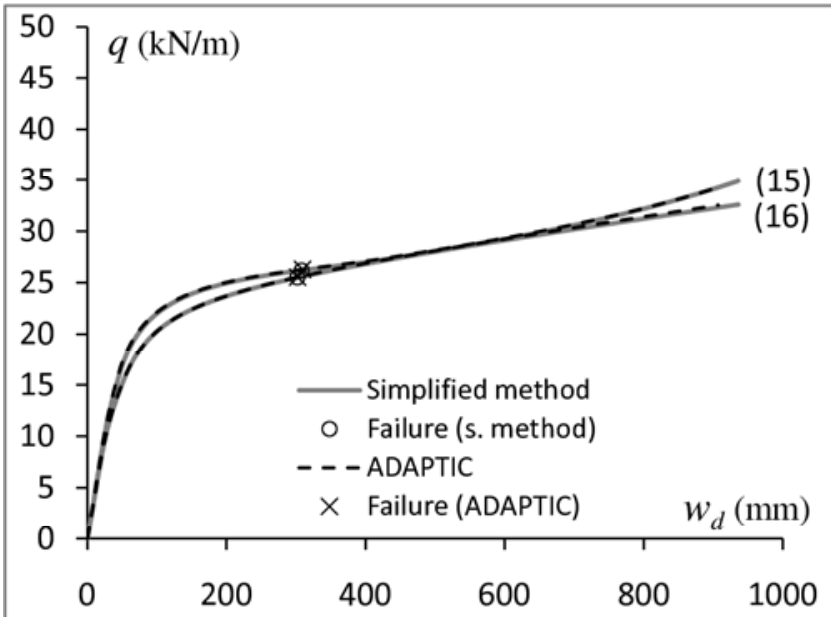

a. Limited effect of axial restraint

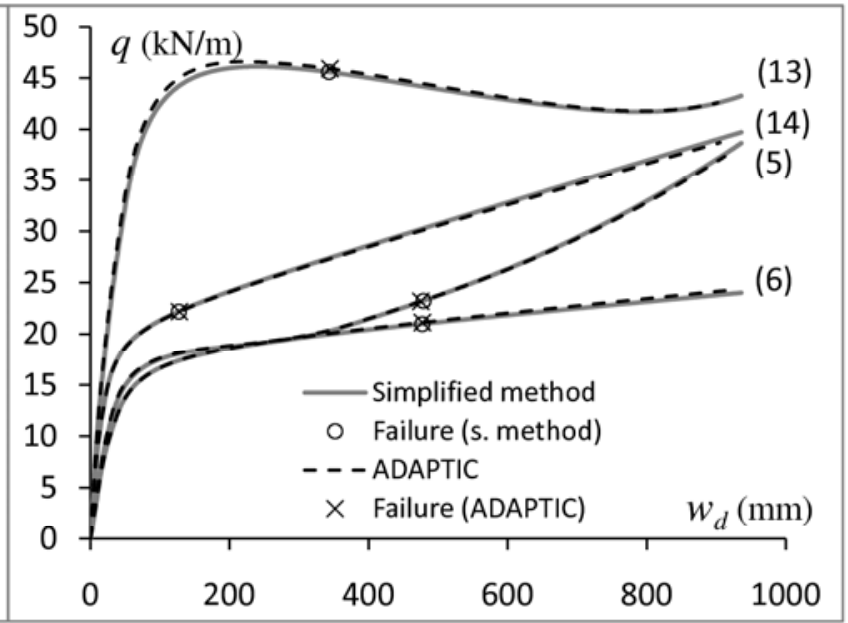

b. Substantial effect of axial restraint

Figure 7. Comparison between p-s Responses of Axially Restrained and Unrestrained Beams

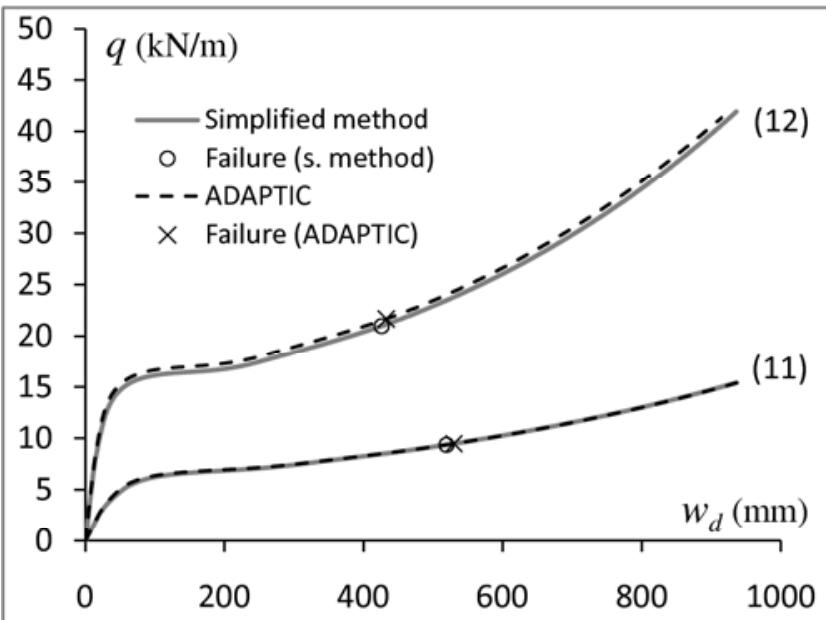

a. Different beam spans

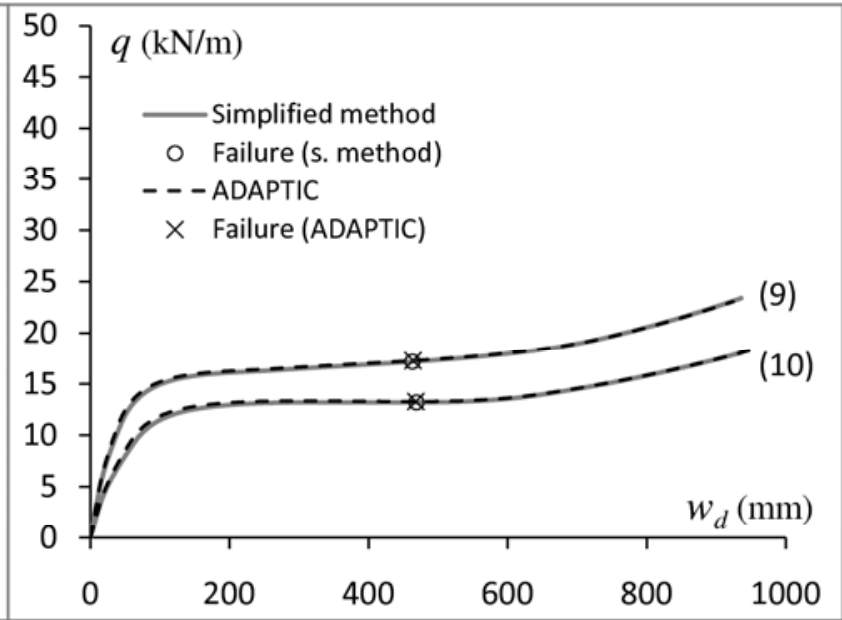

b. Different beam sections

Figure 8. Influence of the Beam Span-to-depth Ratio on the p-s Response

\subsubsection{Interplay between the Connection Parameters}

Figure 6 illustrates how the interplay between the basic connection parameters - strength (especially the balance between the tensile and compressive capacities), stiffness and ductility may influence the response and capacity of bare steel and composite beams respectively. The responses of identical composite beam arrangements with various reinforcement ratios are compared in Figure 6a whereas the effects of increasing the endplate thickness of either bare steel or composite beams are shown in Figure $6 b$.

In addition, the responses of the composite beams (cases 2-5) are compared with the response of the corresponding bare steel arrangement (case 1) in Figure 6a. The composite beams, even when the rebar ratio is relatively low as in case 2, exhibit a notably higher initial stiffness and enhanced response compared to the bare steel. This is justified mainly by the lower beam $L / D$ (higher $D$ due to higher distance between the connection centres of compression), as well as by the higher connection strengths (the strength of the mid-span connection is higher due to the higher lever arm). Another (rather less important) factor is the connection stiffness which is higher in composite beams. 
Failure is associated with the bare steel connection components for both the bare steel and composite arrangements (Table 2) but the bare steel beam exhibits a more ductile behaviour. This arises for two reasons: first, the corresponding available rotation capacity $\left(\theta_{1, \mathrm{f}}\right)$ is lower in the composite cases as shown in Table 2 due to the higher lever arms of the tensile components. In addition, the total rotation capacity $\left(\Phi_{\mathrm{f}}\right)$ of the mid-span connection (and thus the corresponding beam deflection) of the bare steel beam is higher due to higher deformation of the compressive components $\left(\theta_{2}\right.$ in Figure 3$)$.

For composite beams with different connection reinforcement ratios (cases 2-5 in Figure 6a), the mid-span connection characteristics and beam $L / D$ are the same and the differences in response are solely associated with the behaviour of the support connections. The initial responses of these arrangements are very similar and are governed by yielding of the beam bottom flange of the support connection within the compressive stage, whereas the stiffness of this connection has very limited effects at this stage as shown in Figure 6a. However, the stiffness and tensile capacity of the support connection affects the subsequent catenary stage. Especially for high reinforcement ratios (e.g. case 5) the beam axial load becomes tensile prior to yielding of the support connection tensile components and this is associated with a substantial and rather abrupt increase in response.

By increasing the endplate thickness, the connection stiffness and strength of both the mid-span and support connections increase but the ductility may decrease if the bolt capacity becomes critical in both the bare steel and composite cases (7 and 8) shown in Figure 6b. Therefore the response increases, but the ductility decreases and this may be followed by a decrease in capacity as shown in the composite beam response (case 8) where failure takes place within the tensile catenary stage. For the bare steel beam (case 7) on the other hand, the lower ductility is not associated with lower capacity, mainly because failure takes place before development of significant tensile catenary action.

\subsubsection{Beam Axial Restraint and Span-to-depth Ratio}

The presence of axial restraint may enhance beam performance but its effects depend on various structural parameters such as the degree of axial restraint, the beam span-to-depth ratio and the connection stiffness and strength. These parameters define the level and variation of the beam axial load generated in axially restrained beams.

Initially, the beam axial load is compressive, the connections are subjected to combined bending moment and axial load and, depending on the level of the axial load, the response may be governed by compressive arching effects. These effects increase when:

- the beam $L / D$ decreases, and/or

- the support compressive stiffness increases, and/or

- the connection compressive capacities increase (as compared to the tensile).

Whatever the level of compressive arching effects, the beam axial load subsequently becomes tensile, the connection bending moments gradually decrease and the response is governed by tensile catenary effects. If the connection compressive components remain rigid within the compressive stage $\left(\theta_{2}^{\prime}=\theta_{2}=0\right)$, the axial load becomes tensile when the beam deflection becomes equal to approximately $2 D$. On the other hand, when $\theta_{2}^{\prime}>0$ and/or $\theta_{2}>0$ within the compressive stage, the axial load becomes tensile at lower beam deflections, between 0 and $2 D$, depending on the beam $L / D$ and the connection compressive capacities $\left(F^{\prime C}{ }_{\mathrm{Rd}}, F^{C}{ }_{\mathrm{Rd}}\right)$. The tensile catenary effects increase when:

- the stiffness of the tensile components (i.e. connections, beam, support) increases, and/or

- the beam span decreases. 
The responses of various axially restrained beams are compared with the responses of the corresponding unrestrained arrangements in Figure 7. In Figure 7a, the compressive arching effects of the axially restrained beam (case 15) are limited due to the high $L / D$ and the relatively low connection compressive capacity compared to the tensile (Table 2). The axial load becomes tensile at approximately $w=D$, after yielding of the connection tensile components. For this reason, but mainly due to the long span, the tensile catenary effects are initially limited. Therefore, the presence of axial restraint barely enhances performance and the response of case 15 is similar to the response of the corresponding unrestrained arrangement (case 16).

The effects of axial restraint are stressed in Figure 7b, where the responses of two axially restrained beams governed by substantial compressive arching (case 13) and tensile catenary (case 5) effects respectively are presented.

The initial response of case 13 is notably higher compared to the corresponding axially unrestrained arrangement (case 14) due to the low $L / D$ and the high connection compressive capacity (Table 2) which increases the level of compressive axial load. The response of the corresponding axially unrestrained beam (case 14) on the other hand, is limited by yielding of the connection tensile components. Furthermore, the ductility of the unrestrained arrangement is limited by the low rotation capacity of the support connection $\left(\theta^{\prime}{ }_{1, \mathrm{f}}\right)$, since $\theta_{2}^{\prime}$ remains zero due to the high connection compressive capacity. Regarding the axially restrained beam, the development of compressive axial load leads to yielding of the compressive components before rebar failure, the rate of increase in $\theta_{1}^{\prime}$ decreases and the ductility of the beam increases. Subsequently, the mid-span connection becomes critical as shown in Table 2 . However, any reasonable increase in ductility has no effect on capacity since the response beyond the peak of the curve is characterised by softening.

In contrast with case 13 , the response of case 5 exhibits very low compressive arching action due to the combination of high $L / D$ and low connection compressive capacity (Table 2). However, the beam axial load becomes tensile at a relatively low deflection, yielding of the tensile components of the support connection takes place within the tensile stage and the response increases significantly due to tensile catenary action. In this case, any increase in connection ductility would be very effective in increasing capacity.

Figure 8a compares identical arrangements with different beam spans. When the beam span decreases, the response increases regardless of the degree of axial restraint. The enhanced initial response of the short-span beam (case 12) compared to the response of the long-span beam (case 11) shown in Figure 8a is not associated with compressive arching effects. However, the lower span has a significant effect in the subsequent tensile stage since the catenary action depends on the beam span as mentioned before.

In Figure $8 \mathrm{~b}$, the responses of two beam arrangements with identical spans but different cross sections and connection characteristics are compared. As shown in Table 2, the deep beam (case 9) has a substantially lower $L / D$ than the shallow beam (case 10). However, the response of the deep beam is not noticeably higher than the response of the shallow beam because the latter has higher connection compressive capacity. Moreover, the two beams exhibit similar behaviour within the tensile stage since the stiffness and strength of their connection tensile components are similar and their spans are the same. 


\subsection{Concluding Remarks}

It has been established that the beam response and eventual capacity depend on the interplay between the connection parameters (tying capacity, compressive capacity, stiffness and ductility), the beam span-to-depth ratio and the degree of axial restraint. Understanding the effects of each parameter is essential for the development of effective design considerations in enhancing performance. A summary of these considerations is given next.

The response of axially unrestrained beams is analogous to the connection moment-rotation characteristics; therefore, it is most effectively enhanced by increasing the connection strength. In addition, the beam response is enhanced by increasing the connection post-limit stiffness. Therefore, any increase in connection ductility would be effective in increasing beam capacity provided the connection response is characterised by hardening. On the other hand, if the connection post-limit response is perfectly plastic governed by the resistance of the compressive components, the beam capacity is solely associated with the connection strength considering that the compressive components are relatively ductile.

The connection strength and post-limit stiffness have similar effects on the response of axially restrained beams. However, the response of axially restrained beams is enhanced compared to the response of the corresponding axially unrestrained beams due to compressive arching and/or tensile catenary actions.

Compressive arching action develops when the connection moment capacity is governed by the resistance of the tensile components and its effects depend on the connection compressive resistance, the beam axial stiffness in compression and the beam span-to-depth ratio. However, by increasing the connection compressive resistance, the compressive stage increases, the deformation of the compressive components decreases and the deformation of the tensile components increases; consequently, the possibility of development of catenary action prior to failure decreases and the capacity becomes less dependent on the connection ductility.

When the connection moment capacity of axially restrained beams is governed by the compressive components, tensile catenary action develops at relatively low beam deflections; otherwise, tensile catenary action develops after the compressive arching stage, at relatively high beam deflections. The tensile catenary effects increase by increasing the connection tensile post-limit stiffness and/or the beam axial stiffness in tension. By decreasing the compressive arching effects and enhancing the tensile catenary action the beam capacity becomes more dependent on the connection ductility.

Regardless of the above parameters, the responses of the axially restrained and unrestrained beams as well as the compressive arching and tensile catenary effects are higher for the short-span beams.

\section{PERFORMANCE OF ASSEMBLED FLOOR SYSTEMS}

By using the simplified method for prediction of the beam nonlinear static responses (Section 4) as well as the simplified dynamic method and multi-level approach of the Imperial College framework (Section 3), the progressive collapse resistance of a multi-storey building is examined herein. By considering a number of different column removal scenarios depending on the position of the initial damage within the frame, the ability of the corresponding affected floor areas to resist the redistributed loading is assessed. The resulting floor responses are appraised based on the previous observations regarding the connection and beam parameters (Section 5), whereas additional considerations associated with the performance of the assembled grillage approximation are identified. 


\subsection{Layout of the Study}

The general layout of the building is presented in Figure 1. All the floors are considered identical in terms of structure and loading; therefore the single floor model is used for the analysis. The plan view of the floor area, the floor loading and the various column removal scenarios are shown in Figure 9.

For the given layout, two different structures have been designed, considering both bare steel and composite frames, to enable comparisons between performances of the two types. For each structure, the beams have been designed by considering both the ULS and SLS conditions for the floor loading given in Figure 9. The same beam sections have been selected for all the beams in both directions of each frame as shown in Figures 10 and 11 respectively. The depths and sagging moment capacities of the bare steel and composite beams are similar (for the composite beam the concrete slab is included in the beam depth).

Full-depth flush endplate connection types have been used with the arrangements of Figures 10 and 11 for the bare steel and composite frames respectively. The composite connections have been designed for the maximum design shear force which corresponds to the transverse beams, whereas the bare steel connections have been designed based on the stiffness of the composite connections.

Because of the use of the same beam sections and in order to simplify the study, the same endplate arrangements have been considered for all the connections of each frame as shown in Figures 10 and 11. In addition, for the beam-to-column and beam-to-beam connections respectively, the columns and the supporting beams (including the weld preparations shown in Figures 10 and 11) have been considered as rigid. Thus, the resulting connection characteristics are the same for all the connections of each frame. These are presented in Tables 3 and 4. As shown in Table 3, bilinear characteristics with $1 \%$ strain hardening have been considered for the tensile and rigid-plastic characteristics for the compressive connection components respectively.

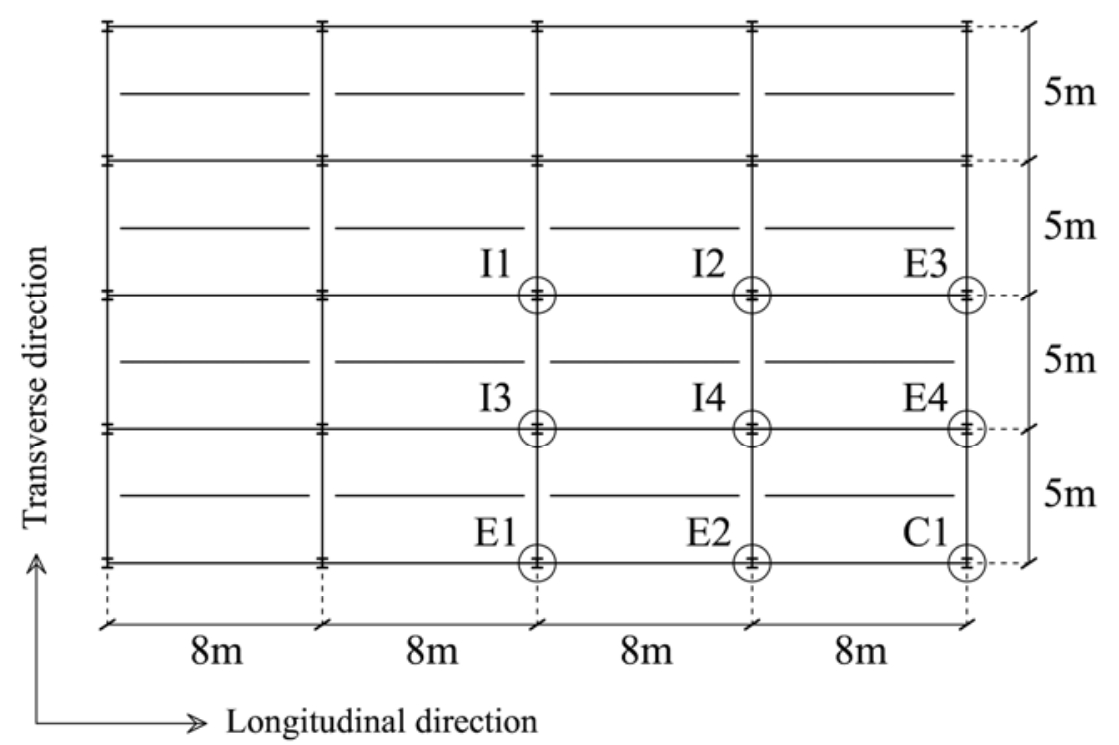

$$
\begin{aligned}
& \text { Floor unfactored loading: } \\
& \text { - Dead load: } \\
& \qquad \begin{array}{l}
g_{k}=4.2 \mathrm{kN} / \mathrm{m}^{2} \\
\text { - Imposed load: } \\
q_{k}=5.0 \mathrm{kN} / \mathrm{m}^{2}
\end{array} \\
& \text { I } i \text { : Removal of Internal } \\
& \quad \text { column } i \\
& \text { E } i \text { : Removal of Edge } \\
& \quad \text { column } i \\
& \mathrm{C} i \text { : Removal of Corner } \\
& \quad \text { column } i
\end{aligned}
$$

Figure 9. Plan View of the Floor Area and Depiction of the Various Column Removal Scenarios 


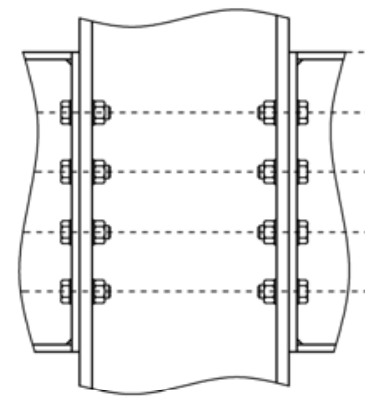

Beam-to-column major-axis

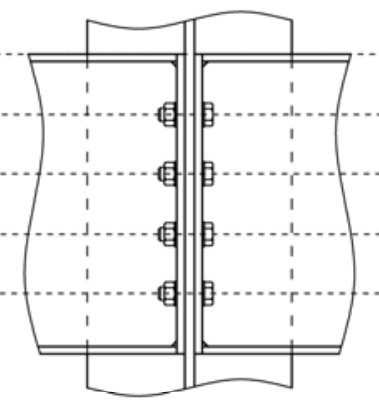

Beam-to-column minor-axis

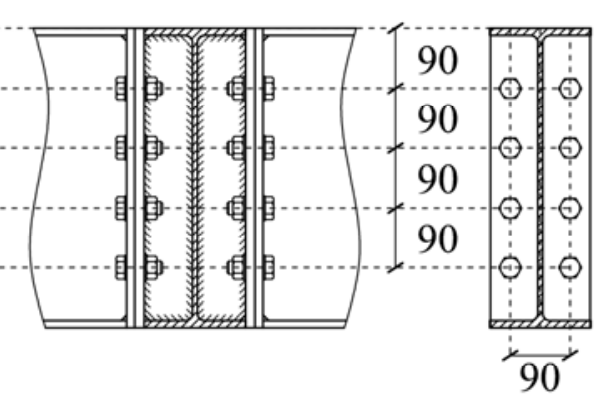

Beam-to-beam

Endplate

Beam [S355]:

UB $457 \times 152 \times 52$

Column [S355]:

UC $305 \times 305 \times 118$

Endplate [S275]:

$450 \times 150 \times 10$

Bolts [8.8]: M20

(Dimensions in $\mathrm{mm}$ )

Figure 10. Bare Steel Connections

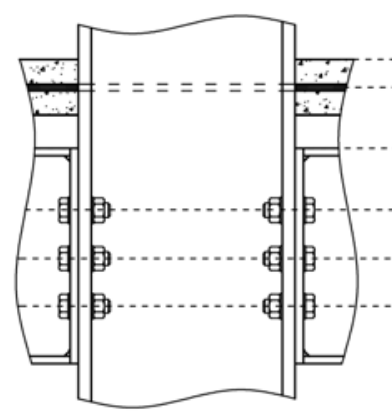

Beam-to-column major-axis

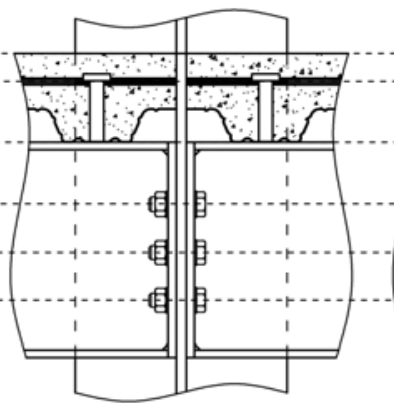

Beam-to-column minor-axis

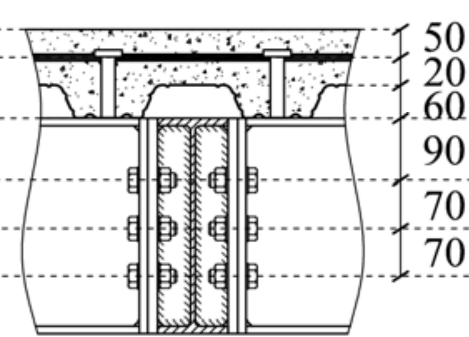

Beam-to-beam

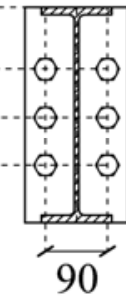

Endplate
Beam [S355]:

UB305x102x33

Column [S355]:

$\mathrm{UC} 305 \times 305 \times 118$

Endplate [S275]:

$312 \times 150 \times 10$

Bolts [8.8]: M20

Concrete [C30]

Rebar [S460]:

$4 \Phi 16$

(Dimensions

in $\mathrm{mm}$ )

Figure 11. Composite Connections

Table 3. Connection Component Characteristics

\begin{tabular}{|c|c|c|c|c|c|c|}
\hline \multirow{2}{*}{$\begin{array}{c}\text { Connection } \\
\text { components }\end{array}$} & \multicolumn{3}{|c|}{ Bare steel connection } & \multicolumn{3}{c|}{ Composite connection } \\
\cline { 2 - 7 } & $F_{\mathrm{Rd}}$ & $K^{\mathrm{e}}$ & $\mu$ & $F_{\mathrm{Rd}}$ & $K^{\mathrm{e}}$ & $\mu$ \\
\hline Reinforcement & $(\mathrm{kN})$ & $(\mathrm{kN} / \mathrm{mm})$ & $(\%)$ & $(\mathrm{kN})$ & $(\mathrm{kN} / \mathrm{mm})$ & $(\%)$ \\
\hline Bolt row 1 & 106.7 & --- & --- & 352.1 & 424.7 & 1 \\
\hline Bolt row 2 & 70.1 & 348.4 & 1 & 98.0 & 453.9 & 1 \\
\hline Bolt row 3 & 70.1 & 346.9 & 1 & 53.8 & 266.1 & 1 \\
\hline Bolt row 4 & 106.7 & 498.5 & 1 & 99.2 & 457.0 & 1 \\
\hline Beam Flange & 886.5 & $\infty$ & 0 & --- & --- & --- \\
\hline
\end{tabular}

Table 4. Connection Parameters

\begin{tabular}{|c|c|c|c|c|c|c|c|}
\hline $\begin{array}{c}\text { Connection } \\
\text { type }\end{array}$ & $S_{\mathrm{J}}^{\prime}$ & $S_{\mathrm{J}}$ & $F^{\prime \mathrm{T}}{ }_{\mathrm{Rd}}$ & $F_{\mathrm{Rd}}^{\mathrm{T}}$ & $F_{\mathrm{f}, \mathrm{Rd}}$ & $\theta_{1, \mathrm{f}}$ & $\theta_{1, \mathrm{f}}$ \\
\hline Bare steel & 100.9 & 101.0 & 353.5 & 353.5 & 886.5 & 84.7 & 84.6 \\
\hline Composite & 93.6 & 81.1 & 603.1 & 251.0 & 565.6 & 32.7 & 92.3 \\
\hline
\end{tabular}




\subsection{Analysis and Discussion}

The beams that are affected by edge or corner column removal when their direction is perpendicular to the corresponding edge are conservatively treated as cantilevers, ignoring the relatively low contribution of the connection in the region of sagging bending moment. On the other hand, the beams that are affected by removal of a penultimate column (I2, I4, E2 in the longitudinal and I3, I4, E4 in the transverse direction respectively) and are oriented perpendicularly to the corresponding edge are treated as axially unrestrained. The remaining beams are considered as axially restrained with the degree of axial restraint approximately defined as described in the previous section.

The beam nonlinear static responses have been obtained by the proposed simplified method and they have been converted to pseudo-static according to the simplified dynamic approach of the Imperial College framework. The floor pseudo-static response for each column removal scenario has been determined from the corresponding responses of the affected beams based on the simplified multi-level assembly approach of the Imperial College method. The pseudo-static responses of the individual beams and the resulting floor pseudo-static responses for the different column removal cases are given in Figures 12 and 13 for the bare steel and composite frames respectively. The floor capacities are associated with failure of the most critical member, whereas the beam capacities have been determined based on the failure criteria described in the previous section. The level of the vertically applied loading (Demand) at the time of column removal is $5.45 \mathrm{kN} / \mathrm{m}^{2}$, and it has been defined based on the combination of actions $g_{k}+0.25 q_{k}$ recommended by the GSA [11]. The capacity-demand ratios for the various column removal scenarios are presented in column (a) of Table 5 .

For the bare steel beams, the critical component is the top bolt row of the support connection regardless of the beam span or the degree of axial restraint as shown in Figure 12a. However, the beams exhibit different levels of ductility. The ductility of the axially unrestrained and cantilever beams with identical beam spans is approximately the same. This shows that neither of the connection compressive capacities of the axially unrestrained beams has been reached before failure. The corresponding axially restrained beams on the other hand, exhibit a rather more ductile behaviour. This is associated with yielding and deformation of the compressive flanges of the support connections and a reduction in the rate of increase in $\theta^{\prime}{ }_{1}$ as discussed in the previous section. However, since the support connections remain critical, the compressive capacities of the mid-span connections should also have been reached since $\theta_{1, \mathrm{f}}^{\prime}$ and $\theta_{1, \mathrm{f}}$ are similar as shown in Table 4. Finally, the ductility of the longitudinal beams is higher than the ductility of the transverse beams due to the longer spans; thus for any column removal scenario, the floor capacity is associated with failure of the transverse beams. This is confirmed in Figures 12b-12d.

The axially restrained bare steel beams exhibit significant compressive arching action, especially the transverse beam due to the low beam $L / D$. This is justified by the relatively high connection compressive capacity, which is substantially higher than the tensile as shown in Table 4 . The responses of the corresponding axially unrestrained beams are limited by the low connection tensile capacities. 


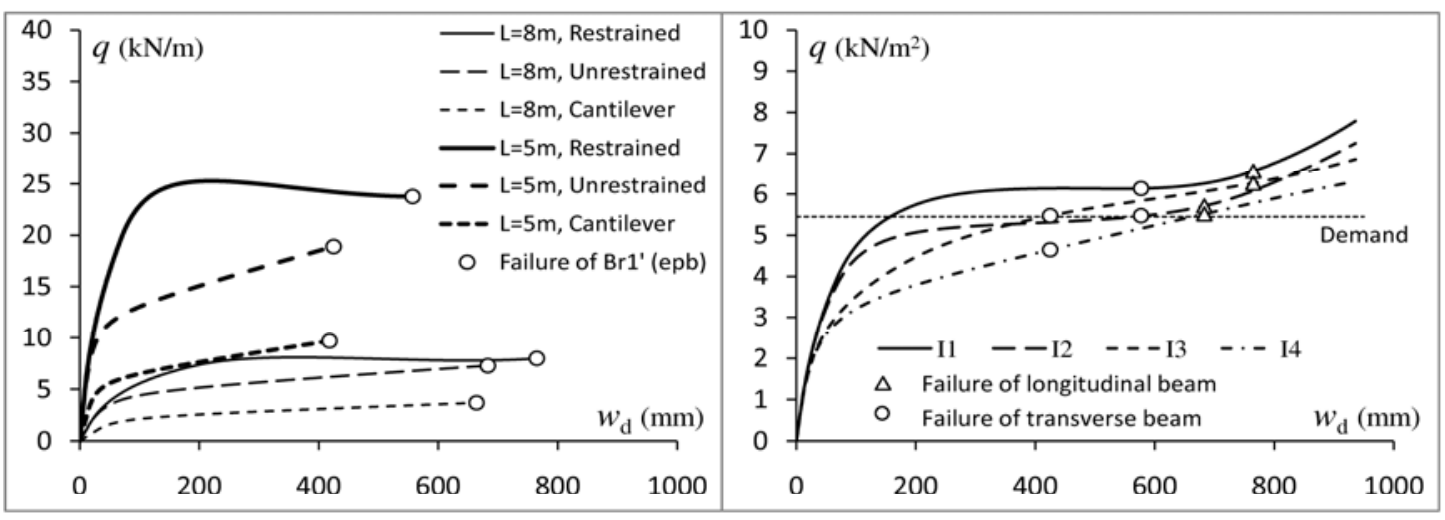

a. P-s responses of individual beams

b. Floor p-s responses - Internal column removal
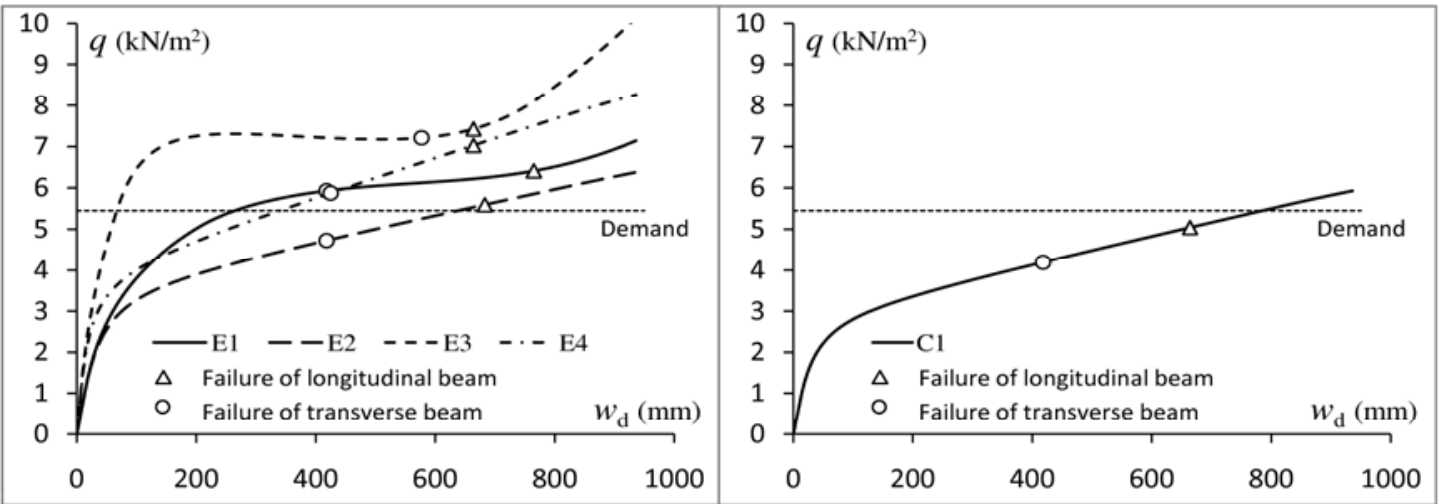

c. Floor p-s responses - Edge column removal

d. Floor p-s responses - Corner column removal

Figure 12. Progressive Collapse Assessment of Bare Steel Frame
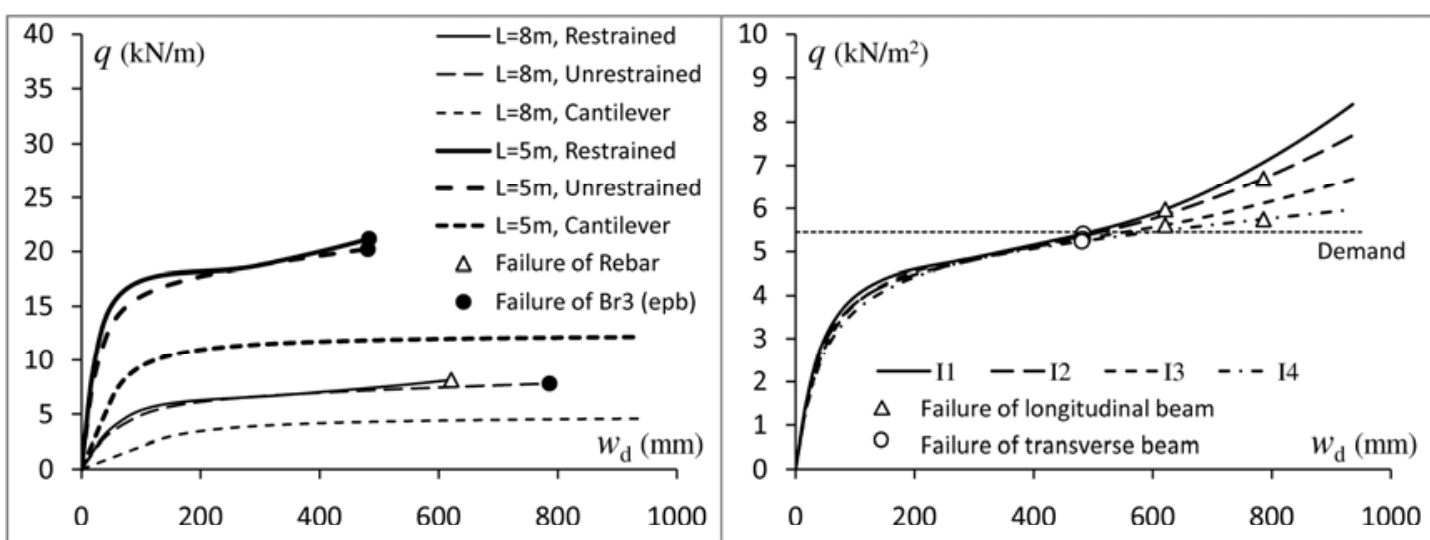

a. P-s responses of individual beams

b. Floor p-s responses - Internal column removal

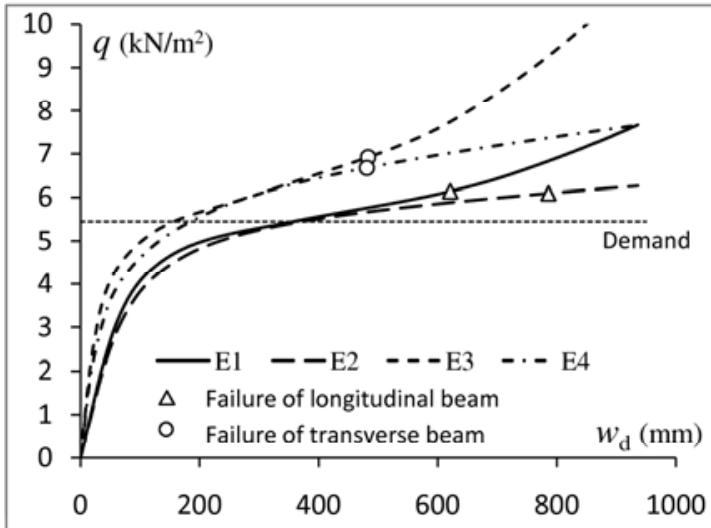

c. Floor p-s responses - Edge column removal

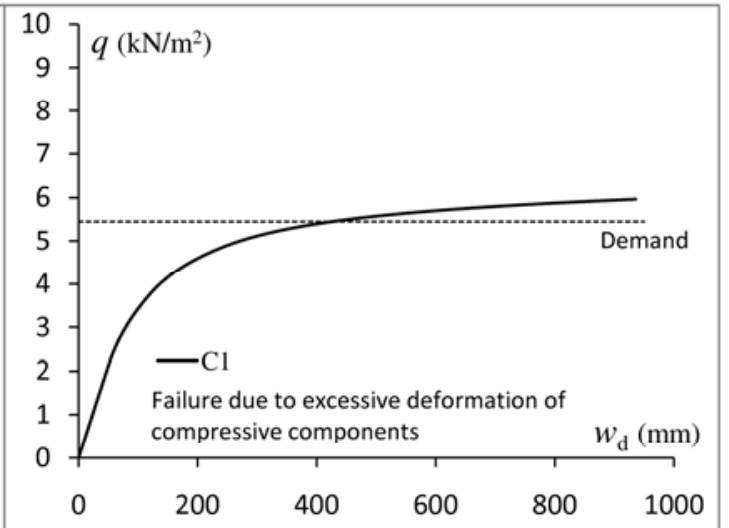

d. Floor p-s responses - Corner column removal

Figure 13. Progressive Collapse Assessment of Composite Frame 
For the composite beams, the critical component varies according to the beam span, degree of axial restraint and stiffness of the mid-span connection as shown in Figure 13a. Regardless of the span of the cantilever beams, the critical component is the beam bottom flange due to the balance between $F^{\prime T}$ Rd and $F_{\mathrm{f}, \mathrm{Rd}}$ (Table 4). For the axially restrained longitudinal beam, the critical component is the reinforcement because, for this arrangement, tensile catenary effects are developed at low beam deflections whereas the deformation of the compressive components is low due to the high beam $L / D$. This justifies the lower ductility compared to the corresponding axially unrestrained beam where the increase in rebar deformation after yielding of the support bottom flange becomes negligible and the bottom bolt row of the mid-span connection becomes critical. Similarly, for the axially restrained and unrestrained transverse beams the critical component is the bottom bolt row of the mid-span connection since the rotation of the support connection is governed by significant deformation of the bottom flange due to the low capacity of this component and the low beam $L / D$. As noted previously for the bare steel frame, the transverse beams are always the critical members as confirmed by Figures $13 \mathrm{~b}$ and 13c, except for the column removal scenarios E1, E2 and C1 where the capacities of the transverse beams are governed by yielding of the beam bottom flanges. Therefore, for the floor areas associated with column removals E1 and E2 failure is associated with the capacities of the longitudinal beams, whereas for the column removal scenario $\mathrm{C} 1$ the grillage is composed simply of cantilevers and failure is associated with the connection compressive resistances of all the beams.

The longitudinal axially restrained composite beam exhibits a similar initial response to the corresponding axially unrestrained beam due to the balance between the connection compressive and tensile capacities, whereas its response subsequently increases due to the stiffness and tying capacity of the support connection. The corresponding transverse beams behave similarly, however the effects of axial restraint are rather more pronounced due to the shorter beam span. Nevertheless, in both the axially restrained cases, failures take place prior to the development of significant catenary action.

By comparing the floor responses shown in Figures $12 b-12 d$ and $13 b-13 d$ with the responses of the corresponding affected beams, it can be established that the floor responses are similar to the responses of their most effective beams, defined as the beams that exhibit the higher responses. The bare steel floor response increases as the degree of axial restraint increases (E1, E3, I3, I2 and especially, I1). The exact opposite happens when the floor areas are axially unrestrained in both directions (E2, E4, I4) and especially when the floor is composed of cantilever beams only (C1). Furthermore, the composite floor areas with the same beam arrangements (i.e. I1-4, E1-E2 and E3-E4) initially behave almost identically regardless of the boundary conditions. These floor responses are directly related to the responses of the corresponding affected beams (Figures 12a and 13a).

The longitudinal axially restrained beams may make a substantial contribution in some cases as in the column removal scenarios I3 and E1. On the other hand, the effects of the secondary beams are limited unless they exhibit a relatively high initial response. Therefore, their contribution may be considered significant in all the composite frame cases and in the column removal scenarios I1, I3 and $\mathrm{E} 1$ of the bare steel frame.

Clearly, the responses of the bare steel floors are limited by the low stiffness and capacities of the connection tensile components whereas the responses of the composite floors are limited by the low capacities of the connection compressive components. To overcome these limitations, the connection tensile and compressive components are enhanced by increasing the endplate thickness and by stiffening the beam flanges respectively. Each modification is implemented individually in order to assess the corresponding effects on responses and capacities. The resulting beam responses 
are shown in Figures 14 and 15 and the corresponding floor capacity-demand ratios are presented in columns (b) and (c) of Table 5.

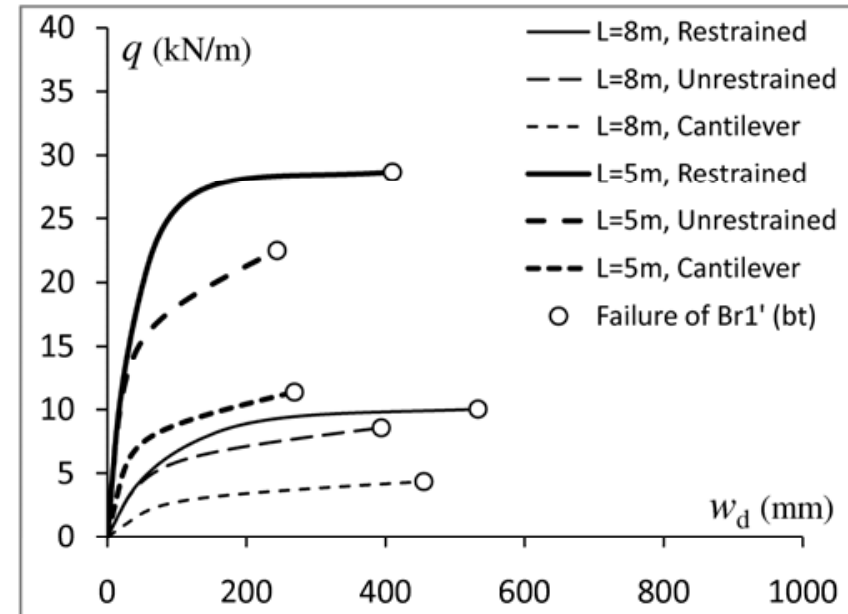

a. P-s responses of bare steel beams

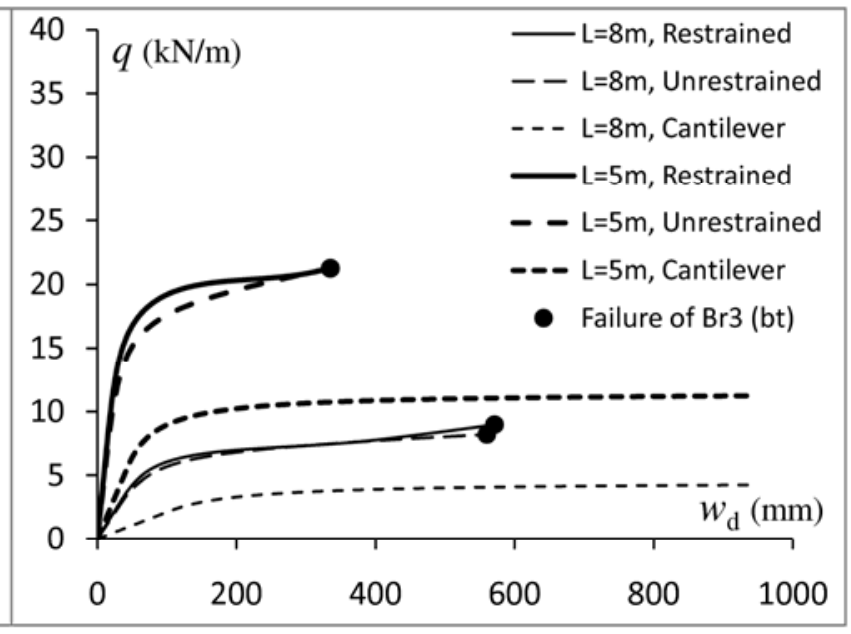

b. P-s responses of composite beams

Figure 14. Beam p-s Responses for $t_{\mathrm{p}}=12 \mathrm{~mm}$

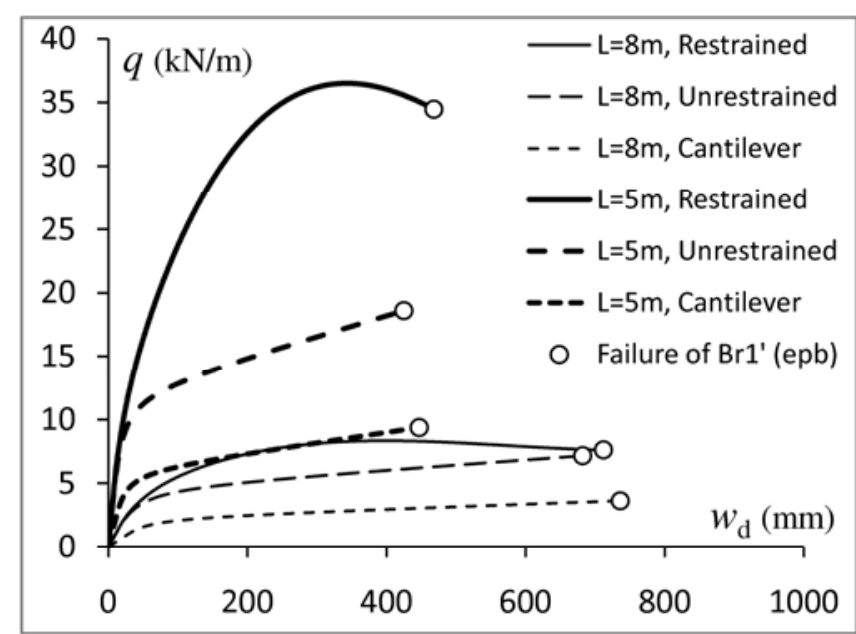

a. P-s responses of bare steel beams

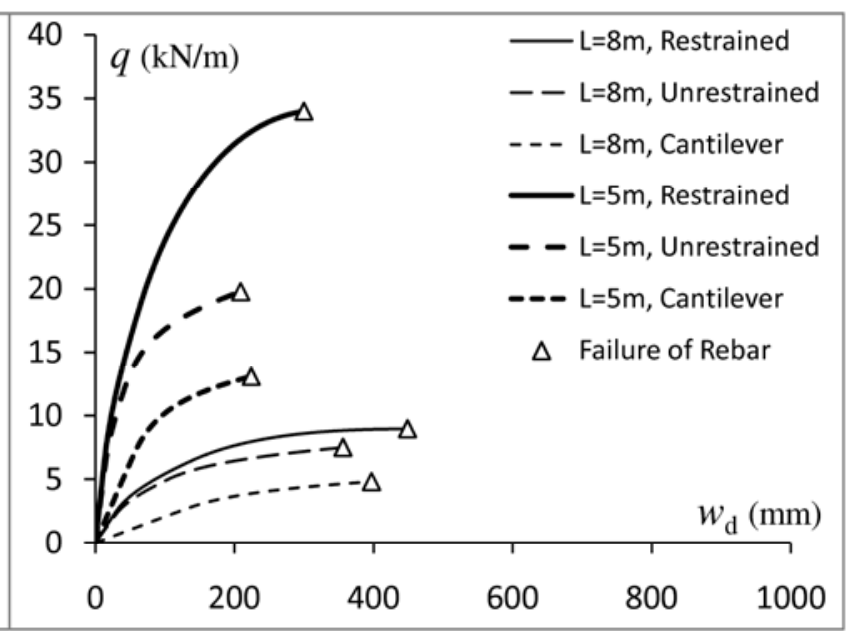

b. P-s responses of composite beams

Figure 15. Beam p-s Responses for $F_{\mathrm{f}, \mathrm{Rd}}=\infty$

Table 5. Capacity-demand Ratios for the Various Column Removal Scenarios

\begin{tabular}{|c|c|c|c|c|c|c|}
\hline \multirow{2}{*}{$\begin{array}{c}\text { Column removal } \\
\text { scenarios }\end{array}$} & \multicolumn{7}{|c|}{ Capacity-Demand ratios $\left(r=q_{\mathrm{Rd}} / q_{\mathrm{sd}}\right.$} \\
\cline { 2 - 7 } & (a) $t_{\mathrm{p}}=10 \mathrm{~mm}$, w/o FS & (b) $t_{\mathrm{p}}=12 \mathrm{~mm}$, w/o FS & (c) $t_{\mathrm{p}}=10 \mathrm{~mm}, \mathrm{w} / \mathrm{FS}$ \\
\cline { 2 - 7 } & Bare steel & Composite & Bare steel & Composite & Bare steel & Composite \\
\hline I1 & 1.13 & 0.99 & 1.35 & 1.01 & 1.40 & 1.34 \\
\hline I2 & 1.00 & 0.98 & 1.23 & 1.00 & 1.23 & 1.26 \\
\hline I3 & 1.00 & 0.97 & 1.13 & 1.01 & 1.01 & 0.94 \\
\hline I4 & 0.85 & 0.96 & 1.02 & 1.00 & 0.84 & 0.88 \\
\hline E1 & 1.09 & 1.13 & 1.24 & 1.18 & 1.10 & 1.10 \\
\hline E2 & 0.87 & 1.12 & 1.06 & 1.12 & 0.86 & 0.98 \\
\hline E3 & 1.32 & 1.27 & 1.60 & 1.23 & 1.87 & 1.83 \\
\hline E4 & 1.08 & 1.22 & 1.27 & 1.23 & 1.06 & 1.12 \\
\hline C1 & 0.77 & 0.89 & 0.90 & 0.80 & 0.75 & 0.97 \\
\hline
\end{tabular}


By increasing the connection endplate thicknesses from 10 to $12 \mathrm{~mm}$, the bare steel and composite beam responses shown in Figures 12a and 13a respectively are modified as shown in Figure 14. As shown in Figure 14a, the responses of the axially unrestrained and cantilever bare steel beams increase but their ductility decreases due to failure of the bolts in tension (Section 5). Similarly, the ductility of the axially restrained beams decreases, but the tensile effects increase. These result in an increase of around 10-30\% in the capacity-demand ratios of the assembled floor arrangements as shown in Table 5. The highest percentages correspond to the floors governed by the responses of axially restrained or unrestrained transverse beams (i.e. I1, I2, E3 and E4), since these beams exhibit the most significant increases in response and capacity.

On the other hand, increasing the endplate thickness is not very effective in enhancing performance of the composite beams as shown in Figure 14b. There is a low increase in the responses of the axially restrained beams but the capacity barely increases due to a reduction in ductility. Moreover, the responses of the cantilever beams decrease due to the low capacities of the beam flanges. Consequently, the floor capacity-demand ratios (Table 5) either increase insignificantly or decrease if the contribution of the cantilever beams is considerable (e.g. C1 and E3).

By stiffening the beam compressive flanges, the responses of both the axially restrained bare steel and composite beams are governed by significant compressive arching effects as shown in Figure 15. These effects are considerably more pronounced in the short-span transverse beams. However, their ductility decreases since the rotations of the support connections are solely associated with deformations of the tensile components. On the other hand, there is no effect in the responses and capacities of the axially unrestrained and cantilever bare steel beams as shown in Figure 15a since, in these cases, the beam flanges remain rigid even without flange stiffening (Figure 12a). The responses of the corresponding composite arrangements increase but their ductility decreases due to rebar failure and this causes some reduction in capacities.

Therefore, by enhancing the connection compressive capacities, the bare steel and composite floor responses increase due to compressive arching action if they are governed by the responses of axially restrained beams (i.e. I1, I2 and E3 where the floor responses are governed by the responses of the axially restrained transverse beams). Thus the corresponding capacity-demand ratios increase as shown in Table 5. Otherwise, the effects of enhancing the connection compressive components are either negligible or negative depending on the corresponding effects on ductility.

\subsection{Concluding Remarks}

This study has been based on several reasonable assumptions, e.g. the use of uniform beam sections and connection characteristics, which was done so as to limit the number of different parameters involved. These assumptions and the conclusions of the previous section facilitate understanding the behaviour of the assembled grillage approximation.

It can be concluded that:

- The loading is redistributed among the remaining members depending on their individual responses.

- The overall grillage response is governed by the beams that exhibit the highest resistances.

- These are the axially restrained beams and/or the beams with the shortest spans and/or the beams that undergo the largest deflections (e.g. connected to the failed column).

- Therefore, the connection and beam parameters that govern beam responses have an analogous influence on grillage performance.

- The floor capacity is usually associated with failure of the short-span beams. 


\section{CONCLUSIONS}

It has been argued that structural engineers require design approaches to guard against progressive collapse that are essentially similar to those used for the ultimate and serviceability limit states i.e. methods that permit quantitative comparisons to be made between alternative arrangements. Further developments to the Imperial College London approach, which aims to provide such a facility, have been briefly presented. Illustrative results for different column removal scenarios for a pair of steel and composite frames have been used to illustrate the effects of different parameters. The findings confirm the complex nature of the interplay between the various physical phenomena, especially the importance of the stage in the load-deformation responses of the individual members selected as the failure criterion. A particularly important feature is whether "failure" occurs in the tensile or the compressive parts of the beam-to-column connections and whether this develops during the compressive arching or tensile membrane stage of the beam's response.

\section{REFERENCES}

[1] Izzuddin, B.A., "Non-linear dynamic analysis of framed structures", $\mathrm{PhD}$ Thesis, Department of Civil and Environmental Engineering, Imperial College, University of London, 1991.

[2] Stylianidis, P., Nethercot, D.A., Izzuddin, B.A., Elghazouli, A.Y., "Progressive Collapse: Failure Criteria used in Engineering Analysis”, Structures Congress'09, Austin, Texas, 2009, pp. 1811-1820.

[3] Stylianidis, P., Nethercot, D.A., "Representation of Connection Behaviour for Progressive Collapse Response”, Int. J. Structural Engineering, Vol. 1, No. 3-4, pp. 340-360.

[4] Izzuddin, B.A., Vlassis, G.A., Elghazouli, A.Y., Nethercot, D.A., “Assessment of Progressive Collapse in Multi-storey Buildings", Structures and Buildings, Proceedings of the Institution of Civil Engineers, 2007, Vol. 160, pp. 197-205.

[5] Izzuddin, B.A., Vlassis, G.A., Elghazouli, A.Y., Nethercot, D.A., "Progressive Collapse of Multi-storey Buildings due to Sudden Column Loss - Part I: Simplified Assessment Framework", Engineering Structures, 2008, Vol. 30, pp. 1308-1318.

[6] Vlassis, G.A., Izzuddin, B.A., Elghazouli, A.Y., Nethercot, D.A., "Progressive Collapse of Multi-storey Buildings due to Sudden Column Loss - Part II: Application", Engineering Structures, 2008, Vol. 30, pp. 1424-1438.

[7] Del Savio, A.A., Nethercot, D.A., Vellasco, P.C.G.S., Andrade, S.A., and Martha, L.F., "Generalised Component-based Model for Beam-to-column Connections including Axial Versus Moment Interaction", Journal of Constructional Steel Research, Vol. 65, pp. 1876-1895.

[8] EN 1993-1-8, Eurocode 3: "Design of Steel Structures - Part 1.8: Design of Joints", Brussels: May 2005.

[9] EN 1994-1-1, Eurocode 4: "Design of Composite Steel and Concrete Structures - Part 1.1: General Rules for Buildings", Brussels: 2004.

[10] Anderson, D., Aribert, J.M., Bode, H., Kronenburger, H.J., "Design Rotation Capacity of Composite Joints", The Structural Engineer, Vol. 78, No. 6, pp. 25-29.

[11] General Services Administration, "Progressive Collapse Analysis and Design Guidelines for New Federal Office Buildings and Major Modernization Projects”, USA, 2003. 


\title{
STRUCTURAL BEHAVIOUR OF ELLIPTICAL HOLLOW SECTIONS UNDER COMBINED COMPRESSION AND UNIAXIAL BENDING
}

\author{
L. Gardner ${ }^{1, *}$, T.M. Chan ${ }^{2}$ and J.M. Abela ${ }^{1}$ \\ ${ }^{1}$ Department of Civil and Environmental Engineering, Imperial College London, \\ London, SW7 2AZ, United Kingdom \\ ${ }^{2}$ School of Engineering, University of Warwick, Coventry, CV4 7AL, United Kingdom \\ *(Corresponding author: E-mail: leroy.gardner@imperial.ac.uk)
}

\begin{abstract}
The structural behaviour of elliptical hollow sections (EHS) has been examined in previous studies under the isolated loading conditions of pure compression and pure bending. This paper examines the response of EHS under combined compression plus uniaxial bending at the cross-sectional level. Structural performance data were initially generated through a series of laboratory stub column tests with various load eccentricities. The measured geometric and material properties of the test specimens, together with the full load-deformation histories have been reported herein. The test data were supplemented by further results generated through parallel numerical studies. Slenderness parameters and limits for EHS under combined compression plus bending were developed following analytical work. Finally, the experimental and numerical data were used to verify proposed interaction expressions for the design of EHS under combined loading; these have been developed in accordance with Eurocode 3 for ease of future incorporation.
\end{abstract}

Keywords: Combined bending and axial compression, Eccentric compression, Elliptical hollow sections, Experiments, Interaction, Oval hollow sections, Steel structures, Testing

\section{INTRODUCTION}

Owing to their aesthetic appeal and sound structural efficiency, hot-finished elliptical hollow sections (EHS) have been adopted in a number of recent projects including the Honda Central Sculpture in Goodwood, UK, the Society Bridge in Braemar, UK (Corus [1]) and the airports at Barajas in Madrid, Spain (Viñuela-Rueda and Martinez-Salcedo [2]) and Heathrow in London, UK. The authors of the present paper have previously conducted extensive laboratory testing, supported by parallel numerical modelling studies, to examine the behaviour of elliptical hollow sections in compression (Chan and Gardner [3]) and bending (Chan and Gardner [4]). On the basis of the findings, slenderness parameters and slenderness limits for the cross-section classification of EHS have been proposed (Gardner and Chan [5]). Further recent studies on the elastic buckling of elliptical hollow sections (Zhu and Wilkinson [6], Ruiz-Terán and Gardner [7], and Silvestre [8]), the response of filled elliptical tubes (Roufegarinejad and Bradford [9], Zhao et al. [10], Yang et al. [11] and Zhao and Packer [12]) and the behaviour of connections to EHS (Bortolotti et al. [13], Choo et al. [14], Pietrapertosa and Jaspart [15] and Willibald et al. [16]) have also been performed. However, there currently remains a lack of verified design guidance for other structural phenomena. Development of such guidance is underway, and this paper focuses on the scenario for combined bending and axial force at cross-section level. Detailed experimental studies are described herein and design recommendations for resistance to combined bending and axial force are presented. 


\section{EXPERIMENTAL STUDY}

\section{$2.1 \quad$ Introduction}

A series of tensile material tests, compressive stub column tests and eccentric compression tests have been carried out to investigate the structural behaviour of hot-finished elliptical hollow sections. All tests were performed in the Structures Laboratory of the School of Engineering, University of Warwick. A total of four tensile coupons, four stub columns under uniform compression and eight stub columns under eccentric compression were tested. Two section sizes were employed - EHS $150 \times 75 \times 5$ and EHS $150 \times 75 \times 6.3$ - both having a cross-sectional aspect ratio of two. All tested material was hot-finished carbon steel, grade S355 supplied by Corus Tubes [17]. This section summarises the testing apparatus, the experimental procedures and the test results obtained.

\subsection{Tensile Coupon Tests}

Tensile coupon tests were performed to establish the basic material stress-strain response; this was subsequently utilised during the analysis of the test results and in the development of numerical models. The tests were carried out in accordance with EN 10002-1 (CEN) [18]. Parallel coupons were machined longitudinally from the two flattest portions of the cross-sections (i.e. the regions of maximum local radius of curvature). Two coupon tests, designated TC1 and TC2, were performed for each section size. The key results from the four coupon tests are summarised in Table 1.

Table 1. Mean Measured Dimensions and Key Results from Tensile Coupon Tests

\begin{tabular}{cccccc}
\hline Tensile coupons & $\begin{array}{c}\text { Width } \\
b_{t c}(\mathrm{~mm})\end{array}$ & $\begin{array}{c}\text { Thickness } \\
t(\mathrm{~mm})\end{array}$ & $\begin{array}{c}\text { Young's } \\
\text { modulus } \\
E\left(\mathrm{~N} / \mathrm{mm}^{2}\right)\end{array}$ & $\begin{array}{c}\text { Yield stress } \\
f_{y}\left(\mathrm{~N} / \mathrm{mm}^{2}\right)\end{array}$ & $\begin{array}{c}\text { Ultimate } \\
\text { tensile stress } \\
f_{u}\left(\mathrm{~N} / \mathrm{mm}^{2}\right)\end{array}$ \\
\hline $150 \times 75 \times 5.0-\mathrm{TC} 1$ & 19.85 & 4.61 & 211800 & 377 & 501 \\
$150 \times 75 \times 5.0-\mathrm{TC} 2$ & 19.85 & 4.63 & 213000 & 365 & 506 \\
$150 \times 75 \times 6.3-\mathrm{TC} 1$ & 19.84 & 6.47 & 216300 & 410 & 529 \\
$150 \times 75 \times 6.3-\mathrm{TC} 2$ & 19.83 & 6.38 & 216600 & 408 & 529 \\
\hline
\end{tabular}

\section{$2.3 \quad$ Stub Column Tests}

Four stub columns were tested in pure axial compression to assess load carrying capacity and deformation capacity. Full load-end shortening curves were recorded, including the post-ultimate range. The nominal lengths of the stub columns were chosen such that they were sufficiently short not to fail by overall buckling, yet still long enough to contain a representative residual stress pattern. The stub column lengths were taken as two times the larger cross-sectional dimension. The stub column test arrangement is shown in Figure 1. The end platens of the testing arrangement were flat and parallel. Four linear variable displacement transducers (LVDTs) were used to determine the end shortening of the stub columns between the end platens of the testing machine. Four linear electrical resistance strain gauges were affixed to each specimen at mid-height, and at the ends of the major and minor axes. The strain gauges were initially used for alignment purposes, and later to modify the end shortening data from the LVDTs to eliminate the elastic deformation of the end platens. Load, strain, displacement and input voltage were all recorded using the data acquisition equipment ORION. 
Measurements of major and minor axis diameters ( $2 a$ and $2 b$, respectively), material thickness $t$ and stub column length $L$ were taken. The mean measured dimensions and maximum geometric local imperfections $\omega_{0}$ of the test specimens for the four stub column specimens are presented in Table 2; cross-section geometry and notation is defined in Figure 2. The cross-sectional area for the EHS stub columns is defined using the exact formulae adopted by the authors in previous studies (Chan and Gardner [3]). Two stub column tests, designated SC1 and SC2, were performed for each section size.

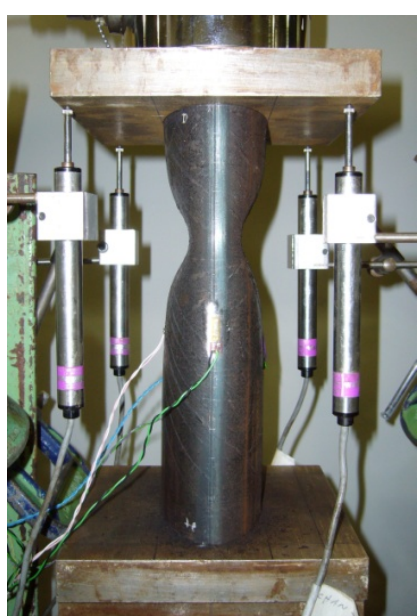

Figure 1. Stub Column Tests

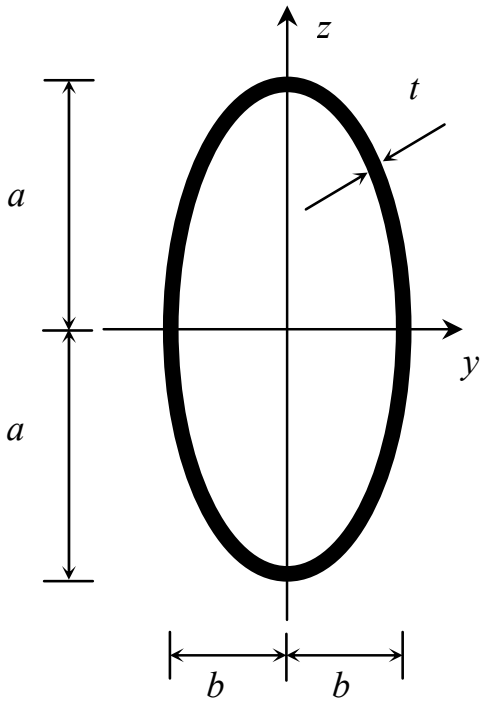

Figure 2. Geometry of an Elliptical Hollow Section

Table 2. Mean Measured Dimensions and Key Results from Stub Column Tests

\begin{tabular}{ccccccc}
\hline $\begin{array}{c}\text { Stub column } \\
\text { designation }\end{array}$ & $\begin{array}{c}\text { Larger } \\
\text { outer } \\
\text { diameter } \\
2 a(\mathrm{~mm})\end{array}$ & $\begin{array}{c}\text { Smaller } \\
\text { outer } \\
\text { diameter } \\
2 b(\mathrm{~mm})\end{array}$ & $\begin{array}{c}\text { Thickness } \\
t(\mathrm{~mm})\end{array}$ & $\begin{array}{c}\text { Length } \\
L(\mathrm{~mm})\end{array}$ & $\begin{array}{c}\text { Measured } \\
\text { maximum local } \\
\text { imperfection } \\
\omega_{0}(\mathrm{~mm})\end{array}$ & $\begin{array}{c}\text { Ultimate } \\
\text { load } \\
N_{u}(\mathrm{kN})\end{array}$ \\
\hline $150 \times 75 \times 5.0-\mathrm{SC} 1$ & 150.25 & 75.80 & 4.85 & 300.00 & 0.099 & 671 \\
$150 \times 75 \times 5.0-\mathrm{SC} 2$ & 150.05 & 76.00 & 4.90 & 300.05 & 0.072 & 676 \\
$150 \times 75 \times 6.3-\mathrm{SC} 1$ & 148.15 & 76.05 & 6.72 & 300.15 & 0.078 & 973 \\
$150 \times 75 \times 6.3-\mathrm{SC} 2$ & 148.85 & 76.05 & 6.64 & 300.15 & 0.036 & 990 \\
\hline
\end{tabular}

Compression tests on stub columns reveal the average compressive response of the cross-sections. Ultimate failure is due to local buckling of the cross-section. For cross-sections comprising slender elements, local buckling may occur in the elastic range. For more stocky cross-sections, local buckling may occur following significant inelastic deformation. Measured end shortening readings from the LVDTs were modified on the basis of the strain gauge readings to account for the elastic deformation of the end platens (that are present in the LVDT measurements) using a similar method to that employed by Rasmussen [19] and Gardner and Nethercot [20]. A summary of the key test results including ultimate test load $N_{u}$ is also given in Table 2. The results of the stub column tests are analysed and discussed in the following section.

\subsection{Unixial Bending and Compression Tests}

The primary aim of the eccentric compression tests was to investigate the cross-section response of EHS under combined bending and axial compression. The load was introduced through hardened steel knife-edges fixed to the ends of the specimens. The load eccentricity was varied to provide a range of proportions of axial load to bending, with the resulting $N_{u} / N_{c, R d}$, where $N_{c, R d}$ is the cross-section compression resistance, ranging between 0.26 and 0.76 . The nominal eccentricities about the minor axis were $25 \mathrm{~mm}$ and $75 \mathrm{~mm}$ whilst the nominal eccentricities about the major axis 
were $25 \mathrm{~mm}$ and $100 \mathrm{~mm}$. The nominal column lengths were $300 \mathrm{~mm}$. The general testing configuration is depicted in Figure 3. The loading, $N$ was applied through the knife-edge at an eccentricity, $e$ to the centroidal axis of the specimen, resulting in a uniform moment $(=\mathrm{Ne})$ along the column length, prior to lateral deformation - see Figure 4a. The loading was recorded by a $1000 \mathrm{kN}$ load cell located at the top end of the columns. Vertical displacement was measured at the loaded end of the columns by two LVDTs, whilst two inclinometers were positioned at each end of the columns to measure end rotation. As discussed by Fujimoto et al. [21], the deformation of the specimens generates a further second order moment $M_{2}=N \delta$, where $\delta$ is the lateral deflection, and the maximum moment at the mid-height is equal to $M_{1+2}=N \times\left(e+\delta_{\text {mid }}\right)-$ see Figure $4 \mathrm{~b}$. An additional LVDT was located at the mid-height of the columns to measure the lateral deflection. Eight linear electrical resistance strain gauges were affixed to the section to measure the longitudinal strain distribution around the section at mid-height. The strain gauge at the extreme fibre, near the lateral LVDT, was offset by $5 \mathrm{~mm}$ to avoid contact with the lateral LVDT. Load, strain, displacement and input voltage were all recorded using the data acquisition equipment ORION.

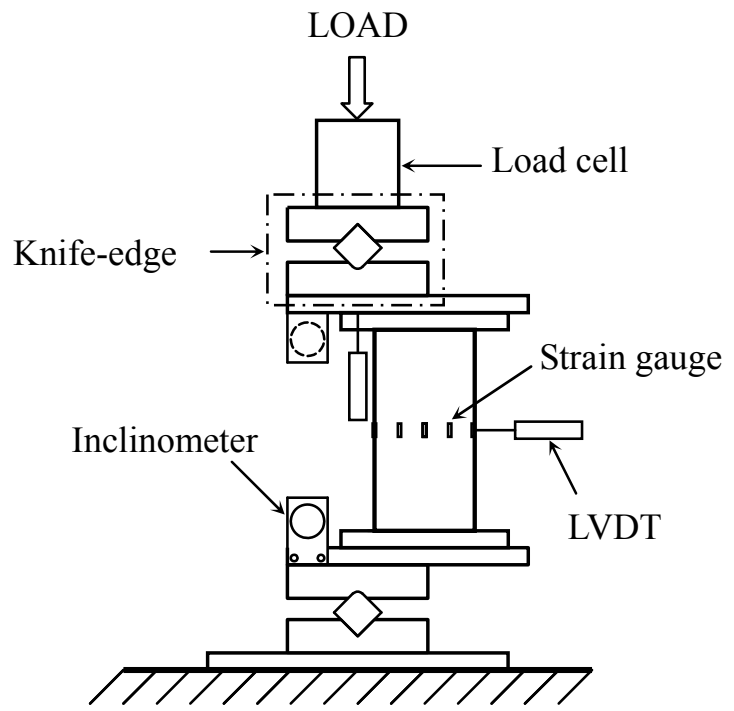

(a) Schematic view

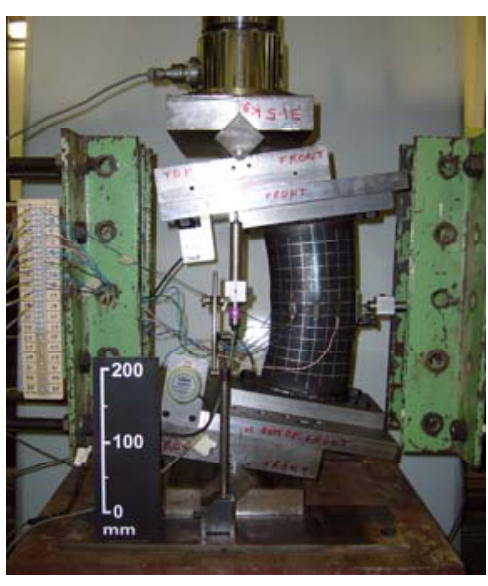

(b) Experimental setup

Figure 3. Eccentric Compression Test Arrangement

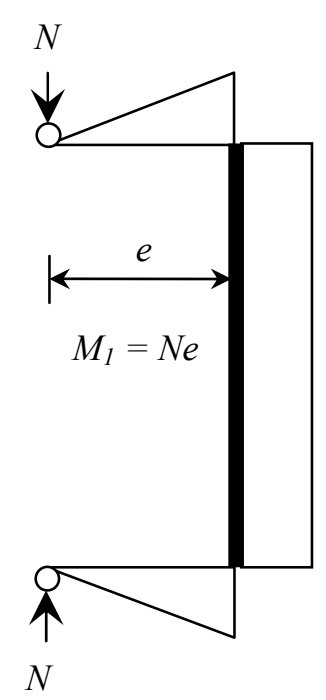

(a) Undeformed specimen

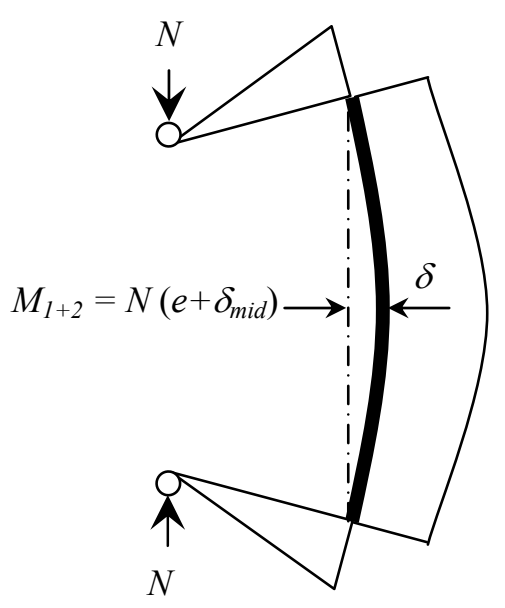

(b) Deformed specimen

Figure 4. Bending Moment due to Eccentric Compression 
The mean measured dimensions and maximum local geometric imperfections $\omega_{0}$ are presented in Table 3. Geometric properties including cross-sectional area and section moduli for the EHS specimens are defined using the exact formulae adopted by the authors in previous studies (Chan and Gardner [3, 4]). The test specimens were labelled such that the nominal section size, type of test, eccentricity axis and eccentricity value can be easily identified. For example, for specimen $150 \times 75 \times 5.0$-MI- 25 , the " $150 \times 75 \times 5.0$ " designates "nominal major diameter $\times$ nominal minor diameter $\times$ nominal thickness"; "MI" indicates an applied eccentric moment about the minor axis; "MA" indicates an applied eccentric moment about the major axis and "25" signifies an eccentricity of $25 \mathrm{~mm}$. The key results from the uniaxial bending and compression tests have been reported in Tables 3 and 4.

Table 3. Mean Measured Dimension and Key Results from the Minor Axis Uniaxial Bending and Compression Tests

\begin{tabular}{|c|c|c|c|c|c|c|c|}
\hline Specimens & $\begin{array}{l}\text { Larger } \\
\text { outer } \\
\text { diameter } \\
2 a(\mathrm{~mm})\end{array}$ & $\begin{array}{l}\text { Smaller } \\
\text { outer } \\
\text { diameter } \\
2 b(\mathrm{~mm})\end{array}$ & $\begin{array}{c}\text { Thickness } \\
t(\mathrm{~mm})\end{array}$ & $\begin{array}{l}\text { Length } \\
L(\mathrm{~mm})\end{array}$ & $\begin{array}{c}\text { Measured } \\
\text { maximum } \\
\text { local imp. } \\
\omega_{0}(\mathrm{~mm})\end{array}$ & $\begin{array}{c}\text { Ultimate } \\
\text { load } \\
N_{u}(\mathrm{kN})\end{array}$ & $\begin{array}{c}\text { Bending } \\
\text { moment } \\
\text { at } N_{u} \text {, } \\
M_{1+2} \\
(\mathrm{kNm})\end{array}$ \\
\hline $150 \times 75 \times 5.0-\mathrm{MI}-25$ & 150.00 & 76.15 & 4.81 & 300.05 & 0.068 & 343 & 10.6 \\
\hline $150 \times 75 \times 5.0-\mathrm{MI}-75$ & 150.20 & 75.90 & 4.88 & 300.00 & 0.080 & 181 & 14.4 \\
\hline $150 \times 75 \times 6.3-\mathrm{MI}-25$ & 148.70 & 76.00 & 6.65 & 300.10 & 0.073 & 500 & 13.6 \\
\hline $150 \times 75 \times 6.3-\mathrm{MI}-75$ & 149.55 & 75.80 & 6.80 & 300.10 & 0.277 & 248 & 19.7 \\
\hline
\end{tabular}

Table 4. Mean Measured Dimension and Key Results from the Major Axis Uniaxial Bending and Compression Tests

\begin{tabular}{|c|c|c|c|c|c|c|c|}
\hline Specimens & $\begin{array}{c}\text { Larger } \\
\text { outer } \\
\text { diameter } \\
2 a(\mathrm{~mm})\end{array}$ & $\begin{array}{l}\text { Smaller } \\
\text { outer } \\
\text { diameter } \\
2 b(\mathrm{~mm})\end{array}$ & $\begin{array}{l}\text { Thickness } \\
t(\mathrm{~mm})\end{array}$ & $\begin{array}{l}\text { Length } \\
L(\mathrm{~mm})\end{array}$ & $\begin{array}{c}\text { Measured } \\
\text { maximum } \\
\text { local imp. } \\
\omega_{0}(\mathrm{~mm})\end{array}$ & $\begin{array}{l}\text { Ultimate } \\
\text { load } \\
N_{u}(\mathrm{kN})\end{array}$ & $\begin{array}{c}\text { Bending } \\
\text { moment } \\
\text { at } N_{u} \text {, } \\
M_{1+2} \\
(\mathrm{kNm}) \\
\end{array}$ \\
\hline $150 \times 75 \times 5.0-\mathrm{MA}-25$ & 150.50 & 75.65 & 4.94 & 300.05 & 0.129 & 490 & 18.5 \\
\hline $150 \times 75 \times 5.0-\mathrm{MA}-100$ & 150.20 & 76.95 & 4.84 & 299.95 & 0.099 & 235 & 27.4 \\
\hline $150 \times 75 \times 6.3-\mathrm{MA}-25$ & 148.40 & 76.10 & 6.72 & 300.10 & 0.060 & 712 & 30.0 \\
\hline $150 \times 75 \times 6.3-\mathrm{MA}-100$ & 148.55 & 76.00 & 6.74 & 300.10 & 0.138 & 342 & 42.4 \\
\hline
\end{tabular}

\section{NUMERICAL SIMULATIONS}

Numerical modelling of the behaviour of elliptical hollow sections subjected to uniaxial bending and compression was undertaken in parallel with the experimental programme. This was performed using the nonlinear finite element (FE) package ABAQUS [22]. The aims of this investigation were initially to replicate the experimental results and validate the numerical models and subsequently to perform parametric studies to generate further structural performance data. Four-noded reduced integration shell elements with six degrees of freedom per node were used in the FE models. These are designated as S4R in the ABAQUS element library, and are suitable for thin or think shell applications [22]. A uniform mesh density of $2 a / 10(a / b) \times 2 a / 10(a / b) \mathrm{mm}$ with an upper bound of $20 \times 20 \mathrm{~mm}$ was employed. Simple support conditions were simulated by restraining suitable degrees of freedom at the ends of the members. 
The tests were modelled using the measured dimensions of the test specimens and measured material stress-strain data. The form of geometric imperfections was taken to be the lowest elastic eigenmode pattern, an example of which is shown in Figure 5.

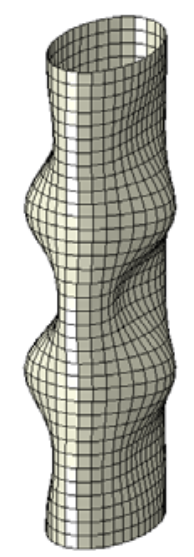

Figure 5. Lowest Elastic Buckling Mode Shape (Eigenmode) for EHS 150×75×5.0-MA-25

The imperfection amplitude $\omega_{0}$ was considered as two fixed fractions of the material thickness $t$ $(t / 10$ and $t / 100)$ in addition to the measured imperfection values. Residual stresses were not included in the models. The true material stress-strain relationships were generated from the engineering stress-strain curves obtained from the tensile coupon tests, and material nonlinearity was incorporated into the numerical models by means of a piecewise linear stress-strain model in order to replicate the strain-hardening region. The modified Riks method [22] was used to solve the geometrically and materially nonlinear models, which enabled the post-ultimate behaviour to be traced. Results from the numerical simulations are tabulated in Table 5, in which, the ratios between the FE ultimate loads (FE $N_{u}$ ) and the experimental ultimate loads (Test $N_{u}$ ) are shown and compared for the different imperfection levels. The overall mean and coefficient of variation (COV) of FE $N_{u} /$ Test $N_{u}$ are also reported.

With the measured imperfections, the mean FE $N_{u} /$ Test $N_{u}$ is 0.99 with a coefficient of variation of $7 \%$. The sensitivity to imperfections may be seen to be generally relatively low with, on average, an $8 \%$ drop in capacity arising from an increase in imperfection amplitude from $t / 100$ to $t / 10$. The sections that are loaded with an eccentricity to the major axis show the greatest variation in response to variation in imperfection amplitude, with larger imperfections limiting progression into the strain hardening regime.

Comparisons between the test and the FE results, in terms of applied moment $M(=N e)$ versus end rotation $\phi$, based on the measured imperfection amplitudes $\omega_{0}$ are shown in Figure 6.

Replication of the tests results was found to be satisfactory with the numerical models able to successfully capture the observed stiffness, ultimate load, overall load-end shortening response and failure patterns. Having verified the general ability of the FE models to replicate the test behaviour, a series of parametric studies was conducted. The primary aim of the parametric studies was to generate additional structural performance data for further load eccentricities and to investigate the influence of cross-section slenderness on the ultimate load-bearing capacity. A piecewise linear material stress-strain model derived from the tensile coupon tests conducted on the $150 \times 75 \times 6.3$ sections was employed throughout the parametric studies and is shown in Figure 7. Initial local geometric imperfections took the form of the lowest elastic eigenvalue with an amplitude of $\omega_{0}=$ $t / 100$, which was close to the measured value and provided the best agreement with the test results, as shown in Table 5 and as found in previous studies [3]. 
Table 5. Comparison of Uniaxial Bending and Compression Test Results with FE Results for Varying Imperfection Amplitude

\begin{tabular}{lccc}
\hline \multirow{2}{*}{ Specimens } & \multicolumn{3}{c}{ FE $N_{u} /$ Test $N_{u}$} \\
\cline { 2 - 4 } & $\omega_{0}=t / 10$ & $\omega_{0}=t / 100$ & Measured $\omega_{0}$ \\
\hline $150 \times 75 \times 5.0-\mathrm{MI}-25$ & 0.97 & 1.01 & 1.01 \\
$150 \times 75 \times 5.0-\mathrm{MI}-75$ & 0.87 & 0.90 & 0.90 \\
$150 \times 75 \times 6.3-\mathrm{MI}-25$ & 1.03 & 1.05 & 1.05 \\
$150 \times 75 \times 6.3-\mathrm{MI}-75$ & 0.91 & 0.93 & 0.93 \\
$150 \times 75 \times 5.0-\mathrm{MA}-25$ & 0.89 & 0.99 & 0.93 \\
$150 \times 75 \times 5.0-\mathrm{MA}-100$ & 0.88 & 1.02 & 0.99 \\
$150 \times 75 \times 6.3-\mathrm{MA}-25$ & 0.92 & 1.09 & 1.09 \\
$150 \times 75 \times 6.3-\mathrm{MA}-100$ & 0.94 & 1.06 & 1.05 \\
Mean & 0.93 & 1.01 & 0.99 \\
COV & 0.06 & 0.07 & 0.07 \\
\hline
\end{tabular}

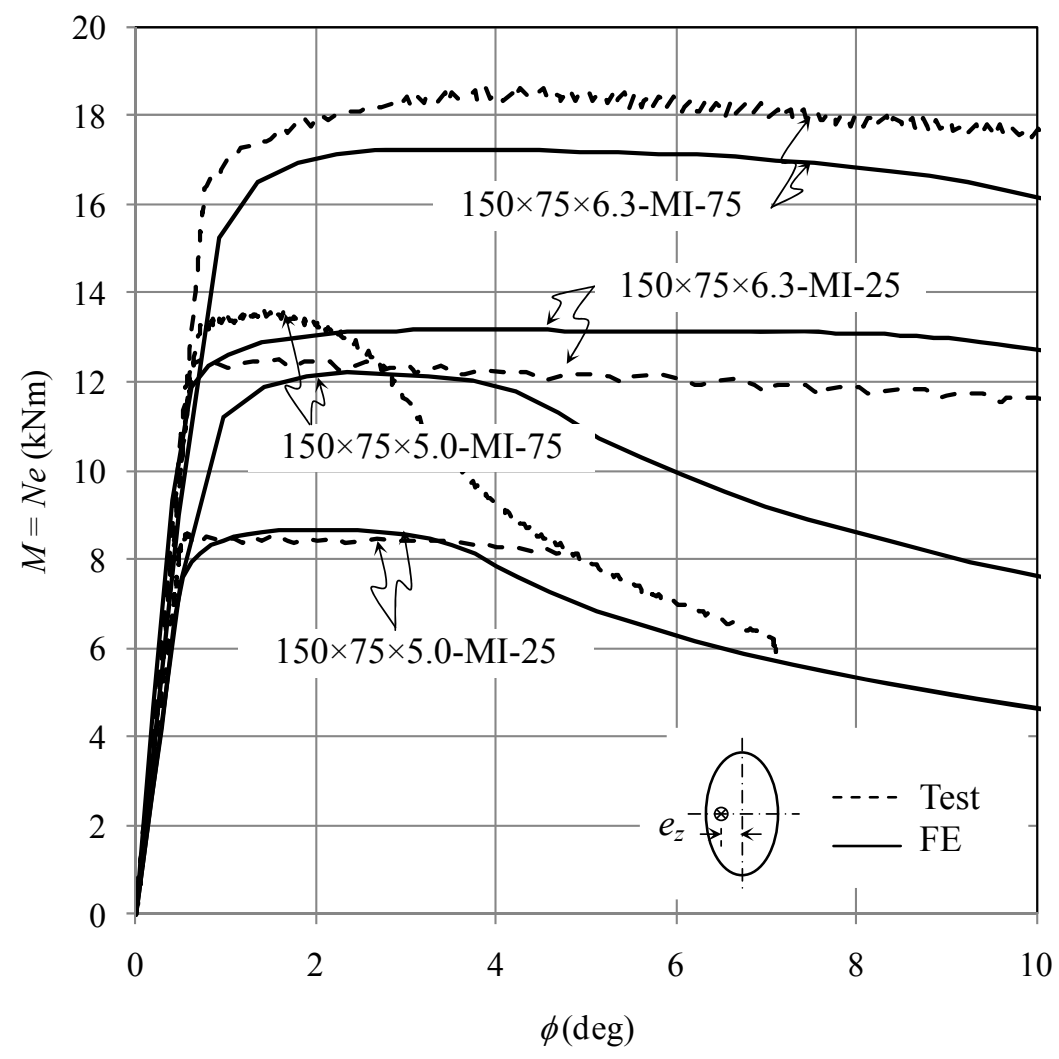

(a) Eccentricity to minor axis 


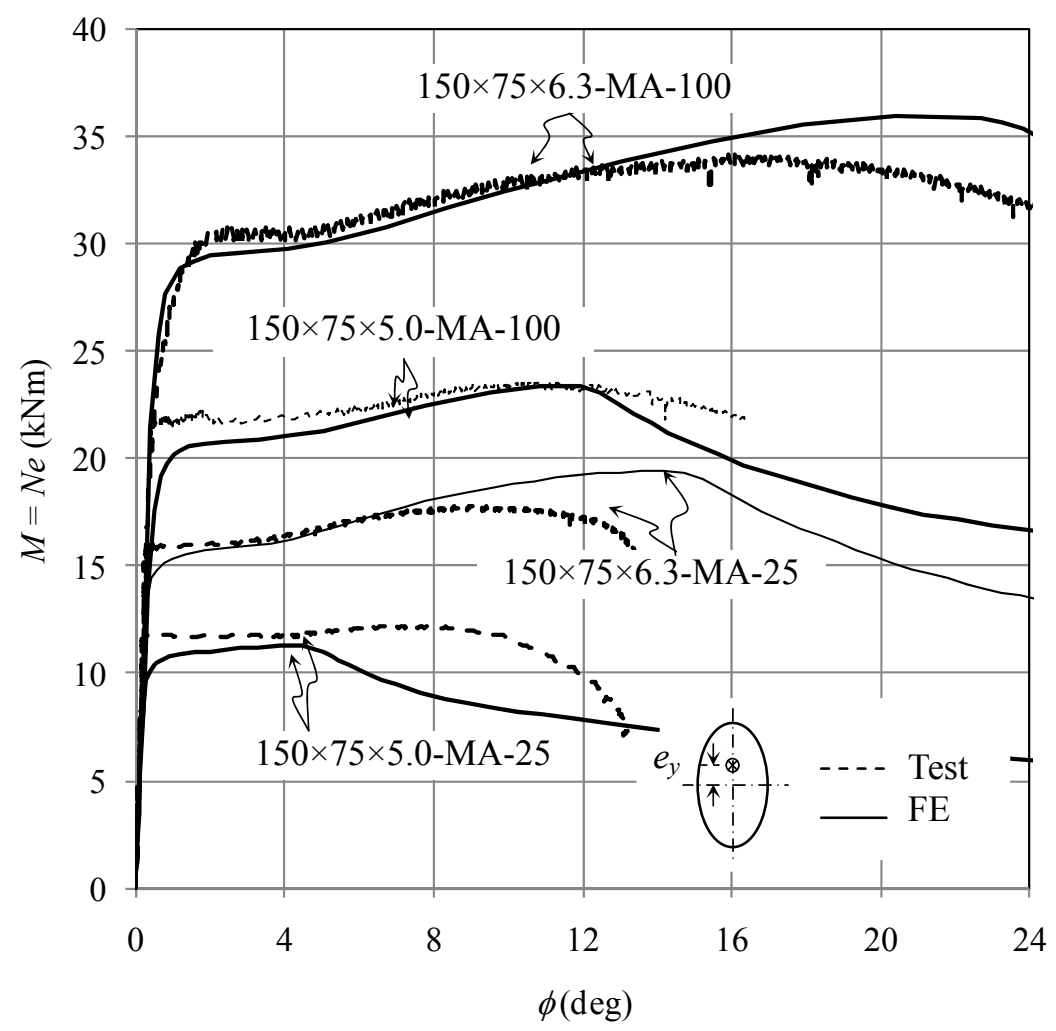

(b) Eccentricity to major axis

Figure 6. Moment Versus Rotation Curves

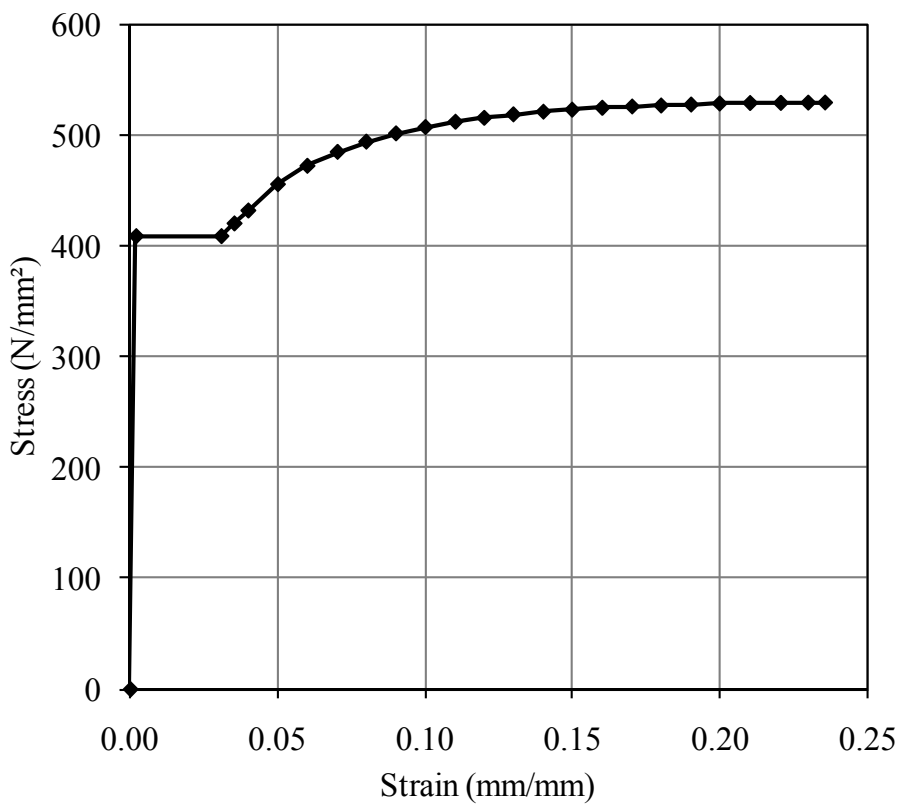

Figure 7. Piecewise Linear Stress-strain Model

The section sizes considered in the parametric studies were $150 \times 75$ and $150 \times 150$ (to generate comparative CHS data) with varying thicknesses to cover a spectrum of cross-section slenderness. The eccentricities considered to the minor axis $\left(e_{z}\right)$ were $10 \mathrm{~mm}, 25 \mathrm{~mm}$ and $75 \mathrm{~mm}$ and to the major axis $\left(e_{y}\right)$ were $1 \mathrm{~mm}, 10 \mathrm{~mm}, 25 \mathrm{~mm}$ and $100 \mathrm{~mm}$. The results are examined in the following section, where they have been utilised for the validation of proposed slenderness parameters and cross-section classification limits for elliptical hollow sections under combined loading. 


\section{SLENDERNESS PARAMETERS UNDER COMBINED LOADING}

\subsection{Introduction}

Cross-section classification of EHS under the individual loading scenarios of pure compression and pure bending has been previously studied by Chan and Gardner [3], [4], Gardner and Chan [5], Ruiz-Terán and Gardner [7] and Zhao and Packer [12]. The aim of this section is to obtain suitable slenderness parameters for EHS under combined compression and uniaxial bending.

Tables 6 and 7 summarise the bounds of this investigation by presenting the slenderness parameters and cross-section classification limits for CHS and EHS in pure compression and pure bending respectively. In these tables, and for the subsequent analyses, $D$ is the diameter of the CHS, $D_{e}$ is the equivalent diameter of the EHS (with $D_{e, c}$ and $D_{e, b}$ being the equivalent diameters for EHS under pure compression and pure bending, respectively), $\varepsilon^{2}=235 / f_{y}$ to allow for a range of yield strengths and $t$ is the cross-section thickness. The slenderness limits presented in BS 5950-1 [23], ANSI/AISC 360-05 [24], AISC [25] and AS 4100 [26] have been converted to their equivalent value with respect to the EN 1993-1-1 [27] slenderness measure, with $E=210000 \mathrm{~N} / \mathrm{mm}^{2}$, for ease of comparison.

The concept of the equivalent diameter, $D_{e}$, stems from extensive analytical work on the elastic buckling of oval hollow sections (OHS) and EHS under pure axial compression conducted by Kempner [28] and Hutchinson [29]. Kempner [28] concluded that the elastic buckling stress of an OHS could be accurately predicted from the classical elastic buckling formula for a circular hollow section (CHS) but with a radius $\left(r_{c r}=D_{e} / 2\right)$ equal to the maximum local radius of curvature of the OHS and that the solution was a lower bound. Hutchinson [29] extended this application of the equivalent diameter to EHS. Table 6 summarises the cross-section slenderness parameters for CHS given in current international codes, as well as the proposed slenderness parameters for EHS published in recent literature.

Table 6. Summary of Slenderness Parameters and Cross-section Classification Limits for Pure Compression for CHS and EHS

\begin{tabular}{|c|c|c|c|c|c|}
\hline & \multirow[t]{2}{*}{ Reference } & \multirow{2}{*}{$\begin{array}{l}\text { Cross-section slenderness } \\
\text { parameter }\end{array}$} & \multicolumn{3}{|c|}{$\begin{array}{c}\text { Equivalent EN 1993-1-1 [27] } \\
\text { slenderness limits }\end{array}$} \\
\hline & & & Class 1 & Class 2 & Class 3 \\
\hline \multirow{4}{*}{ 焉 } & EN 1993-1-1 [27] & $\frac{D}{t} \frac{f_{y}}{235}$ & 50.0 & 70.0 & 90.0 \\
\hline & BS 5950-1 [23] & $\frac{D}{t} \frac{f_{y}}{275}$ & - & - & 93.6 \\
\hline & $\begin{array}{l}\text { ANSI/AISC 360-05 } \\
{[24] \text { and AISC [25] }}\end{array}$ & $\frac{D}{t} \frac{f_{y}}{E}$ & - & - & 98.3 \\
\hline & AS 4100 [26] & $\frac{D}{t} \frac{f_{y}}{250}$ & - & - & 87.2 \\
\hline & $\begin{array}{l}\text { Chan and Gardner [3] } \\
\text { and SCI/BSCA [31] }\end{array}$ & $\frac{D_{e, c}}{t} \frac{f_{y}}{235} ; D_{e, c}=\frac{2 a^{2}}{b}$ & - & - & 90.0 \\
\hline$\underset{I}{M}$ & $\begin{array}{l}\text { Ruiz-Terán and } \\
\text { Gardner [7] }\end{array}$ & $\begin{array}{c}\frac{D_{e, c}}{t} \frac{f_{y}}{235} ; D_{e, c}=2 a\left(1+f\left(\frac{a}{b}-1\right)\right), \\
f=1-2.3\left(\frac{t}{2 a}\right)^{0.6}\end{array}$ & - & - & 90.0 \\
\hline
\end{tabular}


Local buckling of EHS in minor $(z-z)$ axis bending is similar to that in pure axial compression since buckling initiates at the same point i.e. that of greatest radius of curvature (Chan and Gardner [4]). In the case of bending about the major $(y-y)$ axis, local buckling initiates, in general, neither at the point of maximum radius of curvature nor at the extreme compressive fibre, since the former now lies on the neutral axis and the latter is where the section is of greatest stiffness (i.e. minimum local radius of curvature). The point of initiation of elastic local buckling of an EHS in major axis bending can be theoretically located at a critical radius of curvature $r_{c r}$. This is found by identifying the maximum value of the function $r \sigma$ which is the product of the varying radius of curvature of an EHS and an elastic bending stress distribution (Gerard and Becker [30]). The critical radius for major axis bending was found by Gerard and Becker [30] to be $r_{c r}=0.65 a^{2} / b$. For the purposes of defining a slenderness parameter for cross-section classification of an EHS in major axis bending, the critical radius was later modified to $0.4 a^{2} / b$ (i.e. $D_{e}=0.8 a^{2} / b$ ) by Chan and Gardner [4] on the basis of experimental findings, noting that the capacity of structural steel sections is not only influenced by elastic buckling, but may also involve post-buckling and an interaction with material yielding. The analytical work of Gerard and Becker [30] is extended in Section 4.3 of this paper to identify $r_{c r}$ under combined axial load and major axis bending.

Table 7 presents a comparison of cross-section slenderness parameters and limits for CHS in pure bending given in current codes of practice, as well as the corresponding items proposed for EHS.

Table 7. Summary of Slenderness Parameters and Cross-section Classification Limits for Pure Bending for CHS and EHS

\begin{tabular}{|c|c|c|c|c|c|}
\hline & \multirow{2}{*}{ Reference } & \multirow{2}{*}{$\begin{array}{l}\text { Cross-section slenderness } \\
\text { parameter }\end{array}$} & \multicolumn{3}{|c|}{$\begin{array}{c}\text { Equivalent EN 1993-1-1 [27] } \\
\text { slenderness limits }\end{array}$} \\
\hline & & & Class 1 & Class 2 & Class 3 \\
\hline \multirow{4}{*}{ 足 } & EN 1993-1-1 [27] & $\frac{D}{t} \frac{f_{y}}{235}$ & 50.0 & 70.0 & 90.0 \\
\hline & BS 5950-1 [23] & $\frac{D}{t} \frac{f_{y}}{275}$ & 46.8 & 58.5 & 163.8 \\
\hline & $\begin{array}{l}\text { ANSI/AISC 360-05 [24] } \\
\text { and AISC [25] }\end{array}$ & $\frac{D}{t} \frac{f_{y}}{E}$ & 62.6 & - & 277.0 \\
\hline & AS 4100 [26] & $\frac{D}{t} \frac{f_{y}}{250}$ & 53.2 & - & 127.7 \\
\hline$\underset{I}{M}$ & Chan and Gardner [4] & $\begin{array}{c}\frac{D_{e, b}}{t} \frac{f_{y}}{235} \\
\text { where for pure minor axis bending: } \\
\qquad D_{e, b}=\frac{2.0 a^{2}}{b} \\
\text { and for pure major axis bending: } \\
D_{e, b}=\frac{0.8 a^{2}}{b} \text { for } \frac{a}{b}>1.357 \\
D_{e, b}=\frac{2.0 b^{2}}{a} \text { for } \frac{a}{b} \leq 1.357\end{array}$ & 50.0 & 70.0 & 140.0 \\
\hline
\end{tabular}




\subsection{Slenderness Parameter of EHS under Compression and Minor Axis Bending}

For both pure compression and pure minor axis bending, the point of initiation of local buckling coincides with the maximum radius of curvature in the section $\left(r_{\max }=a^{2} / b\right)$, as shown in Figure 8; hence Chan and Gardner [4] proposed that the equivalent diameter $D_{e}$ be taken as $2 a^{2} / b$ for these cases, with the corresponding slenderness parameter being $D_{e} / t \varepsilon^{2}=2 a^{2} / b t \varepsilon^{2}$. The equivalent diameter for EHS in pure compression was refined by Ruiz-Terán and Gardner [7] - see Table 6 to achieve more accurate results over a range of section thicknesses and aspect ratios.

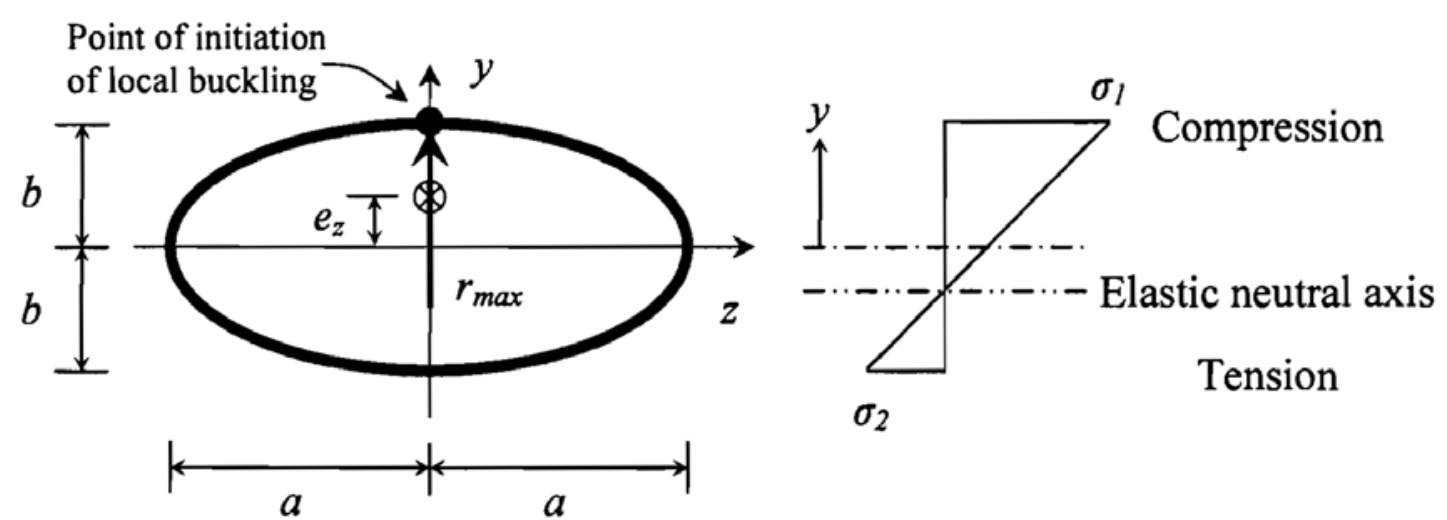

Figure 8. EHS under Combined Compression and Minor Axis Bending

For the case of an EHS under combined compression and minor axis bending, local buckling will clearly initiate at the same point as under compression or minor axis bending in isolation (i.e. the point of maximum radius of curvature); the equivalent diameter may therefore be given by Eq. 1 .

$D_{e, m i}=\frac{2 a^{2}}{b}$

\subsection{Slenderness Parameter of EHS under Compression and Major Axis Bending}

Under combined compression and major axis bending, the critical radius of curvature (i.e. the point of initiation of local buckling) will shift towards the centroidal axis as the compressive part of the loading increases. This shift can be derived as follows.

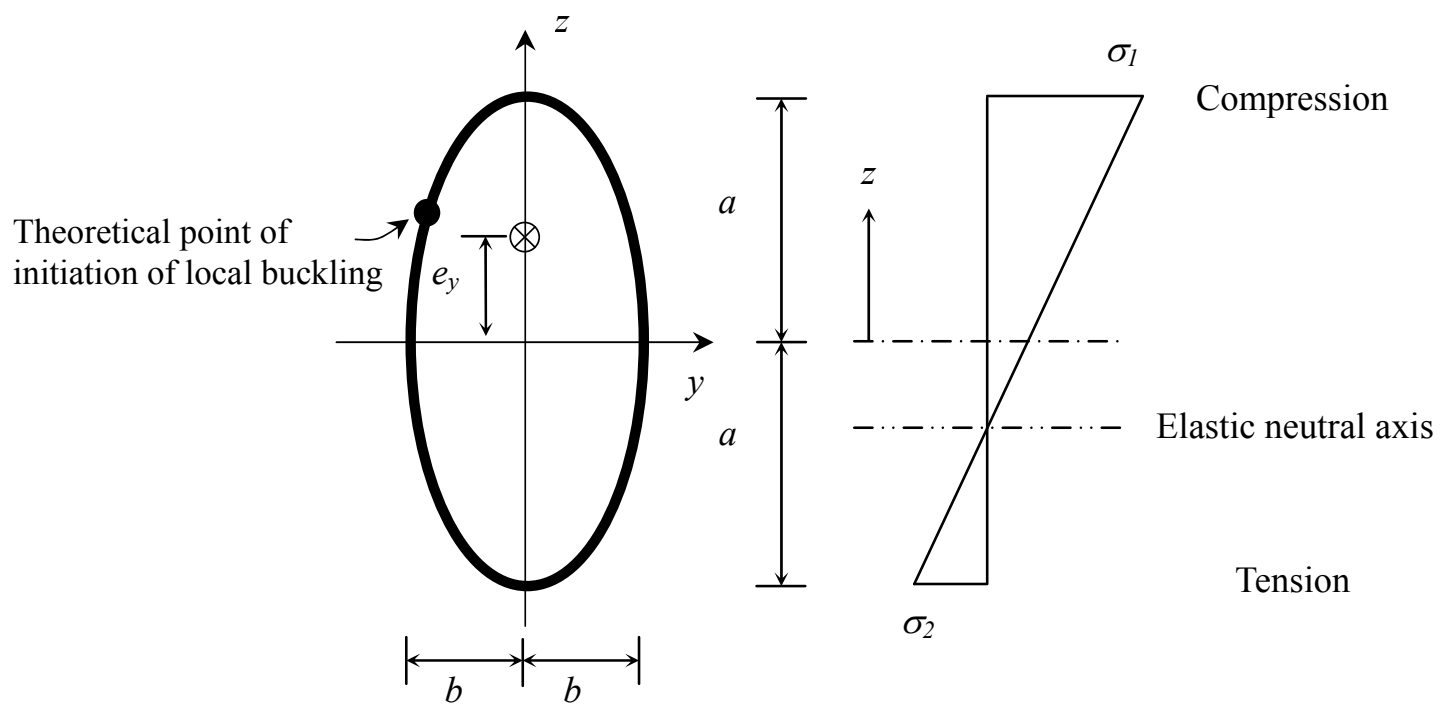

Figure 9. EHS under Combined Compression and Major Axis Bending 
From the general expression of the radius of curvature of an EHS and with reference to Figure 9, we have:

$$
r=\frac{a^{2}}{b}\left\{1-\left[1-\left(\frac{b}{a}\right)^{2}\right]\left(\frac{z}{a}\right)^{2}\right\}^{\frac{3}{2}}
$$

Assuming an elastic combination of compression plus bending, the stress at any location in the cross-section may be obtained from:

$$
\sigma=\frac{\sigma_{1}}{2 a}(\psi(a-z)+a+z)
$$

The location of the initiation of local buckling relative to the centroid of the section $z_{c r} / a$ occurs when the product $r \sigma$ (i.e. the product of Eqs. 2 and 3) is maximised. This yields:

$$
\frac{z_{c r}}{a}=\frac{1}{8(1-\psi)}\left(\sqrt{\left(9+\frac{16}{1-\frac{b^{2}}{a^{2}}}\right)\left(\psi^{2}+1\right)+2 \psi\left(9-\frac{16}{1-\frac{b^{2}}{a^{2}}}\right)}-3 \psi-3\right)
$$

where $\psi$ is the ratio of the end stresses given by:

$\psi=\frac{\sigma_{2}}{\sigma_{1}}$ and $-1 \leq \psi \leq 1$

The factor $\psi$, discussed further in Section 5, varies between 1 and -1 , with $\psi=1$ corresponding to pure compression and $\psi=-1$ corresponding to pure bending. Eq. 4 is plotted in Figure 10 for EHS with various $a / b$ ratios. From this figure it may be seen that for $\psi=1$, buckling initiates at $z / a=0$ (i.e. the point of maximum radius of curvature) for all aspect ratios. The position of initiation of buckling migrates up the section where the greater stresses exist as $\psi$ decreases. This migration is more rapid in sections of low aspect ratio where there is less variation in radius of curvature around the section.

The corresponding radius of curvature $r_{c r}$ (found by substituting $z=z_{c r}$ into Eq. 2), with the associated equivalent diameter $D_{e, m a}$ being two times this value:

$$
D_{e, m a}=\frac{2 a^{2}}{b}\left\{1-\left[1-\left(\frac{b}{a}\right)^{2}\right]\left(\frac{z_{c r}}{a}\right)^{2}\right\}^{\frac{3}{2}}
$$

Substituting Eq. 4 into Eq. 6, and assuming an aspect ratio $a / b=2$ yields the following direct relationship between $D_{e, m a}$ and $\psi$.

$$
D_{e, m a}=4 a\left(1-\frac{3}{256(1-\psi)^{2}}\left(\frac{1}{3} \sqrt{273 \psi^{2}+273-222 \psi}-3 \psi-3\right)^{2}\right)^{\frac{3}{2}}
$$




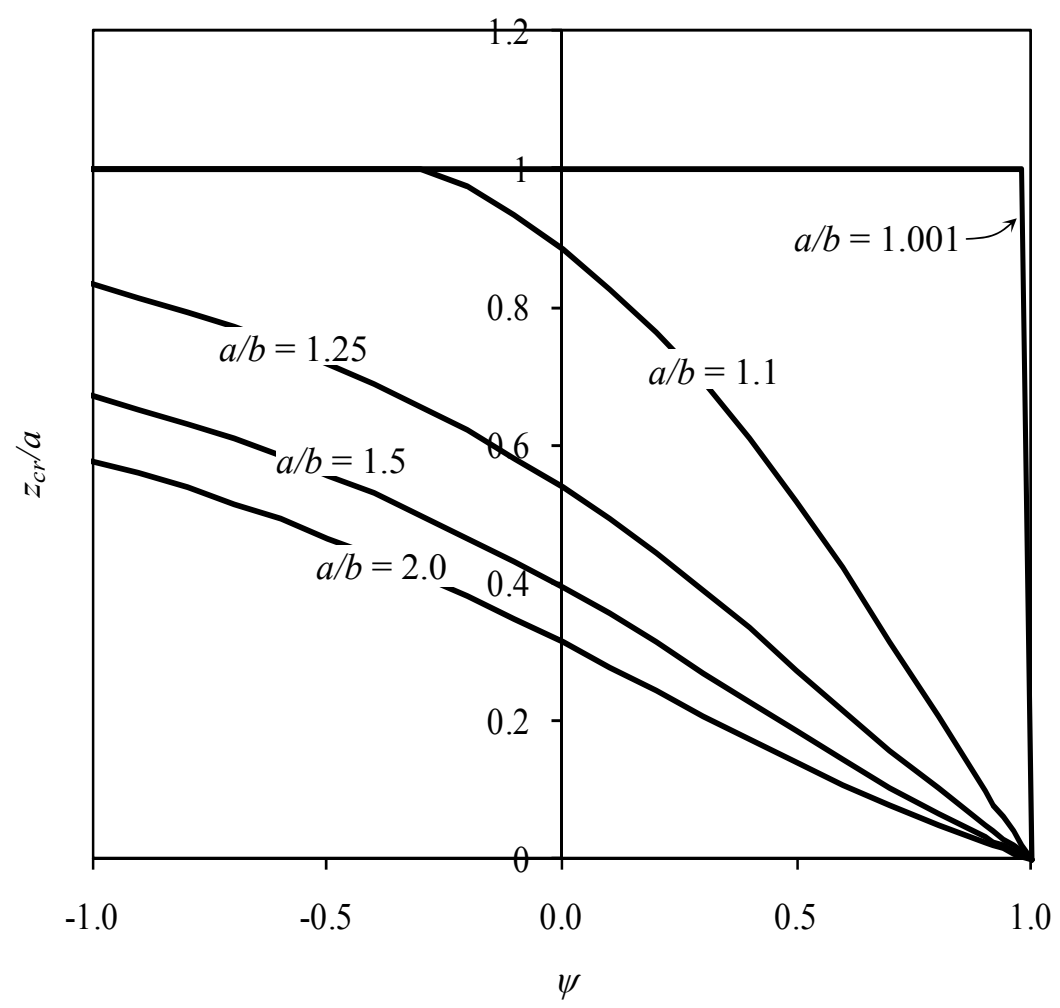

Figure 10. Variation of the Theoretical Position of the

Initiation of Local Buckling with Aspect Ratio $a / b$ and Stress Distribution $\psi$

Eq. 6 is plotted in Figure 11 to show the variation in equivalent diameter $D_{e, m a}$ with the stress ratio $\psi$ for a range of aspect ratios. A linear approximation to the transition in $D_{e, m a}$ with $\psi$ is shown in Figure 11 for $a / b=2.0$ (representing commercially available sections). The linear approximation is given by Eq. 8:

$D_{e, m a}=D_{e, b}+\left(D_{e, c}-D_{e, b}\right)\left(\frac{\psi+1}{2}\right)$

Note that the theoretical end points to Eq. 8, based on approximate elastic buckling arguments, are $D_{e, c}=2 a^{2} / b$ and $D_{e, b}=1.3 a^{2} / b$. However, as presented in Tables 6 and 7 and discussed earlier, these end points have been modified in previous studies based on more rigorous analysis and consideration of observed physical behaviour in tests. For pure compression, Ruiz-Terán and Gardner [7] proposed that $D_{e, c}$ could be taken as:

$D_{e, c}=2 a\left(1+f\left(\frac{a}{b}-1\right)\right), \quad f=1-2.3\left(\frac{t}{2 a}\right)^{0.6}$

though $D_{e, c}=2 a^{2} / b$ could also be conservatively adopted, while for pure bending, Chan and Gardner [4] proposed $D_{e, b}=0.8 a^{2} / b$ for $a / b>1.357$ and $D_{e, b}=2 b^{2} / a$ for $a / b \leq 1.357$. These end points, and a linear transition between them, are compared with equivalent diameters $D_{e, m a}$ obtained from the test and FE results reports herein (for intermediate values of $\psi$ ) and from the literature [3, 4] for pure compression $(\psi=1)$ and pure bending $(\psi=-1)$. The equivalent diameters were determined by comparing elliptical test and FE results with their circular counterparts and then modifying $D_{e}$ until the EHS results were mapped onto the corresponding CHS results. This process is shown schematically in Figure 12, and was carried out, with reference to the interaction expression given in Section 6, for all cases of combined compression plus bending. 


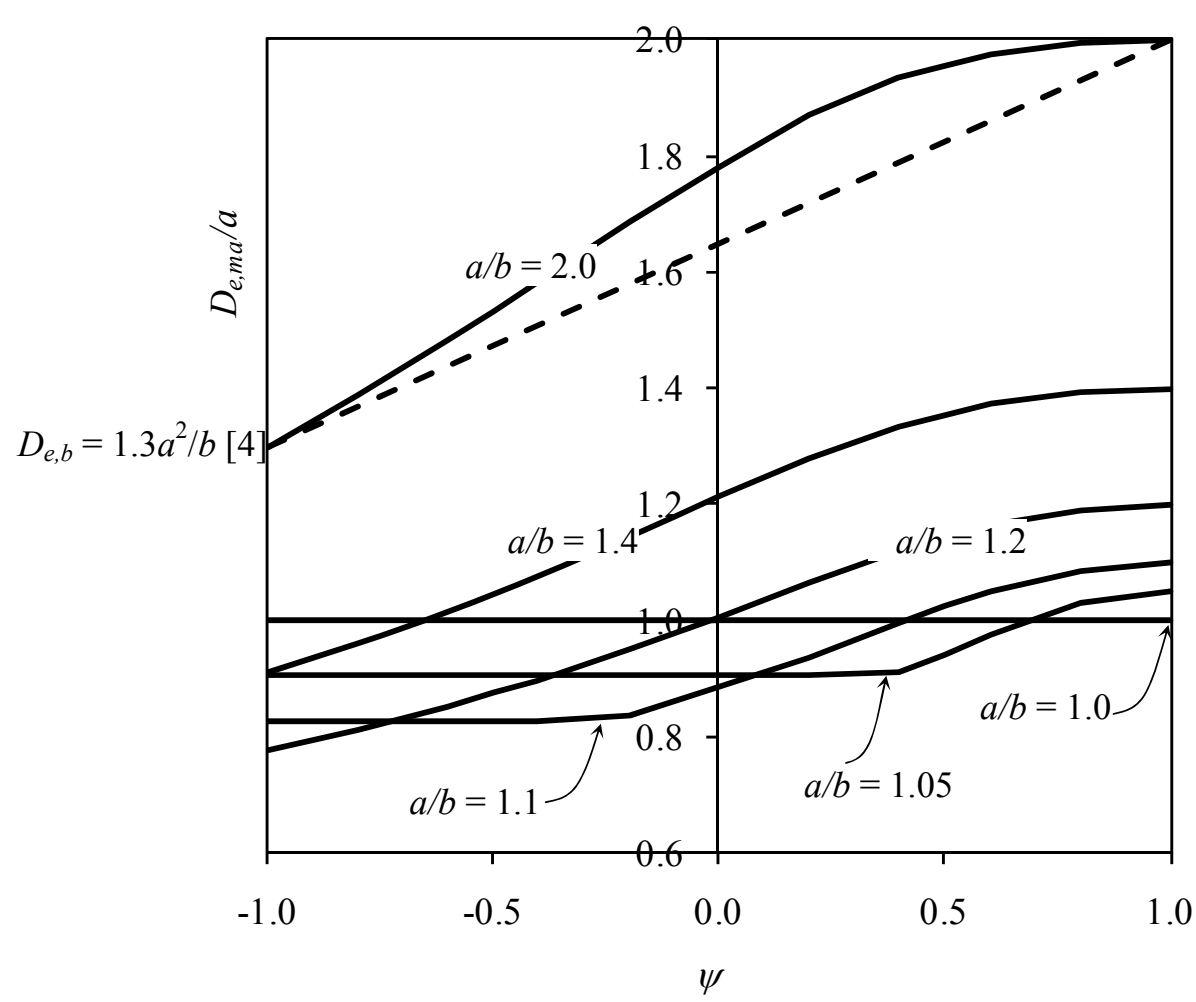

$D_{e, c}=2.0 a^{2} / b[3,28]$

Figure 11. Variation in the Theoretical Equivalent Diameter $D_{e}$ with Stress Ratio $\psi$ and Aspect Ratio $a / b$

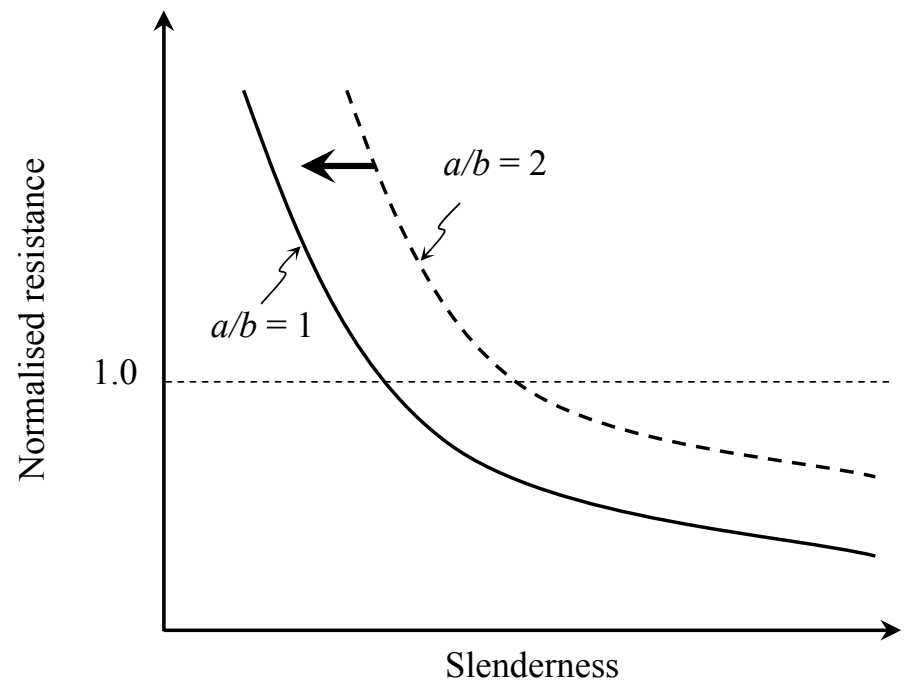

Figure 12. Determination of Equivalent Diameters from Test and FE Results

The obtained equivalent diameters are presented in Figure 13 and compared with the linear transition given by Eq. 8. Note that Figure 13 has two scales on the horizontal axis - the lower one (in terms of $\psi$ ) relates to an elastic stress distribution under combined loading while the upper one (in terms of $\alpha$ ) relates to a plastic stress distribution. The data points corresponding to these two axes were labelled 'elastic' and 'plastic'. For bending, the end point of Eq. 8 is taken as that proposed by Chan and Gardner [4] $-D_{e, b}=0.8 a^{2} / b$, while for compression, the simple $D_{e, c}=2 a^{2} / b$ and the more sophisticated expression of Ruiz-Terán and Gardner [7] are shown, the latter being a function of relative section thickness and is shown for an intermediate value of $t=5.8 \mathrm{~mm}$, which 
is the average section thickness from the parametric studies (with $2 a=150 \mathrm{~mm}$ and $2 b=75 \mathrm{~mm}$ ). The results indicate that the proposed equivalent diameter in bending is appropriate and the simple equivalent diameter in compression $\left(2 a^{2} / b\right)$ is safe but conservative, with more accurate results being obtained from the expression of Ruiz-Terán and Gardner [7]. The linear transition (Eq. 8) may also be seen to be appropriate and may be safely applied with either end point in compression. As described above, the horizontal axis for Figure 13 is also shown in terms of $\alpha$, which relates to the position of the plastic neutral axis and represents the proportion of the cross-section in compression assuming a plastic (rather than an elastic) stress distribution under combined loading. The corresponding data points show that a linear transition in slenderness between $D_{e, c}$ (for $\alpha=1$ ) and $D_{e, b}$ (for $\alpha=0.5$ ) with $\alpha$, given by Eq. 10 is also appropriate.

$$
D_{e, m a}=D_{e, b}+\left(D_{e, c}-D_{e, b}\right)(2 \alpha-1)
$$

Determination of the positions of both the elastic and plastic neutral axes for EHS under combined loading is discussed in Section 5.

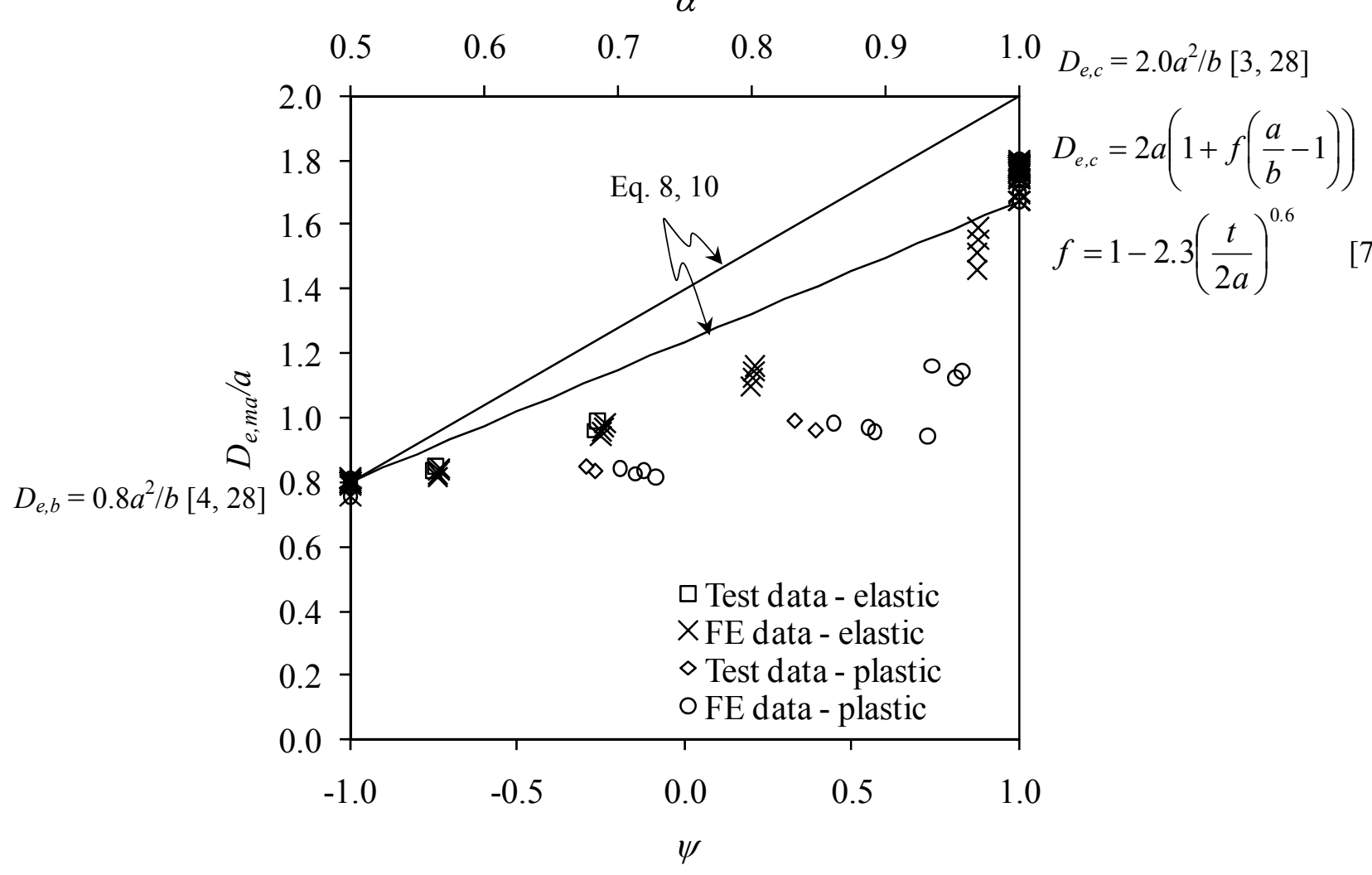

Figure 13. Variation in the Design Equivalent Diameter $D_{e, m a}$ with $\psi$ and $\alpha$ for EHS Cross-sections with $a / b=2.0$

\section{LOCATION OF THE NEUTRAL AXES UNDER COMBINED LOADING}

Location of the position of both the elastic and plastic neutral axes for EHS under combined axial compression and bending is described in this section. The primary focus of this section is on the case of compression plus major axis bending since, under combined compression and minor axis bending the position of the initiation of local buckling (and hence the slenderness parameter) is constant. The described approach may, however, be easily adapted to cover either case. Under combined loading, both the elastic and plastic neutral axes shift relative to their positions under 
bending alone. The particular geometry of an EHS complicates the process of determining this shift, particularly in the case of a plastic stress distribution.

\subsection{Elastic Neutral Axis}

Assuming an elastic stress distribution (i.e. prior to yielding), a cross-section will experience extreme fibre stresses, denoted $\sigma_{1}$ and $\sigma_{2}$, and a linear stress gradient between these points - see Figure 14. The axis of zero stress is termed the elastic neutral axis (ENA).

$$
\text { Compression Compression }
$$

Compression

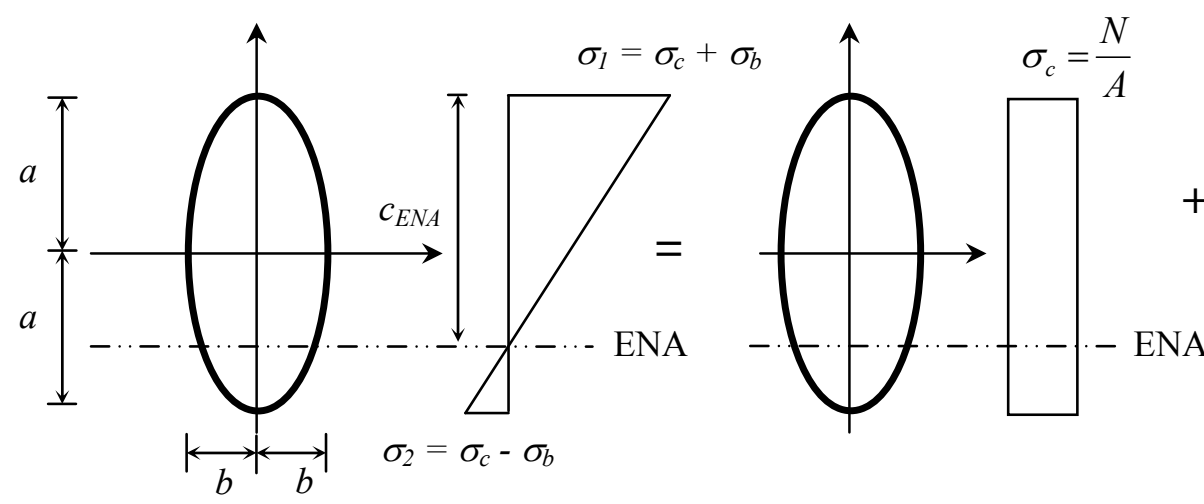

Tension

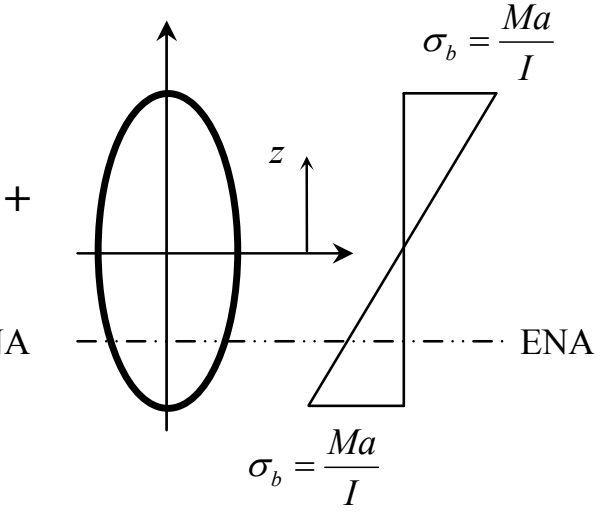

Tension

Figure 14. Elastic Stress Distribution in an EHS under Combined Compression and Major Axis Bending

The distance of the ENA from the top of the cross-section $c_{E N A}$ is given by:

$c_{E N A}=2 a\left(\frac{\sigma_{1}}{\sigma_{1}+\sigma_{2}}\right)=2 a\left(\frac{1}{1+\psi}\right)$

or, in terms of section geometry and applied loading,

$c_{E N A}=a\left(1+\frac{M_{E d}}{N_{E d}} \frac{A a}{I}\right)$

in which $N_{E d}$ is the applied axial compression, $M_{E d}$ is the applied major axis moment, $A$ is the cross-section area and $I$ is the major axis second moment of area. Location of the elastic neutral axis is relevant for Class 3 (and Class 4) cross-sections, whose capacities are determined on the basis of an elastic stress distribution.

\subsection{Plastic Neutral Axis}

An approximate method of locating the plastic neutral axis (PNA) in an EHS under combined compression plus major axis bending is described in this sub-section, with reference to Figure 15.

This area of cross-section in compression may alternatively be expressed as: 


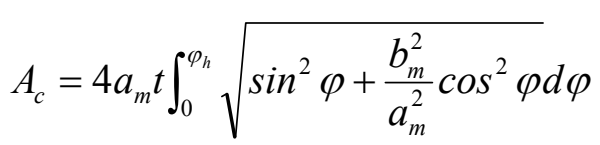

where $a_{m}$ and $b_{m}$ are the half larger and smaller diameters of the ellipse measured to the centreline of the wall thickness (i.e. $a_{m}=a-t / 2$ and $b_{m}=b-t / 2$ ) and $\varphi_{h}$ is defined in Figure 15.

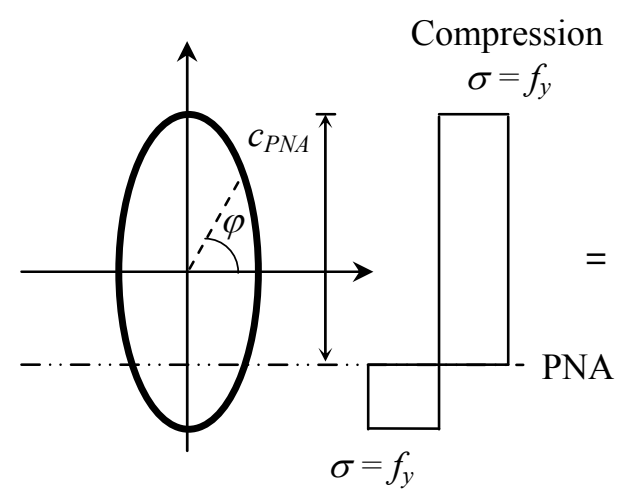

Tension

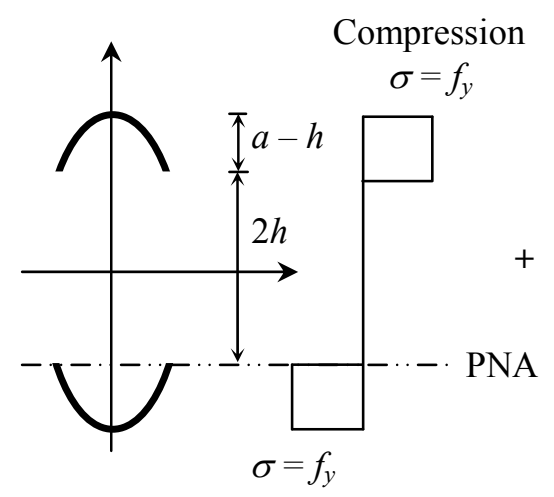

Tension

Figure 15. Plastic Stress Distribution in an EHS under

Combined Compression and Major Axis Bending

For an aspect ratio of 2 , the term $\left(b_{m} / a_{m}\right)^{2}$ ranges between 0.23 and 0.25 , depending on the section thickness. Hence, when considering EHS with an aspect ratio $a / b=2$, for simplicity, this term will be taken as constant value of 0.24. Combining Eqs. 13 and 14 therefore leads to:

$\frac{N_{E d}}{4 a_{m} t f_{y}}=\int_{0}^{\varphi_{h}} \sqrt{\sin ^{2} \varphi+0.24 \cos ^{2} \varphi} d \varphi$

The above integral has been evaluated for a range of values of $\varphi$, plotted in Figure 16 , for 0 to $\pi / 2$. The resulting normalised relationship between $N_{E d}$ and $\varphi_{h}$ may be approximately represented, for simplicity, by the cubic function given below, which has been added to Figure 16.

$\frac{\varphi_{h}}{\pi / 2}=0.25\left(\frac{N_{E d}}{4 a_{m} t f_{y}}\right)^{3}-0.72\left(\frac{N_{E d}}{4 a_{m} t f_{y}}\right)^{2}+1.33\left(\frac{N_{E d}}{4 a_{m} t f_{y}}\right) \quad$ for $a / b=2$

The radius of an ellipse (measure from the centre of the ellipse to its outer perimeter) may be determined at any point from:

$$
r(\varphi)=\frac{a}{1+\left(\frac{a}{b}-1\right) \cos \varphi}
$$


The compressed height $h$ may be calculated from simple geometry as $h=r\left(\varphi_{h}\right) \sin \varphi_{h}$ :

$$
h=\sin \varphi_{h} \frac{a}{1+\left(\frac{a}{b}-1\right) \cos \varphi_{h}}
$$

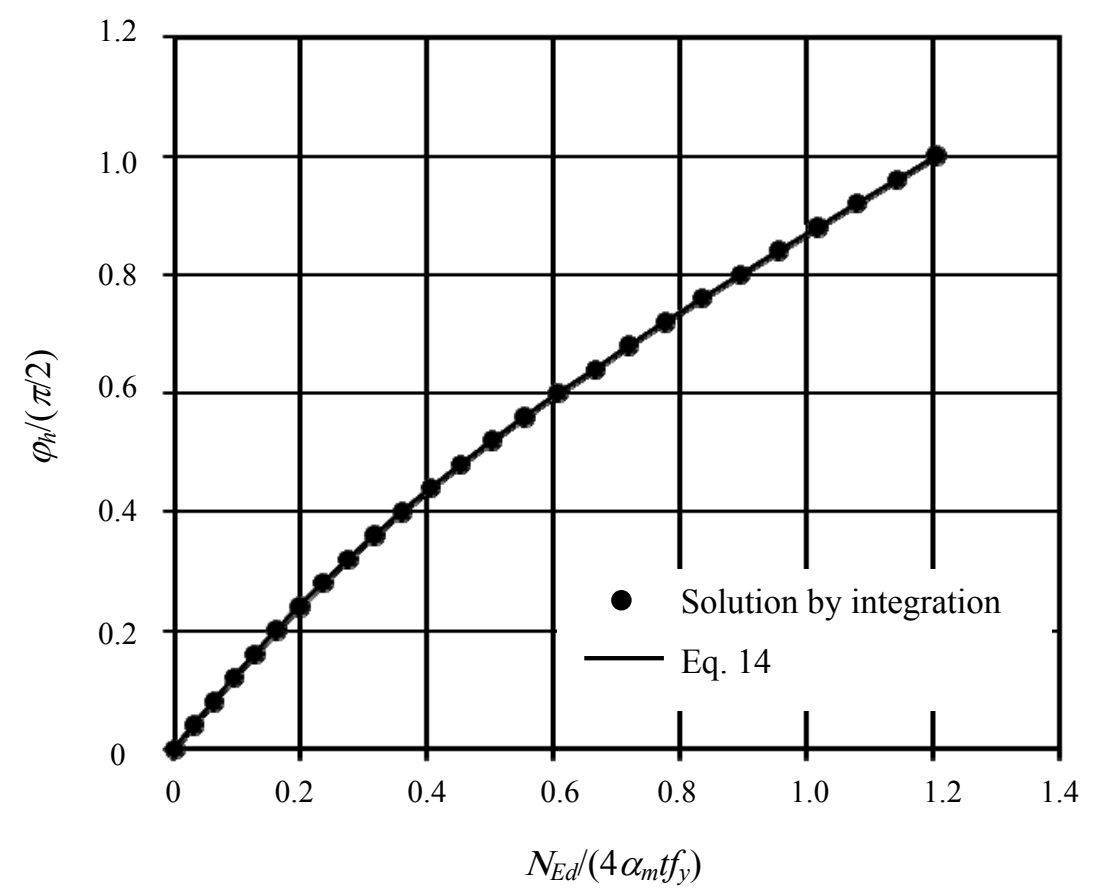

Figure 16. Normalised Relationship between $N$ and $\varphi_{h}$ for $a / b=2$

With reference to Figure 15, the distance from the extreme compressive fibre to the PNA of the cross-section $c_{P N A}$ may be expressed as:

$c_{P N A}=(a-h)+2 h \quad=a+h$

The proportion of the height of the cross-section that is in compression $\alpha_{m a}$ is therefore given by:

$\alpha_{m a}=\frac{c_{P N A}}{2 a}=\frac{1}{2}\left[1+\frac{\sin \varphi_{h}}{1+\left(\frac{a}{b}-1\right) \cos \varphi_{h}}\right]$

where $\varphi_{h}$ may be determined from Eq. 16 .

The same procedure may be repeated for compression plus minor axis bending, yielding a compressed proportion of section $\alpha_{m i}$ of: 
$\alpha_{m i}=\frac{c_{P N A}}{2 b}=\frac{1}{2}\left[1+\frac{\cos \varphi_{h}}{1+\left(\frac{b}{a}-1\right) \sin \varphi_{h}}\right]$

\section{SLENDERNESS LIMITS UNDER COMBINED LOADING}

Cross-sections are placed into discrete behavioural classes based upon their susceptibility to local buckling. The limits of these classes provided in BS 5950-1 [23], ANSI/AISC 360-05 [24], AISC [25], AS 4100 [26] and EN 1993-1-1 [27] were presented in Tables 6 and 7 for CHS sections subjected to pure compression and pure bending. The limits proposed for EHS by Chan and Gardner [3, 4] and Ruiz-Terán and Gardner [7] are also shown. Classification limits for combined axial compression and bending are addressed in this section.

\subsection{Class 3 Slenderness Limit}

In bending, Class 3 cross-sections are those capable of reaching their elastic moment resistance $M_{e l}$, but local buckling prevents attainment of the plastic moment resistance $M_{p l}$. For Class 4 cross-sections, local buckling occurs prior to yielding and resistance is determined on the basis of an effective cross-section.

Under combined axial compression and bending, Class 3 cross-sections must satisfy:

$\frac{N_{E d}}{N_{c, R d}}+\frac{M_{E d}}{M_{e l, R d}} \leq 1.0$

where $N_{E d}$ is the applied axial load (taken as the ultimate load $N_{u}$ from the test or FE model), $N_{c, R d}$ is the yield resistance of the cross-section $\left(A f_{y}\right), M_{E d}$ is the applied bending moment about either the major or minor axis (taken as the moment $\left(M_{1+2}=N_{u}\left(e+\delta_{m i d}\right)\right)$ corresponding to $N_{u}$ from the test or FE model) and $M_{e l, R d}$ is the elastic bending resistance ( $W_{e l} f_{y}$, where $W_{e l}$ is the elastic section modulus) about the corresponding axis. The test and FE results for compression plus bending about the minor axis are plotted in Figure 17, while the results for compression plus bending about the major axis are shown in Figure 18. The equivalent diameters under combined loading have been determined, as proposed in Section 4, from Eq. 1 for compression plus minor axis bending and Eq. 8 for compression plus major axis bending. The value of $\psi$ has been calculated for each load eccentricity. The slenderness limits for pure compression $\left(D_{e} / t \varepsilon^{2}=90\right)$ and pure bending $\left(D_{e} / t \varepsilon^{2}=\right.$ 140) have been added to the figures.

A value of $\left(N_{E d} / N_{c, R d}+M_{E d} / M_{e l, R d}\right)$ greater than unity represents meeting of the Class 3 requirement, whilst a value less than unity indicates a Class 4 cross-section. 


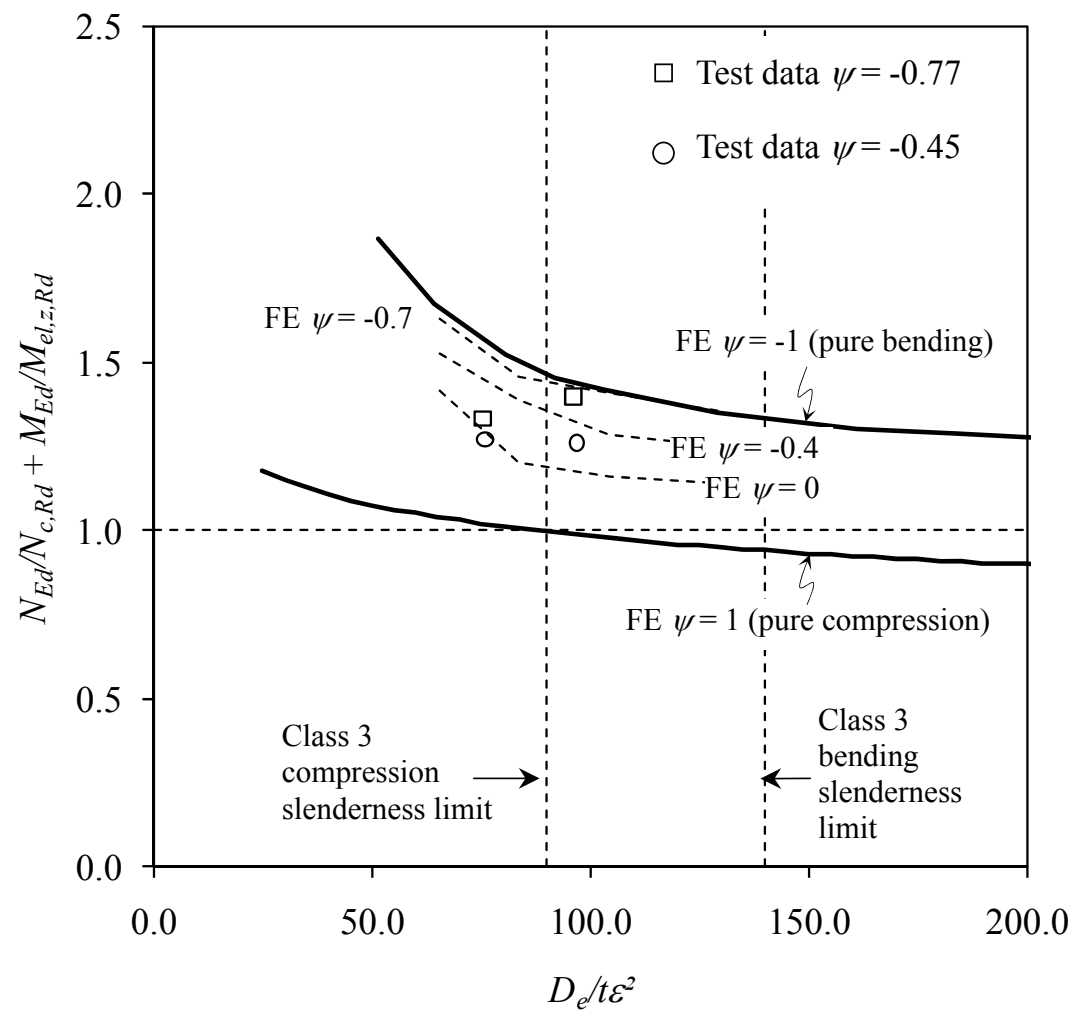

Figure 17. Normalised Resistance under Combined Compression Plus Minor Axis Bending Versus Cross-section Slenderness for EHS with $a / b=2$

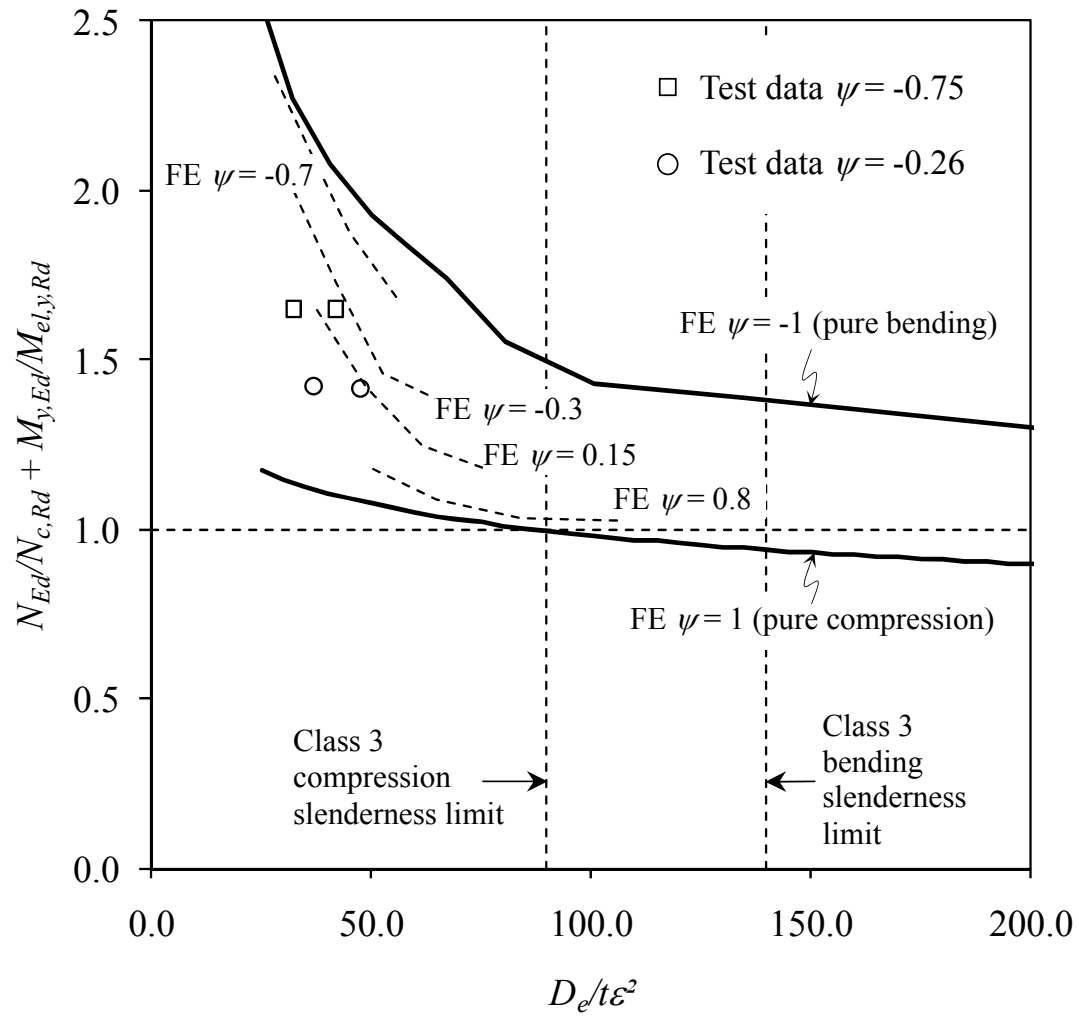

Figure 18. Normalised Resistance under Combined Compression Plus Major Axis Bending Versus Cross-section Slenderness for EHS with $a / b=2$ 
The results from both Figures 17 and 18 indicate a clear transition in structural response as $\psi$ varies from 1 to -1 ; i.e. the normalised resistance $\left(N_{E d} / N_{c, R d}+M_{E d} / M_{e l, R d}\right)$ reduces as the compressed portion of the section, measured through $\psi$ increases. Although not clearly exhibited by the data, the transition in slenderness limit with $\psi$ will be conservatively assumed to be linear (as with other cross-section types in current design standards such as EN 1993-1-1 [27]) leading to:

$$
\frac{D_{e}}{t \varepsilon^{2}}=\frac{2520}{5 \psi+23}
$$

\subsection{Class 1 and 2 Slenderness Limits}

In bending, Class 1 and 2 cross-sections are those capable of reaching their plastic bending moment resistance $M_{p l}$ with the distinction between the two classes made on the basis of rotation capacity. Under combined compression and bending, a cross-section is deemed to be Class 2 (or better) if the fully plastic resistance given by Eq. 24 is exceeded. This expression was derived by Nowzartash and Mohareb [32] and is discussed further in Section 7.2.

$$
2\left(\frac{N_{E d}}{N_{c, R d}}\right)^{1.75}-\left(\frac{N_{E d}}{N_{c, R d}}\right)^{3.5}+\left(\frac{M_{y, E d}}{M_{p l, y, R d}}\right)^{2}+\left(\frac{M_{z, E d}}{M_{p l, z, R d}}\right)^{1.7} \leq 1.0
$$

Figure 19 presents the test and FE results for compression plus major axis bending generated herein on a graph of normalised plastic resistance under combined loading (Eq. 24) versus cross-section slenderness. A value of greater than unity on the vertical axis represents meeting of the requirement for a Class 2 cross-section. For each test and FE model, the compressed proportion of the section $\alpha$ was determined from the loading eccentricity as indicated by Eqs. 20 and 21. In a similar manner to Figures 17 and 18, Figure 19 indicates that there is a transition in slenderness limit with $\alpha$; the higher the value of $\alpha$ (i.e. the greater the proportion of the cross-section in compression), the lower the normalised plastic resistance and the stricter the slenderness limits that is indicated. However, although this transition is apparent, it is proposed to maintain the same Class 2 slenderness limit of $D_{e} / t \varepsilon^{2}=70$ for both compression and bending, and thus, while the slenderness measure varies with $\alpha$ (for compression plus major axis bending), as discussed in Section 4.3, the limit itself does not. This proposal, made for both compression plus major axis bending and compression plus minor axis bending, is in line with the treatment of CHS in EN 1993-1-1 [27]. The same approach is proposed for Class 1 sections, again in line with EN 1993-1-1 [27], with a fixed slenderness limit of $D_{e} / t \varepsilon^{2}=50$. 


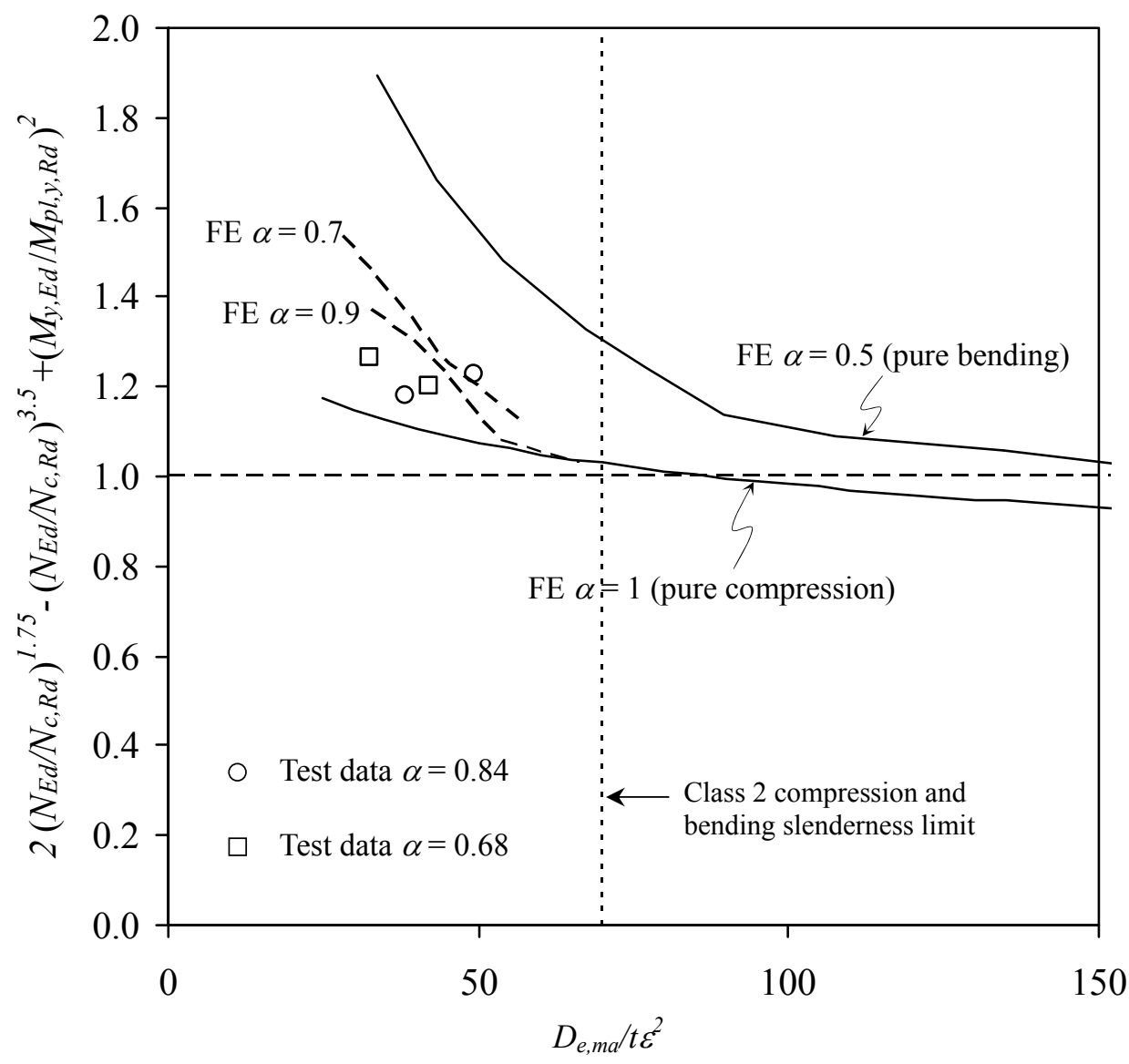

Figure 19. Normalised Plastic Resistance for Combined Compression and Major Axis Bending Versus Cross-section Slenderness for EHS with $a / b=2$

Table 8 summarises the proposed slenderness parameters and classification limits for EHS under combined compression and uniaxial bending determined in Sections 4.3 and 6.1.

Table 8. Summary of Slenderness Parameters and Classification Limits for EHS under Combined Compression and Uniaxial Bending.

\begin{tabular}{c|c|c}
\hline $\begin{array}{c}\text { Cross-section } \\
\text { classification }\end{array}$ & $\begin{array}{c}\text { Proposed } \\
\text { slenderness limits }\end{array}$ & $\begin{array}{c}\text { Cross-section slenderness } \\
\text { Parameter }\end{array}$ \\
\hline Class 1 & $50 \varepsilon^{2}$ & $\begin{array}{c}\text { Compression plus minor }(z-z) \text { axis bending: } \\
D_{e, m i}=\frac{2 a^{2}}{b}\end{array}$ \\
\hline Class 2 & $70 \varepsilon^{2}$ & $\begin{array}{c}\text { Compression plus major }(y-y) \text { axis bending: } \\
D_{e, m a}=D_{e, b}+\left(D_{e, c}-D_{e, b}\right)(2 \alpha-1)\end{array}$ \\
\hline Class 3 & $\frac{2520 \varepsilon^{2}}{5 \psi+23}$ & Compression plus minor $(\mathrm{z}-\mathrm{z})$ axis bending: \\
& & $D_{e, m i}=\frac{2 a^{2}}{b}$ \\
& & Compression plus major $(y-y)$ axis bending: \\
& $D_{e, m a}=D_{e, b}+\left(D_{e, c}-D_{e, b}\right)\left(\frac{\psi+1}{2}\right)$ \\
\hline
\end{tabular}

$\varepsilon=\left(235 / f_{y}\right)^{0.5}=0.81$ for $f_{y}=355 \mathrm{~N} / \mathrm{mm}^{2}$ 


\section{RESISTANCE UNDER COMBINED LOADING}

Based on the above proposals for cross-section classification, the test and FE results are now compared with their respective interaction expressions to assess their suitability for design.

\subsection{Class 3 and Class 4 Cross-sections}

Current design standards (BS 5950-1:2000 [23], ANSI/AISC 360-05 [24] and EN 1993-1-1:2005 [27]) specify a linear interaction between compression and bending for Class 3 and Class 4 cross-sections. This is also applicable as a conservative treatment for Class 1 and 2 cross-sections. For Class 3 sections, the linear interaction may be expressed as:

$\frac{N_{E d}}{N_{c, R d}}+\frac{M_{y, E d}}{M_{p l, y, R d}}+\frac{M_{z, E d}}{M_{p l, z, R d}} \leq 1.0$

For Class 4 sections, the resistances are calculated on the basis of effective sections properties to allow for the occurrence of local buckling prior to yielding:

$$
\frac{N_{E d}}{N_{c, e f f, R d}}+\frac{M_{y, E d}}{M_{e f f, y, R d}}+\frac{M_{z, E d}}{M_{e f f, z, R d}} \leq 1.0
$$

In these expressions $M_{y, E d}$ and $M_{z, E d}$ are the design bending moments about the major $(y-y)$ and minor $(z-z)$ axes, respectively (where $M_{y, E d}=0$ signifies uniaxial minor axis bending only and $M_{z, E d}$ $=0$ major axis bending only), $M_{e l, y, R d}=W_{e l, y} f_{y}$ and $M_{e l, z, R d}=W_{e l, z} f_{y}$ are the design elastic bending resistance about the major $(y-y)$ and minor $(z-z)$ axes, respectively, $M_{\text {eff, }, R d}=W_{\text {eff,y }} f_{y}$ and $M_{\text {eff }, z, R d}=$ $W_{\text {eff, } z} f_{y}$ are the elastic bending resistances about the major $(y-y)$ and minor $(z-z)$ axes, respectively, based on effective section properties, $N_{E d}$ is the design axial force and $N_{c, R d}=A f_{y}$ and $N_{\text {eff, } R d}=A_{\text {eff } f y}$ are the design cross-section resistances under uniform compression based on the gross and effective section areas, respectively. Expressions for determining the effective area (Eq. 27) and effective section modulus (Eq. 28) of EHS have been developed (Chan and Gardner [3, 4], based on modification of the corresponding expressions for CHS given in BS 5950-1 [23].

$$
\begin{aligned}
& A_{e f f}=A\left[\frac{90}{D_{e} / t} \frac{235}{f_{y}}\right]^{0.5} \\
& W_{e f f}=W_{e l}\left[\frac{140}{D_{e} / t} \frac{235}{f_{y}}\right]^{0.25}
\end{aligned}
$$

FE results for EHS with Class 3 cross-sections are compared with the linear elastic interaction curve defined by Eq. 25 in Figure 20; none of the test specimens were Class 3 under combined loading. The graph shows that the linear interaction provides a safe prediction of the FE results and is therefore suitable for design purposes. 


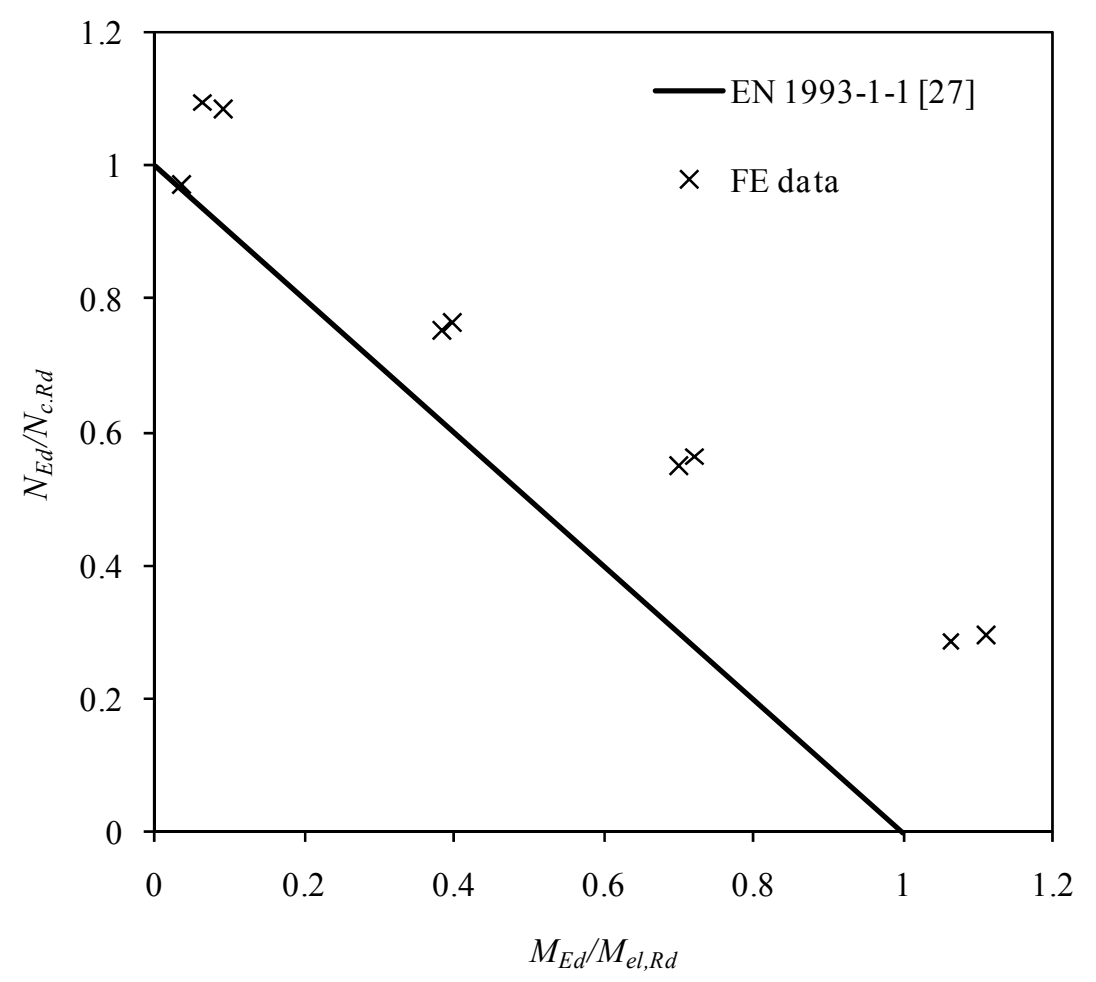

Figure 20. Comparison of Test and FE Results (for Class 3 Cross-sections) with Elastic Interaction Curve for Combined Compression and Bending (about the Major or Minor Axis)

\subsection{Class 1 and Class 2 Cross-sections}

A fully plastic interaction surface for Class 1 and 2 EHS under combined axial compression plus bending has been developed by Nowzartash and Mohareb [32], and is given by Eq. 29.

$2\left(\frac{N_{E d}}{N_{c, R d}}\right)^{1.75}-\left(\frac{N_{E d}}{N_{c, R d}}\right)^{3.5}+\left(\frac{M_{y, E d}}{M_{p l, y, R d}}\right)^{2}+\left(\frac{M_{z, E d}}{M_{p l, z, R d}}\right)^{1.7} \leq 1.0$

where $M_{p l, y, R d}=W_{p l, y} f_{y}$ and $M_{p l, z, R d}=W_{p l, z} f_{y}$ are the design plastic bending resistance about the major and minor axes, respectively.

The results of the test and FE for EHS with Class 1 and 2 cross-sections have been plotted, together with the plastic interaction curve defined by Eq. 29, in Figure 21. The curves may be seen to generally provide safe-side predictions of the test and FE data for both compression plus minor axis bending (Figure 21(a)) and compression plus major axis bending (Figure 21(b), and are therefore recommended for design purposes. It may also be seen that the resistances of the more stocky sections are considerably in excess of the fully plastic resistance, particularly for the case of compression plus major axis bending; this is attributed to the additional capacity resulting from strain hardening. A summary of the resistances of EHS under combined compression and uniaxial bending for all cross-sectional classes is presented in Table 9. 


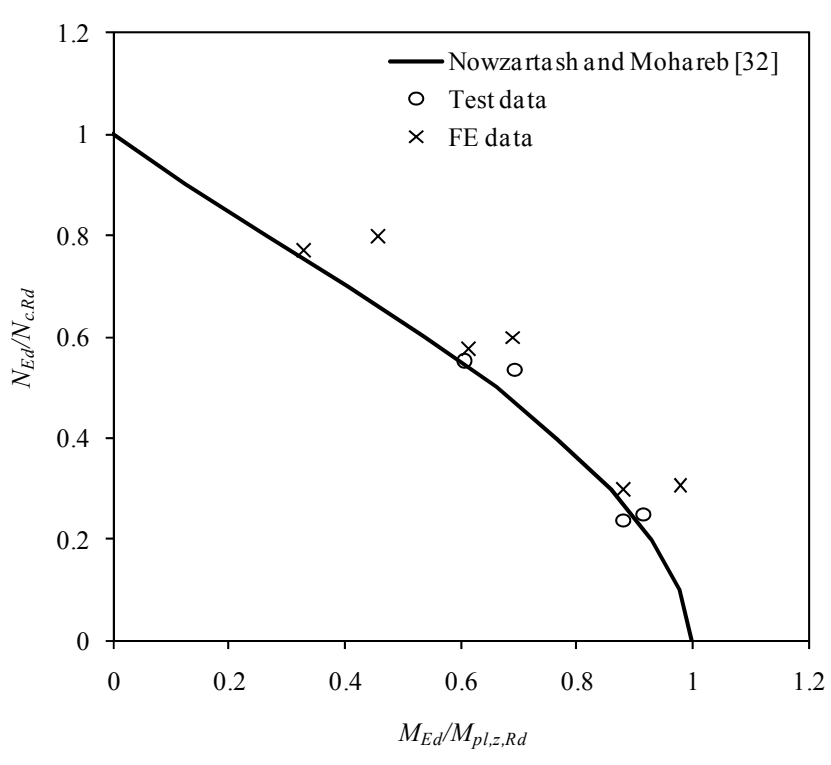

(a) Compression Plus Minor Axis Bending

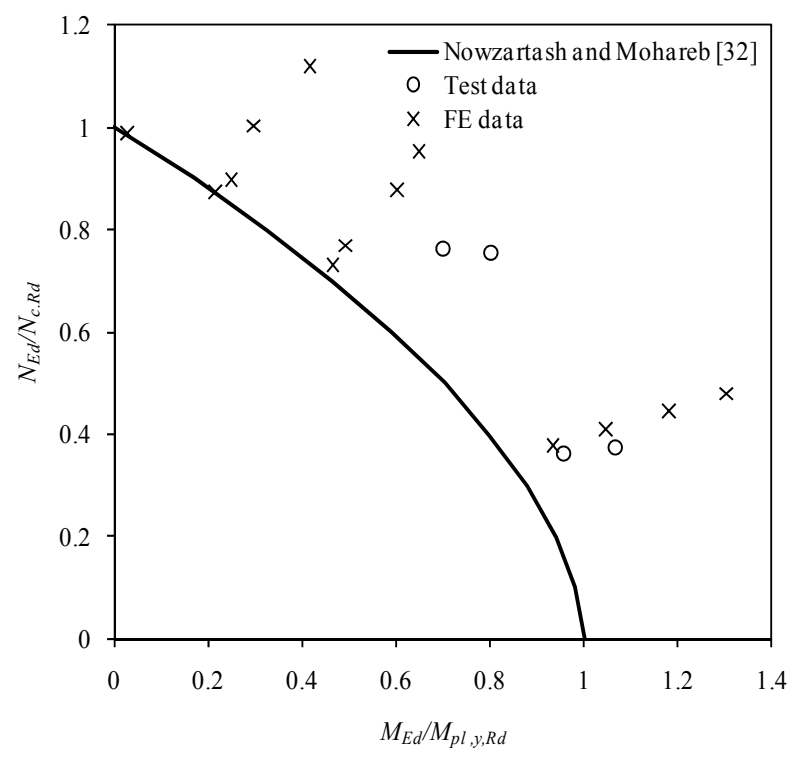

(b) Compression Plus Major Axis Bending

Figure 21. Comparison of Test and FE Results (for Class 1 and 2 Cross-sections) with Plastic Interaction Curves for Combined Compression and Bending

Table 9. Summary of Interaction Formulae for EHS under Combined Compression and Uniaxial Bending

Cross-section classification

Cross-section resistance under combined compression and uniaxial bending

Class 1 and Class 2

$$
2\left(\frac{N_{E d}}{N_{c, R d}}\right)^{1.75}-\left(\frac{N_{E d}}{N_{c, R d}}\right)^{3.5}+\left(\frac{M_{y, E d}}{M_{p l, y, R d}}\right)^{2}+\left(\frac{M_{z, E d}}{M_{p l, z, R d}}\right)^{1.7} \leq 1.0
$$

Class 3

$$
\frac{N_{E d}}{N_{c, R d}}+\frac{M_{y, E d}}{M_{p l, y, R d}}+\frac{M_{z, E d}}{M_{p l, z, R d}} \leq 1.0
$$

Class 4

$$
\frac{N_{E d}}{N_{c, e f f, R d}}+\frac{M_{y, E d}}{M_{e f f, y, R d}}+\frac{M_{z, E d}}{M_{e f f, z, R d}} \leq 1.0
$$

\section{CONCLUSIONS}

The cross-section response of hot-finished elliptical hollow sections (EHS) under combined compression and uniaxial bending has been examined in this study. A total of four tensile coupon tests, four stub columns tests under pure compression and eight under eccentric compression (four about the minor axis and four about the major axis) were performed. Various load eccentricities were considered to vary the proportion of axial load to bending moment. The key material properties, geometric measurements and test results have been reported. Further structural performance data were generated though a parallel finite element study. Equivalent diameters for EHS under compression and uniaxial bending and the corresponding cross-section slenderness limits were derived. On the basis of the experimental and numerical results, fully plastic interaction formulae for Class 1 and 2 cross-sections and an elastic interaction formula for Class 3 
cross-sections were assessed and found to provide safe predictions of the observed physical response. These interaction expressions are therefore recommended for design.

\section{ACKNOWLEDGEMENTS}

The authors would like to thank Corus Tubes for the supply of test specimens, and Colin Banks, Michael Davies and Ryan Griffith (University of Warwick) for their assistance with the experiments, and Dimitrios Moutaftsis for his contribution to the paper.

\section{REFERENCES}

[1] Corus, "Celsius ${ }^{\circledR} 355$ Ovals", Corus Tubes - Structural \& Conveyance Business, 2006.

[2] Viñuela-Rueda, L. and Martinez-Salcedo, J., "Steel Structure and Prestressed Façade of the New Terminal Building”, Hormigon Acero, 2006, Vol. 239, No. 1, pp. 71-84.

[3] Chan, T.M. and Gardner, L., "Compressive Resistance of Hot-rolled Elliptical Hollow Sections", Engineering Structures, 2008, Vol. 30, No. 2, pp. 522-532.

[4] Chan, T.M. and Gardner, L., "Bending Strength of Hot-rolled Elliptical Hollow Sections", Journal of Constructional Steel Research, 2008, Vol. 64, No. 9, pp. 971-986.

[5] Gardner L. and Chan T. M., "Cross-section Classification of Elliptical Hollow Sections", Steel and Composite Structures, 2007, Vol. 7, No. 3, pp. 185-200.

[6] Zhu, Y. and Wilkinson, T., "Finite Element Analysis of Structural Steel Elliptical Hollow Sections in Pure Compression", Proceedings of the 11th International Symposium on Tubular Structures, Québec City, Canada, 2006, pp. 179-186.

[7] Ruiz-Terán, A.M. and Gardner, L., "Elastic Buckling of Elliptical Tubes", Thin-Walled Structures, 2008, Vol. 46, No. 11, pp. 1304-1318.

[8] Silvestre, N., "Buckling Behaviour of Elliptical Cylindrical Shells and Tubes under Compression", International Journal of Solids and Structures, 2008, Vol. 45, No. 16, pp.4427-4447.

[9] Roufegarinejad, A. and Bradford, M.A., "Local Buckling of Thin-walled Elliptical Tubes Containing an Elastic Infill", Proceedings of the 3rd International Conference on Steel and Composite Structures, Manchester, United Kingdom, 2007, pp. 943-948.

[10] Zhao, X.L., Lu, H. and Galteri, S., "Tests of Elliptical Hollow Sections Filled with SCC (Self-Compacting Concrete)", Proceedings of the 5th International Conference on Advances in Steel Structures, Singapore, 2007, pp. 950-955.

[11] Yang, H., Lam, D. and Gardner, L., "Testing and Analysis of Concrete-filled Elliptical Hollow Sections", Engineering Structures, 2008, Vol. 30, No. 12, pp. 3771-3781.

[12] Zhao, X.L. and Packer, J.A., "Tests and Design of Concrete-filled Elliptical Hollow Section Stub Columns", Thin-Walled Structures, 2009, Vol. 47, No. 6-7, pp. 617-628.

[13] Bortolotti, E., Jaspart, J.P., Pietrapertosa, C., Nicaud, G., Petitjean, P.D. and Grimault, J.P., "Testing and Modelling of Welded Joints between Elliptical Hollow Sections", Proceedings of the 10th International Symposium on Tubular Structures, Madrid, Spain, 2003, pp. 259-266.

[14] Choo, Y.S., Liang, J.X. and Lim, L.V., "Static Strength of Elliptical Hollow Section X-joint under Brace Compression", Proceedings of the 10th International Symposium on Tubular Structures, Madrid, Spain, 2003, pp. 253-258.

[15] Pietrapertosa, C. and Jaspart, J.P., "Study of the Behaviour of Welded Joints Composed of Elliptical Hollow Sections", Proceedings of the 10th International Symposium on Tubular Structures, Madrid, Spain, 2003, pp. 601-608. 
[16] Willibald, S., Packer, J.A. and Martinez-Saucedo, G., "Behaviour of Gusset Plate Connections to Ends of Round and Elliptical Hollow Structural Section Members", Canadian Journal of Civil Engineering, 2006, Vol. 33, No. 4, pp. 373-383.

[17] Corus, "Celsius ${ }^{\circledR} 355$ Ovals - Sizes and Resistances Eurocode Version”, Corus Tubes Structural \& Conveyance Business, 2006.

[18] European Committee for Standardization (CEN), "Metallic Materials - Tensile Testing - Part 1: Method of Test at Ambient Temperature", EN 10002-1, 2001.

[19] Rasmussen, K.J.R., "Compression Tests of Stainless Steel Tubular Columns", Investigation Report S770, Centre for Advanced Structural Engineering, University of Sydney, 1990.

[20] Gardner, L. and Nethercot, D.A., "Experiments on Stainless Steel Hollow Sections - Part 1: Material and Cross-sectional Behaviour", Journal of Constructional Steel Research, 2004, Vol. 60, No. 9, pp. 1291-1318.

[21] Fujimoto, T., Mukai, A., Nishiyama, I. and Sakino, K., "Behavior of Eccentrically Loaded Concrete-filled Steel Tubular Columns", Journal of Structural Engineering, ASCE, 2004, Vol. 130, No. 2, pp. 203-212.

[22] ABAQUS. ABAQUS, Version 6.9-1, Pawtucket (USA): Hibbit, Karlsson \& Sorensen, Inc.; 2009.

[23] British Standard, "Structural Use of Steelwork in Building, Part1: Code of Practice for Design - Rolled and Welded Sections", BS 5950-1, BSI, 2000.

[24] American Institute of Steel Construction, Inc. (AISC), "Specification for Structural Steel Buildings", ANSI/AISC 360-05, 2005.

[25] American Institute of Steel Construction, Inc. (AISC), "Load and Resistance Factor Design Specification for Steel Hollow Structural Sections", AISC, 2000.

[26] Australian Standard, "Steel Structures", Standards Australia, Homebush, New South Wales, Australia, AS 4100, 1998.

[27] European Committee for Standardization (CEN), "Eurocode 3: Design of Steel Structures Part 1-1: General Rules and Rules for Buildings", EN 1993-1-1, 2005.

[28] Kempner, J., "Some Results on Buckling and Postbuckling of Cylindrical Shells", Collected Papers on Instability of Shell Structures, NASA TND-1510, 1962, pp. 173-186.

[29] Hutchinson, J.W., "Buckling and Initial Postbuckling Behaviour of Oval Cylindrical Shells under Axial Compression”, Journal of Applied Mechanics, 1968, Vol. 35, No. 1, pp. 66-72.

[30] Gerard, G. and Becker, H., "Handbook of Structural Stability: Part III - Buckling of Curved Plates and Shells", NACA Technical Note 3783, 1957.

[31] SCI/BSCA, "Steel Building Design: Design Data in Accordance with Eurocodes and the UK National Annexes", The Steel Construction Institute and British Constructional Steelwork Association, SCI Publication, 2008, pp. 363.

[32] Nowzartash, F. and Mohareb, M., "Plastic Interaction Relations for Elliptical Hollow Sections", Thin-Walled Structures, 2009, Vol. 47, No. 6-7, pp. 681-691. 


\title{
LOCAL / DISTORTIONAL / GLOBAL MODE COUPLING IN FIXED LIPPED CHANNEL COLUMNS: BEHAVIOUR AND STRENGTH
}

\author{
Pedro B. Dinis ${ }^{1}$, Dinar Camotim ${ }^{1,}$, Eduardo M. Batista ${ }^{2}$ and Eliane Santos ${ }^{2}$ \\ ${ }^{1}$ Department of Civil Engineering and Architecture, ICIST/IST, Technical University of Lisbon, Portugal \\ ${ }^{2}$ Civil Engineering Program, COPPE, Federal University of Rio de Janeiro, Brazil \\ *(Corresponding author: E-mail: dcamotim@civil.ist.utl.pt)
}

\begin{abstract}
This paper reports the available results of an ongoing numerical and experimental investigation on the post-buckling behaviour and strength of fixed-ended cold-formed steel lipped channel columns affected by local/distortional/global (flexural-torsional) mode interaction. Initially, ABAQUS shell finite element results concerning columns exhibiting identical local, distortional and global buckling loads (their geometries are identified through preliminary buckling analyses) are presented and discussed - otherwise identical columns containing critical-mode initial geometrical imperfections with different configurations are analysed. These numerical results include (i) elastic and elastic-plastic post-buckling equilibrium paths, (ii) curves and figures providing the evolution, along a given path, of the column deformed configuration and (iii) the characterisation of the column collapse mechanism. Then, the paper addresses the experimental investigation currently under way at COPPE (Federal University of Rio de Janeiro) and to be fully reported in the near future experimental and numerical results concerning one test are presented and discussed. Finally, the paper closes with some preliminary considerations concerning the applicability of the current Direct Strength Method (DSM) expressions to estimate the ultimate strength of cold-formed steel lipped channel columns experiencing local/distortional/global buckling mode interaction.
\end{abstract}

Keywords: Lipped channel columns, Local/distortional/global mode interaction, Post-buckling behaviour, Shell finite element analysis, Experimental analysis, Ultimate strength, Direct Strength Method (DSM)

\section{INTRODUCTION}

Most cold-formed steel members display very slender thin-walled open cross-sections, a feature making them highly susceptible to several instability phenomena, namely local, distortional and global (flexural or flexural-torsional) buckling (see Figures 1(a)-(d)) - depending on the member length and cross-section shape/dimensions, any of these buckling modes may be critical. Since commonly used cold-formed steel member geometries may lead to similar local, distortional and global buckling stresses, the associated post-buckling behaviour, ultimate strength and collapse mechanism are likely to be strongly affected by interaction phenomena involving those buckling modes.

(a)

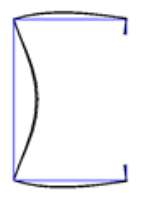

(b)

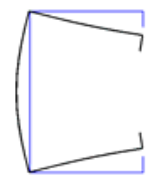

(c)

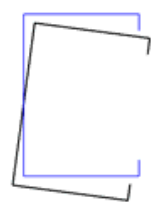

(d)

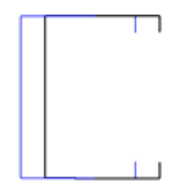

Figure 1. (a) Local, (b) Distortional, (c) Flexural-torsional and (d) Flexural Buckling (Lipped Channel Section)

It is well known that thin-walled members exhibit stable local and global post-buckling behaviours with high and low post-critical strength reserve. On the other hand, recent studies (e.g., Prola and Camotim [1] and Silvestre and Camotim [2]) showed that the distortional post-buckling behaviour fits in between the previous two and exhibits a non-negligible asymmetry with respect to the flange-lip motion (outward or inward). 
Amongst the mode interaction phenomena affecting the column post-buckling behaviour, those stemming from the nearly simultaneous occurrence of local and global buckling are, by far, the better understood indeed, virtually all current hot-rolled and cold-formed steel design codes account for them, either through the "plate effective width" concept (e.g. Batista [3]) or by means of the increasingly popular "Direct Strength Method" (e.g. Schafer [4, 5]). As for the local/distortional interactive buckling of lipped channel columns, it has attracted the attention of several researchers in the recent past: both numerical and experimental investigations have been reported (e.g. References [6-20]), and some of this work already led to the proposal of novel Direct Strength Method approaches to account for this phenomenon [8-15, 18, 20]. Concerning the coupling phenomena involving both distortional and global buckling (distortional/global and local/distortional/global interaction) in cold-formed steel members, the available literature is much more scarce. Indeed, the authors are only aware of some recent publications, mostly dealing with cold-formed carbon steel lipped channel columns: (i) numerical analysis of simply supported columns [21-25] and (ii) both numerical and experimental studies on fixed-ended columns [26] - the few exceptions correspond to numerical analyses of stainless steel lipped channel columns [27] and carbon steel rack-section columns [28]. The aim of the authors' current research effort, which is partially reported in this paper, is to investigate, both numerically and experimentally, the post-buckling behaviour and ultimate strength of fixed-ended carbon steel lipped channel columns affected by local/distortional/global interaction.

The first part of the paper deals with the presentation and discussion of numerical results concerning the (i) elastic and elastic/perfectly-plastic post-buckling behaviour, (ii) ultimate strength and (iii) failure mode nature of cold-formed steel ( $E=210 \mathrm{GPa}, v=0.3$ ) fixed-ended lipped channel columns with cross-section dimensions and lengths leading to virtually coincident local (L), distortional (D) and global (G) buckling loads - the identification of these column geometries requires the performance of preliminary buckling analyses. One analyses a fairly large number of columns that differ only in the initial geometrical imperfection shape - the various configurations dealt with are linear combinations of the competing L, D and $\mathrm{G}$ buckling modes, normalised to exhibit amplitudes equal to $10 \%$ of the wall thickness $t$ (local and distortional modes) and $0.1 \%$ of the column length $L$ (global mode). All the numerical results presented were obtained through finite element analyses carried out in the code ABAQUS [29] that (i) adopt member discretisations into fine 4-node isoparametric shell element meshes (length-to-width ratio roughly equal to 1) and (ii) model the fixed-ended support conditions by attaching rigid plates to the column end cross-sections, which are then only allowed to exhibit longitudinal rigid-body motions - a detailed account of all the modelling issues can be found in [9, 30]. The second part of the paper addresses the experimental investigation currently under way at COPPE (Federal University of Rio de Janeiro) and which will be fully reported in the near future - after providing a brief description of the test program, set-up and procedure, one compares the experimental results and numerical simulations concerning just one of specimens tested. Finally, several numerical ultimate strength values, as well as the whole set of available experimental collapse loads, are used to assess the applicability of the current Direct Strength Method (DSM) expressions to estimate the load-carrying capacity of cold-formed steel lipped channel columns experiencing $\mathrm{L} / \mathrm{D} / \mathrm{G}$ mode interaction - although further numerical and experimental studies are certainly needed, it is still possible to present some preliminary design considerations on the basis of the limited available data.

\section{BUCKLING BEHAVIOUR - COLUMN GEOMETRY SELECTION}

A sequence of buckling analyses (trial-and-error procedure) made it possible to identify a lipped channel column geometry (cross-section dimensions and length) ensuring almost coincident local, distortional and global buckling loads - these dimensions are: $b_{w}=75 \mathrm{~mm}$ (web height), $b_{f}=65 \mathrm{~mm}$ (flange width), $b_{l}=11 \mathrm{~mm}$ (lip width), $t=1.1 \mathrm{~mm}$ (wall thickness) and $L=235 \mathrm{~cm}$ (length). The curve depicted in Figure 2(a) concerns columns with these cross-section dimensions and provides the variation of the critical buckling load $P_{c r}$ with 
the length $L$ (logarithmic scale). As for Figure 2(b), it shows the shapes of the (coincident) $L=235 \mathrm{~cm}$ column local, distortional and flexural-torsional buckling modes. The observation of these ABAQUs buckling results prompts the following remarks:

(i) The $P_{c r}$ Vs. $L$ curve exhibits three distinct zones, corresponding to $\left(\mathrm{i}_{1}\right)$ local buckling $(L<120 \mathrm{~cm}),\left(\mathrm{i}_{2}\right)$ local/distortional "mixed” buckling modes (almost horizontal plateau associated with extremely close buckling loads linked to local/distortional modes with various half-wave numbers) $(120<L<235 \mathrm{~cm})$, and (i $\left.\mathrm{i}_{3}\right)$ global (flexural-torsional) buckling $(L>235 \mathrm{~cm})$.

(ii) Figure 2(a) clearly shows that the $L=235 \mathrm{~cm}$ column has very close $\mathrm{L}, \mathrm{D}$ and $\mathrm{G}$ critical loads, which indicates that the post-buckling behaviour and ultimate strength of such column will be highly affected by local/distortional/global interaction $\left(L \equiv L_{L / D / G}\right)$. The critical buckling loads are $P_{c r . D 4}=55.9 \mathrm{kN}$ (4 distortional half-waves), $P_{c r . D 5}=56.8 \mathrm{kN}$ (5 distortional half-waves), $P_{c r . G}=57.1 \mathrm{kN}$ (single flexural-torsional half-wave) and $P_{c r . L}=57.4 \mathrm{kN}$ (33 web-triggered local half-waves ${ }^{1}$ - the corresponding buckling mode shapes are depicted in Figure 2(b).

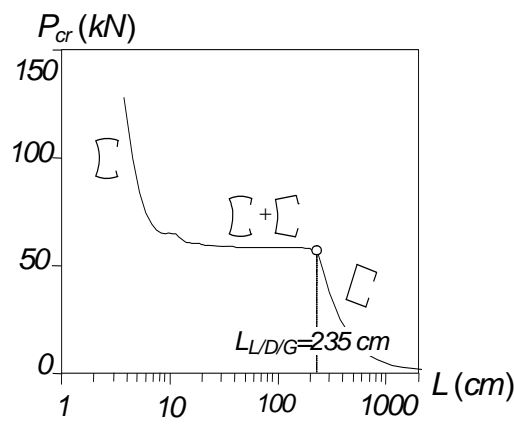

(a)

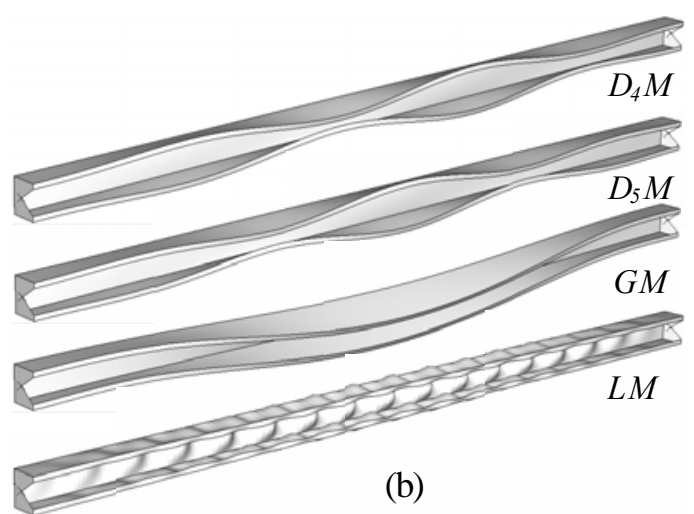

(b)

Figure 2. (a) Column $P_{c r}$ vs. $L$ Curve $\left(b_{w}=75 \mathrm{~mm} ; b_{f}=65 \mathrm{~mm} ; b_{l}=11 \mathrm{~mm} ; t=1.1 \mathrm{~mm}\right)$ and (b) $L_{L / D / G}=235 \mathrm{~cm}$ Column Local, Distortional and Global (Flexural-torsional) Buckling Mode Shapes

\section{POST-BUCKLING BEHAVIOUR UNDER L/D/G MODE INTERACTION}

One now investigates the elastic and elastic-plastic post-buckling behaviour of fixed-ended columns with the geometry identified in the previous section - recall that its critical buckling load is equal to $P_{c r}=55.9 \mathrm{kN}$ ( $\sigma_{c r}=190.4 \mathrm{MPa}$ ) and it exhibits almost coincident local (33 half-waves), distortional (4-5 half-waves) and global (single half-wave) buckling modes.

\subsection{Initial Geometrical Imperfections}

Because in mode interaction studies the commonly used approach of considering critical-mode initial geometrical imperfections ceases to be well defined, due to the presence of more than one competing buckling modes that may be combined arbitrarily, an important issue consists of assessing how the initial geometrical imperfection shape influences the post-buckling behaviour and strength of the structural system under scrutiny - in particular, it is crucial to identify the most detrimental imperfection shape. In order to achieve this goal, one determines column equilibrium paths covering the whole critical-mode imperfection shape range - to ensure that such paths can be meaningfully compared, the following approach is adopted:

\footnotetext{
${ }^{1}$ In fixed-ended lipped channel columns, the distortional buckling loads associated with buckling modes exhibiting consecutive half-wave numbers are always very close - this is why two distortional buckling modes must be considered in this work.
} 
(i) Determine the "pure" critical buckling mode shapes, normalised so that the most relevant displacement has a unit value. Such displacement is ( $\left.\mathrm{i}_{1}\right)$ the mid-span mid-web flexural displacement $\left(w_{L}=1 \mathrm{~mm}-\right.$ local), ( $\left.\mathrm{i}_{2}\right)$ the quarter-span flange-lip corner vertical displacement $\left(v_{D}=1 \mathrm{~mm}-\right.$ distortional $\left.^{2}\right)$ or $\left(\mathrm{i}_{3}\right)$ the mid-span flange-lip corner vertical displacement ${ }^{3}\left(v_{G}=1 \mathrm{~mm}\right.$ - global).

(ii) Scale down the above "pure" modes, leading to local, distortional and global imperfection magnitudes equal to $w_{L .0}=0.1 t, v_{D .0}=0.1 t$ and $v_{G .0}=L / 1000$.

(iii) A given imperfection shape is obtained as a linear combination of the scaled competing buckling mode shapes - its coefficients $C_{L .0}, C_{D .0}$ and $C_{G .0}$ satisfy the condition $\left(C_{L .0}\right)^{2}+\left(C_{D .0}\right)^{2}+\left(C_{G .0}\right)^{2}=1$. A better "feel" and visualisation of the initial imperfection shapes may be obtained by looking at an unit radius sphere drawn in the $C_{L .0}-C_{D .0}-C_{G .0}$ space, as shown in Figure 3(a): each "acceptable" shape lies on this sphere and can be defined by two angles ( $\alpha$ and $\theta$ ). Figures 3(b) display the pure $\mathrm{D}_{4}\left(\alpha=0^{\circ}+\theta=0^{\circ}\right.$ or $180^{\circ}$ - inward or outward flange-lip motions at quarter-span), $\mathrm{G}$ $\left(\alpha=0^{\circ}+\theta=90^{\circ}\right.$ or $270^{\circ}$ - clockwise or counter-clockwise cross-section rotations) and L $\left(\theta=0^{\circ}+\right.$ $\alpha=90^{\circ}$ or $270^{\circ}$ - inward or outward web bending at mid-span) initial imperfection shapes.

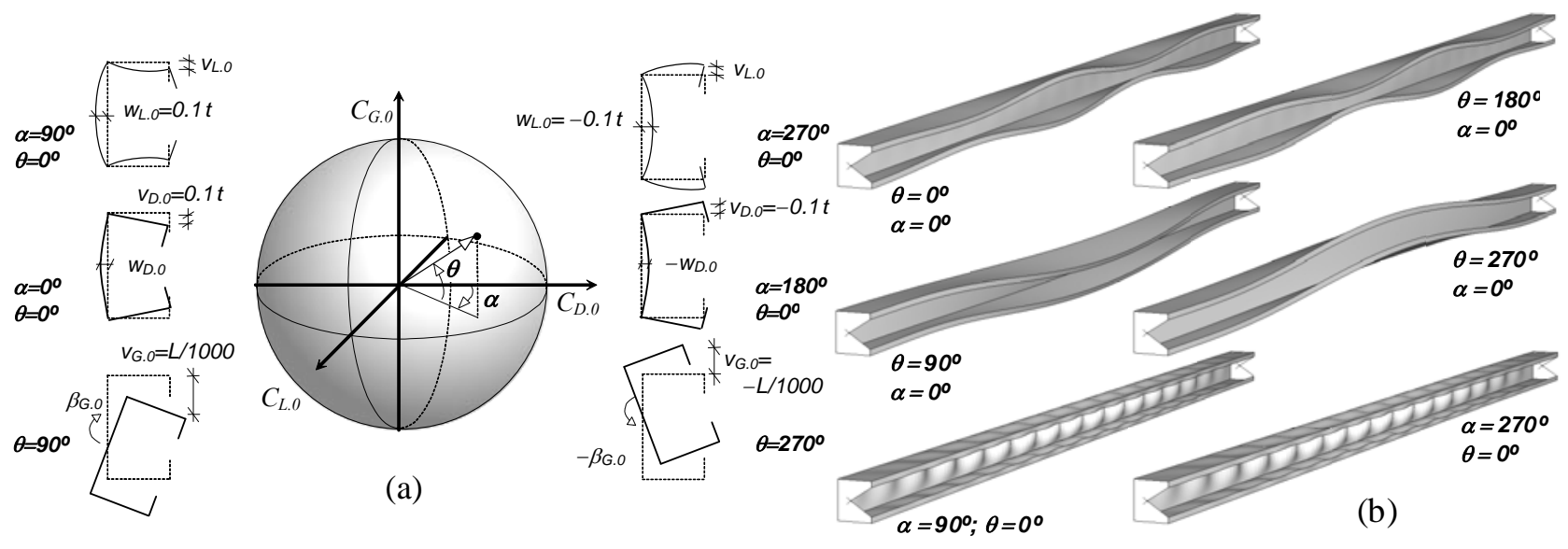

Figure 3. (a) Initial Imperfection Representation in the $C_{L .0}-C_{D .0}-C_{G .0}$ Space and

(b) Pure Distortional $\left(\alpha=0^{\circ}+\theta=0^{\circ} ; 180^{\circ}\right)$, Global $\left(\alpha=0^{\circ}+\theta=90^{\circ} ; 270^{\circ}\right)$ and Local $\left(\theta=0^{\circ}+\alpha=90^{\circ} ; 270^{\circ}\right)$ Initial Imperfection Shapes

\subsection{Elastic Post-Buckling Behaviour}

In order to investigate the elastic post-buckling behaviour of the $L_{L / D / G}$ column, a large number of otherwise identical columns with distinct initial imperfection shapes were analysed. However, due to space limitations, only some of the corresponding numerical results are presented here, adopting the following strategy: (i) presentation of the results concerning columns with the 6 pure critical initial imperfections shown in Figure 3(b), simply designated as $\theta=0^{\circ} ; 180^{\circ}$ (pure $\mathrm{D}_{4}$ distortional), $\theta=90^{\circ} ; 270^{\circ}$ (pure global) and $\alpha=90^{\circ} ; 270^{\circ}$ (pure local) columns; (ii) after observing the previous post-buckling results, identification of the two most detrimental imperfection shape types (i.e., those leading to larger erosions of the column elastic post-buckling strength reserve), which define the "most detrimental imperfection plane"; (iii) presentation of results concerning 24 columns with different initial imperfection shapes lying on the above plane (with $15^{\circ}$ angle intervals).

\footnotetext{
${ }^{2}$ No five half-wave distortional initial geometrical imperfections are dealt with here (only four half-wave ones). There are four and five half-wave distortional buckling modes associated with $P_{c r . D 4}=55.9 \mathrm{kN}$ (the lower value) and $P_{c r . D 5}=56.8 \mathrm{kN}$.

3 This vertical displacement is due to the cross-section rigid-body motion: rotation and a minor-axis translation - since both cause upward or downward vertical displacements, it suffices to define the cross-section rotation sense (clock or counterclockwise).
} 
Figures 4(a)-(c) show the upper parts of the equilibrium paths (i) $P / P_{c r} v s . v / t$ ( $v$ is half the sum of the two flange-lip corner vertical displacements), (ii) $P / P_{c r} v s . w / t$ ( $w$ is the mid-web flexural displacement, measured with respect to the web chord and after deducting the component stemming from the distortional deformation) and (iii) $P / P_{c r} v s$. $\beta$ ( $\beta$ is the web chord rigid-body rotation). It should be noted that $v, w$ and $\beta$ (i) are measured at the quarter-span section indicated in Figure 4(d) (S-S' cross-section), where maximum distortional deformations occurs, and (ii) are well suited to quantify the evolution of the column distortional, local and global deformed configuration components along any given equilibrium path. As for Figures 4(d), they show the deformed configurations of the $\theta=0^{\circ}, 180^{\circ}$ and $\alpha=90^{\circ}$ columns at the advanced post-buckling stage. From the observation of these post-buckling results, the following conclusions are drawn:

(i) All columns exhibit a stable post-buckling behaviour with a small-to-moderate post-critical strength reserve (see the various $P / P_{c r} v s . v / t$ and $P / P_{c r} v s . w / t$ curves displayed). This is somewhat surprising, since a previous study $[22,25]$ on simply supported columns experiencing strong $L / D / G$ mode interaction unveiled the existence of well defined limit points occurring quite below $P / P_{c r}=1.0$.

(ii) Generalised Beam Theory (GBT - e.g. Camotim, et al. [31]) provides the explanation for the distinct post-buckling behaviour nature exhibited by the simply supported and the fixed-ended lipped channel columns. The buckling results depicted in Figure 5(a) provide the variation of the critical buckling load $P_{c r}$ with the column length $L$ (for $L \geq 200 \mathrm{~cm}$ ): (ii ${ }_{1}$ ) the curve yielded by ABAQUS analyses and already shown in Figure 2(a), and $\left(\mathrm{ii}_{2}\right)$ the values obtained from GBT analyses carried out in GBTUL [32, 33] and including 18 deformation modes (4 global +2 distortional +12 local). As for Figure 5(b), it shows the GBT-based modal participation diagram, showing the contributions of each GBT deformation mode to the column buckling modes. Finally, Figures 5(c) display the GBT-based buckling mode shapes of the $L=300,500,700 \mathrm{~cm}$ columns and also the in-plane configurations of the 3 deformation modes that contribute to them. These GBT-based buckling results lead to the following comments:

(ii.1) The buckling curve descending branch corresponds to two distinct single half-wave buckling modes: (ii $\left.{ }_{1}\right)$ distortional-flexural-torsional $\mathbf{( 2 + 4 + 6 )}$, for $235<L \leq 500 \mathrm{~cm}$, and $\left(\mathrm{ii}_{2}\right)$ flexural-torsional $(2+4)$, for $L>500 \mathrm{~cm}$ - the participation of mode 6 (anti-symmetric distortional) gradually fades as the column length increases, until it practically vanishes for $L \approx 500 \mathrm{~cm}$.

(ii.2) This means that the $L=235 \mathrm{~cm}$ column single half-wave critical buckling mode, termed "global" until now, is indeed a "mixed" flexural-torsional-distortional mode, which combines about $35 \%$ of mode $2,40 \%$ of mode 4 and $25 \%$ of mode 6 . The same happened in the simply supported column affected by L/D/G interaction analysed in [22, 25], where it was shown that the presence of mode $\mathbf{6}$ was responsible for the occurrence of (elastic) limit points. But why are there no such limit points in the fixed-ended column equilibrium paths?

(ii.3) Although a fully rational answer to the above question requires further investigation, which is currently under way and will be reported in the near future, it seems fair to anticipate that the explanation for the absence of elastic equilibrium path limit points has to do with both ( $\mathrm{ii}_{1}$ ) the smaller contribution of mode $\mathbf{6}$ (it reached $32 \%$ in the simply supported columns analysed in [22, 25]) and ( $\mathrm{ii}_{2}$ ) the absence of a destabilising effective centroid shift associated with this anti-symmetric distortional deformation mode (e.g., Young and Rasmussen [34]).

(iii) The columns with "global" (this designation will be retained for simplicity) initial imperfections $\left(\theta=90^{\circ}\right.$ or $270^{\circ}$ ) exhibit deformed configurations characterised by quarter-span ( iii $\left._{1}\right)$ small outward flange-lip motions, ( $\left.\mathrm{iii}_{2}\right)$ moderate inward or outward web bending and (iii ${ }_{3}$ ) significant clockwise or counterclockwise rigid-body rotations - the presence of non-null distortional and local (mostly) components indicates $\mathrm{L} / \mathrm{D} / \mathrm{G}$ interaction.

(iv) The small $v$ values exhibited by some equilibrium paths do not correspond to minute distortional deformations. Indeed, they are due to the simultaneous presence of four $\left(D_{4}\right)$ and five $\left(D_{5}\right)$ half-wave distortional components, whose interaction leads to small $v$ values at the quarter-span 
(S-S') cross-section - therefore, this cross-section is not the most convenient to characterise the $\mathrm{L} / \mathrm{D} / \mathrm{G}$ interaction.

(v) The columns with distortional $\left(\theta=0^{\circ}, 180^{\circ}\right)$ or local $\left(\alpha=90^{\circ}, 270^{\circ}\right)$ initial imperfections have deformed configurations with no rigid-body rotations, i.e., only L/D interaction occurs (see Figure 4(d)).

(vi) Because the local $\left(\alpha=90^{\circ}, 270^{\circ}\right)$ initial imperfections always lead to higher column elastic post-buckling strengths than their global and distortional counterparts, one readily concludes that the most adverse $\mathrm{L} / \mathrm{D} / \mathrm{G}$ interaction effects occur for initial imperfections lying in the $\mathrm{C}_{\mathrm{D}}-\mathrm{C}_{\mathrm{G}}$ plane. Note that this conclusion is in line with the findings reported earlier for simply supported columns [22, 25]: the initial imperfection local component plays a lesser role, as far as the post-buckling behaviour of columns experiencing $\mathrm{L} / \mathrm{D} / \mathrm{G}$ interaction is concerned [16].

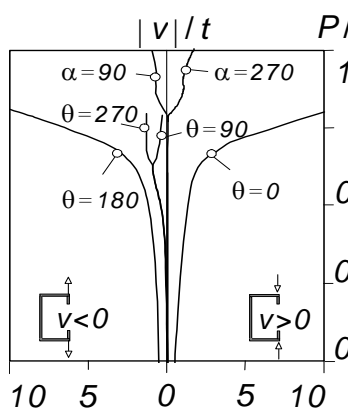

(a)

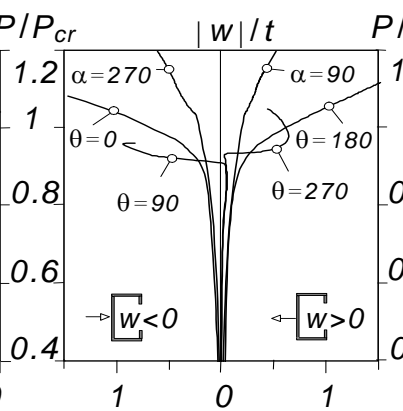

(b)

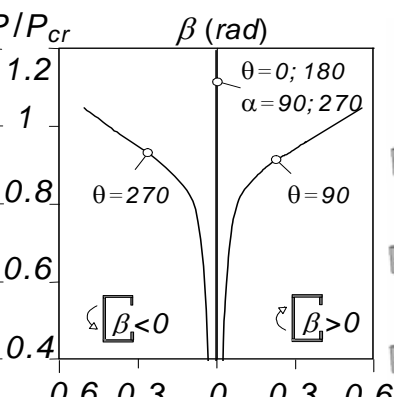

(c)

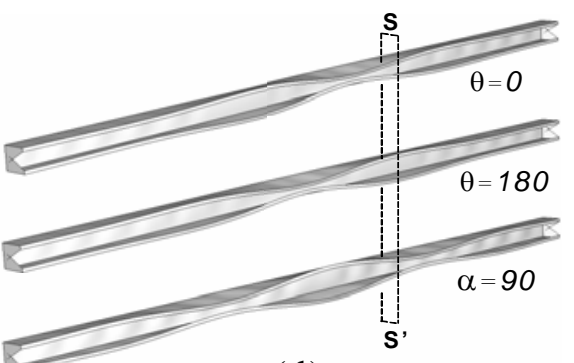

(d)

Figure 4. (a) $P / P_{c r} v s . v / t$, (b) $P / P_{c r} v s . w / t$ and (c) $P / P_{c r} v s . \beta$ Paths for Columns with Pure Imperfections Shapes; (d) Advanced Post-buckling Deformed Configurations of the $\theta=0^{\circ}, \theta=180^{\circ}$ and $\alpha=90^{\circ}$ Columns

(a)

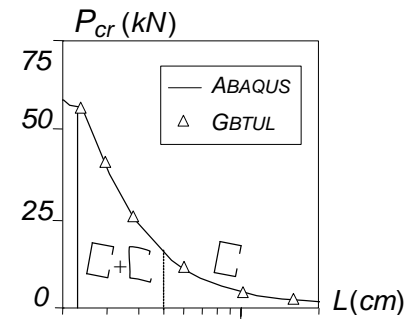

(b)

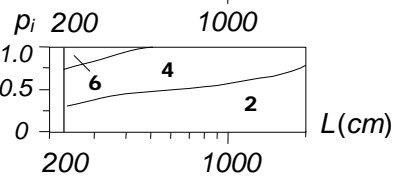

\begin{tabular}{|c|c|c|c|}
\hline$L(\mathrm{~cm})$ & 300 & 500 & 700 \\
\hline $\begin{array}{c}\mathrm{GBT} \\
\text { Buckling } \\
\text { Mode }\end{array}$ & $\square$ & $\square$ & $\square$ \\
\hline
\end{tabular}

(c)

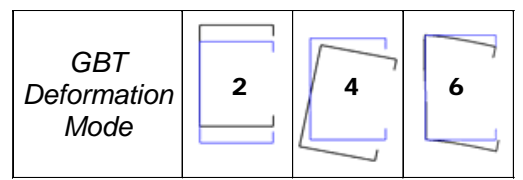

Figure 5. (a) GBT-based $P_{c r}$ values $(L>200 \mathrm{~cm})$, (b) Modal Participation Diagram and (c) In-plane Shapes of the $L=300,500,700 \mathrm{~cm}$ Column Buckling Modes and Participating GBT Deformations Modes

In view of the above facts, attention is now focused on the post-buckling behaviour of columns with 13 initial imperfections located in the $\mathrm{C}_{\mathrm{D}}-\mathrm{C}_{\mathrm{G}}$ plane and corresponding to $0^{\circ}<\theta<180^{\circ}\left(15^{\circ}\right.$ intervals - to ensure $C_{G} \neq 0$, the $\theta=0^{\circ}$ and $180^{\circ}$ columns are replaced by $\theta=1^{\circ}$ and $179^{\circ}$ ones $)^{4}$. Figures 6(a)-(c) show the upper parts of the $P / P_{c r} v s . v / t, P / P_{c r} v s$. $w / t$ and $P / P_{c r} v s . \beta$ equilibrium paths, which now concern mid-span cross-section displacements - due to the relevant presence of $\mathrm{D}_{5}$ distortional deformations (they always come into play, even if only $\mathrm{D}_{4}$ initial imperfections are included in the analysis), this cross-section is more adequate to characterise the $\mathrm{L} / \mathrm{D} / \mathrm{G}$ interaction.

\footnotetext{
${ }^{4}$ Since the column post-buckling behaviour was found to be symmetric with respect to the deformed configuration global component sign (see Fig. 4(c)), there is no need to present post-buckling results concerning the $180^{\circ}<\theta<360^{\circ}$ columns
} 
Figure 6(d) shows the deformed configurations of the $\left(\mathrm{d}_{1}\right) \theta=1^{\circ}$ column (at the peak load) and ( $\left.\mathrm{d}_{2}\right) \theta=90^{\circ}$ column (at advanced post-buckling stage). In order to illustrate some behavioural aspects detected in the above equilibrium paths and not visible in Figures 6(a)-(b), additional results are presented in Figures 7(a)-(c): more detailed representations of the $\theta=90^{\circ}$ curves displayed in Figures 6(a)-(b), together with several column mid-span cross-section deformed configurations. The joint observation of all these post-buckling results prompts the following remarks:

(i) All equilibrium paths shown in Figures 6(a)-(c) merge into single common curves, associated with mid-span $\left(\mathrm{i}_{1}\right)$ clockwise web chord rotations, $\left(\mathrm{i}_{2}\right)$ outward flange-lip motions and $\left(\mathrm{i}_{3}\right)$ outward web bending (i.e., opposing the web bending caused by the distortional component) - this provides clear evidence of strong $\mathrm{L} / \mathrm{D} / \mathrm{G}$ interaction. Moreover, note that, since the column deformed configuration $\mathrm{D}_{5}$ distortional component has always the same sign (outward flange-lip motions at mid-span), the column post-buckling behaviour is symmetric with respect to $\theta=90^{\circ}$.

(ii) The progressive emergence of significant distortional deformations at the column mid-span cross-section means that the $\mathrm{L} / \mathrm{D} / \mathrm{G}$ interaction involves also (or mostly) the non-critical 5 half-wave distortional buckling mode $\left(\mathrm{D}_{5}\right)$. In spite of its slightly higher buckling load, this distortional mode is geometrically more akin to the global and local ones (maximum displacements at mid-span) and plays a key role in the column post-buckling behaviour, as can be seen in Figure $6\left(\mathrm{~d}_{2}\right)$ - note also the visibility of the column deformed configuration local component (barely perceptible in the simply supported columns analysed in [22, 25]).

(iii) The equilibrium paths of the columns with a very small $C_{G .0}$ value $\left(\theta=1^{o} ; 179^{\circ}\right)$ lie clearly above the remaining ones and reach a limit point prior to merging into the common curve - this is due to (iii ${ }_{1}$ ) the decrease of their "excessive" $\mathrm{D}_{4}$ components (see Figure 6( $\left.\mathrm{d}_{1}\right)$ ) and (iii ${ }_{2}$ ) the very close proximity of the singular post-buckling behaviour of the $\theta=0^{\circ} ; 180^{\circ}$ columns, which involves no cross-section rigid-body motions $[22,25]$. As for the other equilibrium paths, they are all "smooth" (particularly those concerning columns with small $C_{D .0}$ values) and evolve in a monotonic fashion.

(iv) The most detrimental initial imperfections, in the sense that they lead to the lowest column post-buckling strength, are the pure "global" ones $\left(\theta=90^{\circ}\right)$ - indeed, the corresponding equilibrium paths shown in Figures 6(a)-(c) lie below all the remaining ones.

(v) In the advanced post-buckling stages $\left(P / P_{c r}>0.93\right.$ and $\left.v / t>5\right)$, a gradual change occurs in the column common deformed configuration - this change is clearly visible in the $\theta=90^{\circ}$ column equilibrium paths depicted in Figures 7(a)-(b). First of all, the rate of increase of the outward web bending displacements $(w)$, measured with respect to the web chord and deducting the distortional component, progressively diminishes, until a "reversal" takes place (i.e., the web deformed configuration local component corresponds now to inward bending) - note also the emergence of a visible web double-curvature bending, stemming from the growth of the deformed configuration "global" component. Secondly, the rate of increase of the flange-lip distortional displacements $(v)$ decreases, until another "reversal" takes place (i.e., the flange-lip assemblies start to move inward) this means that while the mid-span cross-section rigid-body rotation and associated anti-symmetric distortion keep growing (see Figure 7(c)), its symmetric distortion slowly starts to decease.

\subsection{Elastic-Plastic Post-Buckling Behaviour}

Numerical results concerning the elastic/perfectly-plastic post-buckling behaviour and collapse mechanism of the L/D/G column are now presented and discussed. Again due to space limitations, only the most relevant results are dealt with: those that correspond to columns with (i) initial imperfection shapes lying in the $\mathrm{C}_{\mathrm{D}}-\mathrm{C}_{\mathrm{G}}$ plane $\left(1^{\circ}<\theta<179^{\circ}-15^{\circ}\right.$ intervals), and (ii) yield stresses $f_{y}=235,355,520$ $M P a$, i.e., yield-to-critical stress ratios equal to $f_{y} / \sigma_{c r} \approx 1.2,1.9,2.7$. For comparative purposes, some elastic results presented earlier are shown again - they may be viewed as corresponding to $f_{y}=f_{y} / \sigma_{c r}=\infty$. 


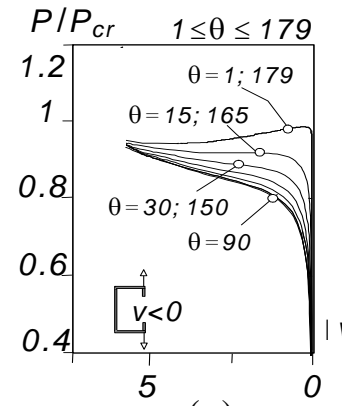

(a)

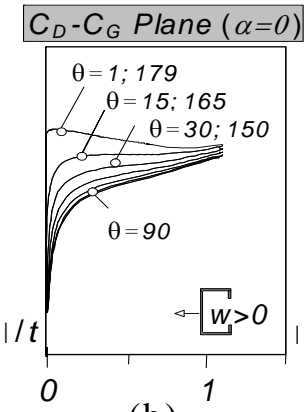

(b)

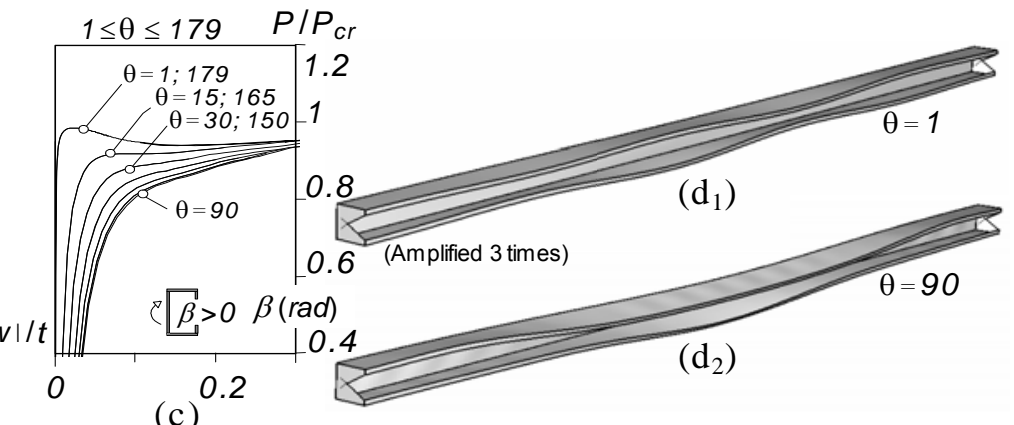

(c)

Figure 6. (a) $P / P_{c r} v s . v / t$, (b) $P / P_{c r} v s . w / t$ and (c) $P / P_{c r} v s . \beta$ Paths for $\mathrm{C}_{\mathrm{D}}-\mathrm{C}_{\mathrm{G}}$ Plane Imperfections, and (d) Deformed Configuration of the $\left(\mathrm{d}_{1}\right)$ the $\theta=1^{\circ}$ (Peak Load) and

$\left(\mathrm{d}_{2}\right)$ the $\theta=90^{\circ}$ (Advanced Post-buckling Stage) Columns

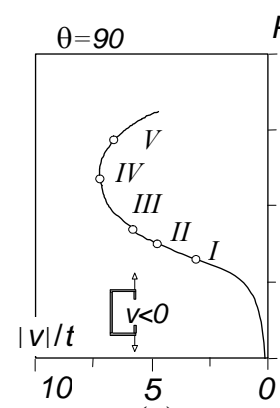

(a)

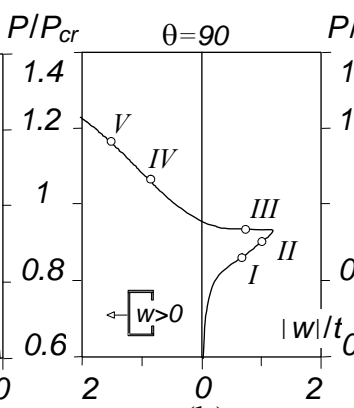

(b)

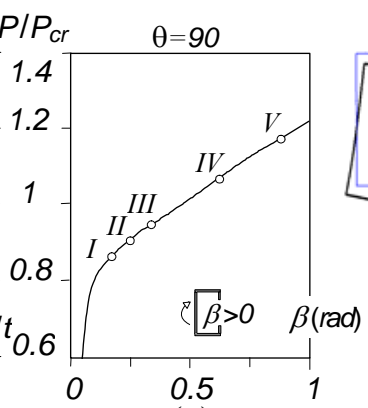

(c)

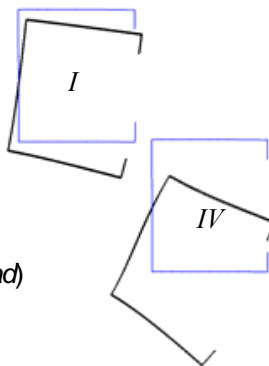

(d)

Figure 7. (a) $P / P_{c r} v s . v / t$, (b) $P / P_{c r} v s . w / t$, and (c) $P / P_{c r} v s . \beta$ Equilibrium Paths, and (c) Post-buckling Evolution of the $\theta=90^{\circ}$ Column Mid-span Cross-section Deformed Configuration

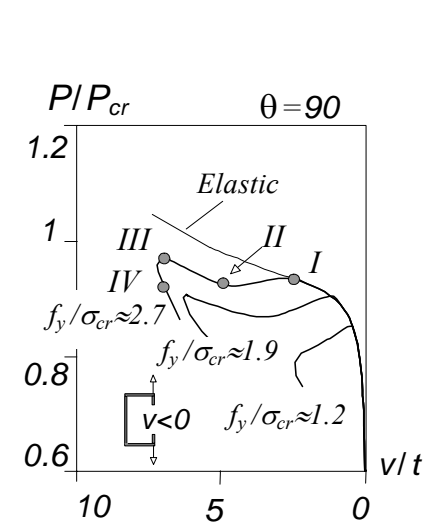

(a)

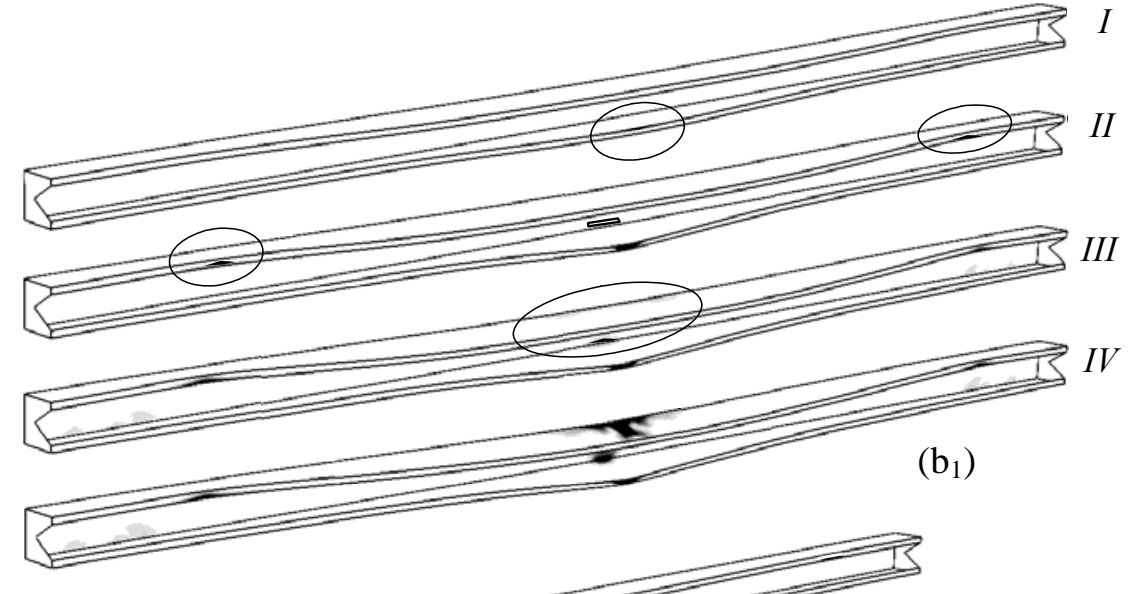

$\left(b_{2}\right)$

Figure 8. (a) Elastic-Plastic $P / P_{c r} v$ s. $v / t$ Equilibrium Paths of Four $\theta=90^{\circ}$ Columns $\left(f_{y} / \sigma_{c r} \approx 1.2,1.9\right.$, $2.7, \infty)$ and (b) Deformed Configuration and Plastic Strain Diagrams of the $\theta=90^{\circ}$ Column with $\left(\mathrm{b}_{1}\right) f_{y} / \sigma_{c r} \approx 2.7$ (Four Equilibrium States Indicated) and $\left(\mathrm{b}_{2}\right) f_{y} / \sigma_{c r} \approx 1.2$ (Onset of Yielding - Peak Load) 
Figure 8(a) shows the upper portions $\left(P / P_{c r}>0.0\right)$ of four equilibrium paths $P / P_{c r} v s . v / t$, concerning $\theta=90^{\circ}$ columns (most detrimental initial imperfections) with different yield stresses. Figure $8\left(\mathrm{~b}_{1}\right)$ concerns the column with $f_{y} / \sigma_{c r} \approx 2.7$ and displays four plastic strain diagrams, corresponding to equilibrium states located along its post-buckling path (as indicated in Figure 8(a)) and including the column collapse mechanism - in order to illustrate the influence of the yield stresses on the column collapse mechanism, Figure $8\left(\mathrm{~b}_{2}\right)$ displays the plastic strain diagrams at the collapse of the $\theta=90^{\circ}$ columns with $f_{y} / \sigma_{c r} \approx 1.2$. As for Figures 9(a)-(b), they show similar elastic-plastic results concerning $\theta=1^{\circ}$ columns (almost pure distortional initial imperfections). Finally, Figure 10 (and its table) provides the column ultimate load ratios $\left(P_{u} / P_{c r}\right)$ for all the $\theta-f_{y}$ combinations considered in this work. After observing these $1^{\circ} \leq \theta \leq 179^{\circ}$ column post-buckling results, one is able to draw the following conclusions:

(i) The characteristics of the column elastic-plastic post-buckling behaviour and collapse mechanism are clearly dependent on the $f_{y} / \sigma_{c r}$ value.

(ii) In columns with $f_{y} / \sigma_{c r}$ close to 1.0 (e.g., $\left.f_{y} / \sigma_{c r} \approx 1.2\right)$ first yielding occurs when the column normal stress distribution is still "fairly uniform" and, therefore, precipitates a rather "abrupt" collapse. The onset of yielding occurs in a significant portion of the "critical (most deformed) cross-section", whose location depends on the initial imperfection shape: (ii ${ }_{1}$ ) for $\theta=1^{o}$, the mid cross-section of the mode $\mathrm{D}_{4}$ inner half-wave with outward motions (see Figure $9\left(b_{2}\right)$ ), which means that yielding begins before mode $\mathrm{D}_{5}$ comes into play; (ii $\left.{ }_{2}\right)$ for $\theta=90^{\circ}$, in the column mid-span, which implies that mode $\mathrm{D}_{5}$ has already become dominant (see Figure $8\left(\mathrm{~b}_{2}\right)$ ).

(iii) In columns with a high $f_{y} / \sigma_{c r}$ value (e.g., $f_{y} / \sigma_{c r} \approx 2.7$, the higher value considered here) first yielding occurs when the column normal stress distribution is already "strongly non-uniform" and, therefore, does not lead to an immediate collapse. Either ( $\mathrm{iii}_{1}$ ) the column remains elastic up until failure, i.e., yielding only starts along the equilibrium path descending branch (e.g., the $\theta=1^{\circ}$ column - see Figure 9(a)), or ( $\mathrm{iii}_{2}$ ) collapse occurs after a mild "snap-through" phenomenon takes place, followed by a subsequent strength increase up to a limit point ${ }^{5}$ (e.g., the $\theta=90^{\circ}$ column - see Figure 8(a)).

(iv) For the $\theta=90^{\circ}$ column with $f_{y} / \sigma_{c r} \approx 2.7$, yielding begins at the bottom lip free end zone located in the vicinity of the column mid-span, as shown by the plastic strain distribution corresponding to the equilibrium state $I$ in Figure $8\left(\mathrm{~b}_{1}\right)$. Then, the plastic strain distribution associated with the equilibrium point $I I$ indicates that yielding also begins at the top lip free end in the eighth-span cross-section zones. The column collapse, which corresponds to the equilibrium path (second) limit point, takes place after the full yielding of the mid-span cross-section web-flange corners, thus forming a "distortional plastic hinge" - see diagram $I I I$ in Figure $8\left(\mathrm{~b}_{1}\right)$. Finally, diagram $I V$ corresponds to a post-collapse equilibrium state and shows that yielding spreads along the upper half of the mid-span cross-section region, while practically all the other column zones remain elastic.

(v) Figure 10 shows that the $\theta=90^{\circ}$ column always exhibits the lowest ultimate load, which means that pure "global" initial imperfections are the most detrimental ones. Concerning the strength erosion due to the $\mathrm{L} / \mathrm{D} / \mathrm{G}$ interaction, the $\theta=90^{\circ}$ column ultimate load is equal to $74 \%\left(f_{y}=235 \mathrm{MPa}\right), 81 \%$ $\left(f_{y}=355 \mathrm{MPa}\right)$ and $89 \%\left(f_{y}=520 \mathrm{MPa}\right)$ of its critical buckling load.

(vi) Figure 10 (and its table) also shows that the variation of $P_{u} / P_{c r}$ with $\theta$ is less pronounced as $f_{y} / \sigma_{c r}$ increases - this is due to the fact that the elastic equilibrium paths concerning the various $\theta$ values are closer to each other when yielding begins (recall that they eventually merge into a common curve). Note that the interval centred at $\theta=90^{\circ}$ for which $P_{u}$ is "almost uniform" (maximum and minimum values no more than $0.5 \%$ apart) grows from $75^{\circ} \leq \theta \leq 105^{\circ}\left(f_{y} / \sigma_{c r} \approx 1.2\right)$ to $15^{\circ} \leq \theta \leq$ $165^{\circ}\left(f_{y} / \sigma_{c r} \approx 2.7\right)$.

\footnotetext{
${ }^{5}$ It is worth noting that, as the $f_{y} / \sigma_{c r}$ ratio increases, the "snap-through" phenomenon becomes less pronounced and the subsequent strength increase is larger.
} 


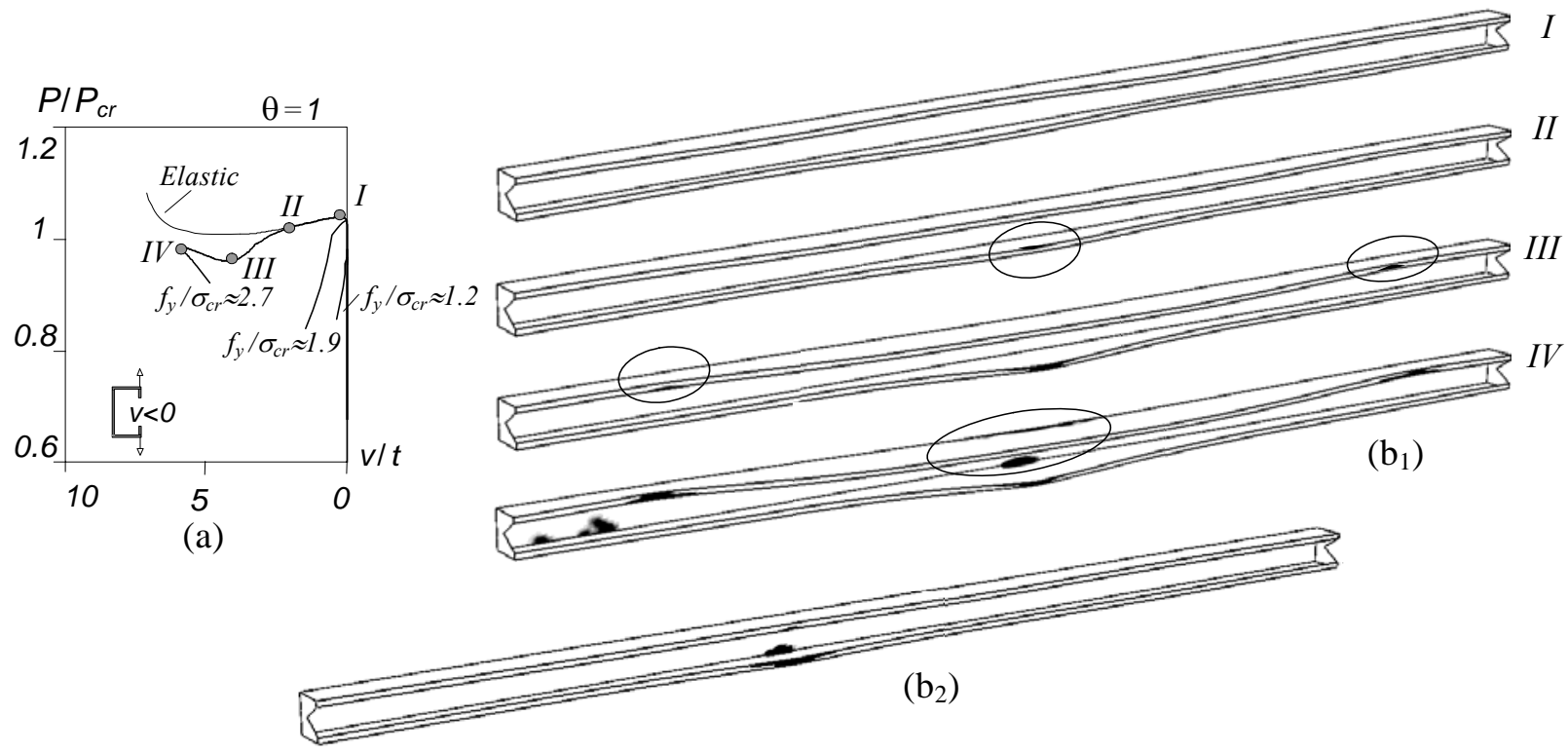

Figure 9. (a) Elastic-plastic $P / P_{c r} v s . v / t$ Equilibrium Paths of Four $\theta=1^{\circ}$ Columns $\left(f_{y} / \sigma_{c r} \approx 1.2,1.9,2.7, \infty\right)$, (b) Deformed Configuration and Plastic Strain Diagrams of the $\theta=1^{\circ}$ Columns with $\left(\mathrm{b}_{1}\right) f_{y} / \sigma_{c r} \approx 2.7$ (Four Equilibrium States Indicated) and (b) $f_{y} / \sigma_{c r} \approx 1.2$ (Onset of Yielding - Peak Load)

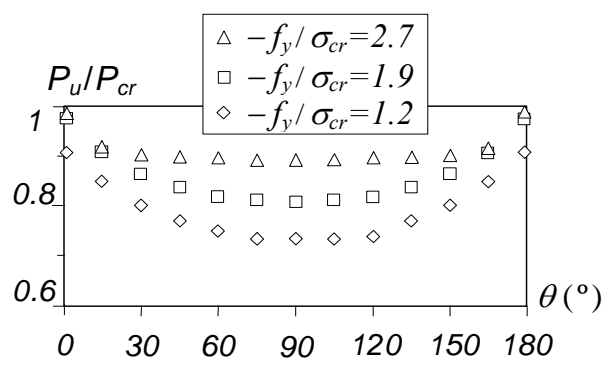

\begin{tabular}{|c|c|c|c|}
\hline \multirow{2}{*}{$\theta\left(^{\circ}\right)$} & \multicolumn{3}{|c|}{$f_{y} / \sigma_{c r}$} \\
\cline { 2 - 4 } & 1.2 & 1.9 & 2.7 \\
\hline 1 & 0.908 & 0.977 & 0.987 \\
15 & 0.851 & 0.908 & 0.919 \\
30 & 0.803 & 0.866 & 0.903 \\
45 & 0.772 & 0.840 & 0.898 \\
60 & 0.751 & 0.819 & 0.898 \\
75 & 0.736 & 0.814 & 0.894 \\
90 & 0.735 & 0.809 & 0.893 \\
\hline
\end{tabular}

\begin{tabular}{|c|c|c|c|}
\hline \multicolumn{4}{|c|}{$f_{y} / \sigma_{c r}$} \\
\hline$\theta\left(^{\circ}\right)$ & 1.2 & 1.9 & 2.7 \\
\hline 90 & 0.735 & 0.809 & 0.893 \\
105 & 0.736 & 0.814 & 0.894 \\
120 & 0.751 & 0.820 & 0.897 \\
135 & 0.771 & 0.841 & 0.899 \\
150 & 0.802 & 0.867 & 0.904 \\
165 & 0.850 & 0.909 & 0.920 \\
179 & 0.909 & 0.978 & 0.988 \\
\hline
\end{tabular}

Figure 10. Variation of $P_{u} / P_{c r}$ with $\theta$ and $f_{y} / \sigma_{c r}\left(1^{\circ} \leq \theta \leq 179^{\circ}\right)$

\section{EXPERIMENTAL INVESTIGATION}

This section addresses the experimental investigation currently under way at COPPE (Federal University of Rio de Janeiro) and will be fully reported in the near future - after providing a brief description of the test program, set-up and procedure, the paper compares the experimental results and numerical simulations concerning one of the specimens tested.

\subsection{Test Program, Set-Up, Procedure and Results}

In order to ensure the occurrence of strong local/distortional/global mode interaction, four fixed-ended column geometries with close local, distortional and global buckling loads were first selected - the experimental investigation involves 9 tests and the specimen dimensions are given in Table 1 (note that, due to fabrication limitations, the wall thickness is always close to $1.1 \mathrm{~mm}$ ), together with the corresponding (i) buckling loads, calculated for $E=210 \mathrm{GPa}$ and $v=0.3$, and (ii) measured ultimate loads. The specimens were cold-formed by press braking and their average yield stress values, obtained from coupon tests, is equal to $342 \mathrm{MPa}$ or $407 \mathrm{MPa}$ (4 tests and a $4.0 \mathrm{MPa}$ 
standard deviation), corresponding to the critical-to-yield load ratios also given in Table 1 ( $P_{y}=A f_{y}$ is the column squash load) - moreover, the coupon tests carried out showed that the steel stress-strain curve exhibited no well-defined yield plateau (see Figure 12(a)).

Figure 11(a) shows the location of the 7 displacement transducers employed to measure the specimens initial geometrical imperfections and displacements during the tests - Figure 11(b) shows a view of the specimen mid-span cross-section surrounded by transducers T3 to T6. In order to measure the specimen initial displacement longitudinal profiles, only transducers T1 to T6 were attached to the moving device, which was subsequently made to travel along the whole column length. Concerning the displacement measurements made during the test, the following methodology was employed:

(i) Transducers T2 to T5 and T7 were kept permanently at the mid-height level, in contact with the specimen by means long steel wires - this arrangement aims at ensuring contact with the specimen even when the cross-section rigid-body motion ceases to be small.

(ii) Transducers T1 and T6 were attached to the moving device, which was kept at the mid-height level during the application of the various load increments. At pre-defined applied load values, loading was stopped and the moving device travelled along the specimen length, thus providing the longitudinal profiles of the flange-lip corner vertical displacements for the load value under consideration.

(iii) During the application of the load increments, the measurements of the 7 transducers (all located at the mid-height level) were continuously recorded and fed into a data acquisition system.

Table 1. Geometries, Buckling Loads and Ultimate Strengths of the Columns Tested

\begin{tabular}{|c|c|c|c|c|c|c|c|c|c|c|c|}
\hline Specimen & $\begin{array}{c}b_{w} \\
(\mathrm{~mm})\end{array}$ & $\begin{array}{c}b_{f} \\
(\mathrm{~mm})\end{array}$ & $\begin{array}{c}b_{l} \\
(\mathrm{~mm})\end{array}$ & $\begin{array}{c}t \\
(\mathrm{~mm})\end{array}$ & $\begin{array}{c}L \\
(\mathrm{~mm})\end{array}$ & $\begin{array}{c}f_{y} \\
(\mathrm{MPa})\end{array}$ & $\begin{array}{c}P_{c r . L} \\
(\mathrm{kN})\end{array}$ & $\begin{array}{c}P_{c r . D} \\
(\mathrm{kN})\end{array}$ & $\begin{array}{c}P_{c r . F T} \\
(\mathrm{kN})\end{array}$ & $\begin{array}{c}P_{c r . D} \\
/ P_{y}\end{array}$ & $\begin{array}{c}P_{u} \\
(\mathrm{kN})\end{array}$ \\
\hline $\begin{array}{c}1 \\
2\end{array}$ & 81 & 72 & 12 & 1.07 & 2850 & 342 & 43.8 & 42.9 & 45.4 & 0.43 & $\begin{array}{c}31.5 \\
29.0 \\
30.7\end{array}$ \\
\hline $\begin{array}{c}4 \\
5\end{array}$ & 75 & 65 & 11 & 1.07 & 2350 & 342 & 48.8 & 47.5 & 49.6 & 0.55 & $\begin{array}{c}33.0 \\
31.2\end{array}$ \\
\hline 6 & 71 & 60 & 11 & 1.07 & 2100 & 342 & 51.9 & 51.8 & 52.9 & 0.64 & $\begin{array}{c}35.1 \\
34.0\end{array}$ \\
\hline $\begin{array}{l}8 \\
9\end{array}$ & 76 & 60 & 10 & 1.11 & 2350 & 407 & 49.0 & 47.7 & 47.5 & 0.49 & $\begin{array}{c}36.5 \\
34.1\end{array}$ \\
\hline
\end{tabular}

(a)
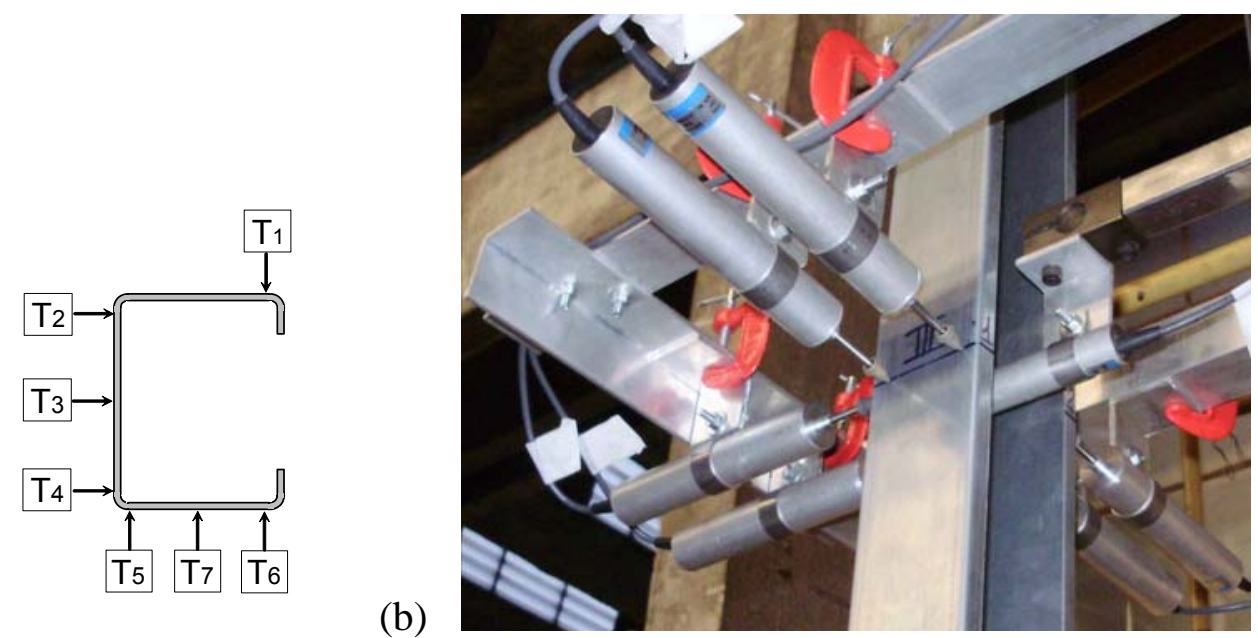

Figure 11. (a) Displacement Transducer Cross-section Locations and (b) View of the Moving

Device used to Obtain the Longitudinal Profiles of Some Measured Displacements 


\subsection{Comparison between Numerical and Experimental Results}

The comparison between numerical and experimental results concerns just one test carried out at COPPE the specimen has mid-line dimensions $b_{w}=76 \mathrm{~mm}, b_{f}=64 \mathrm{~mm}, b_{l}=11 \mathrm{~mm}, t=1.07 \mathrm{~mm}$ and $L=235.2 \mathrm{~cm}$ (specimen 4), i.e., very similar to those considered in the numerical investigation reported earlier. The ABAQUS shell finite element numerical simulations performed exhibit the following characteristics:

(i) The steel is deemed homogeneous and isotropic, with an elastic-plastic behaviour described by a multi-linear model that $\left(\mathrm{i}_{1}\right)$ assumes $E=211 \mathrm{GPa}, v=0.3$ and $f_{y}=342 \mathrm{MPa}$ (coupon test average values) and $\left(\mathrm{i}_{2}\right)$ approximates the measured stress-strain curve, prior to the yield plateau, by linear segments connecting the experimental curve points concerning four stress values $\left(\sigma=0.55 f_{y}\right.$, $0.80 f_{y}, 0.93 f_{y}$ and $f_{y}$ ) - Figure 12(a) presents a comparison between the experimental stress-strain curve and the multi-linear one adopted to model it in the numerical simulations.

(ii) The column end sections are fixed: with the sole exception of the rigid-body longitudinal displacement of the loaded end section, which is free, all the displacements and rotations are fully prevented.

(iii) Both the residual stresses (not measured in the tested specimens) and corner effects are neglected.

(iv) The initial geometrical imperfections model those measured in the tested specimen - they are obtained by means of the procedure illustrated in Figure 12(b) and described next. For each of the 6 cross-section displacements measured along the specimen length (transducers T1 to T6 - see Figure 11(a)), the Fourier transform approach is used to obtain a linear combination of trigonometric functions that approximates the experimental values - Figure 12(b) shows a comparison between the experimental and numerical initial values of the horizontal displacements $d_{4}$ occurring along the bottom web-flange longitudinal edge (measured by transducer T4). The 6 initial displacement approximation functions are then incorporated into the shell finite element mesh - whenever necessary, a linear displacement variation along the cross-section wall mid-line is assumed between the equally spaced web, flange or lip nodes.

Figure 13(a) show the comparison between the equilibrium paths $P v s . d_{1}$ and $P v s . d_{6}$, where $d_{1}$ and $d_{6}$ are the mid-span vertical displacements of the flange-lip corners (positive upward) (see Figure 11(a)), (i) obtained during the test carried out at COPPE and (ii) provided by the ABAQUS analysis the table below provides the experimental $\left(P_{u . E}\right)$ and numerical $\left(P_{u . N}\right)$ ultimate load values. As for Figure 13(b), it shows numerical and experimental representations of the column failure mode. The observation of these results prompts the following remarks:

(i) The numerical post-buckling equilibrium paths follow fairly closely their experimental counterparts (note, in particular, that the $d_{l}$ numerical curve practically coincides with the experimental one) and exhibit very similar peak loads $-P_{u . E}$ is only $0.3 \%$ above $P_{u . N}$. Moreover, they provide clear evidence of distortional/global interaction - indeed, they concern $\left(\mathrm{i}_{1}\right)$ counter-clockwise rigid-body rotations (both $d_{1}$ and $d_{6}$ are positive, i.e., upward) and (i $\left.\mathrm{i}_{2}\right)$ outward motions of the flange-lip assemblies $\left(d_{l}\right.$ is larger than $\left.d_{6}\right)$ at the mid-span cross-section.

(ii) However, there are some differences between the experimental and numerical curves, as the latter exhibits ( $\mathrm{ii}_{1}$ ) a considerably higher ductility (displacements at collapse about twice those measured in the test) and ( $\mathrm{ii}_{2}$ ) a very small (almost imperceptible) snap-through phenomenon - note that this phenomenon is much less pronounced than that depicted in Figure 8(a), which is probably due to the different stress-strain curves adopted to model the steel material behaviour (linear and multi-linear).

(iii) As shown in Figure 13(b), there is a quite satisfactory match between the ABAQUs failure mode and the collapse mechanism observed during the test: both are almost symmetric and provide evidence of distortional/global interaction. Note, however, that local deformations are not perceptible in either of them (recall that they were clearly visible in the elastic post-buckling advanced stages - see Figure $\left.6\left(d_{2}\right)\right)$ 
(a)

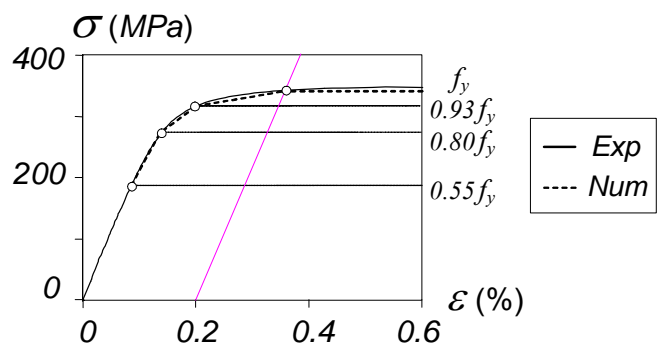

(b)

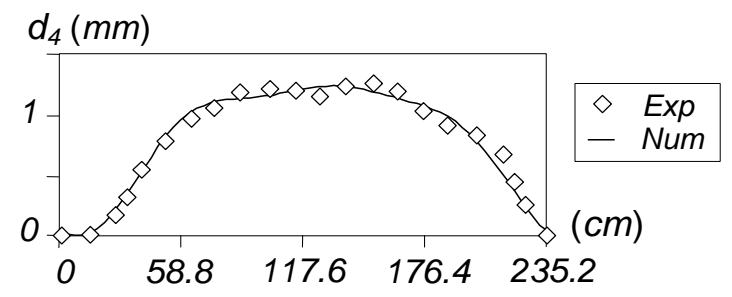

Figure 12. Comparison between the Experimentally Obtained and Numerically Modelled

(a) Stress-strain Curve and (b) $d_{4}$ Displacement Values along the Bottom Web-flange Longitudinal Edge

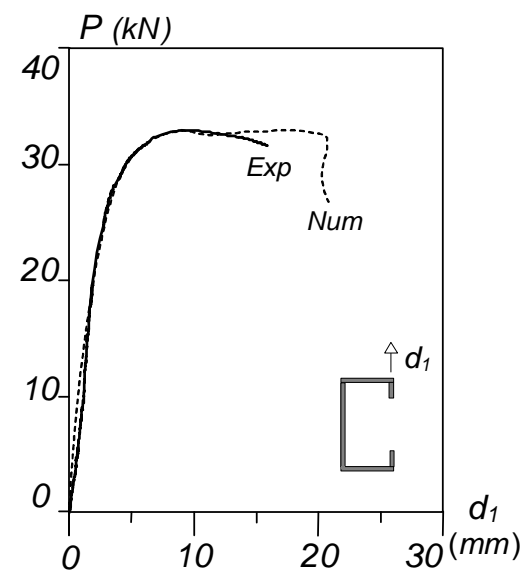

(a)
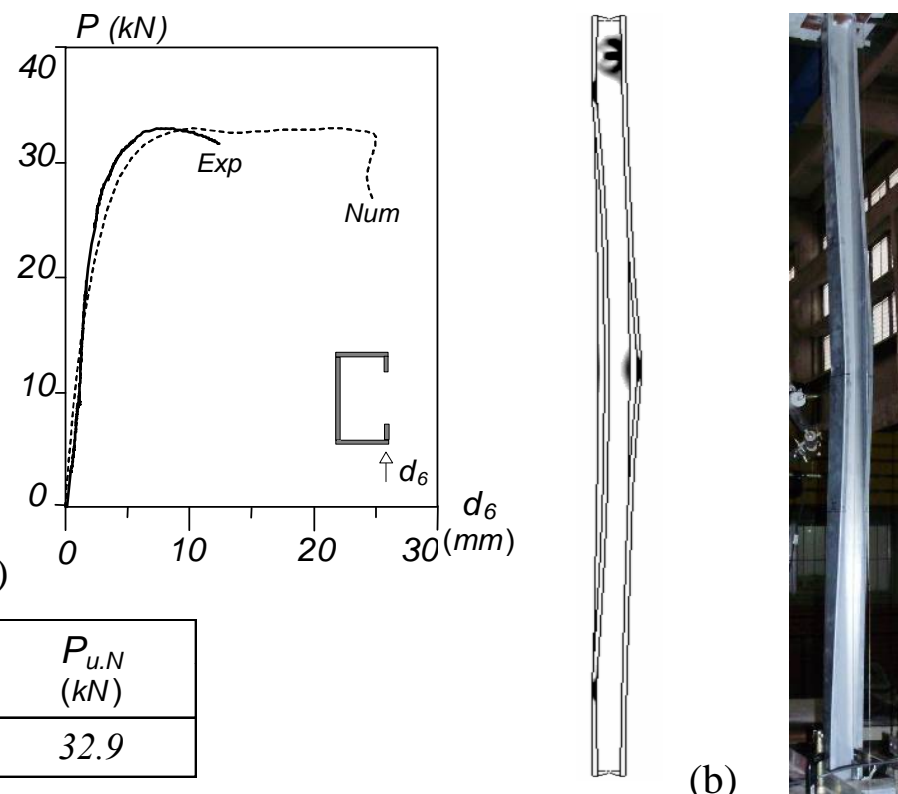

Figure 13. Numerical and Experimental Results

(a) Post-buckling Equilibrium Paths $P$ vs. $d_{1}$ and $P$ vs. $d_{6}$, together with the Corresponding Ultimate Loads, and (b) Failure Mode Representations

\section{PRELIMINARY DESIGN CONSIDERATIONS}

Until the beginning of this century, the well-known Effective Width Method was the only universally accepted design procedure to estimate the ultimate strength of thin-walled cold-formed steel members affected by local (and later also distortional) buckling phenomena. However, the advent of increasingly more complex cross-section shapes (e.g., those exhibiting several lips and/or intermediate stiffeners) made the determination of their effective properties a very laborious and time-consuming task, thus paving the way for the development of the Direct Strength Method (DSM), originally proposed by Schafer and Peköz [4] and having its roots on earlier work carried out by Hancock and his collaborators at the University of Sydney. Besides overcoming the difficulties associated with the determination of the effective cross-section properties, the DSM also provides a rational and systematic framework for the design of thin-walled members with arbitrary cross-section shapes, loadings or failure modes - the ultimate strength prediction is obtained solely on the basis of the member elastic buckling and yield stresses. However, as pointed out by Schafer (e.g., Schafer [5]), further research is needed before the DSM approach can be successfully applied to members affected by interaction phenomena involving distortional buckling, namely that addressed in this work. 
Therefore, the aim of this section is to present some preliminary considerations concerning the applicability of the current DSM expressions to estimate the load-carrying capacity of cold-formed steel lipped channel columns affected by $\mathrm{L} / \mathrm{D} / \mathrm{G}$ mode interaction. It is worth noting that these considerations are based on the rather limited "data bank" of numerical and experimental ultimate strength values obtained in the course of the current and previous research efforts carried out by the authors. The numerical values concern elastic/perfectly-plastic steel $(E=210 \mathrm{GPa}, v=0.3)$ columns with (i) pinned (P) or fixed (F) end sections, (ii) critical-mode global initial imperfections (the most detrimental ones) with $L / 1000$ amplitude and (iii) three yield stresses $\left(f_{y}=235,355,520 \mathrm{MPa}\right)$ - the pinned-ended values were obtained in a previous $\mathrm{L} / \mathrm{D} / \mathrm{G}$ interaction investigation [22, 25], involving columns with $b_{w}=92 \mathrm{~mm}, b_{f}=65 \mathrm{~mm}$, $b_{l}=10 \mathrm{~mm}, t=1.2 \mathrm{~mm}$ and $L=152 \mathrm{~cm}$. The experimental results concern 9 tests carried out at COPPE - the ultimate loads measured are given in Table 1.

The DSM expressions correspond to "Winter-type" design curves, which (i) were calibrated against a large number of experimental and/or numerical results, and (ii) prescribe that the column nominal strengths against local, distortional and global failure $\left(P_{n l}, P_{n d}\right.$ and $\left.P_{n g}\right)$ are given by Schafer [5]

$$
\begin{aligned}
& \left\{\begin{array}{l}
P_{n l}=P_{y} \quad \text { if } \quad \lambda_{l} \leq 0.776 \\
P_{n l}=P_{y}\left(\frac{P_{c r l}}{P_{y}}\right)^{0.4}\left[1-0.15\left(\frac{P_{c r l}}{P_{y}}\right)^{0.4}\right] \quad \text { if } \quad \lambda_{l}>0.776
\end{array}\right. \\
& \left\{\begin{array}{l}
P_{n d}=P_{y} \quad \text { if } \quad \lambda_{d} \leq 0.561 \\
P_{n d}=P_{y}\left(\frac{P_{c r d}}{P_{y}}\right)^{0.6}\left[1-0.25\left(\frac{P_{c r d}}{P_{y}}\right)^{0.6}\right] \quad \text { if } \quad \lambda_{d}>0.561
\end{array}\right. \\
& \left\{\begin{array}{llll}
P_{n g}=P_{y} & 0.658^{\lambda_{g}^{2}} & \text { if } & \lambda_{g} \leq 1.5 \\
P_{n g}=P_{y} & \frac{0.877}{\lambda_{g}^{2}} & \text { if } & \lambda_{g}>1.5
\end{array}\right.
\end{aligned}
$$

where (i) $\lambda_{l}=\left(P_{y} / P_{c r l}\right)^{0.5}, \lambda_{d}=\left(P_{y} / P_{c r d}\right)^{0.5}$ and $\lambda_{g}=\left(P_{y} / P_{c r g}\right)^{0.5}$, (ii) $P_{y}$ is the squash load and (iii) $P_{c r l}$, $P_{c r d}$ and $P_{c r g}$ are the local, distortional and global (flexural, torsional or flexural-torsional) critical buckling loads. In order to capture possible local/global interaction effects, the current DSM approach replaces $P_{y}$ by $P_{n g}$ in Eq. 1 . In fact, $P_{n g}$ appears in the DSM expressions concerning local failure that are included in the most recent versions of the Australian/New Zealander [35] and North American [36] specifications for cold-formed steel structures.

Figures 14(a)-(d) show the variation of the $P_{u} / P_{y}$ stress ratios with the slenderness $\lambda_{d}$ (note that one has always $\lambda_{d} \approx \lambda_{l} \approx \lambda_{g}$ ) for the ultimate strength values of all the lipped channel column analysed numerically or tested experimentally. These figures also include five DSM "Winter-type" curves corresponding to (i) local (L), distortional (D) and global (G) column failure (Eqs. 1-3), (ii) local/global (L/G) (Eqs. 1 with $P_{y}$ replaced by $P_{n g}$ ) and (iii) distortional/global interactive failure (Eqs. 2 with $P_{y}$ replaced by $\left.P_{n g}\right)^{6}$. The observation of the results presented in Figures 14(a)-(d) leads to the following conclusions:

\footnotetext{
${ }^{6}$ Note that the DSM curve concerning distortional/global interactive failures has not yet been properly calibrated against experimental and/or numerical results. It was obtained through the same approach followed to handle the local/global interactive failures.
} 
(i) Both the numerical and experimental ultimate loads results fall below the predictions yielded by the individual (L, D and G) DSM design curves, which provides evidence of the occurrence of ultimate strength erosion due to the $\mathrm{L} / \mathrm{D} / \mathrm{G}$ mode interaction.

(ii) The DSM L/G curve provides (ii ${ }_{1}$ ) "almost perfect" predictions of the (numerical) pinned-ended column ultimate loads and $\left(\mathrm{ii}_{2}\right)$ conservative estimates of the numerical fixed-ended column ultimate loads - indeed, the latter are very close to the DSM global curve.

(iii) All but one of the 9 experimental ultimate load ratios (fixed-ended columns) fall below the DSM L/G curve. However, all of them are also nicely "aligned" in the close vicinity of the D/G curve, making it possible to say that this curve provides accurate and (practically always) safe estimates of the ultimate loads measured during the tests.

(iv) Although further numerical and experimental investigations are needed before definite conclusions can be drawn, these preliminary results suggest that the $D / G$ curve may serve as the basis for the development of a DSM design expression able to cover lipped channel columns experiencing local/distortional/global mode interaction.
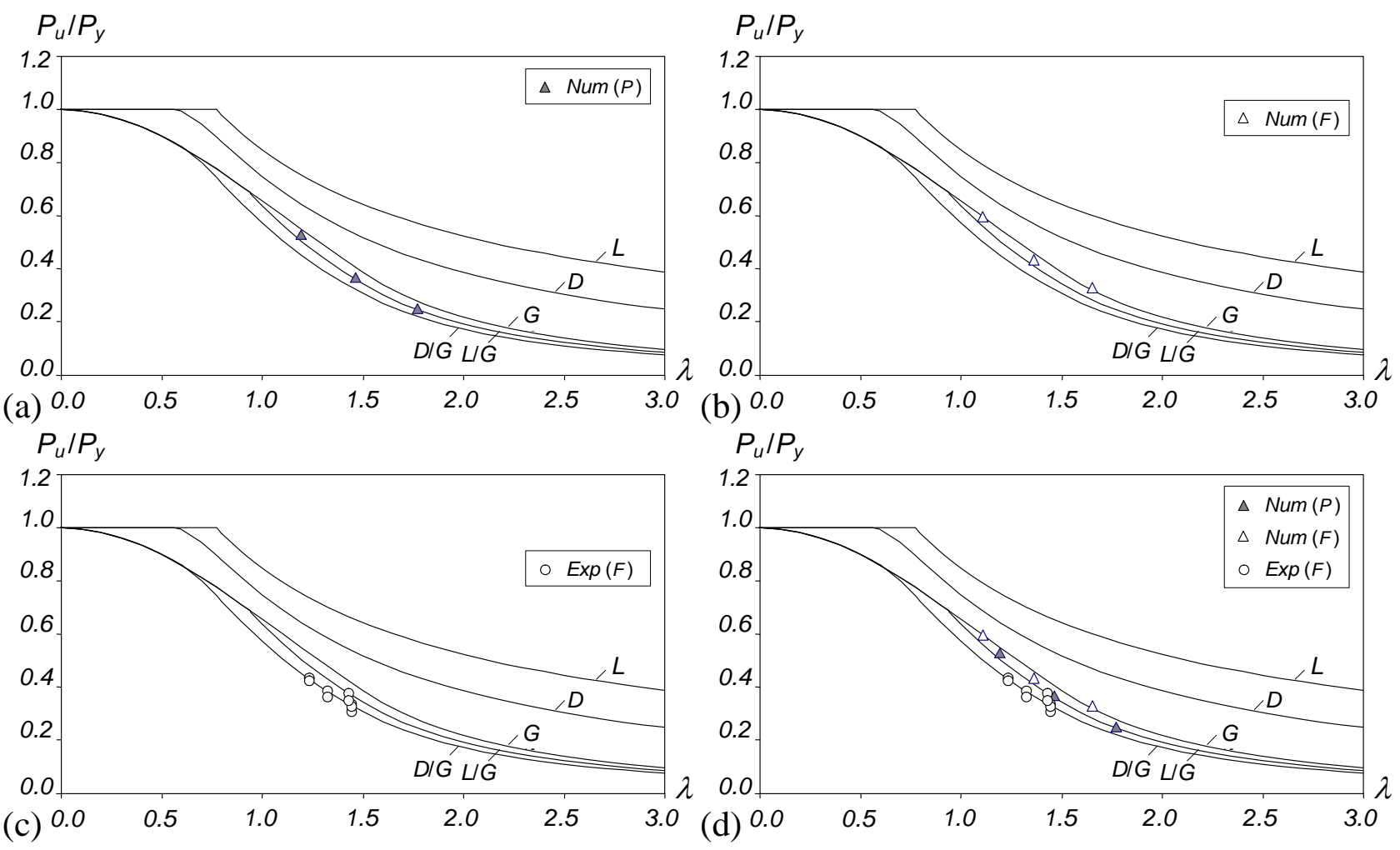

Figure 14. Variation of $P_{u} / P_{y}$ with $\lambda_{d}=\lambda_{l}=\lambda_{g}$ for the (a) Pinned-ended (Numerical Values),

(b) Fixed-ended (Numerical Values) (c) Fixed-ended (Experimental Values) and

(d) All (Numerical/Experimental Values) Lipped Channel Columns

\section{CONCLUSION}

This paper reported the available results of an ongoing investigation on the post-buckling behaviour and strength of fixed-ended cold-formed steel lipped channel columns experiencing local/distortional/global mode interaction, whose geometries were identified through "trial-and-error" buckling analyses. Initially, shell finite element elastic (mostly) and elastic-plastic post-buckling results concerning otherwise identical columns with critical-mode initial imperfections, exhibiting different configurations and sharing a common amplitude, were presented and discussed in detail. It was found that (i) global initial imperfections are 
the most detrimental ones and (ii) the $\mathrm{L} / \mathrm{D} / \mathrm{G}$ mode interaction causes noticeable column ultimate strength erosion - its quantification requires an extensive parametric study and is planned for the near future. Then, an overview of the experimental investigation currently under way at COPPE/UFRJ was presented - a full report will be available soon. After providing a brief account of the test program, set-up, procedure and results, the comparison between the experimental and numerical results concerning one column specimen were presented and discussed in some detail - a fairly good agreement was found. Finally, the paper closed with some preliminary considerations on the DSM design of cold-formed steel lipped channel columns affected by local/distortional/global mode interaction.

\section{REFERENCES}

[1] Prola, L.C. and Camotim, D., "On the Distortional Post-buckling Behavior of Cold-formed Lipped Channel Steel Columns”, Proceedings SSRC Annual Stability Conference, Seattle 2002, pp. 571-590.

[2] Silvestre, N. and Camotim, D., "Local-plate and Distortional Post-buckling Behavior of Cold-formed Steel Lipped Channel Columns with Intermediate Stiffeners”, Journal of Structural Engineering, ASCE, 2006, Vol. 132, No. 4, pp. 529-540.

[3] Batista, E.M., "Local-global Buckling Interaction Procedures for the Design of Cold-formed Columns: Effective Width and Direct Method Integrated Approach”, Thin-Walled Structures, 2009, Vol. 47, No. 11, pp. 1218-1231.

[4] Schafer, B.W. and Pekoz, T. "Direct Strength Prediction of Cold-formed Steel Members Using Numerical Elastic Buckling Solutions”, In: Shanmugam, N.E., Liew, J.Y.R., Thevendran, V. (Eds.). Thin-Walled Structures - Research and Development. Elsevier, 1998, pp. 137-144.

[5] Schafer, B.W., "Review: The Direct Strength Method of Cold-formed Steel Member Design", Journal of Constructional Steel Research, 2008, Vol. 64, No. 7-8, pp. 766-778.

[6] Schafer, B.W. and Peköz, T., "Laterally Braced Cold-formed Steel Members with Edge Stiffened Flanges”, Journal of Structural Engineering, 1999, ASCE, Vol. 125, No. 2, pp. 118-127.

[7] Ungureanu, V. and Dubina, D., "Recent Research Advances on ECBL Approach - Part I: Plastic-elastic Interactive Buckling of Cold-formed Steel Sections”, Thin-Walled Structures, 2004, Vol. 42, No. 2, pp. 177-194.

[8] Yang, D. and Hancock, G., "Compression Tests of High Strength Steel Columns with Interaction between Local and Distortional Buckling”, Journal of Structural Engineering, ASCE, 2004, Vol. 130, No. 12, pp. 1954-1963.

[9] Dinis, P.B., Camotim, D. and Silvestre, N., "FEM-based Analysis of the Local-plate/Distortional Mode Interaction in Cold-formed Steel Lipped Channel Columns”, Computers \& Structures, 2007, Vol. 85, No. 19-20, pp. 1461-1474.

[10] Hancock, G., Yap, D. and Yang, D., "Interaction Buckling in High Strength Cold-formed Steel Compression Members", Proceedings of $6^{\text {th }}$ International Conference on Steel \& Aluminum Structures (ICSAS’07), Beale, R. (Ed.), Oxford 2007, pp. 14-25.

[11] Silvestre, N., Camotim, D. and Dinis, P.B., "DSM Design of Fixed Lipped Channel Columns Against Local-plate/Distortional Interactive Buckling”, Proceedings of $6^{\text {th }}$ International Conference on Steel \& Aluminum Structures (ICSAS’07), Beale, R. (Ed.), Oxford 2007, pp. 752-759.

[12] Kwon, Y.B., Kim, B.S. and Hancock, G.J., "Compression Tests for the High Strength Cold-formed Steel Columns Undergoing Interaction between Local and Distortional Buckling”, Proceedings of Gregory J. Hancock Symposium, K. Rasmussen, T. Wilkinson (eds.), Sydney 2008, pp. 13-20. 
[13] Camotim, D., Dinis, P.B. and Silvestre, N., "Local/Distortional Mode Interaction in Lipped Channel Steel Columns: Post-buckling Behaviour, Strength and DSM Design”, Proceedings of Fifth International Conference on Thin-Walled Structures, Mahendran, M. (Ed.), Brisbane 2008, pp. 99-114.

[14] Kwon, Y.B., Kim, B.S. and Hancock, G.J., "Compression Tests of High Strength Cold-formed Steel Channels with Buckling Interaction”, Journal of Constructional Steel Research, 2009, Vol. 65, No. 2, pp. 278-289.

[15] Silvestre, N., Camotim, D. and Dinis, P.B., "Direct Strength Prediction of Lipped Channel Columns Experiencing Local-plate/Distortional Interaction”, Advanced Steel Construction An International Journal, 2009, Vol. 5, No. 1, 2009, pp. 45-67.

[16] Yapp, D. and Hancock, G.J., "Interaction of Local and Distortional Modes in Thin-walled Sections", Proceedings of Sixth International Conference on Advances in Steel Structures (ICASS’09), Chan, S.L. (Ed.), Hong Kong, 2009, pp. 35-48.

[17] Young, B., Camotim, D. and Silvestre, N., "Ultimate Strength and Design of Lipped Channel Columns Experiencing Local/Distortional Mode Interaction - Part I: Experimental Investigation", Proceedings of Sixth International Conference on Advances in Steel Structures (ICASS’09), Chan, S.L. (Ed.), Hong Kong, 2009, pp. 460-469.

[18] Silvestre, N., Camotim, D. and Young, B., "Ultimate Strength and Design of Lipped Channel Columns Experiencing Local/Distortional Mode Interaction - Part II: DSM Design Approach”, Proceedings of Sixth International Conference on Advances in Steel Structures (ICASS'09), Chan, S.L. (Ed.), Hong Kong, 2009, pp. 470-479.

[19] Dinis, P.B., Young, B. and Camotim, D., "On the Effect of Local/Distortional Mode Interaction on the Post-buckling Behaviour and Ultimate Strength of Fixed-ended Lipped Channel Columns", Proceedings of IJSSD Symposium on Progress in Structural Stability and Dynamics, Rasheed, H. (Ed.), Hong Kong, 2009, pp. 191-198.

[20] Silvestre, N., Camotim, D. and Dinis, P.B., "Direct Strength Approach to the Design of Lipped Channel Steel Columns Against Local/Distortional Interactive Buckling”, Submitted for Publication, 2010.

[21] Dinis, P.B. and Camotim, D., "Post-buckling Analysis of Cold-formed Steel Lipped Channel Columns Affected by Distortional/Global Mode Interaction”, Proceedings of SSRC Annual Stability Conference, Nashville, 2008, pp. 405-431.

[22] Dinis, P.B. and Camotim, D., "Local/Distortional/Global Buckling Mode Interaction in Cold-formed Steel Lipped Channel Columns", Proceedings of SSRC Annual Stability Conference, Phoenix, 2009, pp. 295-323.

[23] Dinis, P.B. and Camotim, D., "Coupled Instabilities with Distortional Buckling in Cold-formed Steel Lipped Channel Columns”, Thin-Walled Structures, Accepted for Publication, 2010.

[24] Dinis, P.B. and Camotim, D., "Post-buckling Behaviour and Strength of Cold-formed Steel Lipped Channel Columns Experiencing Distortional/Global Interaction”, Computers \& Structures, 2011, Vol. 89, No. 3-4, pp. 422-434.

[25] Dinis, P.B. and Camotim, D., "Local/Distortional/Global Buckling Mode Interaction in Simply Supported Cold-formed Steel Lipped Channel Columns”, International Journal of Structural Stability and Dynamics, Accepted for Publication, 2011.

[26] Dinis, P.B., Camotim, D., Batista, E.M. and Santos, E., "Local/Distortional/Global Mode Coupling in Fixed Lipped Channel Columns: Behaviour and Strength”, Proceedings of $6^{\text {th }}$ International Conference on Advances in Steel Structures (ICASS’09), Chan, S.L. (Ed.), Hong Kong, 2009, pp. 19-34.

[27] Rossi, B., Jaspart, J.-P. and Rasmussen, K.R., "Combined Distortional and Overall Flexural-Torsional Buckling of Cold-Formed Stainless Steel Sections: Experimental Investigations”, Journal of Structural Engineering, ASCE, 2010, Vol. 136, No. 4, pp. 354-360. 
[28] Dinis, P.B. and Camotim, D., "Local/Distortional/Global Buckling Mode in Cold-formed Steel Rack-section Columns”, Proceedings of SSRC Annual Stability Conference, Orlando 2010, pp. 481-504.

[29] Simulia Inc., Abaqus Standard (Version 6.7-5), 2008.

[30] Dinis, P.B. and Camotim, D., "On the Use of Shell Finite Element Analysis to Assess the Local Buckling and Post-buckling Behaviour of Cold-formed Steel Thin-walled Members", Proceedings of III European Conference on Computational Mechanics: Solids, Structures and Coupled Problems in Engineering, (III ECCM), C.A.M. Soares et al. (Eds.), Lisboa, 2006, pp. 689. (Full Paper in CD-Rom Proceedings)

[31] Camotim, D., Silvestre, N., Gonçalves, R. and Dinis, P.B., "GBT Analysis of Thin-walled Members: New Formulations and Applications", Thin-Walled Structures: Recent Advances and Future Trends in Thin-Walled Structures Technology, Loughlan, J. (Ed.), Bath, 2004, pp. 137-168.

[32] Bebiano, R., Silvestre, N. and Camotim, D., "GBTUL 1.0 $\beta$ - Code for Buckling and Vibration Analysis of Thin-Walled Members”, Freely Available at $h t t p: / / w w w . c i v i l . i s t . u t l . p t / g b t, 2008$.

[33] Bebiano, R., Silvestre, N. and Camotim, D., "GBTUL - A Code for the Buckling Analysis of Cold-formed Steel Members”, Proceedings of $19^{\text {th }}$ International Specialty Conference on Recent Research and Developments in Cold-Formed Steel Design and Construction, LaBoube, R., Yu, W.-W. (Eds.), St. Louis, 2008, pp. 61-79.

[34] Young, B. and Rasmussen, K.J., "Shift of Effective Centroid in Channel Columns", Journal of Structural Engineering, ASCE, 1999, Vol. 125, No. 5, pp. 524-531.

[35] AS/NZS4600, Cold-Formed Steel Structures, Australian Standard/New Zealand Standard 4600, Standards Australia, Sydney, 2005.

[36] NAS, North American Specification for the Design of Cold-Formed Steel Structural Members (AISI-S100-07), American Iron and Steel Institute (AISI), Washington DC, 2007. 